\title{
Traceless Templated Amide-Forming Ligations
}

Alberto Osuna Gálvez and Jeffrey W. Bode

Laboratorium für Organische Chemie, ETH Zürich,

CH-8093 Zürich, Switzerland,

bode@org.chem.ethz.ch 


\section{Table of Contents}

General Information

Chemical Synthesis

Streptavidin Expression and Purification

Kinetic Experiments

Representative Procedure for the Kinetics Measurement of the Reaction of 1a with 2a

LC-MS Chromatogram of the Last Point from the Reaction of 1a with $2 \mathrm{a}$ and Tetravalent $\mathrm{S}$

Figure 3a-1 Experiments

Figure 3a-2 Experiments

Figure 3a-3 Experiments

Figure 3a-4 Experiments

Preparation of Complex 1a-S

Conversion over Time Plot of the Reaction of 1-S with 2a

Figure 3a-4 Experiments and Non-Linear Model Fit

Acylboronate 2a Loading Studies 


\section{General Information}

Reagents were purchased from Acros, Sigma-Aldrich, TCl, Fluka, Fluorochem or ABCR and used without further purification, with the following exceptions. Reagent $\mathbf{S 2 1}$ was synthesized in the lab according to the literature procedure. ${ }^{1}$ Reagent $\mathbf{S 2 3}$ and $\mathrm{TMSCl}$ were purified by distillation prior to use.

Thin layer chromatography (TLC) was performed on glass-backed plates pre-coated with silica gel (Merck, Silica Gel 60 F254), which were visualized by fluorescence quenching under UV light or by staining (using ninhydrin or $\mathrm{KMnO}_{4}$ solutions). Flash column chromatography was performed on Silicycle Silica Flash F60 (230-400 Mesh) using a forced flow of air at 0.5-1.0 bar. Melting points (m.p.) were measured on an Electrothermal Mel-Temp melting point apparatus and were uncorrected. NMR spectra were measured on VARIAN Mercury 300 MHz, 75 MHz, Bruker Avance 400 MHz, 100 MHz or Bruker AV-II 600 MHz, 150 MHz. Chemical shifts are expressed in parts per million (ppm) and are referenced to $\mathrm{CDCl}_{3} 7.26 \mathrm{ppm}, 77.0 \mathrm{ppm}$; acetone- $d_{6} 2.05$ ppm, 29.8 and 206.3 ppm; DMSO- $d_{6} 2.50$ ppm, 39.5 ppm; CD $_{3} \mathrm{OD} 3.31$ ppm, 49.0 ppm. Coupling constants are reported as Hertz $(\mathrm{Hz})$. Splitting patterns are indicated as follows: br, broad; br s, broad singlet; s, singlet; $d$, doublet; $t$, triplet; $q$, quartet; $p$, pentet; sx, sextet; sp, septet; dd, doublet of doublets; dt, doublet of triplets; td, triplet of doublets; qd, quartet of doublets; ddd, doublet of doublet of doublets; tdd, triplet of doublet of doublets; m, multiplet. Infrared (IR) spectra were recorded on a JASCO FT/IR-4100 spectrophotometer and are reported as wavenumber $\left(\mathrm{cm}^{-1}\right)$. Optical rotations were measured with a Jasco P-2000 polarimeter with a 100-mm path length cell operating at the sodium D line (589 nm), at 23-24 ${ }^{\circ} \mathrm{C}$ and reported as $[\alpha]_{\mathrm{D}}$ (concentration $\mathrm{g} / 100 \mathrm{~mL}$, solvent). High-resolution mass spectra were measured on a Bruker Daltonics maXis ESI- QTOF or Bruker solariX ESI/MALDI-FTICR by the mass spectrometry service of the Laboratorium für Organische Chemie at the ETH Zürich. LC-MS was performed on a Waters H-class Acuity HPLC connected to a SQ detector 2. HPLC (high performance liquid chromatography) was performed on JASCO analytical and preparative instruments. Unless otherwise stated, analytical and preparative reverse-phase HPLC were performed using Shiseido C18 UG120 $5 \mu \mathrm{m}(4.6 \mathrm{~mm}$ I.D. $\times 250 \mathrm{~mm})$ and YMC C18 $(20 \mathrm{~mm}$ I.D. $\times 250 \mathrm{~mm})$ columns with flow rates $1.0 \mathrm{~mL} / \mathrm{min}$ and $10 \mathrm{~mL} / \mathrm{min}$ respectively, using $\mathrm{MQ}-\mathrm{H}_{2} \mathrm{O}$ with $0.1 \%$ TFA (eluent $\mathrm{A}$ ) and $\mathrm{HPLC}$ grade $\mathrm{CH}_{3} \mathrm{CN}$ with $0.1 \%$ TFA (eluent B). UV-Vis spectra, and DNA and protein concentration measurements were performed on a Thermo NanoDrop 2000c spectrophotometer. 
For protein analysis, sodium dodecyl sulfate-polyacrylamide gel electrophoresis (SDS-PAGE) was carried out in a Mini-PROTEAN Tetra Cell system (Bio-Rad) connected to a PowerPac Basic (BioRad) programmable power supply. Protein electrophoresis samples $(2-5 \mu \mathrm{g}$ protein) were treated with an equal volume of a sample buffer, Laemmli $2 x$ Concentrate (Sigma) and heated to $95{ }^{\circ} \mathrm{C}$ for 5 minutes to denature the protein sample when necessary. ${ }^{2}$ Samples were loaded (typically a $10 \mu \mathrm{L}$ loading volume) onto commercially available Mini-PROTEAN TGX Precast Protein Gels (Bio-Rad) with a gradient gel percentage of either $8-16 \%$ or $7.5 \%$. A commercially available $10-180 \mathrm{kDa}$ pre-stained protein ladder (Thermo Fisher) was typically applied to one well $(5 \mu \mathrm{L})$ of each gel for the assignment of apparent molecular masses. Gels were run for 30 minutes at $200 \mathrm{~V}$ in a running buffer $(25 \mathrm{mM}$ Tris, $192 \mathrm{mM}$ Glycine, $0.1 \%$ (w/v) SDS, $\mathrm{pH}$ 8.3). Protein bands were subsequently visualized by incubating the gels in a staining solution ( $0.1 \%$ Coommasie Brilliant Blue R 250, 40\% MeOH, 10\% acetic acid) with gentle agitation for 1 hour. This was followed by a destaining protocol in which the gels were gently agitated in a destaining solution (40\% $\mathrm{MeOH}, 10 \%$ acetic acid) for several hours, replenishing the solution every hour until the background of the gel became fully destained.

All FPLC (Fast Protein Liquid Chromatography) protein purifications were performed on an ÄKTA pure chromatography system (GE Healthcare) using the UNICORN 6.3 Workstation system control software. All purifications were carried out at $4{ }^{\circ} \mathrm{C}$. All buffers were freshly prepared, filtered and degassed immediately prior to use. Anion exchange chromatography purifications were performed using the strong ion exchange Mono Q 5/50 GL column (purchased from GE Healthcare). All protein purifications were monitored at $280 \mathrm{~nm}$.

Fluorescence was measured using a Tecan Infinite ${ }^{\circledR} 200$ PRO plate reader. 96-Well plates were purchased from TPP. Measurements were typically performed with the plate cover on. Fluorescence was measured at $\lambda_{\mathrm{ex}}=430 \mathrm{~nm}, \lambda_{\mathrm{em}}=485 \mathrm{~nm}$. 


\section{Chemical Synthesis}

Synthesis of 7-diethylamino-2-oxo-2H-chromene-3-carboxamidoethylammonium trifluoroacetate (S3)

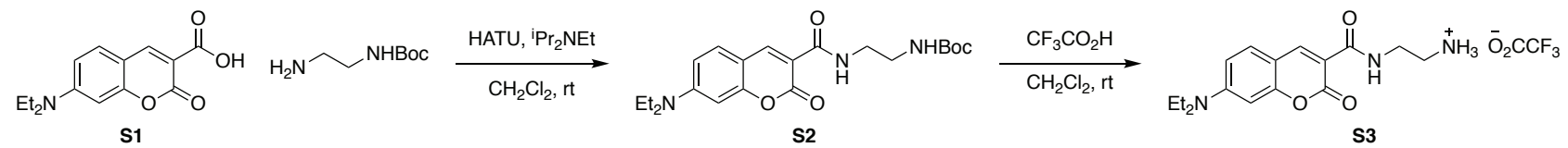
A round-bottom flask was charged with 7-diethylaminocoumarin-3-carboxylic acid (\$1, $960 \mathrm{mg}, 3.7 \mathrm{mmol}$, 1.00 equiv) and HATU (1.55 g, $4.1 \mathrm{mmol}, 1.10$ equiv). The solids were suspended in $\mathrm{CH}_{2} \mathrm{Cl}_{2}(30 \mathrm{~mL})$ and ${ }^{i} \mathrm{Pr}_{2} \mathrm{NEt}$ (1.66 mL, $9.2 \mathrm{mmol}, 2.50$ equiv) was added. The suspension was stirred at $\mathrm{rt}$ until all the suspended solids completely dissolved. tert-Butyl-2-aminoethyl carbamate ( $760 \mu \mathrm{L}, 4.8 \mathrm{mmol}, 1.30$ equiv) was added and the solution stirred at rt overnight. The solution was poured into $0.5 \mathrm{M}$ aq. $\mathrm{HCl}$ and extracted with $\mathrm{CH}_{2} \mathrm{Cl}_{2}$. The organic phase was collected, neutralized with sat. aq. $\mathrm{NaHCO}_{3}$ and extracted again with $\mathrm{CH}_{2} \mathrm{Cl}_{2}$. The organic extracts were collected, dried with $\mathrm{Na}_{2} \mathrm{SO}_{4}$, filtered and evaporated in vacuo. The residue was purified by column chromatography on silica gel (eluting with $\mathrm{CH}_{2} \mathrm{Cl}_{2} / \mathrm{MeOH}=100: 3$ ) to give $\mathbf{S 2}$ as a bright yellow solid $(1.20 \mathrm{~g}, 80 \%) ;{ }^{1} \mathrm{H}$ NMR $\left(500 \mathrm{MHz}, \mathrm{CDCl}_{3}\right): \delta 8.95(\mathrm{t}, J=6.2 \mathrm{~Hz}, 1 \mathrm{H}), 8.68(\mathrm{~s}, 1 \mathrm{H})$, $7.42(\mathrm{dd}, 3 \mathrm{H}, \mathrm{ArH}), 7.1(\mathrm{t}, J=8.9,1.1 \mathrm{~Hz}, 1 \mathrm{H}), 6.66(\mathrm{ddd}, J=8.9,2.5,1.0 \mathrm{~Hz}, 1 \mathrm{H}), 6.51(\mathrm{br} \mathrm{s}, 1 \mathrm{H}), 5.10(\mathrm{br} \mathrm{s}$, 1H), $3.55(\mathrm{q}, J=6.0 \mathrm{~Hz}, 2 \mathrm{H}), 3.45(\mathrm{q}, J=6.8 \mathrm{~Hz}, 4 \mathrm{H}), 3.35(\mathrm{t}, J=5.9 \mathrm{~Hz}, 2 \mathrm{H}), 1.43(\mathrm{~s}, 9 \mathrm{H}), 1.23(\mathrm{t}$, $J=6.9 \mathrm{~Hz}, 6 \mathrm{H}) ;{ }^{13} \mathrm{C}$ NMR $\left(126 \mathrm{MHz}, \mathrm{CDCl}_{3}\right): \delta 164.0,162.7,157.7,156.1,152.5,148.2,131.3,110.3,108.7$, $97.0,79.4,45.4,41.1,39.8,28.5,12.5$.

In a round-bottom flask, carbamate $\mathbf{S} 2\left(810 \mathrm{mg}, 2.0 \mathrm{mmol}, 1.0\right.$ equiv) was dissolved in $\mathrm{CH}_{2} \mathrm{Cl}_{2}(6 \mathrm{~mL})$. Trifluoroacetic acid $(2 \mathrm{~mL})$ was added and the mixture stirred at $\mathrm{rt}$ for $1 \mathrm{~h}$. The solution was evaporated by rotavap and $\mathrm{Et}_{2} \mathrm{O}$ was added to the crude. The solids were collected by vacuum filtration, washed with $\mathrm{Et}_{2} \mathrm{O}$ and dried in vacuo to give ammonium salt $\mathbf{S} 3$ as a bright yellow solid (786 mg, $94 \%$ ). m.p. $198-202{ }^{\circ} \mathrm{C}$; ${ }^{1} \mathrm{H}$ NMR $\left(500 \mathrm{MHz}, \mathrm{CD}_{3} \mathrm{OD}\right): \delta 8.63(\mathrm{~m}, 1 \mathrm{H}), 7.56-7.52(\mathrm{~m}, 1 \mathrm{H}), 6.85-6.80(\mathrm{~m}, 1 \mathrm{H}), 6.56(\mathrm{~s}, 1 \mathrm{H}), 3.69(\mathrm{t}$, $J=5.8 \mathrm{~Hz}, 2 \mathrm{H}$ ), $3.53(\mathrm{q}, J=7.2 \mathrm{~Hz}, 4 \mathrm{H}), 3.17(\mathrm{t}, J=5.6 \mathrm{~Hz}, 2 \mathrm{H}), 1.24(\mathrm{t}, J=7.1 \mathrm{~Hz}, 6 \mathrm{H}) ;{ }^{13} \mathrm{C}$ NMR $\left(126 \mathrm{MHz}, \mathrm{CD}_{3} \mathrm{OD}\right): \delta 166.8,163.9,162.9$ (q, $\left.J=35.6 \mathrm{~Hz}\right), 159.3,154.8,149.6,132.7,119.3$ (q, $J=290.0 \mathrm{~Hz}$ ), 111.7, 109.7, 109.4, 97.3, 46.0, 41.1, 38.5, 12.7; IR (thin film): v 3318, 2976, 1691, 1616, 1578, 1509, 1418, 1352, 1187, $1131 \mathrm{~cm}^{-1}$; ESI-HRMS calcd for $\mathrm{C}_{16} \mathrm{H}_{22} \mathrm{~N}_{3} \mathrm{O}_{3}[\mathrm{M}+\mathrm{H}]^{+} 304.1656$, found 304.1652. 


\section{Synthesis of 4-(N-tert-butoxycarbonyl-N-(N'-methyl-N'-propargylcarbamoyloxy)amino)butanoic acid} (S6)

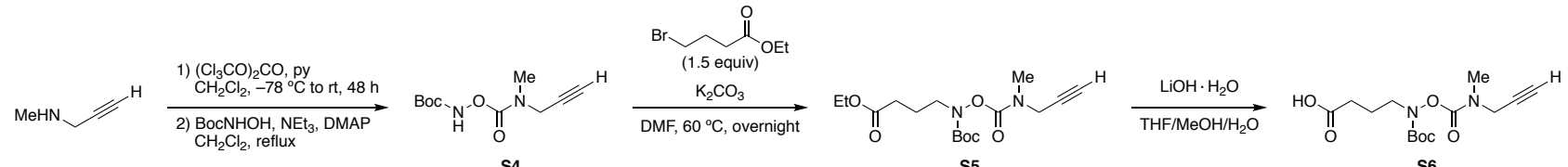

Following a reported procedure, ${ }^{4}$ a $100 \mathrm{~mL}$ Schlenk flask was charged with triphosgene $(2.96 \mathrm{~g}, 10.0 \mathrm{mmol}$, 0.33 equiv) and purged with $\mathrm{N}_{2}$ gas. $\mathrm{CH}_{2} \mathrm{Cl}_{2}(40 \mathrm{~mL})$ was added under $\mathrm{N}_{2}$ and the solution cooled to $-78{ }^{\circ} \mathrm{C}$. Pyridine (242 $\mu \mathrm{L}, 3.0 \mathrm{mmol}, 0.10$ equiv) and a solution of $N$-methylpropargylamine $(2.66 \mathrm{~mL}, 30.0 \mathrm{mmol}$, 1.00 equiv) in $\mathrm{CH}_{2} \mathrm{Cl}_{2}(5 \mathrm{~mL})$ were added sequentially under $\mathrm{N}_{2}$. The reaction was removed from the cooling bath and stirred at rt for $72 \mathrm{~h}$. The solvents were removed by evaporation and the residue purified by Kugelrohr distillation $\left(100^{\circ} \mathrm{C}\right.$, high vacuum) to give the corresponding carbamoyl chloride as a colorless oil $(2.22 \mathrm{~g}, 56 \%)$, which was taken directly to the next step.

In a round-bottom flask, $N$-tert-butoxycarbonylhydroxylamine $(2.93 \mathrm{~g}, 22.0 \mathrm{mmol}, 1.30$ equiv $)$ and DMAP (210 mg, $1.70 \mathrm{mmol}, 0.10$ equiv) were added. The solids were dissolved in $\mathrm{CH}_{2} \mathrm{Cl}_{2}$ (35 mL) under $\mathrm{N}_{2}$. Triethylamine $(3.13 \mathrm{~mL}, 22.0 \mathrm{mmol}, 1.30$ equiv) followed by a solution of the distilled carbamoyl chloride above $\left(2.22 \mathrm{~g}, 16.8 \mathrm{mmol}, 1.00\right.$ equiv) in $\mathrm{CH}_{2} \mathrm{Cl}_{2}(3 \mathrm{~mL})$ were added to the mixture. The reaction was refluxed and stirred overnight. After cooling to rt, the reaction was quenched with $0.5 \mathrm{M}$ aq. $\mathrm{HCl}$. The phases were separated and the aqueous phase extracted with $\mathrm{CH}_{2} \mathrm{Cl}_{2}$. The organic extracts were collected, dried with $\mathrm{Na}_{2} \mathrm{SO}_{4}$, filtered and evaporated in vacuo. The residue was purified by column chromatography on silica gel (eluting with EtOAc/hexanes $=1: 4)$ to give hydroxylamine $\mathbf{S 4}$ as a viscous oil (16.5 mmol, quant.); ${ }^{1} \mathrm{H}$ NMR $\left(500 \mathrm{MHz}, \mathrm{CDCl}_{3}\right): \delta 7.85(\mathrm{br} \mathrm{s}, 1 \mathrm{H}), 4.17-4.10(\mathrm{~m}, 2 \mathrm{H}), 3.09-2.99(\mathrm{~m}, 3 \mathrm{H}), 2.28(\mathrm{br} \mathrm{s}, 1 \mathrm{H}), 1.48(\mathrm{~s}$, 9H); ${ }^{13} \mathrm{C}$ NMR (126 MHz, $\mathrm{CDCl}_{3}$ ): $\delta$ 156.3, 156.1 (CO rotamers), 155.5 (CO rotamers), 83.1, 77.7, 73.1, 39.2 ( $\mathrm{N}-\mathrm{CH}_{3}$ rotamers), $38.1\left(\mathrm{~N}-\mathrm{CH}_{3}\right.$ rotamers), $34.7\left(\mathrm{~N}-\mathrm{CH}_{2}\right.$ rotamers), $33.2\left(\mathrm{~N}-\mathrm{CH}_{2}\right.$ rotamers), 28.1 ; IR (thin film): v 3261, 2979, 1725, 1369, 1251, $1120 \mathrm{~cm}^{-1}$; ESI-HRMS calcd for $\mathrm{C}_{10} \mathrm{H}_{16} \mathrm{~N}_{2} \mathrm{NaO}_{4}[\mathrm{M}+\mathrm{Na}]^{+} 251.1002$, found 251.1011.

A round-bottom flask was charged with hydroxylamine $\mathbf{S} 4\left(2.0 \mathrm{~g}, 8.8 \mathrm{mmol}, 1.00\right.$ equiv) and $\mathrm{K}_{2} \mathrm{CO}_{3}(3 \mathrm{~g}$, $22 \mathrm{mmol}, 2.50$ equiv). The solids were suspended in DMF $(40 \mathrm{~mL})$ and ethyl 3-bromopropanoate $(1.85 \mathrm{~mL}$, $95 \%$ purity, $12.3 \mathrm{mmol}, 1.40$ equiv) was added. The suspension was stirred at $60^{\circ} \mathrm{C}$ overnight and filtered through celite. The filtrate was diluted with EtOAc/hexanes (4:1) and washed with $\mathrm{H}_{2} \mathrm{O} /$ brine. The organic 
extracts were collected, dried with $\mathrm{Na}_{2} \mathrm{SO}_{4}$, filtered and evaporated in vacuo. The residue was purified by column chromatography on silica gel (eluting with EtOAc/hexanes $=1: 5$ to $1: 3$ ) to give hydroxylamine $\mathbf{S} 5$ as a viscous oil $(2.23 \mathrm{~g}, 74 \%) ;{ }^{1} \mathrm{H}$ NMR $\left(500 \mathrm{MHz}, \mathrm{CDCl}_{3}\right): \delta 4.14-4.10(\mathrm{~m}, 4 \mathrm{H}), 3.66(\mathrm{t}, J=7.2 \mathrm{~Hz}, 2 \mathrm{H}), 3.03$ (br s, 3H), 2.40 (t, J = $7.5 \mathrm{~Hz}, 2 \mathrm{H}), 2.27$ (t, $J=2.4 \mathrm{~Hz}, 1 \mathrm{H}), 1.91(\mathrm{p}, J=7.1 \mathrm{~Hz}, 2 \mathrm{H}), 1.46(\mathrm{~s}, 9 \mathrm{H}), 1.24(\mathrm{t}$, $J=7.1 \mathrm{~Hz}, 3 \mathrm{H}$ ); ${ }^{13} \mathrm{C}$ NMR (126 MHz, $\mathrm{CDCl}_{3}$ ): $\delta$ 173.2, 154.9, 154.7 (CO rotamers), 154.2 (CO rotamers), 82.3, 78.0, 72.9, 60.5, 49.9, $39.1\left(\mathrm{~N}-\mathrm{CH}_{3}\right.$ rotamers $), 38.4\left(\mathrm{~N}-\mathrm{CH}_{3}\right.$ rotamers $), 34.9\left(\mathrm{~N}_{-} \mathrm{CH}_{2}\right.$ rotamers $), 33.4$ ( $\mathrm{N}-\mathrm{CH}_{2}$ rotamers), 31.4, 28.3, 22.8, 14.4; IR (thin film): $v 3261,2979,1728,1368,1159,1105 \mathrm{~cm}^{-1}$; ESIHRMS calcd for $\mathrm{C}_{16} \mathrm{H}_{27} \mathrm{~N}_{2} \mathrm{O}_{6}[\mathrm{M}+\mathrm{H}]^{+} 343.1864$, found 343.1862 .

In a round-bottom flask ethyl ester $\mathbf{S} 5(1.14 \mathrm{~g}, 3.33 \mathrm{mmol}, 1.00$ equiv) and lithium hydroxide monohydrate (420 mg, $10.0 \mathrm{mmol}, 3.00$ equiv) were introduced and dissolved in $\mathrm{THF} / \mathrm{MeOH} / \mathrm{H}_{2} \mathrm{O}(5: 2: 1,10 \mathrm{~mL}$ ). The solution was stirred for $3 \mathrm{~h}$ at $\mathrm{rt}$ and acidified with $\mathrm{HCl} 1 \mathrm{M}$ to $\mathrm{pH}$ 1-2. The suspension was extracted with $\mathrm{CH}_{2} \mathrm{Cl}_{2}$. The organic extracts were collected, dried with $\mathrm{Na}_{2} \mathrm{SO}_{4}$, filtered and evaporated in vacuo. The residue was purified by column chromatography on silica gel (eluting with $\mathrm{CH}_{2} \mathrm{Cl}_{2} / \mathrm{MeOH} / \mathrm{AcOH}=100: 2: 0.5$ ) to give carboxylic acid $\mathbf{S 6}$ as a white solid (609 mg, 58\%). m.p. $63-68{ }^{\circ} \mathrm{C} ;{ }^{1} \mathbf{H} \mathbf{N M R}\left(500 \mathrm{MHz}, \mathrm{CDCl}_{3}\right): \delta 4.14$ (br s, 2H), 3.70 (t, J = 6.7 Hz, 2H), 3.05 (br s, 3H), 2.50 (t, J = 7.3 Hz, 2H), 2.29 (t, J = 2.4 Hz, 1H), 1.94 (p, $J=7.0 \mathrm{~Hz}, 2 \mathrm{H}), 1.48(\mathrm{~s}, 9 \mathrm{H}) ;{ }^{13} \mathrm{C}$ NMR $\left(126 \mathrm{MHz}, \mathrm{CDCl}_{3}\right): \delta 173.2,154.9,154.7$ (CO rotamers), 154.2

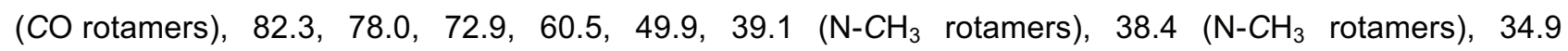
( $\mathrm{N}-\mathrm{CH}_{2}$ rotamers), $33.4\left(\mathrm{~N}-\mathrm{CH}_{2}\right.$ rotamers), 31.4, 28.3, 22.8, 14.4; IR (thin film): v 3261, 2979, 1728, 1368, 1159, $1105 \mathrm{~cm}^{-1}$; ESI-HRMS calcd for $\mathrm{C}_{16} \mathrm{H}_{27} \mathrm{~N}_{2} \mathrm{O}_{6}[\mathrm{M}+\mathrm{H}]^{+} 343.1864$, found 343.1862 .

Synthesis of $\mathrm{N}$-(7-diethylamino-2-oxo-2H-chromene-3-carboxamidoethylcarbamoyl)propyl)- $\mathrm{N}$-tertbutoxycarbonyl-O-(N'-methyl-N'-propargylcarbamoyl)hydroxylamine (S7)

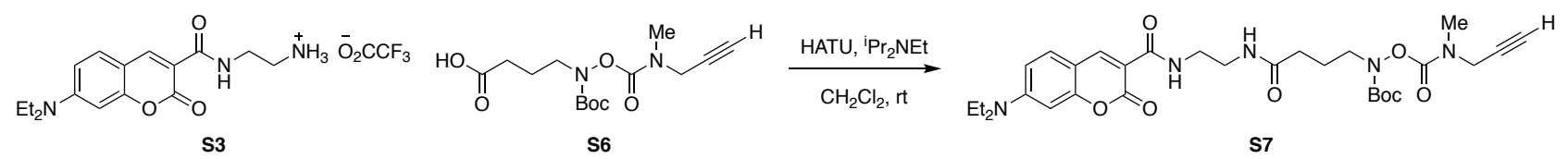

A round-bottom flask was charged with carboxylic acid S6 (491 mg, $1.56 \mathrm{mmol}, 1.00$ equiv) and HATU (654 mg, $1.72 \mathrm{mmol}, 1.10$ equiv). The solids were dissolved in $\mathrm{CH}_{2} \mathrm{Cl}_{2}(10 \mathrm{~mL})$ and ${ }^{\mathrm{i}} \mathrm{Pr}_{2} \mathrm{NEt}(840 \mu \mathrm{L}$, $4.7 \mathrm{mmol}, 3.00$ equiv) was added. After stirring for $5 \mathrm{~min}$ at $\mathrm{rt}$, the mixture became a clear yellowish solution. Ammonium salt S3 $(780 \mathrm{mg}, 1.87 \mathrm{mmol}, 1.20$ equiv) was added and the reaction stirred at $\mathrm{rt}$ for $5 \mathrm{~h}$. The 
reaction was quenched with $\mathrm{HCl} 0.5 \mathrm{M}$, extracted with $\mathrm{CH}_{2} \mathrm{Cl}_{2}$ and the organic phase washed with sat. aq. $\mathrm{NaHCO}_{3}$ and $\mathrm{H}_{2} \mathrm{O} /$ brine. The organic extracts were collected, dried with $\mathrm{Na}_{2} \mathrm{SO}_{4}$, filtered and evaporated in vacuo. The residue was purified by column chromatography on silica gel (eluting with $\mathrm{CH}_{2} \mathrm{Cl}_{2} / \mathrm{MeOH} / \mathrm{NEt}_{3}=100: 1: 1$ ) followed by another column chromatography on silica gel (eluting with $\left.\mathrm{EtOAc} / \mathrm{NEt}_{3}=100: 1\right)$ to give $\mathbf{S 7}$ as a yellow solid $(572 \mathrm{mg}, 61 \%)$. m.p. $109-114{ }^{\circ} \mathrm{C} ;{ }^{1} \mathbf{H} \mathbf{N M R}(500 \mathrm{MHz}$, $\left.\mathrm{CDCl}_{3}\right): \delta 9.01(\mathrm{t}, J=6.0 \mathrm{~Hz}, 1 \mathrm{H}), 8.66(\mathrm{~s}, 1 \mathrm{H}), 7.43(\mathrm{~d}, J=9.0 \mathrm{~Hz}, 1 \mathrm{H}), 6.69(\mathrm{br} \mathrm{s}, 1 \mathrm{H}), 6.66(\mathrm{dd}, J=9.0$, $2.4 \mathrm{~Hz}, 1 \mathrm{H}), 6.50(\mathrm{dd}, J=2.4,0.7 \mathrm{~Hz}, 1 \mathrm{H}), 4.10(\mathrm{br} \mathrm{s}, 2 \mathrm{H}), 3.64(\mathrm{t}, J=6.6 \mathrm{~Hz}, 2 \mathrm{H}), 3.57(\mathrm{q}, J=6.1 \mathrm{~Hz}, 2 \mathrm{H})$, 3.47-3.41 (m, 6H), $3.01(\mathrm{br} \mathrm{s}, 3 \mathrm{H}), 2.33-2.24(\mathrm{~m}, 3 \mathrm{H}), 1.93(\mathrm{p}, J=7.0 \mathrm{~Hz}, 2 \mathrm{H}), 1.44(\mathrm{~s}, 9 \mathrm{H}), 1.23(\mathrm{t}$, $J=7.1 \mathrm{~Hz}, 6 \mathrm{H}) ;{ }^{13} \mathrm{C}$ NMR $\left(126 \mathrm{MHz}, \mathrm{CDCl}_{3}\right): \delta 172.9,164.6,162.7,157.8,155.1,154.9$ (CO rotamers), 154.2 (CO rotamers), 152.6, 148.3, 131.4, 110.3, 110.1, 108.6, 96.9, 82.3, 78.0, 72.9, 50.0, 45.4, 40.9, 39.3, $39.1\left(\mathrm{~N}-\mathrm{CH}_{3}\right.$ rotamers), $38.4\left(\mathrm{~N}-\mathrm{CH}_{3}\right.$ rotamers $), 34.9\left(\mathrm{~N}-\mathrm{CH}_{2}\right.$ rotamers $), 33.6,33.5\left(\mathrm{~N}^{-} \mathrm{CH}_{2}\right.$ rotamers $), 28.3$, 23.6, 12.5; IR (thin film): $v 3309,2975,1698,1616,1509,1417,1351,1228,1134 \mathrm{~cm}^{-1}$; ESI-HRMS calcd for $\mathrm{C}_{30} \mathrm{H}_{42} \mathrm{~N}_{5} \mathrm{O}_{8}[\mathrm{M}+\mathrm{H}]^{+} 600.3028$, found 600.3020 .

\section{Synthesis of $\boldsymbol{N}^{\alpha}$-(4-dimethylaminophenylazo)benzenesulfonyl)- $\boldsymbol{N}^{\S}$-tert-butoxycarbonyl-L-lysine (S9)}

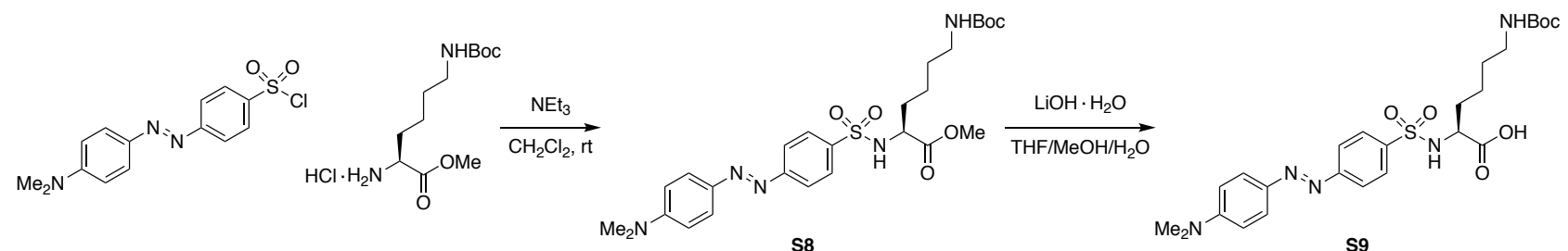

To a round-bottom flask $N^{\varepsilon}$-tert-butoxycarbonyl-L-lysine methyl ester hydrochloride $(594 \mathrm{mg}, 2.00 \mathrm{mmol}$, 1.10 equiv) was added and dissolved in $\mathrm{CH}_{2} \mathrm{Cl}_{2}$. Triethylamine $(711 \mu \mathrm{L}, 5.0 \mathrm{mmol}, 2.50$ equiv) and 4dimethylaminophenylazo)benzenesulfonyl chloride $(576 \mathrm{mg}, 1.78 \mathrm{mmol}, 1.00$ equiv) were added sequentially. The reaction was stirred at rt for $2 \mathrm{~h}$, poured into a separation funnel, washed with $\mathrm{H}_{2} \mathrm{O} / \mathrm{brine}$ and extracted with $\mathrm{CH}_{2} \mathrm{Cl}_{2}$. The organic extracts were collected, dried with $\mathrm{Na}_{2} \mathrm{SO}_{4}$, filtered and evaporated in vacuo. The residue was purified by column chromatography on silica gel (eluting with $\mathrm{CH}_{2} \mathrm{Cl}_{2} / \mathrm{MeOH}=100: 2.5$ ) to give $\mathbf{S 8}$ as a bright red solid (633 mg, 65\%). m.p. $192-195{ }^{\circ} \mathrm{C}$; ${ }^{1} \mathbf{H} \mathbf{~ N M R}$ $\left(500 \mathrm{MHz}, \mathrm{CDCl}_{3}\right): \delta$ 7.96-7.89 (m, 6H), $6.78(\mathrm{~d}, J=9.4 \mathrm{~Hz}, 2 \mathrm{H}), 5.27(\mathrm{~d}, J=9.1 \mathrm{~Hz}, 1 \mathrm{H}), 4.56(\mathrm{br} \mathrm{s}, 1 \mathrm{H})$, $3.94(\mathrm{ddd}, J=9.1,7.8,5.0 \mathrm{~Hz}, 1 \mathrm{H}), 3.49(\mathrm{~s}, 3 \mathrm{H}), 3.14(\mathrm{~s}, 6 \mathrm{H}), 3.11-3.03(\mathrm{~m}, 2 \mathrm{H}), 1.80-1.72(\mathrm{~m}, 1 \mathrm{H}), 1.70-$ $1.60(\mathrm{~m}, 1 \mathrm{H}), 1.47-1.33(\mathrm{~m}, 12 \mathrm{H}) ;{ }^{13} \mathrm{C}$ NMR $\left(126 \mathrm{MHz}, \mathrm{CDCl}_{3}\right): \delta 172.1,156.2,155.5,153.4,143.6,139.0$, $128.4,126.2,122.6,111.8,79.3,55.7,52.7,40.5,40.2,33.0,29.5,28.6,22.2$; IR (thin film): v 3311, 2932 , 
1742, 1681, 1606, 1520, 1366, $1161 \mathrm{~cm}^{-1}$; ESI-HRMS calcd for $\mathrm{C}_{26} \mathrm{H}_{38} \mathrm{~N}_{5} \mathrm{O}_{6} \mathrm{~S}[\mathrm{M}+\mathrm{H}]^{+} 548.2537$, found 548.2533; $[\alpha]_{\mathrm{D}}^{25}:+117.3\left(c=0.48, \mathrm{CHCl}_{3}\right)$.

A round-bottom flask was charged with $\mathbf{S 8}(273 \mathrm{mg}, 0.50 \mathrm{mmol}, 1.00$ equiv) and lithium hydroxide monohydrate (84 mg, $2.0 \mathrm{mmol}, 2.00$ equiv). The solids were dissolved in $\mathrm{THF} / \mathrm{MeOH} / \mathrm{H}_{2} \mathrm{O}(4: 1: 1,5 \mathrm{~mL})$ and the mixture stirred at rt overnight. The reaction was quenched with $1 \mathrm{M}$ aqueous oxalic acid till the solution displayed a $\mathrm{pH}$ 1-2. The suspension was extracted with $\mathrm{CH}_{2} \mathrm{Cl}_{2}$, the organic extracts collected, dried with $\mathrm{Na}_{2} \mathrm{SO}_{4}$, filtered and evaporated in vacuo to give $\mathbf{S 9}$ as a red solid (340 mg, quant). m.p. $149-153{ }^{\circ} \mathrm{C}$; ${ }^{1} \mathrm{H}$ NMR (500 MHz, CD $\left.{ }_{3} \mathrm{OD}\right): \delta 7.95(\mathrm{~d}, J=8.9 \mathrm{~Hz}, 2 \mathrm{H}), 7.89(\mathrm{~d}, J=8.9 \mathrm{~Hz}, 2 \mathrm{H}), 7.86(\mathrm{~d}, J=9.2 \mathrm{~Hz}, 2 \mathrm{H})$, $6.84(\mathrm{~d}, J=9.3 \mathrm{~Hz}, 2 \mathrm{H}), 3.85(\mathrm{dd}, J=8.5,5.3 \mathrm{~Hz}, 1 \mathrm{H}), 3.12(\mathrm{~s}, 6 \mathrm{H}), 3.02-2.94(\mathrm{~m}, 2 \mathrm{H}), 1.79-1.71(\mathrm{~m}, 1 \mathrm{H})$, 1.67-1.59 (m, 1H), 1.47-1.31 (m, 13H); ${ }^{13} \mathrm{C}$ NMR (126 MHz, $\left.\mathrm{CD}_{3} \mathrm{OD}\right): \delta 174.8,158.5,156.8,154.9,144.8$, 142.0, 129.3, 126.7, 123.3, 112.6, 79.9, 57.1, 41.0, 40.4, 33.7, 30.3, 28.8, 23.8; IR (thin film): v 3273, 2931, 1699, 1603, 1520, 1364, $1135 \mathrm{~cm}^{-1}$; ESI-HRMS calcd for $\mathrm{C}_{25} \mathrm{H}_{35} \mathrm{~N}_{5} \mathrm{NaO}_{6} \mathrm{~S}[\mathrm{M}+\mathrm{Na}]^{+} 556.2200$, found $556.2194 ;[\alpha]_{D}^{25}:+55.2\left(c=0.28, \mathrm{CH}_{3} \mathrm{OH}\right)$.

\section{General procedure A: Preparation of precursors S10-S12.}
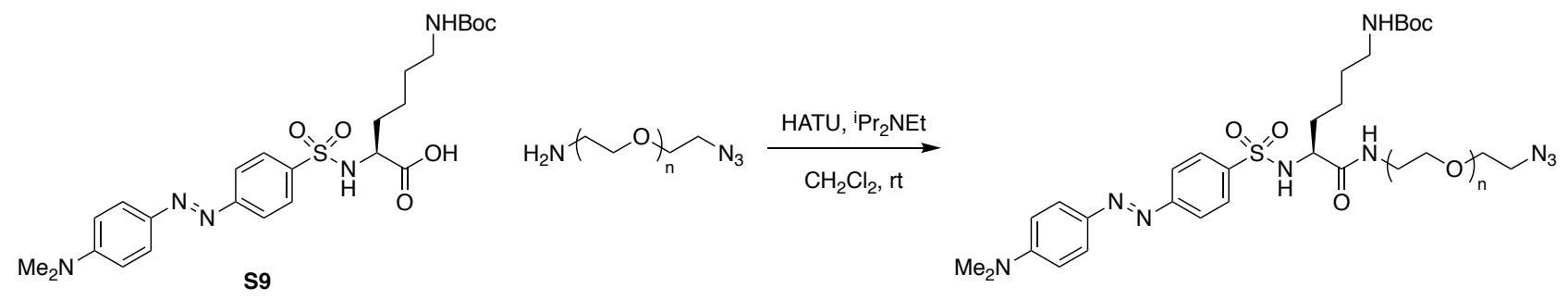

$$
\begin{array}{ll}
\mathrm{n}=3 & \mathrm{~s} 10 \\
\mathrm{n}=6 & \mathrm{~s} 11 \\
\mathrm{n}=10 & \mathrm{~s} 12
\end{array}
$$

To a round-bottom flask containing carboxylic acid $\mathbf{S 9}$ and $\mathrm{HATU}$ was added $\mathrm{CH}_{2} \mathrm{Cl}_{2}$ (final concentration $0.1 \mathrm{M})$. ${ }^{\mathrm{i}} \mathrm{Pr}_{2} \mathrm{NEt}$ was added and the mixture stirred for $5 \mathrm{~min}$ at $\mathrm{rt}$, turning from a suspension to a clear solution. O-(2-Aminoethyl)-O'-(2-azidoethyl)polyethylene glycol was added and the mixture stirred at rt overnight. The reaction was washed with saturated aqueous $\mathrm{NaHCO}_{3}$ and extracted with $\mathrm{CH}_{2} \mathrm{Cl}_{2}$. The organic extracts were collected, dried with $\mathrm{Na}_{2} \mathrm{SO}_{4}$, filtered and evaporated in vacuo. The residue was purified by column chromatography on silica gel. 
(S)-N-(11-Azido-3,6,9-trioxaundecyl)-2-(4-dimethylaminophenylazo)benzenesulfonamido)-6-(tertbutoxycarbonylamino) hexanamide (S10)

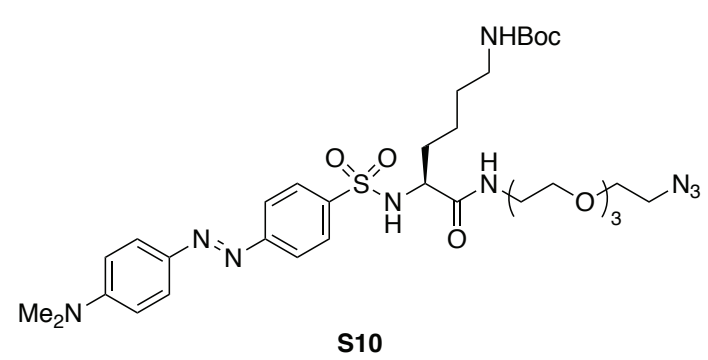

Prepared following General procedure A with S9 (300 mg, $0.56 \mathrm{mmol}, 1.00$ equiv), 11-azido-3,6,9-trioxaundecan-1amine (139 $\mu \mathrm{L}, 95 \%$ purity, $0.67 \mathrm{mmol}, 1.20$ equiv), HATU (240 mg, $0.63 \mathrm{mmol}, 1.10$ equiv) and ${ }^{\mathrm{i}} \mathrm{Pr}_{2} \mathrm{NEt}(293 \mu \mathrm{L}$, $1.70 \mathrm{mmol}, 3.00$ equiv). Isolated by column chromatography on silica gel (eluting with $\left.\mathrm{CH}_{2} \mathrm{Cl}_{2} / \mathrm{MeOH}=100: 4\right)$ to give $\mathbf{S} 10$ as a red solid (310 mg, 85\%). m.p. $135-139{ }^{\circ} \mathrm{C}$; ${ }^{1} \mathrm{H}$ NMR $\left(500 \mathrm{MHz}, \mathrm{CDCl}_{3}\right): \delta$ 7.99-7.87 (m, 6H), $6.78(\mathrm{~d}, J=9.0 \mathrm{~Hz}, 2 \mathrm{H}), 6.75(\mathrm{br} \mathrm{s}, 1 \mathrm{H}), 5.93-5.81(\mathrm{~m}, 1 \mathrm{H})$, $4.69(\mathrm{br} \mathrm{s}, 1 \mathrm{H}), 3.72-3.60(\mathrm{~m}, 10 \mathrm{H}), 3.59-3.52(\mathrm{~m}, 2 \mathrm{H}), 3.44-3.35(\mathrm{~m}, 4 \mathrm{H}), 3.33-3.27(\mathrm{~m}, 2 \mathrm{H}), 3.12(\mathrm{~s}, 6 \mathrm{H})$, 3.10-3.03 (m, 1H), 3.02-2.94 (m, 1H) 1.74-1.59 (m, 2H), 1.48-1.22 (m, 13H); ${ }^{13} \mathrm{C} \mathrm{NMR}\left(126 \mathrm{MHz}, \mathrm{CDCl}_{3}\right): \delta$ $170.9,156.6,155.3,153.4,143.5,139.1,128.5,126.3,122.6,111.8,79.5,70.8,70.7,70.7,70.4,70.1,69.5$, 56.8, 50.8, 40.5, 39.5, 39.4, 32.4, 29.6, 28.6, 21.6; IR (thin film): v 3347, 3259, 2930, 2864, 2103, 1682, 1646, 1523, 1369, $1141 \mathrm{~cm}^{-1}$; ESI-HRMS calcd for $\mathrm{C}_{33} \mathrm{H}_{52} \mathrm{~N}_{9} \mathrm{O}_{8} \mathrm{~S}\left[\mathrm{M}+\mathrm{H}^{+} 734.3654\right.$, found 734.3648 ; $[\alpha]_{D}{ }^{25}$ : $+47.4\left(c=0.62, \mathrm{CHCl}_{3}\right)$.

(S)-N-(20-Azido-3,6,9,12,15,18-hexaoxaeicosyl)-2-(4-dimethylaminophenylazo) benzenesulfonamido)6-(tert-butoxycarbonylamino)hexanamide (S11)

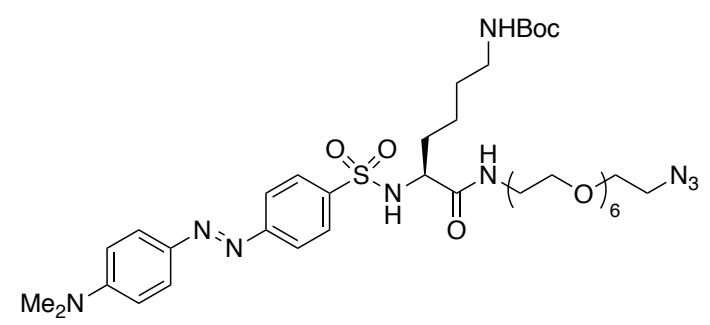

S11

Prepared following General procedure A with S9 $(71.6 \mathrm{mg}$, $0.13 \mathrm{mmol}, \quad 1.00$ equiv), 20 -azido-3,6,9,12,15,18hexaoxaeicosan-1-amine $(50 \mu \mathrm{L}, 90 \%$ purity, $0.13 \mathrm{mmol}$, 1.0 equiv), HATU (53.5 mg, $0.14 \mathrm{mmol}, 1.10$ equiv) and ' $\mathrm{Pr}_{2} \mathrm{NEt}(72 \mu \mathrm{L}, 0.4 \mathrm{mmol}, 3.00$ equiv). Isolated by column chromatography on silica gel (eluting with $\left.\mathrm{CH}_{2} \mathrm{Cl}_{2} / \mathrm{MeOH}=100: 4\right)$ to give $\mathbf{S 1 1}$ as a red solid $(76.3 \mathrm{mg}, 69 \%)$. m.p. $87-90{ }^{\circ} \mathrm{C} ;{ }^{1} \mathrm{H}$ NMR $\left(500 \mathrm{MHz}, \mathrm{CDCl}_{3}\right): \delta 7.94(\mathrm{~d}, \mathrm{~J}=8.7 \mathrm{~Hz}, 2 \mathrm{H}), 7.91-7.86(\mathrm{~m}, 4 \mathrm{H}), 6.80(\mathrm{br}, 1 \mathrm{H}), 6.75$ $(\mathrm{d}, J=9.2 \mathrm{~Hz}, 2 \mathrm{H}), 5.91(\mathrm{br}, 1 \mathrm{H}), 4.73(\mathrm{br}, 1 \mathrm{H}), 3.72-3.49(\mathrm{~m}, 23 \mathrm{H}), 3.45-3.35(\mathrm{~m}, 4 \mathrm{H}), 3.32-3.27(\mathrm{~m}, 2 \mathrm{H})$, $3.12(\mathrm{~s}, 6 \mathrm{H}), 3.10-3.02(\mathrm{~m}, 1 \mathrm{H}), 3.01-2.93(\mathrm{~m}, 1 \mathrm{H}), 1.75-1.58(\mathrm{~m}, 2 \mathrm{H}), 1.45(\mathrm{~s}, 9 \mathrm{H}), 1.43-1.18(\mathrm{~m}, 4 \mathrm{H})$;

${ }^{13} \mathrm{C}$ NMR $\left(126 \mathrm{MHz}, \mathrm{CDCl}_{3}\right): \delta 170.9,156.6,155.7,153.3,143.7,139.2,128.5,125.9,122.6,111.6,79.4$, $70.8,70.8,70.7,70.7,70.6,70.6,70.6,70.6,70.6,70.4,70.1,69.5,56.8,50.8,40.4,39.5,39.5,32.4,29.6$, 
28.6, 21.6; IR (thin film): $v 3335,3259,2926,2866,2103,1683,1645,1607,1520,1369,1140 \mathrm{~cm}^{-1}$; ESI-HRMS calcd for $\mathrm{C}_{39} \mathrm{H}_{63} \mathrm{~N}_{9} \mathrm{NaO}_{11} \mathrm{~S}[\mathrm{M}+\mathrm{Na}]^{+} 888.4260$, found 888.4252; $[\alpha]_{D}{ }^{25}:+30.9\left(c=0.78, \mathrm{CHCl}_{3}\right)$.

\section{(S)-N-(32-Azido-3,6,9,12,15,18,21,24,27,30-decaoxadotriacontyl)-2-(4-dimethylaminophenylazo)}

\section{benzenesulfonamido)-6-(tert-butoxycarbonylamino)hexanamide (S12)}

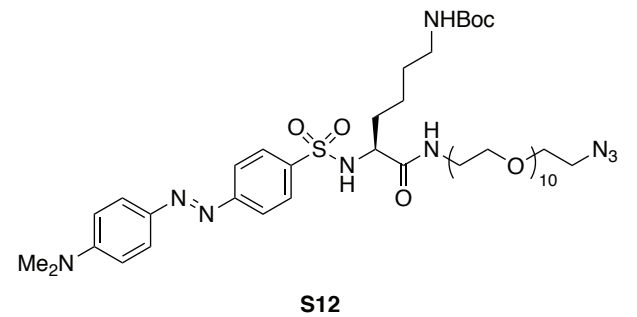

Prepared following General procedure A with $\mathbf{5 9}(40.6 \mathrm{mg}$, $76 \mu \mathrm{mol}, \quad 1.00 \quad$ equiv), $\quad 32$-azido-3,6,9,12,15,18,21,24,27,30decaoxadotriacontan-1-amine $(50 \mu \mathrm{L}, 90 \%$ purity, $80 \mu \mathrm{mol}$, 1.05 equiv), HATU (32 mg, $85 \mu \mathrm{mol}, 1.10$ equiv) and ${ }^{\mathrm{i}} \mathrm{Pr}_{2} \mathrm{NEt}$

(42 $\mu \mathrm{L}, 250 \mu \mathrm{mol}, 3.00$ equiv). Isolated by column chromatography on silica gel (eluting with $\left.\mathrm{CH}_{2} \mathrm{Cl}_{2} / \mathrm{MeOH}=100: 5\right)$ to give $\mathbf{S} 12$ as a red solid (46.8 mg, 59\%). ${ }^{1} \mathbf{H} \mathbf{~ N M R}\left(500 \mathrm{MHz}, \mathrm{CDCl}_{3}\right): \delta 7.94(\mathrm{~d}$, $J=8.7 \mathrm{~Hz}, 2 \mathrm{H}), 7.92-7.87(\mathrm{~m}, 4 \mathrm{H}), 6.83(\mathrm{br}, 1 \mathrm{H}), 6.76(\mathrm{~d}, J=9.3 \mathrm{~Hz}, 2 \mathrm{H}), 5.91(\mathrm{~d}, J=7.3 \mathrm{~Hz}, 1 \mathrm{H}), 4.74(\mathrm{br}$, $1 \mathrm{H}), 3.68-3.62(\mathrm{~m}, 31 \mathrm{H}), 3.61-3.58(\mathrm{~m}, 2 \mathrm{H}), 3.57-3.51(\mathrm{~m}, 2 \mathrm{H}), 3.45-3.35(\mathrm{~m}, 4 \mathrm{H}), 3.34-3.24(\mathrm{~m}, 2 \mathrm{H}), 3.12(\mathrm{~s}$, $6 \mathrm{H}), 3.10-3.03(\mathrm{~m}, 1 \mathrm{H}), 3.01-2.93(\mathrm{~m}, 1 \mathrm{H}), 1.74-1.56(\mathrm{~m}, 2 \mathrm{H}), 1.45(\mathrm{~s}, 9 \mathrm{H}), 1.42-1.34(\mathrm{~m}, 2 \mathrm{H}), 1.33-1.20(\mathrm{~m}$, $2 \mathrm{H}) ;{ }^{13} \mathrm{C}$ NMR $\left(126 \mathrm{MHz}, \mathrm{CDCl}_{3}\right): \delta 170.9,156.6,155.6,153.3,143.6,139.2,128.5,126.0,122.6,111.7$, $79.4,70.8,70.8,70.7,70.7,70.6,70.6,70.6,70.6,70.5,70.4,70.1,69.6,56.8,50.8,40.5,39.6,39.4,32.5$, 29.6, 28.6, 21.6; IR (thin film): $v$ 3334, 3258, 2867, 2104, 1682, 1646, 1607, 1522, 1369, $1140 \mathrm{~cm}^{-1}$; ESI-HRMS calcd for $\mathrm{C}_{47} \mathrm{H}_{83} \mathrm{~N}_{10} \mathrm{O}_{15} \mathrm{~S}\left[\mathrm{M}+\mathrm{NH}_{4}\right]^{+} 1059.5755$, found 1059.5736; $[\alpha]_{\mathrm{D}}{ }^{25}:+35.3\left(c=0.65, \mathrm{CHCl}_{3}\right)$.

\section{Synthesis of (S)-N-(4-Azidobutyl)-2-(4-dimethylaminophenylazo)benzenesulfonamido)-6-(tert-} butoxycarbonylamino) hexanamide (S14)

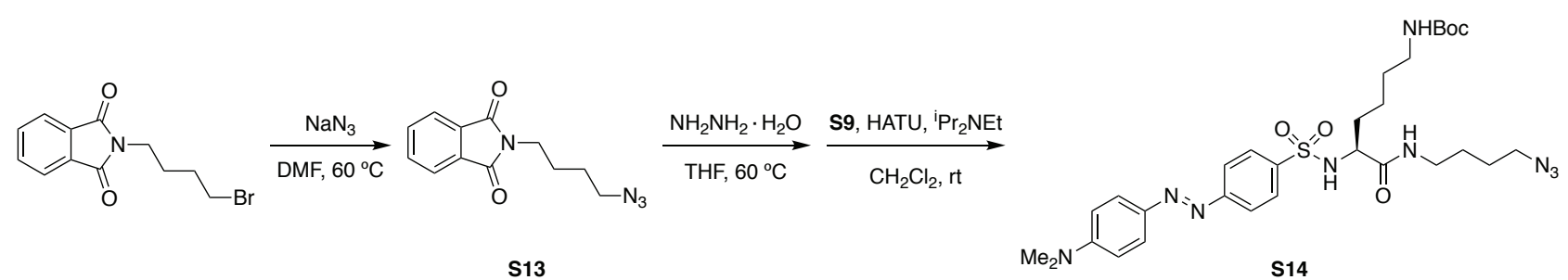

A round-bottom flask was charged with $\mathrm{N}$-(4-bromobutyl)phthalimide ${ }^{5}(1.41 \mathrm{~g}, 5.0 \mathrm{mmol}, 1.00$ equiv) and sodium azide $(1.0 \mathrm{~g}, 15.0 \mathrm{mmol}, 3.00$ equiv). The solids were suspended in DMF $(10 \mathrm{~mL})$ and the mixture stirred for $6 \mathrm{~h}$ at $60{ }^{\circ} \mathrm{C}$. The reaction was cooled to rt, poured into $\mathrm{H}_{2} \mathrm{O} / \mathrm{brine}$ and extracted with EtOAc/hexanes (2:1). The organic extracts were collected, dried with $\mathrm{Na}_{2} \mathrm{SO}_{4}$, filtered and evaporated in vacuo to give $\mathbf{S} 13$ as a white solid $(1.08 \mathrm{~g}, 89 \%)$ without further purification. m.p. $34-36{ }^{\circ} \mathrm{C} ;{ }^{1} \mathbf{H}$ NMR 
$\left(500 \mathrm{MHz}, \mathrm{CDCl}_{3}\right): \delta 7.87(\mathrm{~m}, 2 \mathrm{H}), 7.75-7.70(\mathrm{~m}, 2 \mathrm{H}), 3.72(\mathrm{t}, J=7.0 \mathrm{~Hz}, 2 \mathrm{H}), 3.33(\mathrm{t}, J=6.8 \mathrm{~Hz}, 2 \mathrm{H}), 1.81-$ $1.74(\mathrm{~m}, 2 \mathrm{H}), 1.68-1.60(\mathrm{~m}, 2 \mathrm{H}) ;{ }^{13} \mathrm{C}$ NMR $\left(126 \mathrm{MHz}, \mathrm{CDCl}_{3}\right): \delta 168.5,134.1,132.2,123.4,51.0,37.4,26.4$, 26.0; IR (thin film): $v$ 2942, 2094, 1708, 1396, $1043 \mathrm{~cm}^{-1}$; ESI-HRMS calcd for $\mathrm{C}_{12} \mathrm{H}_{12} \mathrm{~N}_{4} \mathrm{NaO}_{2}[\mathrm{M}+\mathrm{Na}]^{+}$ 267.0852 , found 267.0855 .

To a round-bottom flask containing a solution of $\mathbf{S} 13(37.0 \mathrm{mg}, 0.15 \mathrm{mmol}, 1.10$ equiv) in THF (2 mL) was added hydrazine monohydrate $\left(50 \mu \mathrm{L}, 1.0 \mathrm{mmol}, 7.00\right.$ equiv). The solution was stirred at $60{ }^{\circ} \mathrm{C}$ for $4 \mathrm{~h}$, cooled to rt, diluted with $\mathrm{CH}_{2} \mathrm{Cl}_{2}$ and extracted with $0.2 \mathrm{M} \mathrm{HCl}$. The acidic aqueous extracts were basified with $1 \mathrm{M}$ aq. $\mathrm{NaOH}$ until $\mathrm{pH}>14$, extracted with $\mathrm{CH}_{2} \mathrm{Cl}_{2}$, dried with $\mathrm{Na}_{2} \mathrm{SO}_{4}$, filtered and concentrated in rotavap (complete drying of the sample was avoided).

A separate round-bottom flask was charged with carboxylic acid $\mathbf{S 9}$ (74.6 $\mathrm{mg}, 0.14 \mathrm{mmol}, 1.00$ equiv) and HATU (57 mg, $0.15 \mathrm{mmol}, 1.10$ equiv). The solid were suspended in $\mathrm{CH}_{2} \mathrm{Cl}_{2}(1 \mathrm{~mL})$ and ${ }^{\mathrm{i}} \mathrm{Pr}_{2} \mathrm{NEt}(100 \mu \mathrm{L}$, $0.56 \mathrm{mmol}, 4.00$ equiv) was added. The mixture was stirred for $5 \mathrm{~min}$ at $\mathrm{rt}$, turning from a suspension to a clear solution. To this solution were added the concentrated extracts from above, and the mixture was stirred at rt overnight. The mixture was poured into a separation funnel, washed with $\mathrm{H}_{2} \mathrm{O} /$ brine and extracted with $\mathrm{CH}_{2} \mathrm{Cl}_{2}$. The organic extracts were collected, dried with $\mathrm{Na}_{2} \mathrm{SO}_{4}$, filtered and evaporated in vacuo. The residue was purified by column chromatography on silica gel (eluting with $\mathrm{CH}_{2} \mathrm{Cl}_{2} / \mathrm{MeOH}=100: 4$ ) to give S14 as a red solid (42.4 mg, $48 \%$ over two steps). m.p. $166-169{ }^{\circ} \mathrm{C} ;{ }^{1} \mathrm{H}$ NMR $\left(500 \mathrm{MHz}, \mathrm{CDCl}_{3}\right): \delta 7.96$ (d, $J=8.7 \mathrm{~Hz}, 2 \mathrm{H}), 7.92-7.88(\mathrm{~m}, 4 \mathrm{H}), 6.76(\mathrm{~d}, J=9.2 \mathrm{~Hz}, 2 \mathrm{H}), 6.57(\mathrm{t}, J=5.4 \mathrm{~Hz}, 1 \mathrm{H}), 5.88(\mathrm{~d}, J=6.7 \mathrm{~Hz}, 1 \mathrm{H})$, $4.68(\mathrm{t}, J=6.0 \mathrm{~Hz}, 1 \mathrm{H}), 3.63(\mathrm{td}, J=6.9,4.4 \mathrm{~Hz}, 1 \mathrm{H}), 3.24-3.20(\mathrm{~m}, 2 \mathrm{H}), 3.20-3.16(\mathrm{~m}, 2 \mathrm{H}), 3.12(\mathrm{~s}, 6 \mathrm{H})$, 2.98-2.91 (m, 1H), 1.73-1.64 (m, 2H), 1.54-1.17 (m, 18H); ${ }^{13} \mathrm{C}$ NMR (126 MHz, $\left.\mathrm{CDCl}_{3}\right): \delta 171.1,157.1$, 155.9, 153.3, 143.7, 138.6, 128.6, 125.9, 122.7, 111.6, 79.9, 56.6, 51.1, 40.4, 39.1, 38.7, 31.4, 29.4, 28.6, 26.8, 26.2, 21.0; IR (thin film): $v$ 3356, 3262, 2928, 1683, 1650, 1607, 1541, 1367, 1162, $1142 \mathrm{~cm}^{-1}$; ESI-HRMS calcd for $\mathrm{C}_{29} \mathrm{H}_{43} \mathrm{~N}_{9} \mathrm{NaO}_{5} \mathrm{~S}[\mathrm{M}+\mathrm{Na}]^{+} 652.3000$, found 652.2995; $[\alpha]_{\mathrm{D}}{ }^{25}:+13.1\left(c=0.25, \mathrm{CHCl}_{3}\right)$. 
General procedure B: Preparation of precursors S16-S19
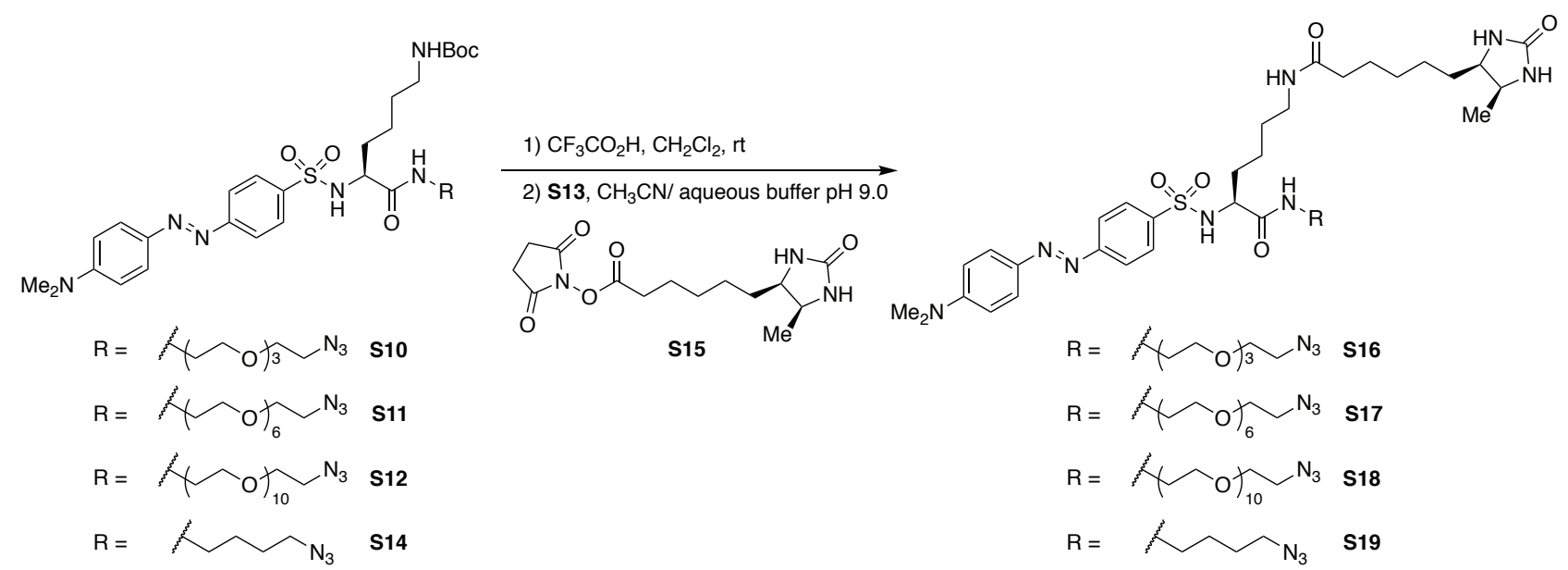

Boc-carbamate (S10, S14, S12 or S14) was dissolved in $\mathrm{CH}_{2} \mathrm{Cl}_{2} / \mathrm{CF}_{3} \mathrm{CO}_{2} \mathrm{H}(1: 1,0.05 \mathrm{M}$ final concentration) and the mixture stirred for $1 \mathrm{~h}$ at rt. The reaction was basified with $1 \mathrm{M} \mathrm{NaOH}$ to $\mathrm{pH}>12$, extracted with $\mathrm{CH}_{2} \mathrm{Cl}_{2}$, dried with $\mathrm{Na}_{2} \mathrm{SO}_{4}$, filtered and evaporated in vacuo.

To the crude obtained above was added d-desthiobiotin succinimidyl ester (S15). The solids were dissolved in DMF and $1 \mathrm{M}$ aqueous buffer pH 9.0 [prepared by dissolving $\mathrm{NaHCO}_{3}\left(0.42 \mathrm{~g}, 5.0 \mathrm{mmol}\right.$ ) and $\mathrm{Na}_{2} \mathrm{CO}_{3}$ (10.0 g, $95.0 \mathrm{mmol}$ ) in distilled water (final volume $100 \mathrm{~mL}$ ), final $\mathrm{pH}$ was adjusted using $1 \mathrm{M} \mathrm{NaOH}$ and $\mathrm{HCl}$ solutions]. The reaction was stirred at rt overnight, diluted with $\mathrm{CH}_{2} \mathrm{Cl}_{2}$, washed with $\mathrm{H}_{2} \mathrm{O} /$ brine and extracted with $\mathrm{CH}_{2} \mathrm{Cl}_{2}$. The organic extracts were collected, dried with $\mathrm{Na}_{2} \mathrm{SO}_{4}$, filtered and evaporated in vacuo. The residue was purified by column chromatography on silica gel.

(S)-N-(11-Azido-3,6,9-trioxaundecyl)-2-(4-dimethylaminophenylazo)benzenesulfonamido)-6-(6-

((4R,5S)-5-methyl-2-oxoimidazolidin-4-yl)hexanamido)hexanamide (S16)

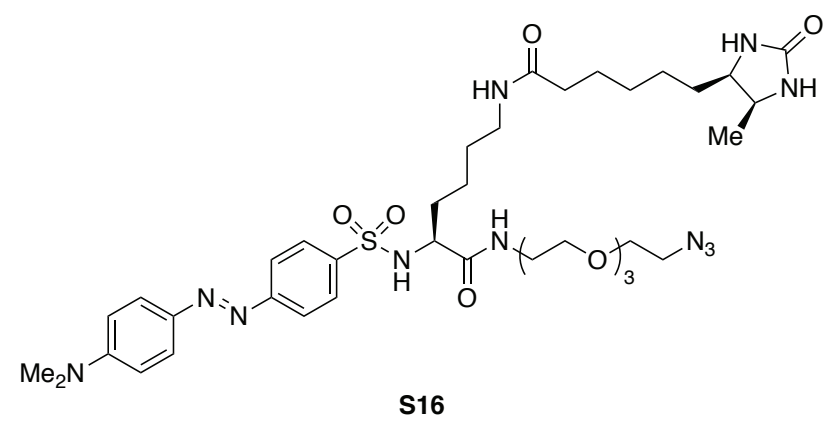

Prepared following General procedure B with S10 (150 mg, $0.20 \mathrm{mmol}, 1.00$ equiv) and $\mathbf{S} 15$ (90 mg, $0.27 \mathrm{mmol}, \quad 1.30$ equiv). Isolated by column chromatography on silica gel (eluting with $\left.\mathrm{CH}_{2} \mathrm{Cl}_{2} / \mathrm{MeOH}=100: 7\right)$ to give $\mathbf{S} 16$ as a red solid (134 mg, 81\%). m.p. $135-139{ }^{\circ} \mathrm{C} ;{ }^{1} \mathrm{H}$ NMR $(500 \mathrm{MHz}$, $\left.\mathrm{CD}_{3} \mathrm{OD}\right): \delta 7.95(\mathrm{~d}, J=8.9 \mathrm{~Hz}, 2 \mathrm{H}), 7.91(\mathrm{~d}, J=8.8 \mathrm{~Hz}, 2 \mathrm{H}), 7.88(\mathrm{~d}, J=9.2 \mathrm{~Hz}, 2 \mathrm{H}), 6.85(\mathrm{~d}, J=9.2 \mathrm{~Hz}$, $2 \mathrm{H}), 3.84-3.73(\mathrm{~m}, 2 \mathrm{H}), 3.70-3.67(\mathrm{~m}, 1 \mathrm{H}), 3.66-3.61(\mathrm{~m}, 6 \mathrm{H}), 3.60-3.57(\mathrm{~m}, 2 \mathrm{H}), 3.52-3.49(\mathrm{~m}, 2 \mathrm{H}), 3.37-$ $3.34(\mathrm{~m}, 2 \mathrm{H}), 3.33-3.25(\mathrm{~m}, 2 \mathrm{H}), 3.15-3.06(\mathrm{~m}, 9 \mathrm{H}), 2.15(\mathrm{t}, \mathrm{J}=7.6 \mathrm{~Hz}, 2 \mathrm{H}), 1.69-1.53(\mathrm{~m}, 4 \mathrm{H}), 1.51-1.24(\mathrm{~m}$, 
$11 \mathrm{H}), 1.10(\mathrm{~d}, J=6.5 \mathrm{~Hz}, 3 \mathrm{H}) ;{ }^{13} \mathrm{C}$ NMR (126 MHz, $\left.\mathrm{CD}_{3} \mathrm{OD}\right): \delta 176.1,173.6,166.2,156.8,154.9,144.8$, $141.5,129.4,126.8,123.4,112.6,71.6,71.5,71.3,71.1,70.2,57.9,57.4,52.7,51.8,40.4,40.2,40.0,37.0$, $34.0,30.7,30.2,29.7,27.1,26.9,23.9,15.6$; IR (thin film): $v 3250,2931,2860,2100,1709,1645,1607$, 1369, $1141 \mathrm{~cm}^{-1}$; ESI-HRMS calcd for $\mathrm{C}_{38} \mathrm{H}_{59} \mathrm{~N}_{11} \mathrm{NaO}_{8} \mathrm{~S}[\mathrm{M}+\mathrm{Na}]^{+} 852.4161$, found 852.4144; [ $\left.\alpha\right]_{\mathrm{D}}{ }^{25}:+48.9$ $\left(c=0.33, \mathrm{CH}_{3} \mathrm{OH}\right)$.

(S)-N-(20-Azido-3,6,9,12,15,18-hexaoxaeicosyl)-2-(4-dimethylaminophenylazo)benzenesulfonamido)6-(6-((4R,5S)-5-methyl-2-oxoimidazolidin-4-yl)hexanamido)hexanamide (S17)

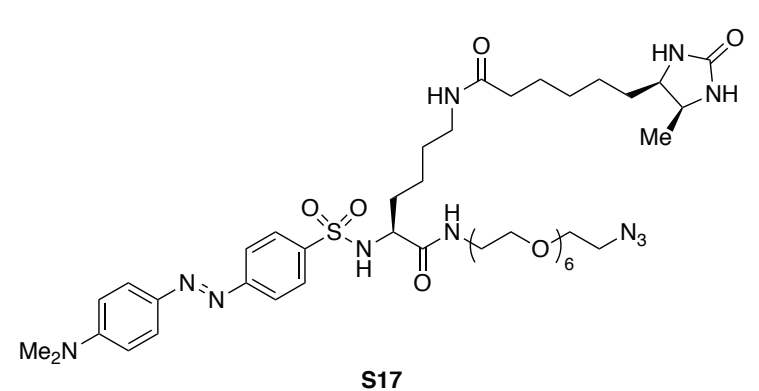

Prepared following General procedure B with $\mathbf{S 1 1}(60 \mathrm{mg}$, $0.07 \mathrm{mmol}, 1.00$ equiv) and $\mathbf{S} 15(25 \mathrm{mg}, 0.07 \mathrm{mmol}$, 1.00 equiv). Isolated by column chromatography on silica gel (eluting with $\mathrm{CH}_{2} \mathrm{Cl}_{2} / \mathrm{MeOH}=100: 8$ to $100: 10$ ) to give S17 as a red solid (45 mg, 67\%). m.p. $105-109{ }^{\circ} \mathrm{C}$; ${ }^{1} \mathrm{H}$ NMR $\left(500 \mathrm{MHz}, \mathrm{CDCl}_{3}\right): \delta 7.94(\mathrm{~d}, J=8.6 \mathrm{~Hz}, 2 \mathrm{H})$, 7.89-7.84 (m, 4H), $7.18(\mathrm{~d}, J=8.2 \mathrm{~Hz}, 2 \mathrm{H}), 6.74(\mathrm{~d}, J=9.2 \mathrm{~Hz}, 2 \mathrm{H}), 6.33(\mathrm{br}, 1 \mathrm{H}), 6.01(\mathrm{br}, 1 \mathrm{H}), 5.10(\mathrm{br}$, 1H), 3.90-3.82 (m, 1H), 3.82-3.75 (m, 1H), 3.74-3.68 (m, 1H), 3.67-3.59 (m, 18H), 3.59-3.54 (m, 2H), 3.52$3.47(\mathrm{~m}, 2 \mathrm{H}), 3.39-3.29(\mathrm{~m}, 4 \mathrm{H}), 3.24-3.15(\mathrm{~m}, 4 \mathrm{H}), 3.10(\mathrm{~s}, 6 \mathrm{H}), 2.23-2.13(\mathrm{~m}, 2 \mathrm{H}), 1.75-1.57(\mathrm{~m}, 4 \mathrm{H}), 1.55-$ $1.22(\mathrm{~m}, 10 \mathrm{H}), 1.12(\mathrm{~d}, J=6.7 \mathrm{~Hz}, 3 \mathrm{H}) ;{ }^{13} \mathrm{C}$ NMR $\left(126 \mathrm{MHz}, \mathrm{CDCl}_{3}\right): \delta 173.6,171.5,164.2,155.5,153.2$, 143.6, 139.7, 128.2, 125.8, 122.6, 111.6, 70.8, 70.7, 70.7, 70.6, 70.6, 70.5, 70.5, 70.2, 70.1, 69.5, 56.7, 56.1, 51.6, 50.8, 40.4, 39.3, 38.7, 35.8, 32.4, 29.6, 28.4, 28.2, 25.6, 25.3, 22.0, 15.8; IR (thin film): v 3245, 2927, 2860, 2102, 1709, 1641, 1607, 1551, 1370, 1139, $1087 \mathrm{~cm}^{-1}$; ESI-HRMS calcd for $\mathrm{C}_{44} \mathrm{H}_{75} \mathrm{~N}_{12} \mathrm{O}_{11} \mathrm{~S}\left[\mathrm{M}+\mathrm{NH}_{4}\right]^{+}$ 979.5393, found 979.5381; $[\alpha]_{\mathrm{D}}^{25}:+44.4\left(c=1.37, \mathrm{CHCl}_{3}\right)$.

\section{(S)-N-(32-Azido-3,6,9,12,15,18,21,24,27,30-decaoxadotriacontyl)-2-(4-dimethylaminophenylazo)}

\section{benzenesulfonamido)-6-(6-((4R,5S)-5-methyl-2-oxoimidazolidin-4-yl)hexanamido)hexanamide (S18)}

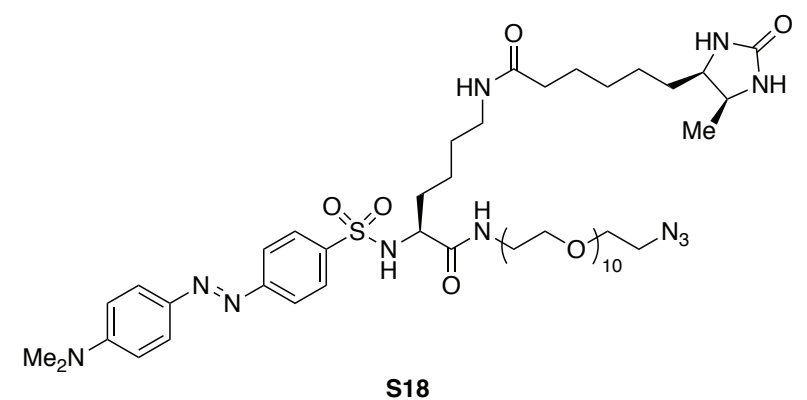

Prepared following General procedure B with $\mathbf{S 1 2}$ (33 mg, $32 \mu \mathrm{mol}, 1.00$ equiv) and $\mathbf{S} 15$ (15 mg, $50 \mu \mathrm{mol}$, 1.50 equiv). Isolated by column chromatography on silica gel (eluting with $\mathrm{CH}_{2} \mathrm{Cl}_{2} / \mathrm{MeOH}=100: 10$ ) to give 
S18 as a red gum (30 mg, 84\%). ${ }^{1} \mathrm{H}$ NMR $\left(500 \mathrm{MHz}, \mathrm{CDCl}_{3}\right): \delta 7.95(\mathrm{~d}, \mathrm{~J}=8.9 \mathrm{~Hz}, 2 \mathrm{H}), 7.92-7.87(\mathrm{~m}, 4 \mathrm{H})$, $7.16(\mathrm{~d}, J=8.4 \mathrm{~Hz}, 1 \mathrm{H}), 7.07(\mathrm{t}, J=5.6 \mathrm{~Hz}, 1 \mathrm{H}), 6.76(\mathrm{~d}, J=9.3 \mathrm{~Hz}, 2 \mathrm{H}), 6.21(\mathrm{t}, J=4.8 \mathrm{~Hz}, 1 \mathrm{H}), 5.72(\mathrm{br}$, 1H), $4.82(\mathrm{br}, 1 \mathrm{H}), 3.92-3.85(\mathrm{~m}, 1 \mathrm{H}), 3.84-3.78(\mathrm{~m}, 1 \mathrm{H}), 3.74-3.69(\mathrm{~m}, 1 \mathrm{H}), 3.68-3.60(\mathrm{~m}, 38 \mathrm{H}), 3.60-3.56$ (m, 2H), 3.53-3.49 (m, 1H), 3.40-3.36 (m, 2H), 3.35-3.29 (m, 2H), 3.26-3.16 (m, 4H), 3.12 (s, 6H), 2.25-2.17 $(\mathrm{m}, 2 \mathrm{H}), 1.79-1.58(\mathrm{~m}, 4 \mathrm{H}), 1.56-1.29(\mathrm{~m}, 10 \mathrm{H}), 1.14(\mathrm{~d}, J=6.6 \mathrm{~Hz}, 3 \mathrm{H}) ;{ }^{13} \mathrm{C}$ NMR $\left(126 \mathrm{MHz}, \mathrm{CDCl}_{3}\right): \delta$ 173.6, 171.4, 163.9, 155.4, 153.3, 143.6, 139.7, 128.3, 126.1, 122.6, 111.7, 70.8, 70.8, 70.8, 70.7, 70.7, $70.7,70.7,70.7,70.7,70.6,70.6,70.6,70.6,70.3,70.2,69.5,56.6,56.2,51.7,50.8,40.5,39.3,38.7,35.8$, 32.4, 29.6, 28.4, 27.9, 25.7, 25.3, 21.8, 15.8; IR (thin film): v 3258, 2861, 2102, 1698, 1644, 1604, 1364, 1140, $1088 \mathrm{~cm}^{-1}$; ESI-HRMS calcd for $\mathrm{C}_{52} \mathrm{H}_{87} \mathrm{~N}_{11} \mathrm{NaO}_{15} \mathrm{~S}[\mathrm{M}+\mathrm{Na}]^{+} 1160.5996$, found 1160.5977; [ $\left.\alpha\right]_{D}{ }^{25}$ : $+32.6\left(c=0.49, \mathrm{CHCl}_{3}\right)$.

(S)-N-(4-Azidobutyl)-2-(4-dimethylaminophenylazo)benzenesulfonamido)-6-(6-((4R,5S)-5-methyl-2oxoimidazolidin-4-yl)hexanamido)hexanamide (S19)

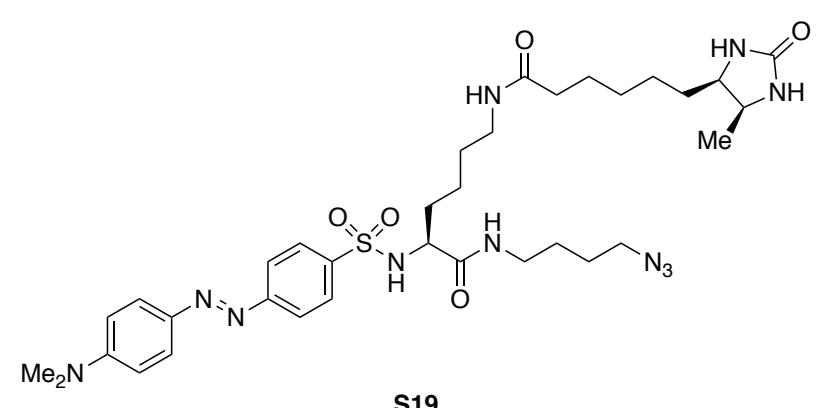

S19
Prepared following General procedure B with $\mathbf{S 1 4}$ (37.0 mg, $0.06 \mathrm{mmol}, 1.00$ equiv) and $\mathbf{S 1 5}(31.0 \mathrm{mg}$, $0.10 \mathrm{mmol}, 1.70$ equiv). Isolated by column chromatography on silica gel (eluting with $\left.\mathrm{CH}_{2} \mathrm{Cl}_{2} / \mathrm{MeOH}=100: 7\right)$ to give $\mathbf{S 1 9}$ as a red solid (32.1 mg, 74\%). m.p. $140-144{ }^{\circ} \mathrm{C} ;{ }^{1} \mathrm{H}$ NMR $(500 \mathrm{MHz}$,

$\left.\mathrm{CD}_{3} \mathrm{OD}\right): \delta 7.94(\mathrm{~d}, J=8.7 \mathrm{~Hz}, 2 \mathrm{H}), 7.92-7.84(\mathrm{~m}, 4 \mathrm{H}), 6.85(\mathrm{~d}, J=9.2 \mathrm{~Hz}, 2 \mathrm{H}), 3.85-3.77(\mathrm{~m}, 1 \mathrm{H}), 3.73-3.63$ $(\mathrm{m}, 2 \mathrm{H}), 3.20-3.15(\mathrm{~m}, 2 \mathrm{H}), 3.14-3.04(\mathrm{~m}, 7 \mathrm{H}), 3.01-2.89(\mathrm{~m}, 2 \mathrm{H}), 2.14(\mathrm{t}, J=7.5 \mathrm{~Hz}, 2 \mathrm{H}), 1.67-1.52(\mathrm{~m}, 4 \mathrm{H})$, 1.51-1.23 (m, 15H), $1.09(\mathrm{~d}, J=6.5 \mathrm{~Hz}, 3 \mathrm{H}) ;{ }^{13} \mathrm{C}$ NMR (126 MHz, CD $\left.{ }_{3} \mathrm{OD}\right): \delta$ 176.1, 173.6, 166.2, 156.9, $155.0,144.8,141.5,129.4,126.8,123.4,112.6,57.9,57.4,52.7,52.1,40.4,40.0,39.8,37.0,34.0,30.7$, 30.2, 29.7, 27.5, 27.2, 27.1, 26.9, 23.9, 15.6; IR (thin film): v 3252, 2928, 2098, 1706, 1645, 1608, 1557, 1371, $1162 \mathrm{~cm}^{-1}$; ESI-HRMS calcd for $\mathrm{C}_{34} \mathrm{H}_{52} \mathrm{~N}_{11} \mathrm{O}_{5} \mathrm{~S}[\mathrm{M}+\mathrm{H}]^{+} 726.3868$, found $726.3859 ;[\alpha]_{D}{ }^{25}:+15.2$ $\left(c=0.65, \mathrm{CH}_{3} \mathrm{OH}\right)$ 
General procedure C: Synthesis of reagents 1a-1d precursors (Boc-1a-Boc-1d)
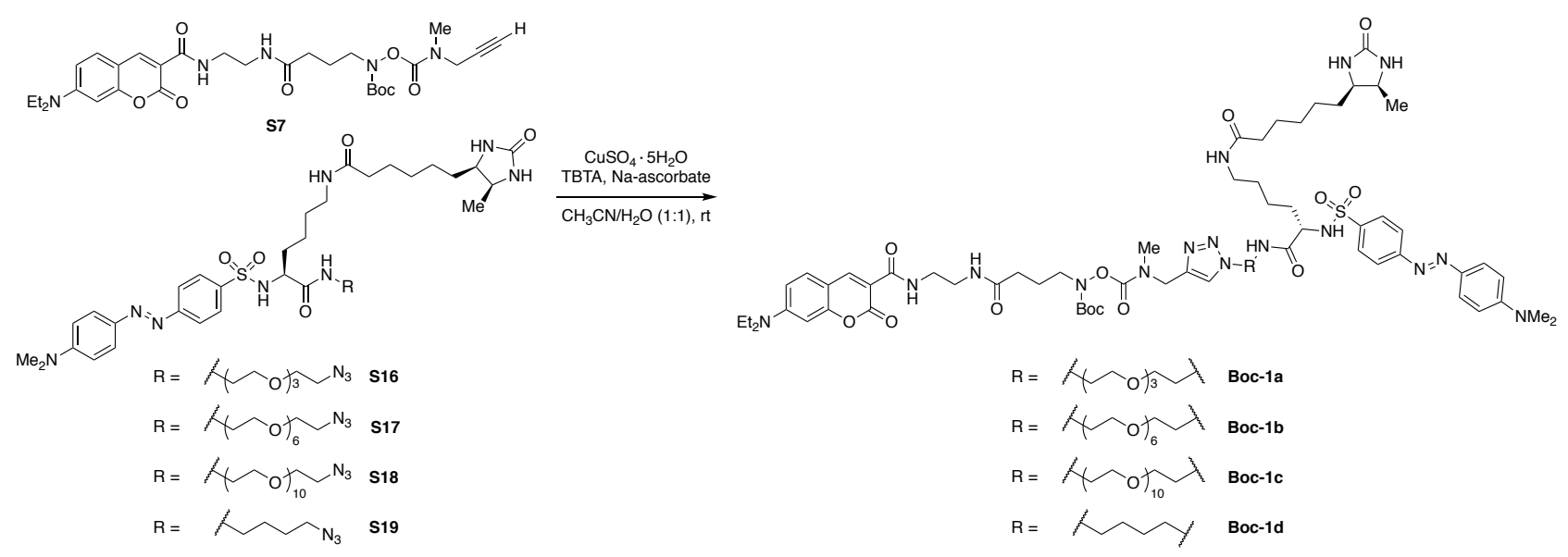

To a round-bottom flask were added alkyne S7, azide reagent (S16, S17, S18 or S19), copper sulfate pentahydrate and tris((1-benzyl-1H-1,2,3-triazol-4-yl)methyl)amine (TBTA). The solids were suspended in $\mathrm{CH}_{3} \mathrm{CN} / \mathrm{H}_{2} \mathrm{O}(1: 1,2 \mathrm{~mL})$, and sodium ascorbate (30 mg, $150 \mu \mathrm{mol}, 4.00$ equiv) was added. The reaction was stirred at $\mathrm{rt}$ for $3 \mathrm{~h}$ and filtered. The filtrate was purified by preparative reverse-phase HPLC (YMC C18 column, gradient of $20-95 \% \mathrm{CH}_{3} \mathrm{CN} / \mathrm{H}_{2} \mathrm{O}+0.1 \%$ TFA for $28 \mathrm{~min}$ ).

\section{Reagent 1a precursor (Boc-1a)}

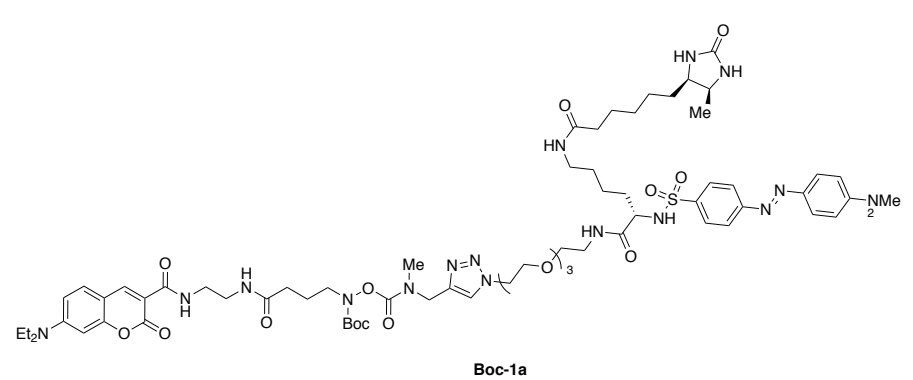

Prepared following General procedure C with S7 $(22.5 \mathrm{mg}, 38 \mu \mathrm{mol}, 1.00$ equiv), $\mathbf{S 1 6}$ (31.2 mg, $38 \mu \mathrm{mol}, 1.00$ equiv), copper sulfate pentahydrate (9.8 mg, $38 \mu \mathrm{mol}, 1.00$ equiv), tris((1-benzyl-1H-1,2,3-triazol-4-yl)methyl)amine

(4.0 mg, $8 \mu \mathrm{mol}, 0.20$ equiv) and sodium ascorbate ( $30 \mathrm{mg}, 150 \mu \mathrm{mol}, 4.00$ equiv). Purified by preparative reverse-phase HPLC $\left(t_{R}=23.0 \mathrm{~min}\right)$. The corresponding peak was collected, neutralized with sat. aq. $\mathrm{NaHCO}_{3}$, diluted with brine, extracted with $\mathrm{CH}_{2} \mathrm{Cl}_{2} / \mathrm{MeOH}$, dried with $\mathrm{Na}_{2} \mathrm{SO}_{4}$, filtered and evaporated in vacuo to give Boc-1a as an orange solid (39.1 mg, 73\%). m.p. $169-174{ }^{\circ} \mathrm{C} ;{ }^{1} \mathrm{H}$ NMR $\left(500 \mathrm{MHz}, \mathrm{CDCl}_{3}\right): \delta$ $9.01(\mathrm{t}, J=6.0 \mathrm{~Hz}, 1 \mathrm{H}), 8.65(\mathrm{~s}, 1 \mathrm{H}), 7.92(\mathrm{~d}, J=8.6 \mathrm{~Hz}, 2 \mathrm{H}), 7.87-7.82(\mathrm{~m}, 4 \mathrm{H}), 7.41(\mathrm{~d}, J=8.9 \mathrm{~Hz}, 1 \mathrm{H})$, $7.26(\mathrm{br}, 1 \mathrm{H}), 7.16(\mathrm{~d}, J=7.0 \mathrm{~Hz}, 1 \mathrm{H}), 6.72(\mathrm{~d}, J=9.2 \mathrm{~Hz}, 2 \mathrm{H}), 6.62(\mathrm{dd}, J=9.0,2.5 \mathrm{~Hz}, 1 \mathrm{H}), 6.45(\mathrm{~d}, J=2.4$ Hz, 1H), 6.35 (br, 1H), 5.82 (br s, 1H), 5.05 (br s, 1H), 4.52 (br, 4H), 3.90-3.77 (m, 4H), 3.72-3.38 (m, 19H), 3.34-3.27 (m, 2H), 3.24-3.18 (m, 2H), 3.17-3.11 (m, 2H), 3.09 (s, 6H), 3.02-2.93 (m, 3H), $2.28(\mathrm{t}, J=7.5 \mathrm{~Hz}$, 2H), $2.15(\mathrm{t}, J=7.2 \mathrm{~Hz}, 2 \mathrm{H}), 1.90(\mathrm{p}, J=6.8 \mathrm{~Hz}, 2 \mathrm{H}), 1.74-1.55(\mathrm{~m}, 4 \mathrm{H}), 1.50-1.17(\mathrm{~m}, 28 \mathrm{H}), 1.10(\mathrm{~d}$, 
$J=6.5 \mathrm{~Hz}, 3 \mathrm{H}) ;{ }^{13} \mathrm{C}$ NMR $\left(126 \mathrm{MHz}, \mathrm{CDCl}_{3}\right): \delta 173.4,172.8,171.4,164.4,163.9,162.6,157.7,155.4,155.1$ ( $\mathrm{N}-\mathrm{CO}$ rotamers), 155.0, 154.3 ( $\mathrm{N}-\mathrm{CO}$ rotamers), 153.1, 152.7, 148.2, 148.2, 143.5, 139.6, 131.3, 128.2, $125.7,124.0,122.5,111.4,110.1,109.6,108.3,96.5,82.2,82.1,70.5,70.4,70.2,69.4,69.3,56.7,56.0$, 51.5, 50.2, 50.1, 45.1, 45.0 ( $\mathrm{N}-\mathrm{CH}_{2}$ rotamers), $44.1\left(\mathrm{~N}-\mathrm{CH}_{2}\right.$ rotamers), 40.5, 40.4, 40.3, 39.2, 39.2, 38.6, 35.8, $35.3\left(\mathrm{~N}-\mathrm{CH}_{3}\right.$ rotamers), $34.3\left(\mathrm{~N}-\mathrm{CH}_{3}\right.$ rotamers $), 33.4,32.4,29.7,29.5,28.4,28.2,25.6,25.3,23.5$, 22.0, 15.7, 12.4; IR (thin film): $v$ 3302, 2927, 1697, 1603, 1511, 1419, 1362, 1228, $1133 \mathrm{~cm}^{-1}$; ESI-HRMS calcd for $\mathrm{C}_{68} \mathrm{H}_{101} \mathrm{~N}_{16} \mathrm{O}_{16} \mathrm{~S}[\mathrm{M}+\mathrm{H}]^{+} 1429.7297$, found 1429.7279; $[\alpha]_{D}{ }^{25}:+22.8\left(c=1.65, \mathrm{CHCl}_{3}\right)$.

\section{Reagent 1b precursor (Boc-1b)}

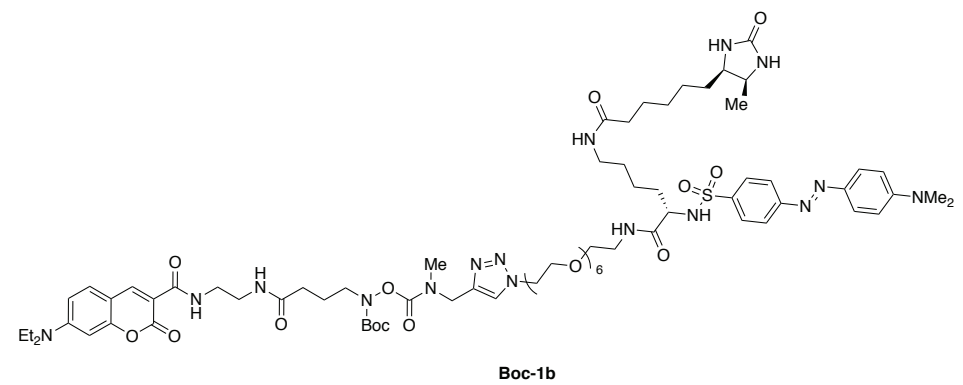

Prepared following General procedure C with $\mathbf{S} 7(21.8 \mathrm{mg}, 36 \mu \mathrm{mol}, 1.00$ equiv), $\mathbf{S} 17$ (35.0 mg, $36 \mu \mathrm{mol}, \quad 1.00$ equiv), copper sulfate pentahydrate $(9.1 \mathrm{mg}, 36 \mu \mathrm{mol}$, 1.00 equiv), tris((1-benzyl-1H-1,2,3-triazol-4-

yl)methyl)amine ( $4.0 \mathrm{mg}, 8 \mu \mathrm{mol}, 0.20$ equiv) and sodium ascorbate ( $30 \mathrm{mg}, 150 \mu \mathrm{mol}, 4.00$ equiv). Purified by preparative reverse-phase HPLC $\left(t_{R}=23.2 \mathrm{~min}\right)$. The corresponding peak was collected, neutralized with sat. aq. $\mathrm{NaHCO}_{3}$, diluted with brine, extracted with $\mathrm{CH}_{2} \mathrm{Cl}_{2} / \mathrm{MeOH}$, dried with $\mathrm{Na}_{2} \mathrm{SO}_{4}$, filtered and evaporated in vacuo to give Boc-1 b as a sticky orange solid (28.3 mg, 50\%). ${ }^{1} \mathrm{H} \mathrm{NMR}\left(500 \mathrm{MHz}, \mathrm{CDCl}_{3}\right): \delta 9.01(\mathrm{~m}, 1 \mathrm{H})$, $8.65(\mathrm{~s}, 1 \mathrm{H}), 7.99-7.72(\mathrm{~m}, 7 \mathrm{H}), 7.42(\mathrm{~d}, J=8.9 \mathrm{~Hz}, 1 \mathrm{H}), 7.24(\mathrm{br}, 1 \mathrm{H}), 7.15(\mathrm{~d}, J=8.2 \mathrm{~Hz}, 1 \mathrm{H}), 6.99-6.82$ (br, 1H), $6.73(\mathrm{~d}, J=8.7 \mathrm{~Hz}, 2 \mathrm{H}), 6.63(\mathrm{dd}, J=9.0,2.3 \mathrm{~Hz}, 1 \mathrm{H}), 6.46(\mathrm{~s}, 1 \mathrm{H}), 6.36(\mathrm{br}, 1 \mathrm{H}), 5.78(\mathrm{br}, 1 \mathrm{H})$, $4.98(\mathrm{br}, 1 \mathrm{H}), 4.60-4.47(\mathrm{~m}, 4 \mathrm{H}), 3.91-3.77(\mathrm{~m}, 4 \mathrm{H}), 3.73-3.67(\mathrm{~m}, 1 \mathrm{H}), 3.65-3.53(\mathrm{~m}, 19 \mathrm{H}), 3.51-3.40(\mathrm{~m}$, 8H), 3.37-3.29 (m, 2H), 3.25-3.15 (m, 3H), 3.10 (s, 6H), 3.03-2.94 (m, 3H), $2.28(\mathrm{t}, J=7.5 \mathrm{~Hz}, 2 \mathrm{H}), 2.22-2.14$ $(\mathrm{m}, 2 \mathrm{H}), 1.91(\mathrm{p}, J=7.1 \mathrm{~Hz}, 2 \mathrm{H}), 1.76-1.56(\mathrm{~m}, 4 \mathrm{H}), 1.52-1.26(\mathrm{~m}, 19 \mathrm{H}), 1.24-1.16(\mathrm{~m}, 8 \mathrm{H}), 1.12(\mathrm{~d}$, $J=6.5 \mathrm{~Hz}, 3 \mathrm{H}) ;{ }^{13} \mathrm{C}$ NMR $\left(126 \mathrm{MHz}, \mathrm{CDCl}_{3}\right): \delta 173.5,172.9,171.5,164.5,164.0,162.7,157.8,155.6,155.2$ (N-CO rotamers), 155.1, 154.4 (N-CO rotamers), 153.2, 152.8, 148.3, 143.6, 143.5, 139.7, 131.4, 128.3, 125.8, 124.0, 122.6, 111.6, 110.2, 109.8, 108.4, 96.6, $82.3\left(\mathrm{~N}-\mathrm{C}\left(\mathrm{CH}_{3}\right)_{3}\right.$ rotamers $), 82.1\left(\mathrm{~N}-\mathrm{C}\left(\mathrm{CH}_{3}\right)_{3}\right.$ rotamers), 70.6, 70.5, 70.5, 70.5, 70.2, 69.6, 69.5, 56.7, 56.1, 51.6, 50.3, 50.1, 45.2, 45.1 ( $\mathrm{N}-\mathrm{CH}_{2}$ rotamers), $44.2\left(\mathrm{~N}-\mathrm{CH}_{2}\right.$ rotamers), 40.7, 40.4, 39.3, 39.3, 38.7, 35.8, $35.3\left(\mathrm{~N}-\mathrm{CH}_{3}\right.$ rotamers $), 34.4\left(\mathrm{~N}-\mathrm{CH}_{3}\right.$ rotamers $)$, $33.6,32.4,29.6,28.5,28.3,28.1,25.7,25.3,23.6,22.0,15.8,12.5$; IR (thin film): $v$ 3308, 2931, 2867, 1697 , 
1603, 1511, 1353, $1133 \mathrm{~cm}^{-1}$; ESI-HRMS calcd for $\mathrm{C}_{74} \mathrm{H}_{112} \mathrm{~N}_{16} \mathrm{NaO}_{19} \mathrm{~S}[\mathrm{M}+\mathrm{Na}]^{+}$1583.7903, found 1583.7896; $[\alpha]_{\mathrm{D}}^{25}:+15.7\left(c=1.4, \mathrm{CHCl}_{3}\right)$.

\section{Reagent 1c precursor (Boc-1c)}

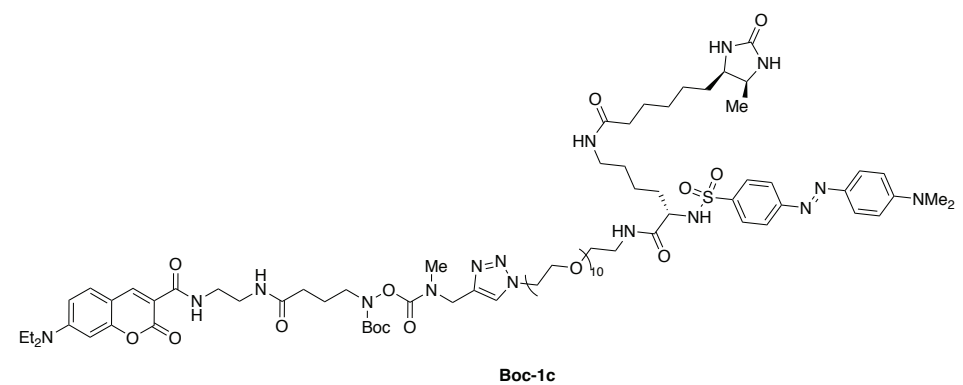

Prepared following General procedure C with S7 $(20.0 \mathrm{mg}, 18 \mu \mathrm{mol}, 1.00$ equiv), $\mathbf{S} 18$ (12.0 mg, $18 \mu \mathrm{mol}, \quad 1.00$ equiv), copper sulfate pentahydrate $(4.4 \mathrm{mg}, 18 \mu \mathrm{mol}$, 1.00 equiv), tris((1-benzyl-1H-1,2,3-triazol-4-

yl)methyl)amine ( $2.0 \mathrm{mg}, 4 \mu \mathrm{mol}, 0.20$ equiv) and sodium ascorbate (16 mg, $80 \mu \mathrm{mol}, 5.00$ equiv). Purified by preparative reverse-phase HPLC $\left(t_{R}=23.1 \mathrm{~min}\right)$. The corresponding peak was collected, neutralized with sat. aq. $\mathrm{NaHCO}_{3}$, diluted with brine, extracted with $\mathrm{CH}_{2} \mathrm{Cl}_{2} / \mathrm{MeOH}$, dried with $\mathrm{Na}_{2} \mathrm{SO}_{4}$, filtered and evaporated in vacuo to give Boc-1c as a sticky orange solid (19.5 mg, 63\%). ${ }^{1} \mathrm{H}$ NMR $\left(500 \mathrm{MHz}, \mathrm{CDCl}_{3}\right): \delta 9.01$ (d, $J=6.0 \mathrm{~Hz}, 1 \mathrm{H}), 8.66(\mathrm{~s}, 1 \mathrm{H}), 7.95(\mathrm{~d}, J=8.6 \mathrm{~Hz}, 2 \mathrm{H}), 7.90-7.85(\mathrm{~m}, 4 \mathrm{H}), 7.42(\mathrm{~d}, J=8.9 \mathrm{~Hz}, 1 \mathrm{H}), 7.26(\mathrm{br}$, $1 \mathrm{H}), 7.17(\mathrm{~d}, J=8.2 \mathrm{~Hz}, 1 \mathrm{H}), 6.94-6.78(\mathrm{br}, 1 \mathrm{H}), 6.74(\mathrm{~d}, J=9.2 \mathrm{~Hz}, 2 \mathrm{H}), 6.64(\mathrm{dd}, J=9.0,2.4 \mathrm{~Hz}, 1 \mathrm{H}), 6.47$ $(\mathrm{d}, J=9.0,2.4 \mathrm{~Hz}, 1 \mathrm{H}), 6.39(\mathrm{br}, 1 \mathrm{H}), 5.77(\mathrm{br}, 1 \mathrm{H}), 4.93(\mathrm{br}, 1 \mathrm{H}), 4.60-4.49(\mathrm{~m}, 4 \mathrm{H}), 3.90-3.83(\mathrm{~m}, 3 \mathrm{H})$, 3.83-3.77 (m, 1H), 3.73-3.68 (m, 1H), 3.66-3.54 (m, 35H), 3.52-3.49 (m, 2H), 3.47-3.41 (m, 6H), 3.38-3.31 (m, 2H), 3.26-3.16 (m, 3H), 3.11 (s, 6H), 3.02-2.95 (m, 3H), $2.29(\mathrm{t}, J=7.6 \mathrm{~Hz}, 2 \mathrm{H}), 2.24-2.16(\mathrm{~m}, 2 \mathrm{H}), 1.91$ $(\mathrm{p}, J=7.1 \mathrm{~Hz}, 2 \mathrm{H}), 1.76-1.58(\mathrm{~m}, 4 \mathrm{H}), 1.53-1.33(\mathrm{~m}, 19 \mathrm{H}), 1.31-1.19(\mathrm{~m}, 8 \mathrm{H}+\mathrm{H}$ grease $), 1.13(\mathrm{~d}, J=6.5 \mathrm{~Hz}$, $3 \mathrm{H}) ;{ }^{13} \mathrm{C}$ NMR $\left(126 \mathrm{MHz}, \mathrm{CDCl}_{3}\right): \delta 173.6,172.9,171.6,164.6,164.0,162.7,157.8,155.6,155.2(\mathrm{~N}-\mathrm{CO}$ rotamers), 155.1, 154.4 (N-CO rotamers), 153.2, 152.8, 148.3, 143.6, 143.5, 139.7, 131.4, 128.3, 125.8, 124.0, 122.6, 111.6, 110.2, 109.9, 108.4, 96.7, $82.3\left(\mathrm{~N}-\mathrm{C}\left(\mathrm{CH}_{3}\right)_{3}\right.$ rotamers $), 82.1\left(\mathrm{~N}-\mathrm{C}\left(\mathrm{CH}_{3}\right)_{3}\right.$ rotamers $), 70.7$, 70.6, 70.6, 70.6, 70.6, 70.5, 70.5, 70.4, 70.4, 70.4, 70.4, 70.1, 69.7, 69.5, 56.7, 56.2, 51.7, 50.3, 50.1, 45.2, $45.1\left(\mathrm{~N}-\mathrm{CH}_{2}\right.$ rotamers), $44.2\left(\mathrm{~N}-\mathrm{CH}_{2}\right.$ rotamers $), 40.7,40.4,39.3,39.3,38.6,35.8,35.3\left(\mathrm{~N}-\mathrm{CH}_{3}\right.$ rotamers $)$, $34.4\left(\mathrm{~N}-\mathrm{CH}_{3}\right.$ rotamers), 33.6, 32.3, 29.8, 28.4, 28.3, 28.0, 25.7, 25.3, 23.6, 21.9, 15.8, 12.5; IR (thin film): v $3310,2924,1699,1603,1513,1364,1135 \mathrm{~cm}^{-1}$; ESI-HRMS calcd for $\mathrm{C}_{82} \mathrm{H}_{130} \mathrm{~N}_{16} \mathrm{O}_{23} \mathrm{~S}[\mathrm{M}+2 \mathrm{H}]^{2+} 869.4602$, found 869.4619; $[\alpha]_{D}^{25}:+17.9\left(c=0.95, \mathrm{CHCl}_{3}\right)$. 


\section{Reagent 1d precursor (Boc-1d)}

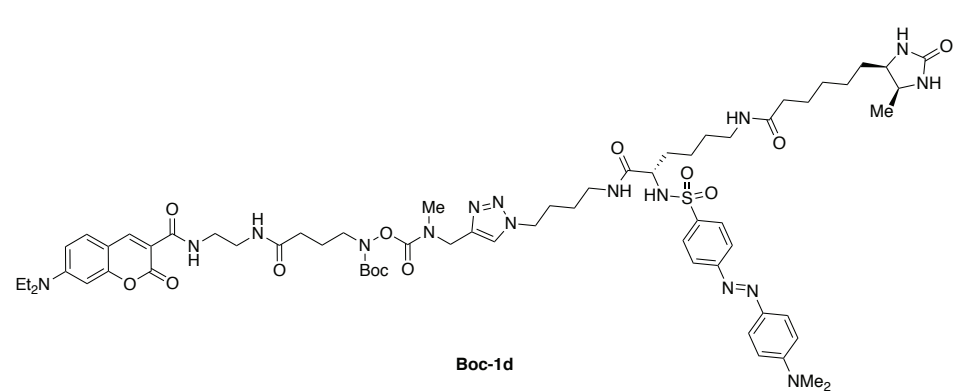

Prepared following General procedure C with $\mathbf{S} 7$ (16.5 mg, $28 \mu \mathrm{mol}, 1.00$ equiv), $\mathbf{S 1 9}$ (20.0 mg, $28 \mu \mathrm{mol}, 1.0$ equiv), copper sulfate pentahydrate $(7.1 \mathrm{mg}, 28 \mu \mathrm{mol}, 1.00$ equiv), tris((1-benzyl-1H-1,2,3-triazol-4-

yl)methyl)amine ( $3.0 \mathrm{mg}, 6 \mu \mathrm{mol}, 0.20$ equiv) and sodium ascorbate ( $25 \mathrm{mg}, 125 \mu \mathrm{mol}, 4.50$ equiv). Purified by preparative reverse-phase HPLC $\left(t_{R}=23.4 \mathrm{~min}\right)$. The corresponding peak was collected, neutralized with sat. aq. $\mathrm{NaHCO}_{3}$, diluted with brine, extracted with $\mathrm{CH}_{2} \mathrm{Cl}_{2} / \mathrm{MeOH}$, dried with $\mathrm{Na}_{2} \mathrm{SO}_{4}$, filtered and evaporated in vacuo to give Boc-1d as an orange solid (16.6 mg, 45\%). m.p. 97-102 ${ }^{\circ} \mathrm{C} ;{ }^{1} \mathbf{H ~ N M R ~}\left(500 \mathrm{MHz}, \mathrm{CDCl}_{3}\right): \delta$ $9.04(\mathrm{t}, J=6.0 \mathrm{~Hz}, 1 \mathrm{H}), 8.66(\mathrm{~s}, 1 \mathrm{H}), 7.94(\mathrm{~d}, J=8.7 \mathrm{~Hz}, 2 \mathrm{H}), 7.91-7.81(\mathrm{~m}, 4 \mathrm{H}), 7.43(\mathrm{~d}, J=8.9 \mathrm{~Hz}, 1 \mathrm{H})$, 7.28-7.22 (br, 1H), 7.22-7.07 (br, 1H), 6.98-6.84 (br, 1H), $6.73(\mathrm{~d}, J=8.8 \mathrm{~Hz}, 2 \mathrm{H}), 6.64(\mathrm{dd}, J=9.0,2.4 \mathrm{~Hz}$, 1H), $6.47(\mathrm{~d}, J=2.4 \mathrm{~Hz}, 1 \mathrm{H}), 6.29(\mathrm{br}, 1 \mathrm{H}), 5.82(\mathrm{br} \mathrm{s}, 1 \mathrm{H}), 5.12(\mathrm{br} \mathrm{s}, 1 \mathrm{H}), 4.58-4.44(\mathrm{~m}, 2 \mathrm{H}), 4.30-4.15(\mathrm{~m}$, 2H), $3.91(\mathrm{~m}, 1 \mathrm{H}), 3.84(\mathrm{td}, J=9.2,4.0 \mathrm{~Hz}, 1 \mathrm{H}), 3.74-3.68(\mathrm{~m}, 1 \mathrm{H}), 3.67-3.60(\mathrm{~m}, 2 \mathrm{H}), 3.59-3.53(\mathrm{~m}, 2 \mathrm{H})$, 3.49-3.38 (m, 6H), $3.24(\mathrm{br}, 1 \mathrm{H}), 3.16(\mathrm{br}, 1 \mathrm{H}), 3.10(\mathrm{~s}, 6 \mathrm{H}), 3.07-2.93(\mathrm{~m}, 5 \mathrm{H}), 2.32-2.25(\mathrm{~m}, 2 \mathrm{H}), 2.23-2.15$ (m, 2H), $1.89(\mathrm{p}, J=7.0 \mathrm{~Hz}, 2 \mathrm{H}), 1.83-1.55(\mathrm{~m}, 6 \mathrm{H}), 1.53-1.36(\mathrm{~m}, 16 \mathrm{H}), 1.35-1.26(\mathrm{~m}, 4 \mathrm{H}), 1.26-1.19(\mathrm{~m}$, 7H), $1.15(\mathrm{~d}, J=6.5 \mathrm{~Hz}, 3 \mathrm{H}) ;{ }^{13} \mathrm{C}$ NMR $\left(126 \mathrm{MHz}, \mathrm{CDCl}_{3}\right): \delta 173.6,173.0,171.6,164.7,164.0,162.8,157.8$, 155.5, 155.3 (N-CO rotamers), 155.2, 154.3 (N-CO rotamers), 153.3, 152.9, 148.4, 143.7, 143.5, 139.6, $131.4,128.2,126.0,123.0,122.6,111.7,110.3,109.7,108.4,96.6,82.4\left(\mathrm{~N}-\mathrm{C}\left(\mathrm{CH}_{3}\right)_{3}\right.$ rotamers $), 82.3$ $\left(\mathrm{N}-\mathrm{C}\left(\mathrm{CH}_{3}\right)_{3}\right.$ rotamers $), 56.7,56.2,51.8,50.1,50.0,45.3\left(\mathrm{~N}-\mathrm{CH}_{2}\right.$ rotamers $), 45.2,44.3\left(\mathrm{~N}-\mathrm{CH}_{2}\right.$ rotamers $)$, 40.8, 40.5, 39.3, 38.8, 38.6, 35.7, $35.5\left(\mathrm{~N}_{-} \mathrm{CH}_{3}\right.$ rotamers), $34.6\left(\mathrm{~N}-\mathrm{CH}_{3}\right.$ rotamers $), 33.5,32.4,29.8,29.6$, 28.3, 27.8, 27.5, 26.3, 25.7, 25.3, 23.5, 22.0, 15.8, 12.6; IR (thin film): v 3306, 2931, 1697, 1603, 1511, 1362, $1134 \mathrm{~cm}^{-1}$; ESI-HRMS calcd for $\mathrm{C}_{64} \mathrm{H}_{92} \mathrm{~N}_{16} \mathrm{NaO}_{13} \mathrm{~S}[\mathrm{M}+\mathrm{Na}]^{+}$1347.6643, found 1347.6630; [ $\left.\alpha\right]_{D}{ }^{25}$ : $+30.4\left(c=0.83, \mathrm{CHCl}_{3}\right)$. 
Representative procedure for the synthesis of starting materials $1 \mathrm{a}-1 \mathrm{~d}$
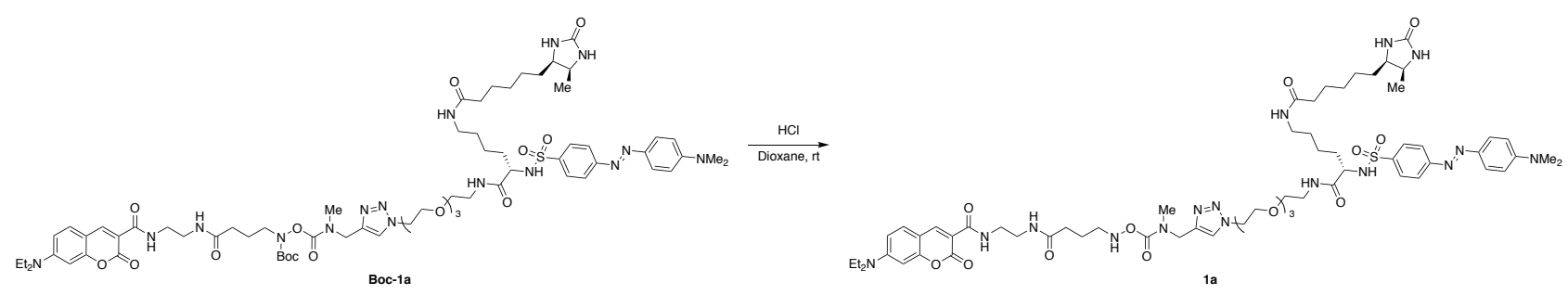

Boc-1a precursor $(25.0 \mathrm{mg}, 17.5 \mu \mathrm{mol}, 1.00$ equiv) was introduced in a vial and dissolved in the minimal amount of $\mathrm{MeOH}(\sim 50 \mu \mathrm{L}) . \mathrm{HCl}(4 \mathrm{M}$ in dioxane, $0.5 \mathrm{~mL},>100$ equiv) was added and the reaction stirred at $\mathrm{rt}$ for $30 \mathrm{~min}$. $\mathrm{Et}_{2} \mathrm{O}(5 \mathrm{~mL})$ was added to precipitate the product. The mixture was centrifuged, the supernatant discarded. The precipitate was washed with $\mathrm{Et}_{2} \mathrm{O}$, centrifuged again and dried in vacuo after discarding the supernatant to give a red solid $(19.1 \mathrm{mg}, 83 \%)$. The solid was unstable as a concentrated solution at rt, so the spectral data could not be collected. Instead, the solid was stored in the fridge (stable for several months) and stock solutions were prepared prior to use for kinetics experiments. A typical LC-MS trace of a freshly prepared solution of $1 \mathrm{a}$ in $\mathrm{CH}_{3} \mathrm{CN} / \mathrm{H}_{2} \mathrm{O}$ is shown below.

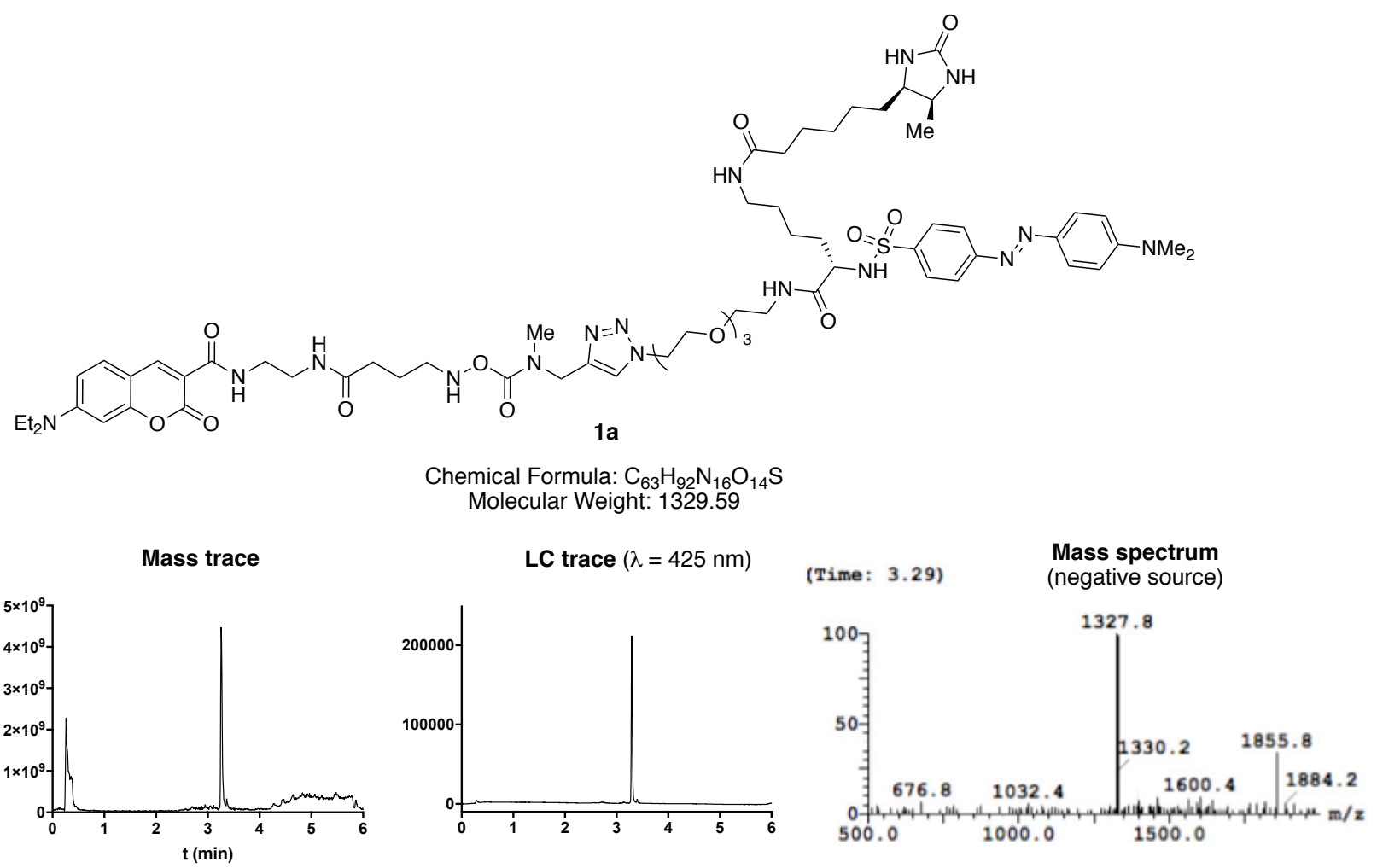




\section{Synthesis of 10-(4-fluorobenzoyl)-3-ethynyl-10-fluoro-9-oxa-10a-aza-10-boraphenanthrene (S24)}

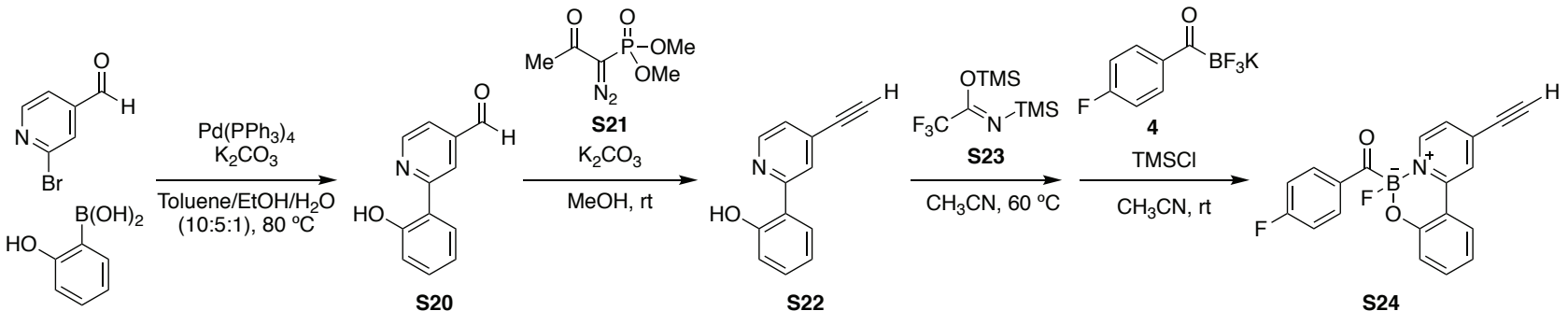

A Schlenk flask was charged with 2-bromo-4-formylpyridine $(1.86 \mathrm{~g}, 10.0 \mathrm{mmol}, 1.00$ equiv), 2-hydroxyphenylboronic acid (1.66 g, $12.0 \mathrm{mmol}, 1.20$ equiv), $\mathrm{Pd}\left(\mathrm{PPh}_{3}\right)_{4}(115 \mathrm{mg}, 0.10 \mathrm{mmol}, 0.01$ equiv) and potassium carbonate $\left(2.80 \mathrm{~g}, 20.0 \mathrm{mmol}, 2.00\right.$ equiv) and the atmosphere replaced with $\mathrm{N}_{2}$ gas. A mixture of toluene/EtOH/ $\mathrm{H}_{2} \mathrm{O}(10: 5: 1,45 \mathrm{~mL}$, degassed) was introduced and the suspension vigorously stirred at $80^{\circ} \mathrm{C}$ overnight. The reaction was cooled to rt, diluted with EtOAc and filtered through Celite. The solvents were removed by rotary evaporation and the residue purified by column chromatography on silica gel (eluting with toluene) to give $\mathbf{S 2 0}$ as an orange solid (1.31 g, 66\%). m.p. $136-138{ }^{\circ} \mathrm{C} ;{ }^{1} \mathbf{H} \mathbf{~ N M R}(500 \mathrm{MHz}$, $\left.\mathrm{CDCl}_{3}\right): \delta 10.15-10.12(\mathrm{~m}, 1 \mathrm{H}), 8.77-8.70(\mathrm{~m}, 1 \mathrm{H}), 8.33-8.25(\mathrm{~m}, 1 \mathrm{H}), 7.92-7.83(\mathrm{~m}, 1 \mathrm{H}), 7.67-7.60(\mathrm{~m}, 1 \mathrm{H})$, 7.39-7.33 (m, 1H), 7.08-7.02 (m, 1H), 6.98-6.92 (m, 1H); ${ }^{13} \mathrm{C}$ NMR (126 MHz, CD $\left.{ }_{3} \mathrm{OD}\right): \delta 191.1,160.0$, 159.7, 147.6, 142.9, 132.5, 126.5, 119.6, 119.3, 119.0, 118.6, 118.3; IR (thin film): v 2837, 2719, 1697, 1552, 1483, 1423, 1312, $1230 \mathrm{~cm}^{-1}$; ESI-HRMS calcd for $\mathrm{C}_{12} \mathrm{H}_{10} \mathrm{NO}_{2}[\mathrm{M}+\mathrm{H}]^{+} 200.0706$, found 200.0705 .

Aldehyde S20 (890 mg, $4.5 \mathrm{mmol}, 1.00$ equiv) and potassium carbonate (1.25 g, $9.0 \mathrm{mmol}, 2.00$ equiv) were introduced into a round-bottom flask. The solids were suspended in $\mathrm{MeOH}(15 \mathrm{~mL})$ and Ohira-Bestmann reagent (S21, $950 \mathrm{mg}, 5.0 \mathrm{mmol}, 1.10$ equiv) was added. The reaction was stirred at $\mathrm{rt}$ for $2 \mathrm{~h}$; strong gas evolution was observed during the course of the reaction. The reaction was filtered through celite and silica gel was added to the filtrate (to support the crude material in silica). The suspension was evaporated and dried in vacuo. The silica-supported crude was purified by column chromatography on silica gel (eluting with toluene/hexanes (1:1)) to give $\mathbf{S 2 2}$ as a yellow crystalline solid (452 mg, 51\%). m.p. $131-133{ }^{\circ} \mathrm{C} ;{ }^{1} \mathbf{H}$ NMR $\left(400 \mathrm{MHz}, \mathrm{CDCl}_{3}\right): \delta 8.50$ (dd, $\left.J=5.2,1.0 \mathrm{~Hz}, 1 \mathrm{H}\right), 7.99(\mathrm{br} \mathrm{s}, 1 \mathrm{H}), 7.79(\mathrm{dd}, J=8.0,1.6 \mathrm{~Hz}, 1 \mathrm{H}), 7.35$ (ddd, $J=8.5,7.2,1.6 \mathrm{~Hz}, 1 \mathrm{H}), 7.30(\mathrm{dd}, J=5.3,1.5 \mathrm{~Hz}, 1 \mathrm{H}), 7.06(\mathrm{dd}, J=8.2,1.3 \mathrm{~Hz}, 1 \mathrm{H}), 6.94$ (ddd, $J=8.2,7.2$, $1.3 \mathrm{~Hz}, 1 \mathrm{H}), 3.40$ (s, 1H); ${ }^{13} \mathrm{C}$ NMR $\left(126 \mathrm{MHz}, \mathrm{CDCl}_{3}\right): \delta 160.1,158.2,146.1,132.3,132.1,126.3,123.8$, 121.9, 119.1, 118.9, 118.3, 82.7, 81.0; IR (thin film): v 3221, 2106, 1600, 1503, 1426, $1252 \mathrm{~cm}^{-1}$; ESI-HRMS calcd for $\mathrm{C}_{13} \mathrm{H}_{10} \mathrm{NO}[\mathrm{M}+\mathrm{H}]^{+}$196.0757, found 196.0758 . 
Acylboronate $\mathbf{S 2 4}$ was synthesized according to a modification of our reported procedure. ${ }^{6}$ A Schlenk flask was charged with S22 (309 mg, $1.58 \mathrm{mmol}, 1.00$ equiv) and the atmosphere replaced with $\mathrm{N}_{2}$ gas. $\mathrm{CH}_{3} \mathrm{CN}$ $(1.5 \mathrm{~mL})$ and reagent $\mathbf{S} 23(525 \mu \mathrm{L}, 2.0 \mathrm{mmol}, 1.25$ equiv) were added sequentially and the mixture stirred at $60{ }^{\circ} \mathrm{C}$ for $1 \mathrm{~h}$. The reaction was allowed to cool to rt and the solvent was evaporated to dryness. The residue was redissolved in $\mathrm{CH}_{3} \mathrm{CN}(2 \mathrm{~mL})$. The solution was transferred to a round-bottom flask containing a suspension of KAT 4 (368 mg, 1.60 mmol, 1.00 equiv) in $\mathrm{CH}_{3} \mathrm{CN}(8 \mathrm{~mL})$, followed by the addition of TMSCl (203 $\mu \mathrm{L}, 1.60 \mathrm{mmol}, 1.00$ equiv). The suspension was stirred at $\mathrm{rt}$ for $5 \mathrm{~h}$, neutralized with sat. aq. $\mathrm{NaHCO}_{3}$ and extracted with $\mathrm{CH}_{2} \mathrm{Cl}_{2}$. The organic extracts were collected, dried with $\mathrm{Na}_{2} \mathrm{SO}_{4}$, filtered and evaporated in vacuo (bath temperature $<30^{\circ} \mathrm{C}$ ). The residue was purified by column chromatography on silica gel (eluting with acetone/hexanes $=1: 5$, crude material was dry-loaded) to give $\mathbf{S} 24$ as a crystalline yellow solid (416 mg, 76\%). m.p. $>150{ }^{\circ} \mathrm{C}$ (decomp.); ${ }^{1} \mathrm{H}$ NMR (600 MHz, $\left.\mathrm{CDCl}_{3}\right): \delta 8.43$ (dd, $\left.J=6.2,0.7 \mathrm{~Hz}, 1 \mathrm{H}\right), 8.21$ (ddd, $J=9.0,5.7,0.8 \mathrm{~Hz}, 2 \mathrm{H}$ ), $8.09(\mathrm{~d}, J=1.5 \mathrm{~Hz}, 1 \mathrm{H}), 7.73(\mathrm{dd}, J=8.0,1.5 \mathrm{~Hz}, 1 \mathrm{H}), 7.56(\mathrm{dd}, J=6.2$, $1.6 \mathrm{~Hz}, 1 \mathrm{H}), 7.38$ (ddd, $J=8.3,7.2,1.6 \mathrm{~Hz}, 1 \mathrm{H}), 7.11(\mathrm{t}, J=8.8 \mathrm{~Hz}, 2 \mathrm{H}), 7.02$ (ddd, $J=8.3,1.1,0.4 \mathrm{~Hz}, 1 \mathrm{H}$ ), 6.96 (ddd, $J=8.3,7.2,1.2 \mathrm{~Hz}, 1 \mathrm{H}), 3.67(\mathrm{~s}, 1 \mathrm{H}) ;{ }^{13} \mathrm{C}$ NMR $\left(151 \mathrm{MHz}, \mathrm{CDCl}_{3}\right): \delta 227.1$ (br), 165.5 (d, $J=252.7 \mathrm{~Hz}$ ), $155.3(\mathrm{~d}, J=5.1 \mathrm{~Hz}), 150.0,142.4(\mathrm{~d}, J=6.2 \mathrm{~Hz}), 137.1,136.4,135.1,131.3(\mathrm{~d}, J=9.1 \mathrm{~Hz})$, 125.6, 125.1, 123.1, 120.9, 120.6, 116.0, $115.4(\mathrm{~d}, J=21.5 \mathrm{~Hz}), 87.6,79.7 ;{ }^{19} \mathrm{~F} \mathrm{NMR}\left(471 \mathrm{MHz}, \mathrm{CDCl}_{3}\right): \delta$ $-107.0,-158.6$; ${ }^{11} \mathrm{~B}$ NMR $\left(160 \mathrm{MHz}, \mathrm{CDCl}_{3}\right): \delta 2.08$; IR (thin film): $v 3286,3065,2116,1626,1586,1538$, 1496, 1409, 1226, 1087, $1051 \mathrm{~cm}^{-1}$; ESI-HRMS calcd for $\mathrm{C}_{20} \mathrm{H}_{12} \mathrm{BF}_{2} \mathrm{NNaO}_{2}[\mathrm{M}+\mathrm{Na}]^{+} 370.0821$, found 370.0823.

Synthesis of $N$-(11-azido-2,6,9-trioxaundecyl)-6-((4R,5S)-5-methyl-2-oxoimidazolidin-4-yl)hexanamide (S25)
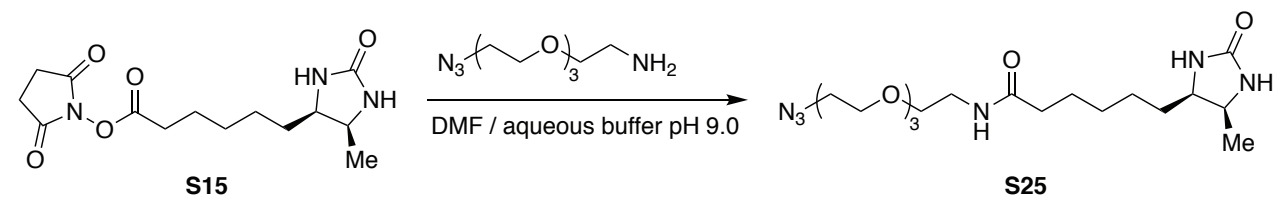

In a round-bottom flask were introduced d-desthiobiotin succinimidyl ester $(\mathbf{S} 15,211 \mathrm{mg}, 0.68 \mathrm{mmol}$, 1.00 equiv) and 11-azido-3,6,9-trioxaundecanamine ( $160 \mu \mathrm{L}, 0.75,1.10$ equiv). The solids were dissolved in DMF (1 mL) and $1 \mathrm{M}$ aqueous buffer $\mathrm{pH} 9.0\left(1 \mathrm{~mL}\right.$, prepared by dissolving $\mathrm{NaHCO}_{3}(0.42 \mathrm{~g}, 5.0 \mathrm{mmol})$ and $\mathrm{Na}_{2} \mathrm{CO}_{3}(10.0 \mathrm{~g}, 95.0 \mathrm{mmol}$ ) in distilled water (final volume $100 \mathrm{~mL}$ ), final $\mathrm{pH}$ was adjusted using $1 \mathrm{M} \mathrm{NaOH}$ and $\mathrm{HCl}$ solutions). The reaction was stirred at rt overnight, diluted with $\mathrm{CH}_{2} \mathrm{Cl}_{2}$, washed with $\mathrm{H}_{2} \mathrm{O} /$ brine and extracted with $\mathrm{CH}_{2} \mathrm{Cl}_{2}$. The organic extracts were collected, dried with $\mathrm{Na}_{2} \mathrm{SO}_{4}$, filtered and evaporated in 
vacuo. The residue was purified by column chromatography on silica gel (eluting with $\mathrm{EtOAc} / \mathrm{MeOH}=100: 20)$ to give $\mathbf{S} 25$ as a pale yellow oil (271 $\mathrm{mg}$, quant.). The spectral data was in accordance with the literature. ${ }^{71} \mathrm{H}$ NMR $\left(500 \mathrm{MHz}, \mathrm{CDCl}_{3}\right): \delta 6.27(\mathrm{br} \mathrm{s}, 1 \mathrm{H}), 5.11(\mathrm{br} \mathrm{s}, 1 \mathrm{H}), 4.55(\mathrm{br} \mathrm{s}, 1 \mathrm{H})$, 3.87-3.80 (m, 1H), 3.73-3.61 (m, 11H), 3.56 (dd, $J=5.7,4.6 \mathrm{~Hz}, 2 \mathrm{H}), 3.47-3.42(\mathrm{~m}, 2 \mathrm{H}), 3.39(\mathrm{dd}, J=5.5$, 4.6 Hz, 2H), $2.18(\mathrm{t}, J=7.4 \mathrm{~Hz}, 2 \mathrm{H}), 1.66(\mathrm{p}, J=7.2 \mathrm{~Hz}, 2 \mathrm{H}), 1.55-1.22(\mathrm{~m}, 6 \mathrm{H}), 1.13(\mathrm{~d}, J=6.5 \mathrm{~Hz}, 3 \mathrm{H})$; ${ }^{13} \mathrm{C}$ NMR $\left(126 \mathrm{MHz}, \mathrm{CDCl}_{3}\right): \delta 173.1,163.4,70.9,70.7,70.7,70.4,70.2,70.1,56.2,51.5,50.8,39.3,36.3$, 29.6, 28.9, 26.2, 25.4, 15.9 .

\section{Synthesis of $\mathrm{N}$-(11-(4-(10-(4-fluorobenzoyl)-10-fluoro-9-oxa-10a-aza-10-boraphenanthren-3-yl)-1H-}

\section{1,2,3-triazol-1-yl)-3,6,9-trioxaundecyl)-6-((4R,5S)-5-methyl-2-oxoimidazolidin-4-yl)hexanamide (2a)}

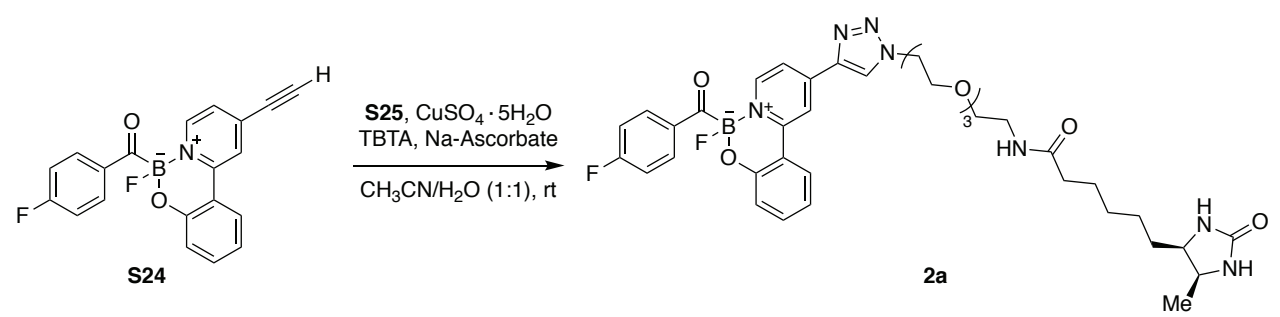

A round-bottom flask was charged with $\mathbf{S} 24(48.9 \mathrm{mg}, 0.14 \mathrm{mmol}, 1.00$ equiv), $\mathbf{S} 25$ (57.2 $\mathrm{mg}, 0.14 \mathrm{mmol}$, 1.00 equiv), copper sulfate pentahydrate $(34.0 \mathrm{mg}, 0.14 \mathrm{mmol}, 1.00$ equiv) and tris((1-benzyl-1H-1,2,3triazol-4-yl)methyl)amine (TBTA, $17.0 \mathrm{mg}, 0.03 \mathrm{mmol}, 0.20$ equiv). The solids were suspended in $\mathrm{CH}_{3} \mathrm{CN} / \mathrm{H}_{2} \mathrm{O}(1: 1,2 \mathrm{~mL})$ and sodium ascorbate $(80 \mathrm{mg}, 0.40 \mathrm{mmol}, 2.80$ equiv) was added. The reaction was stirred at rt overnight and filtered. The filtrate was purified by preparative reverse-phase HPLC (YMC C18 column, gradient of $20-95 \% \mathrm{CH}_{3} \mathrm{CN} / \mathrm{H}_{2} \mathrm{O}+0.1 \%$ TFA for $28 \mathrm{~min}, t_{\mathrm{R}}=21.5 \mathrm{~min}$ ). The corresponding peak was collected, diluted with brine, extracted with $\mathrm{CH}_{2} \mathrm{Cl}_{2}$, dried with $\mathrm{Na}_{2} \mathrm{SO}_{4}$, filtered and evaporated in vacuo to give 2a as a yellow solid (23 mg, 22\%). m.p. $69-75{ }^{\circ} \mathrm{C} ;{ }^{1} \mathrm{H}$ NMR $\left(600 \mathrm{MHz}, \mathrm{CDCl}_{3}\right): \delta 8.65$ (br s, $\left.1 \mathrm{H}\right), 8.56$ (s, $1 \mathrm{H}), 8.45(\mathrm{~d}, J=6.2 \mathrm{~Hz}, 1 \mathrm{H}), 8.23(\mathrm{dd}, J=8.4,5.8 \mathrm{~Hz}, 2 \mathrm{H}), 7.94$ (ddd, $J=6.3,1.7,0.9 \mathrm{~Hz}, 1 \mathrm{H}$ ), 7.92 (dd, $J=8.1,1.6 \mathrm{~Hz}, 1 \mathrm{H}), 7.36(\mathrm{ddd}, J=8.5,7.2,1.5 \mathrm{~Hz}, 1 \mathrm{H}), 7.12(\mathrm{t}, J=8.8 \mathrm{~Hz}, 2 \mathrm{H}), 7.02(\mathrm{dd}, J=8.3,1.1 \mathrm{~Hz}$, 1H), 6.96 (ddd, $J=8.2,7.2,1.2 \mathrm{~Hz}, 1 \mathrm{H}), 6.37(\mathrm{~s}, 1 \mathrm{H}), 5.29(\mathrm{br}, 1 \mathrm{H}), 4.67(\mathrm{dd}, J=5.8,4.1 \mathrm{~Hz}, 2 \mathrm{H}), 3.95(\mathrm{t}$, $J=5.4 \mathrm{~Hz}, 2 \mathrm{H}), 3.80(\mathrm{p}, J=7.1 \mathrm{~Hz}, 1 \mathrm{H}), 3.69-3.58(\mathrm{~m}, 8 \mathrm{H}), 3.53-3.47(\mathrm{~m}, 2 \mathrm{H}), 3.38(\mathrm{q}, J=5.4 \mathrm{~Hz}, 2 \mathrm{H}), 2.10$ $(\mathrm{t}, J=7.4 \mathrm{~Hz}, 2 \mathrm{H}), 1.59(\mathrm{p}, J=7.3 \mathrm{~Hz}, 2 \mathrm{H}), 1.49-1.17(\mathrm{~m}, 6 \mathrm{H}), 1.09(\mathrm{~d}, J=6.5 \mathrm{~Hz}, 3 \mathrm{H}) ;{ }^{13} \mathrm{C}$ NMR $(151 \mathrm{MHz}$, $\left.\mathrm{CDCl}_{3}\right): \delta 227.9(\mathrm{br}), 173.2,165.5(\mathrm{~d}, J=252.7 \mathrm{~Hz}), 163.5,155.1(\mathrm{~d}, J=4.9 \mathrm{~Hz}), 150.2,144.3,143.3,142.9$ (d, $J=5.8 \mathrm{~Hz}), 136.5,134.7,131.3(\mathrm{~d}, J=9.1 \mathrm{~Hz}), 125.8,125.3,120.8,120.4,119.0,116.7,115.8,115.4(\mathrm{~d}$, $J=21.5 \mathrm{~Hz}), 70.6,70.6,70.5,70.1,70.0,69.2,56.1,51.5,50.8,39.2,36.1,29.6,28.8,26.0,25.4,15.9$; 
${ }^{19} \mathrm{~F}$ NMR $\left(471 \mathrm{MHz}, \mathrm{CDCl}_{3}\right): \delta-107.0,-158.2 ;{ }^{11} \mathrm{~B}$ NMR $\left(160 \mathrm{MHz}, \mathrm{CDCl}_{3}\right): \delta 2.09$; IR (thin film): v 3298, 2932, 2867, 1696, 1634, 1588, 1546, 1499, 1454, $1230 \mathrm{~cm}^{-1}$; ESI-HRMS calcd for $\mathrm{C}_{38} \mathrm{H}_{47} \mathrm{BF}_{2} \mathrm{~N}_{7} \mathrm{O}_{7}[\mathrm{M}+\mathrm{H}]^{+}$ 762.3599, found 762.3593; $[\alpha]_{\mathrm{D}}{ }^{25}:+9.9\left(c=0.34, \mathrm{CHCl}_{3}\right)$.

\section{Synthesis of $\mathrm{N}$-(20-(4-(10-(4-fluorobenzoyl)-10-fluoro-9-oxa-10a-aza-10-boraphenanthren-3-yl)-1 $H$ -}

\section{1,2,3-triazol-1-yl)-3,6,9,12,15,18-hexaoxaeicosyl)-6-((4R,5S)-5-methyl-2-oxoimidazolidin-4-} yl)hexanamide (2b)

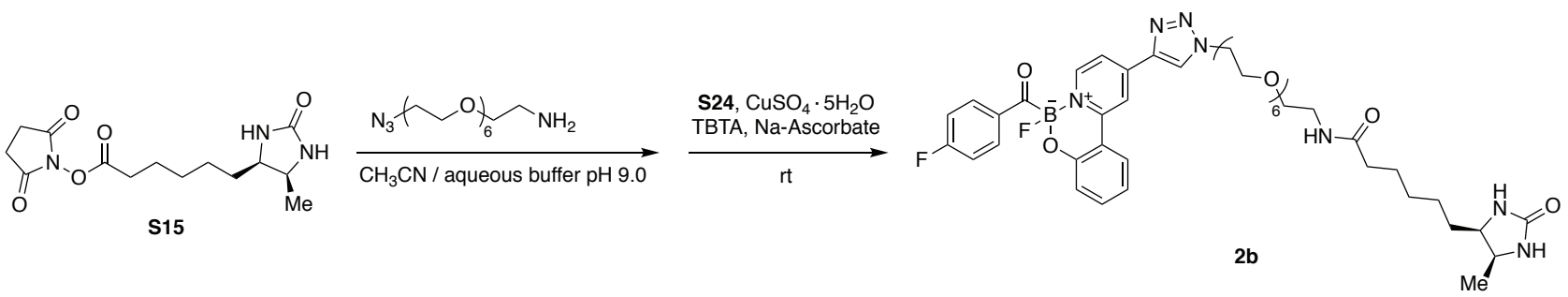

To a round-bottom flask were added $\mathbf{S} 15(50.0 \mathrm{mg}, 0.16 \mathrm{mmol}, 1.30$ equiv) and 20-azido-3,6,9,12,15,18hexaoxaeicosan-1-amine ( $50 \mu \mathrm{L}, 90 \%$ purity, $0.13 \mathrm{mmol}, 1.00$ equiv). The solids were suspended in $\mathrm{CH}_{3} \mathrm{CN}$ $(1.5 \mathrm{~mL})$ and aqueous buffer $\mathrm{pH} 9.0(0.5 \mathrm{~mL}$, prepared as describe above for the synthesis of S25). The mixture was stirred at $\mathrm{rt}$ for $2 \mathrm{~h}$ and $\mathbf{S} 24(52 \mathrm{mg}, 0.15 \mathrm{mmol}, 1.20$ equiv) was added, followed by copper sulfate pentahydrate $(32.0 \mathrm{mg}, 0.13 \mathrm{mmol}, 1.00$ equiv), tris((1-benzyl-1H-1,2,3-triazol-4-yl)methyl)amine (TBTA, $15.0 \mathrm{mg}, 0.03 \mathrm{mmol}, 0.20$ equiv) and sodium ascorbate (120 mg, $0.60 \mathrm{mmol}, 4.6$ equiv). The solution was stirred at $\mathrm{rt}$ for $2 \mathrm{~h}$ and filtered. The filtrate was purified by preparative reverse-phase HPLC (YMC C18 column, gradient of $20-95 \% \mathrm{CH}_{3} \mathrm{CN} / \mathrm{H}_{2} \mathrm{O}+0.1 \%$ TFA for $28 \mathrm{~min}, t_{\mathrm{R}}=22.2 \mathrm{~min}$ ). The corresponding peak was collected, diluted with brine, extracted with $\mathrm{CH}_{2} \mathrm{Cl}_{2}$, dried with $\mathrm{Na}_{2} \mathrm{SO}_{4}$, filtered and evaporated in vacuo to give $\mathbf{2 b}$ as a yellow solid (24.1 mg, $21 \%$ over two steps). ${ }^{1} \mathbf{H}$ NMR $\left(600 \mathrm{MHz}, \mathrm{CDCl}_{3}\right): \delta 8.66(\mathrm{~d}, \mathrm{~J}=1.6 \mathrm{~Hz}$, 1H), $8.62(\mathrm{~s}, 1 \mathrm{H}), 8.45(\mathrm{~d}, J=6.3 \mathrm{~Hz}, 1 \mathrm{H}), 8.22(\mathrm{dd}, J=8.6,5.8 \mathrm{~Hz}, 2 \mathrm{H}), 7.97(\mathrm{dd}, J=6.3,1.7 \mathrm{~Hz}, 1 \mathrm{H}), 7.92$ (dd, $J=8.2,1.6 \mathrm{~Hz}, 1 \mathrm{H}$ ), 7.35 (ddd, $J=8.5,7.2,1.6 \mathrm{~Hz}, 1 \mathrm{H}$ ), 7.10 (t, $J=8.7 \mathrm{~Hz}, 2 \mathrm{H}$ ), 7.00 (dd, $J=8.3$, $1.1 \mathrm{~Hz}, 1 \mathrm{H}), 6.95$ (ddd, $J=8.2,7.2,1.2 \mathrm{~Hz}, 1 \mathrm{H}), 6.54(\mathrm{t}, J=5.6 \mathrm{~Hz}, 1 \mathrm{H}), 5.45(\mathrm{br} \mathrm{s}, 1 \mathrm{H}), 4.78(\mathrm{br} \mathrm{s}, 1 \mathrm{H})$, 4.67-4.63 (m, 2H), 3.96-3.92 (m, 2H), 3.79 (p, J = 7.0 Hz, 1H), 3.67-3.63 (m, 3H), 3.63-3.60 (m, 7H), 3.60$3.57(\mathrm{~m}, 2 \mathrm{H}), 3.57-3.52(\mathrm{~m}, 8 \mathrm{H}), 3.52-3.49(\mathrm{~m}, 2 \mathrm{H}), 3.41-3.36(\mathrm{~m}, 2 \mathrm{H}), 2.15(\mathrm{t}, J=7.4 \mathrm{~Hz}, 2 \mathrm{H}), 1.62(\mathrm{p}$, $J=7.2 \mathrm{~Hz}, 2 \mathrm{H}), 1.50-1.18(\mathrm{~m}, 6 \mathrm{H}), 1.08(\mathrm{~d}, J=6.5 \mathrm{~Hz}, 3 \mathrm{H}) ;{ }^{13} \mathrm{C} \mathrm{NMR}\left(151 \mathrm{MHz}, \mathrm{CDCl}_{3}\right): \delta 227.6,173.2$, $165.4(\mathrm{~d}, J=252.5 \mathrm{~Hz}), 163.7,155.1(\mathrm{~d}, J=4.8 \mathrm{~Hz}), 150.1,144.5,143.2,142.8(\mathrm{~d}, J=5.7 \mathrm{~Hz}), 136.5,134.6$, $131.3(\mathrm{~d}, J=7.1 \mathrm{~Hz}), 125.9,125.5,120.7,120.3,119.0,116.8,115.7,115.3$ (d, $J=21.5 \mathrm{~Hz}), 70.6,70.6$, $70.6,70.6,70.6,70.6,70.5,70.5,70.2,70.0,69.2,56.1,51.5,50.9,39.2,36.1,29.6,28.8,26.1,25.4,15.9$; 
${ }^{19} \mathrm{~F}$ NMR $\left(471 \mathrm{MHz}, \mathrm{CDCl}_{3}\right): \delta-107.2,-158.3 ;{ }^{11} \mathrm{~B}$ NMR $\left(160 \mathrm{MHz}, \mathrm{CDCl}_{3}\right): \delta 2.15$; IR (thin film): v 3284, 2864, 1697, 1632, 1228, $1091 \mathrm{~cm}^{-1}$; ESI-HRMS calcd for $\mathrm{C}_{44} \mathrm{H}_{59} \mathrm{BF}_{2} \mathrm{~N}_{7} \mathrm{O}_{10}[\mathrm{M}+\mathrm{H}]^{+} 894.4387$, found 894.4380; $[\alpha]_{D}^{25}:+3.4\left(c=1.15, \mathrm{CHCl}_{3}\right)$.

\section{Synthesis of $\mathrm{N}$-(32-(4-(10-(4-fluorobenzoyl)-10-fluoro-9-oxa-10a-aza-10-boraphenanthren-3-yl)-1H-} 1,2,3-triazol-1-yl)-3,6,9,12,15,18,21,24,27-decaoxadotriacontyl)-6-((4R,5S)-5-methyl-2-oxoimidazolidin4-yl)hexanamide (2c)

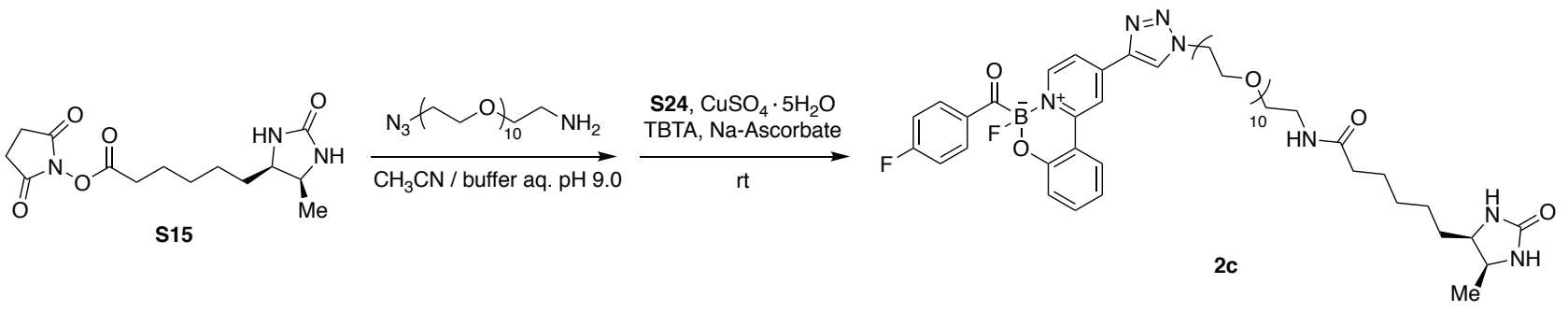

To a round-bottom flask were added $\mathbf{S 1 5}(32.0 \mathrm{mg}, 102 \mu \mathrm{mol}, 1.50$ equiv) and 32-azido3,6,9,12,15,18,21,24,27,30-decaoxadotriacontan-1-amine (40 $\mu \mathrm{L}, 90 \%$ purity, $68 \mu \mathrm{mol}, 1.0$ equiv). The solids were suspended in $\mathrm{CH}_{3} \mathrm{CN}(1.5 \mathrm{~mL})$ and aqueous buffer $\mathrm{pH} 9.0(0.5 \mathrm{~mL}$, prepared as describe above for the synthesis of S25). The mixture was stirred at $\mathrm{rt}$ for $4 \mathrm{~h}$ and $\mathbf{S 2 4}(26.0 \mathrm{mg}, 75 \mu \mathrm{mol}, 1.10$ equiv) was added, followed by copper sulfate pentahydrate $(17.0 \mathrm{mg}, 68 \mu \mathrm{mol}, 1.00$ equiv), tris((1-benzyl-1H-1,2,3-triazol-4yl)methyl)amine (TBTA, $7.2 \mathrm{mg}, 14 \mu \mathrm{mol}, 0.20$ equiv) and sodium ascorbate ( $55 \mathrm{mg}, 270 \mu \mathrm{mol}, 4.00$ equiv). The solution was stirred at rt for $2 \mathrm{~h}$ and filtered. The filtrate was purified by preparative reverse-phase HPLC (YMC C18 column, gradient of $20-95 \% \mathrm{CH}_{3} \mathrm{CN} / \mathrm{H}_{2} \mathrm{O}+0.1 \%$ TFA for $28 \mathrm{~min}, t_{\mathrm{R}}=22.3 \mathrm{~min}$ ). The corresponding peak was collected, diluted with brine, extracted with $\mathrm{CH}_{2} \mathrm{Cl}_{2}$, dried with $\mathrm{Na}_{2} \mathrm{SO}_{4}$, filtered and evaporated in vacuo to give $2 \mathrm{c}$ as a sticky yellow solid (28.1 mg, $38 \%$ over two steps). ${ }^{1} \mathrm{H}$ NMR (600 MHz, $\left.\mathrm{CDCl}_{3}\right): \delta 8.65(\mathrm{~d}, J=1.7 \mathrm{~Hz}, 1 \mathrm{H}), 8.60(\mathrm{~s}, 1 \mathrm{H}), 8.44(\mathrm{~d}, J=6.3 \mathrm{~Hz}, 1 \mathrm{H}), 8.22(\mathrm{dd}, J=8.6,5.8 \mathrm{~Hz}, 2 \mathrm{H}), 7.97$ $(\mathrm{dd}, J=6.3,1.7 \mathrm{~Hz}, 1 \mathrm{H}), 7.92(\mathrm{dd}, J=8.1,1.6 \mathrm{~Hz}, 1 \mathrm{H}), 7.35(\mathrm{ddd}, J=8.5,7.2,1.6 \mathrm{~Hz}, 1 \mathrm{H}), 7.10(\mathrm{t}$, $J=8.7 \mathrm{~Hz}, 2 \mathrm{H}), 7.00(\mathrm{dd}, J=8.3,1.2 \mathrm{~Hz}, 1 \mathrm{H}), 6.95(\mathrm{ddd}, J=8.2,7.1,1.2 \mathrm{~Hz}, 1 \mathrm{H}), 6.44(\mathrm{t}, J=5.4 \mathrm{~Hz}, 1 \mathrm{H})$, $5.34(\mathrm{br}, 1 \mathrm{H}), 4.76(\mathrm{br}, 1 \mathrm{H}), 4.68-4.60(\mathrm{~m}, 2 \mathrm{H}), 3.95(\mathrm{t}, J=4.9 \mathrm{~Hz}, 2 \mathrm{H}), 3.81(\mathrm{p}, J=6.7 \mathrm{~Hz}, 1 \mathrm{H}), 3.70-3.49$ (m, 39H), 3.44-3.38 (m, 2H), $2.16(\mathrm{t}, J=7.4 \mathrm{~Hz}, 2 \mathrm{H}), 1.63(\mathrm{p}, J=7.2 \mathrm{~Hz}, 2 \mathrm{H}), 1.52-1.19(\mathrm{~m}, 6 \mathrm{H}), 1.10(\mathrm{~d}$, $J=6.5 \mathrm{~Hz}, 3 \mathrm{H}) ;{ }^{13} \mathrm{C}$ NMR $\left(151 \mathrm{MHz}, \mathrm{CDCl}_{3}\right): \delta 227.6,173.1,165.4$ (d, $\left.J=252.5 \mathrm{~Hz}\right), 163.6,155.1$ (d, $J=4.8 \mathrm{~Hz}), 150.1,144.5,143.2,142.8(\mathrm{~d}, J=5.6 \mathrm{~Hz}), 136.5,134.5,131.3$ (d, $J=8.2 \mathrm{~Hz}), 125.8,125.5$, 120.7, 120.3, 119.0, 116.8, 115.7, 115.3 (d, J = 21.5 Hz), 70.7, 70.7, 70.6, 70.6, 70.6, 70.3, 70.0, 69.2, 56.1, 
$51.5,50.9,39.3,36.2,29.6,28.9,26.1,25.4,15.9 ;{ }^{19} \mathrm{~F}$ NMR $\left(471 \mathrm{MHz}, \mathrm{CDCl}_{3}\right): \delta-107.3,-158.4 ;{ }^{11} \mathrm{~B}$ NMR $\left(160 \mathrm{MHz}, \mathrm{CDCl}_{3}\right.$ ): $\delta$ 1.96; IR (thin film): $v$ 3319, 2866, 1698, 1632, 1228, $1100 \mathrm{~cm}^{-1}$; ESI-HRMS calcd for $\mathrm{C}_{52} \mathrm{H}_{74} \mathrm{BF}_{2} \mathrm{KNN}_{7} \mathrm{O}_{14}[\mathrm{M}+\mathrm{K}]^{+} 1108.4995$, found $1100.4998 ;[\alpha]_{\mathrm{D}}^{25}:+1.5\left(c=1.40, \mathrm{CHCl}_{3}\right)$.

Synthesis of $N$-(4-azidobutyl)-6-((4R,5S)-5-methyl-2-oxoimidazolidin-4-yl)hexanamide (S26)

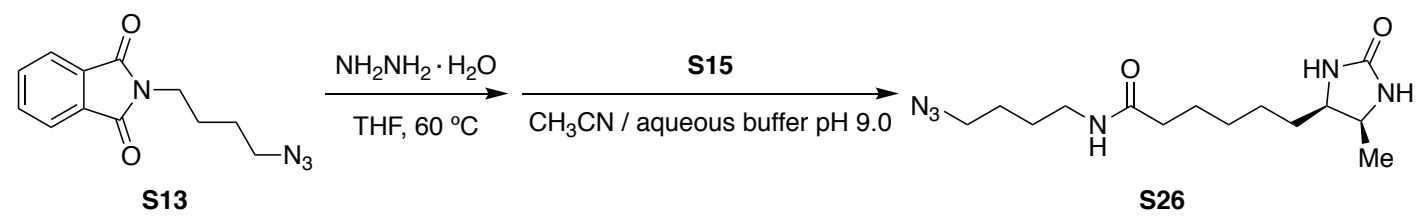

To a round-bottom flask containing a solution of $\mathbf{S} 13(244.2 \mathrm{mg}, 1.0 \mathrm{mmol}, 1.00$ equiv) in THF (2 mL) was added hydrazine monohydrate $\left(260 \mu \mathrm{L}, 5.0 \mathrm{mmol}, 5.00\right.$ equiv). The solution was stirred at $60{ }^{\circ} \mathrm{C}$ for $3 \mathrm{~h}$, cooled to rt, diluted with $\mathrm{CH}_{2} \mathrm{Cl}_{2}$, filtered and extracted with $\mathrm{HCl} 0.2 \mathrm{M}$. The acidic aqueous extracts were basified with $\mathrm{NaOH} 1 \mathrm{M}$ till $\mathrm{pH}>14$, extracted with $\mathrm{CH}_{2} \mathrm{Cl}_{2}$, dried with $\mathrm{Na}_{2} \mathrm{SO}_{4}$, filtered and concentrated in the rotavap (complete drying of the sample was avoided).

A separate round-bottom flask was charged with $\mathbf{S 1 5}(350.0 \mathrm{mg}, 1.1 \mathrm{mmol}, 1.10$ equiv). The solid was dissolved in $\mathrm{CH}_{3} \mathrm{CN}(5 \mathrm{~mL})$ and aqueous buffer $\mathrm{pH} 9.0$ (2 mL, prepared as describe above for the synthesis of S25), followed by addition of the concentrated $\mathrm{CH}_{2} \mathrm{Cl}_{2}$ extracts from above. The solution was stirred at $\mathrm{rt}$ overnight, diluted with $\mathrm{CH}_{2} \mathrm{Cl}_{2}$, washed with $\mathrm{H}_{2} \mathrm{O}$ /brine and extracted with $\mathrm{CH}_{2} \mathrm{Cl}_{2} / \mathrm{MeOH}$ (100:5). The organic extracts were collected, dried with $\mathrm{Na}_{2} \mathrm{SO}_{4}$, filtered and evaporated in vacuo. The residue was purified by column chromatography on silica gel (eluting with $\mathrm{CH}_{2} \mathrm{Cl}_{2} / \mathrm{MeOH}=100: 8$ ) to give $\mathbf{S} 26$ as a white solid (196.4 mg, 63\%). m.p. $54-56{ }^{\circ} \mathrm{C} ;{ }^{1} \mathrm{H}$ NMR $\left(500 \mathrm{MHz}, \mathrm{CD}_{3} \mathrm{OD}\right): \delta 3.83$ (p, J=6.7 Hz, $1 \mathrm{H}$ ), 3.71 (q, J= $7.2 \mathrm{~Hz}$, $1 \mathrm{H}), 3.37-3.29(\mathrm{~m}, 2 \mathrm{H}), 3.21(\mathrm{t}, J=6.3 \mathrm{~Hz}, 2 \mathrm{H}), 2.21(\mathrm{t}, J=7.4 \mathrm{~Hz}, 2 \mathrm{H}), 1.69-1.55(\mathrm{~m}, 6 \mathrm{H}), 1.54-1.27(\mathrm{~m}$, $6 \mathrm{H}), 1.12(\mathrm{~d}, J=6.4 \mathrm{~Hz}, 3 \mathrm{H}) ;{ }^{13} \mathrm{C}$ NMR $\left(126 \mathrm{MHz}, \mathrm{CD}_{3} \mathrm{OD}\right): \delta 176.2,166.2,57.4,52.7,52.1,39.7,37.0,30.7$, 30.2, 27.7, 27.3, 27.2, 26.9, 15.6, 15.6; IR (thin film): v 3278, 2093, 1702, 1642, 1538, 1444, $1259 \mathrm{~cm}^{-1}$; ESIHRMS calcd for $\mathrm{C}_{14} \mathrm{H}_{26} \mathrm{~N}_{6} \mathrm{NaO}_{2}[\mathrm{M}+\mathrm{Na}]^{+} 333.2009$, found 333.2015; $[\alpha]_{D}{ }^{25}:+8.2\left(c=0.90, \mathrm{CH}_{3} \mathrm{OH}\right)$. 
Synthesis of $\mathrm{N}$-(4-(4-(10-(4-fluorobenzoyl)-10-fluoro-9-oxa-10a-aza-10-boraphenanthren-3-yl)-1H-1,2,3triazol-1-yl)butyl)-6-((4R,5S)-5-methyl-2-oxoimidazolidin-4-yl)hexanamide (2d)

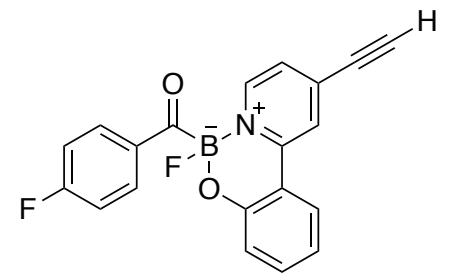

S24

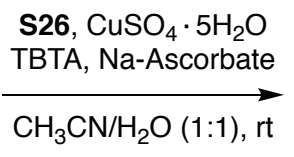

F

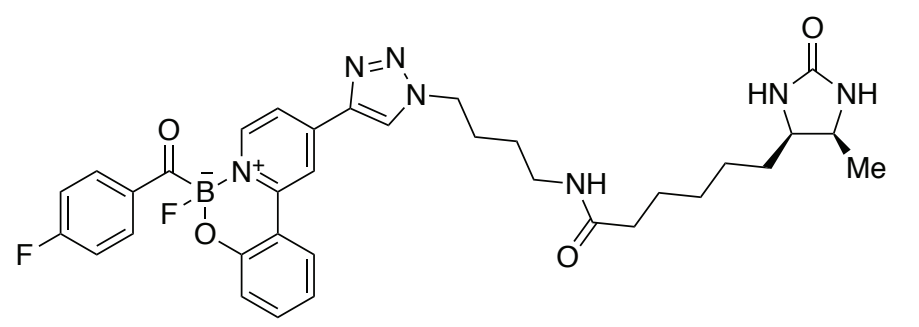

2d

A round-bottom flask was charged with $\mathbf{S 2 4}(34.7 \mathrm{mg}, 0.10 \mathrm{mmol}, 1.00$ equiv), $\mathbf{S} 26$ (31.3mg, $0.10 \mathrm{mmol}$, 1.0 equiv), copper sulfate pentahydrate $(25.0 \mathrm{mg}, 0.10 \mathrm{mmol}, 1.00$ equiv $)$ and tris((1-benzyl-1H-1,2,3-triazol4-yl)methyl)amine (TBTA, $10.0 \mathrm{mg}, 0.02 \mathrm{mmol}, 0.20$ equiv). The solids were suspended in $\mathrm{CH}_{3} \mathrm{CN} / \mathrm{H}_{2} \mathrm{O}(1: 1$, $5 \mathrm{~mL}$ ) and sodium ascorbate ( $80 \mathrm{mg}, 0.40 \mathrm{mmol}, 4.00$ equiv) was added. The reaction was stirred at $\mathrm{rt}$ for $3 \mathrm{~h}$ and filtered. The filtrate was purified by column chromatography on silica gel (eluting with $\left.\mathrm{CH}_{2} \mathrm{Cl}_{2} / \mathrm{MeOH}=100: 10\right)$ to give $2 \mathbf{d}$ as a yellow solid $(60.3 \mathrm{mg}, 92 \%)$. m.p. $108-113^{\circ} \mathrm{C}$ (decomp.); ${ }^{1} \mathbf{H} \mathbf{N M R}$ $\left(600 \mathrm{MHz}, \mathrm{CDCl}_{3}\right): \delta 8.59(\mathrm{br} \mathrm{s}, 1 \mathrm{H}), 8.45(\mathrm{br}, 1 \mathrm{H}), 8.42(\mathrm{~d}, J=5.8 \mathrm{~Hz}, 1 \mathrm{H}), 8.24(\mathrm{dd}, J=8.6,5.8 \mathrm{~Hz}, 2 \mathrm{H})$, $7.94(\mathrm{br}, 1 \mathrm{H}), 7.89(\mathrm{~d}, J=7.9 \mathrm{~Hz}, 1 \mathrm{H}), 7.33(\mathrm{t}, J=7.5 \mathrm{~Hz}, 1 \mathrm{H}), 7.12(\mathrm{t}, J=8.7 \mathrm{~Hz}, 2 \mathrm{H}), 6.98(\mathrm{dd}, J=8.2$, $1.0 \mathrm{~Hz}, 1 \mathrm{H}), 6.90(\mathrm{t}, J=7.4 \mathrm{~Hz}, 1 \mathrm{H}), 6.22(\mathrm{br} \mathrm{s}, 1 \mathrm{H}), 5.68(\mathrm{br} \mathrm{s}, 1 \mathrm{H}), 4.71(\mathrm{br} \mathrm{s}, 1 \mathrm{H}), 4.46(\mathrm{t}, J=6.7 \mathrm{~Hz}, 2 \mathrm{H})$, $3.81(\mathrm{p}, J=6.7 \mathrm{~Hz}, 1 \mathrm{H}), 3.70-3.59(\mathrm{~m}, 1 \mathrm{H}), 3.35-3.25(\mathrm{~m}, 2 \mathrm{H}), 2.17(\mathrm{t}, J=7.2 \mathrm{~Hz}, 2 \mathrm{H}), 2.03-1.90(\mathrm{~m}, 2 \mathrm{H})$, 1.68-1.59 (m, 2H), 1.57-1.50 (m, 2H), 1.48-1.20 (m, 6H), $1.08(\mathrm{~d}, J=6.5 \mathrm{~Hz}, 3 \mathrm{H}) ;{ }^{13} \mathrm{C}$ NMR (151 MHz, $\left.\mathrm{CDCl}_{3}\right): \delta 228.1(\mathrm{br}), 173.6,165.5(\mathrm{~d}, J=252.9 \mathrm{~Hz}), 163.8,155.1(\mathrm{~d}, J=4.7 \mathrm{~Hz}), 150.1,144.3,143.3,142.8$ (d, $J=5.6 \mathrm{~Hz}), 136.5,134.7,131.3(\mathrm{~d}, J=9.0 \mathrm{~Hz}), 125.9,124.5,120.8,120.3,118.9,116.7,115.8,115.4$ (d, $J=21.5 \mathrm{~Hz}), 56.1,51.6,50.1,38.3,36.1,29.6,28.6,27.4,26.7,25.9,25.4,15.9 ;{ }^{19} \mathrm{~F}$ NMR $(471 \mathrm{MHz}$, $\mathrm{CDCl}_{3}$ ): $\delta-106.9,-158.2 ;{ }^{11} \mathrm{~B}$ NMR $\left(160 \mathrm{MHz}, \mathrm{CDCl}_{3}\right.$ ): $\delta$ 2.02; IR (thin film): v 3285, 2934, 1697, 1633, 1229 , 1119, $1054 \mathrm{~cm}^{-1}$; ESI-HRMS calcd for $\mathrm{C}_{34} \mathrm{H}_{38} \mathrm{BF}_{2} \mathrm{~N}_{7} \mathrm{NaO}_{4}[\mathrm{M}+\mathrm{Na}]^{+} 680.2945$, found 680.2946; [ $\left.\alpha\right]_{\mathrm{D}}{ }^{25}:+6.1$ $\left(c=0.52, \mathrm{CHCl}_{3}\right)$. 
Synthesis of $\mathrm{N}$-(2-(4-(4-fluorobenzamido)butanamido)ethyl)-7-(diethylamino)-2-oxo-2H-chromene-3carboxamide (3)

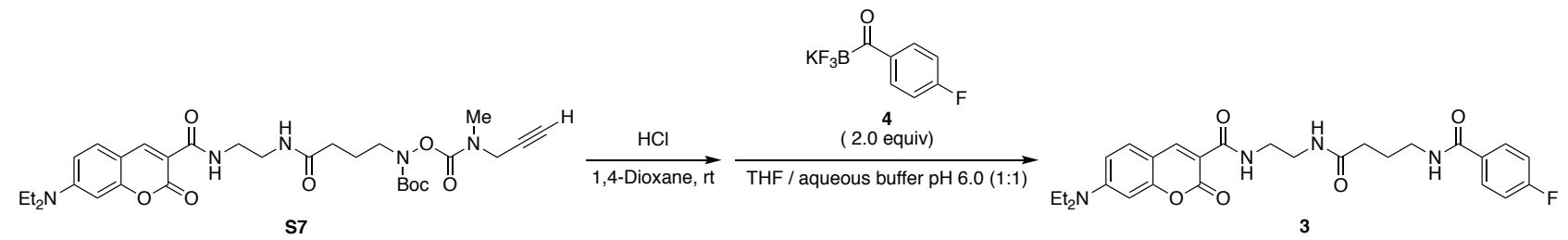

Boc-protected hydroxylamine $\mathbf{S 7}$ (100 $\mathrm{mg}, 0.16 \mathrm{mmol}, 1.00$ equiv) was introduced in a round-bottom flask. $\mathrm{HCl}$ (4 $\mathrm{M}$ in 1,4-dioxane, $0.50 \mathrm{~mL}, 2.0 \mathrm{mmol}, 12.5$ equiv) was added and the mixture stirred at $\mathrm{rt}$ for $30 \mathrm{~min}$. $\mathrm{Et}_{2} \mathrm{O}(20 \mathrm{~mL})$ was added and the resulting precipitate collected by vacuum filtration and dried in vacuo. The solid was transferred to a round-bottom flask charged with KAT 4 (73.6 mg, $0.32 \mathrm{mmol}, 2.00$ equiv). The solids were dissolved in THF / aqueous buffer $\mathrm{pH} 6.0(1: 1,4 \mathrm{~mL})$ and the solution stirred at rt for $3 \mathrm{~h}$. The reaction was diluted with $\mathrm{CH}_{2} \mathrm{Cl}_{2}$, washed with $\mathrm{H}_{2} \mathrm{O}$ /brine and extracted with $\mathrm{CH}_{2} \mathrm{Cl}_{2}$. The organic extracts were collected, dried with $\mathrm{Na}_{2} \mathrm{SO}_{4}$, filtered and evaporated in vacuo. The residue was purified by column chromatography on silica gel (eluting with $\left.\mathrm{CH}_{2} \mathrm{Cl}_{2} / \mathrm{MeOH}=100: 3\right)$ to give amide 3 as a yellow solid (66.4 mg, 81\%). m.p. $171-174{ }^{\circ} \mathrm{C} ;{ }^{1} \mathrm{H}$ NMR $\left(500 \mathrm{MHz}, \mathrm{CDCl}_{3}\right): \delta 9.08(\mathrm{t}, J=6.1 \mathrm{~Hz}, 1 \mathrm{H}), 8.58(\mathrm{~s}, 1 \mathrm{H}), 7.86(\mathrm{dd}, J=8.8$, $5.3 \mathrm{~Hz}, 2 \mathrm{H}), 7.66(\mathrm{t}, J=5.2 \mathrm{~Hz}, 1 \mathrm{H}), 7.34(\mathrm{~d}, J=9.0 \mathrm{~Hz}, 1 \mathrm{H}), 7.07-6.99(\mathrm{~m}, 3 \mathrm{H}), 6.62(\mathrm{dd}, J=9.0,2.5 \mathrm{~Hz}$, 1H), $6.44(\mathrm{~d}, J=2.3 \mathrm{~Hz}, 1 \mathrm{H}), 3.60-3.55(\mathrm{~m}, 2 \mathrm{H}), 3.49-3.40(\mathrm{~m}, 8 \mathrm{H}), 2.38-2.33(\mathrm{~m}, 2 \mathrm{H}), 1.95(\mathrm{p}, J=6.3 \mathrm{~Hz}$, 2H), $1.23(\mathrm{t}, J=7.1 \mathrm{~Hz}, 6 \mathrm{H}) ;{ }^{13} \mathrm{C}$ NMR $\left(126 \mathrm{MHz}, \mathrm{CDCl}_{3}\right): \delta 173.7,166.5,165.0,164.7$ (d, $\left.J=251.0 \mathrm{~Hz}\right)$, 162.8, 157.8, 152.9, 148.3, 131.3, $130.8(\mathrm{~d}, J=3.1 \mathrm{~Hz}), 129.5(\mathrm{~d}, J=8.8 \mathrm{~Hz}), 115.4(\mathrm{~d}, J=21.8 \mathrm{~Hz}), 110.2$, 109.6, 108.4, 96.6, 45.2, 41.3, 40.2, 39.3, 34.4, 24.5, 12.5; ${ }^{19} \mathrm{~F}$ NMR $\left(471 \mathrm{MHz}, \mathrm{CDCl}_{3}\right): \delta-109.1$; IR (thin film): $v 3309,2927,1698,1615,1579,1529,1506,1417,1351,1227,1188,1134 \mathrm{~cm}^{-1}$; ESI-HRMS calcd for $\mathrm{C}_{27} \mathrm{H}_{32} \mathrm{FN}_{4} \mathrm{O}_{5}[\mathrm{M}+\mathrm{H}]^{+}$511.2351, found 511.2345 .

\section{Streptavidin Mutants Expression and Purification}

Streptavidin mutants were expressed and purified by following the literature procedures. ${ }^{8,9}$ Plasmids pET21a-Streptavidin-Glutamate_Tag and pET21a-Streptavidin-Dead Aspartate loop were purchased from Addgene (plasmids \#46367 and \#46368 respectively). The Glu6 tag was deleted from the former plasmid by PCR, employing 5'-TAATAAAAGCTTGCGGCCG-3' and 5'-GGAAGCAGCGGACGGTTT-3' as the 
corresponding primers. Expressed denatured monomers were combined in a 1:1 ratio and refolded. Tetramers were purified by FPLC anion-exchange chromatography (eluting with Tris buffer $20 \mathrm{mM}, \mathrm{pH} 8.0$, linear gradient of $0-1 \mathrm{M} \mathrm{NaCl}$ over $100 \mathrm{CV}$, as described). The corresponding peaks were collected and spin-filtered into buffer aq. pH $6.0(25 \mathrm{mM}$, prepared by dissolving citric acid monohydrate $(663 \mathrm{mg}$, $3.2 \mathrm{mmol}$ ) and sodium citrate anhydrous $(5.63 \mathrm{~g}, 21.8 \mathrm{mmol})$ in distilled water $(1 \mathrm{~L})$; the final $\mathrm{pH}$ was adjusted using $1 \mathrm{M} \mathrm{NaOH}$ and $\mathrm{HCl}$ solutions). Aliquots of each peak were added equal volumes of 2x Laemmli buffer and incubated at rt (to avoid streptavidin to unfold). Samples were analyzed by SDSPAGE (using a $7.5 \%$ precast gel) and visualized by staining with CBB. Both the elution chromatogram and the gel were in agreement with the literature. ${ }^{9}$

a.

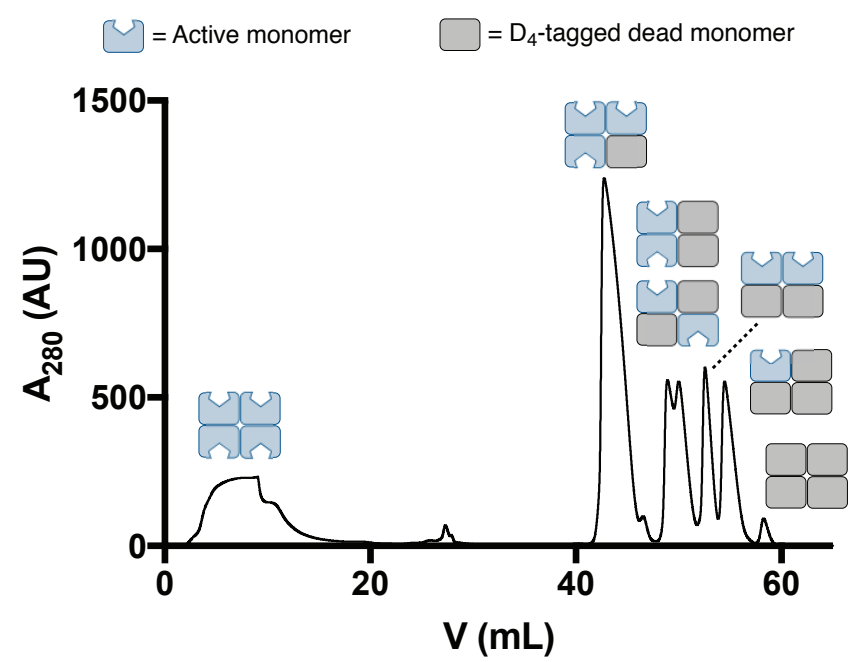

b.
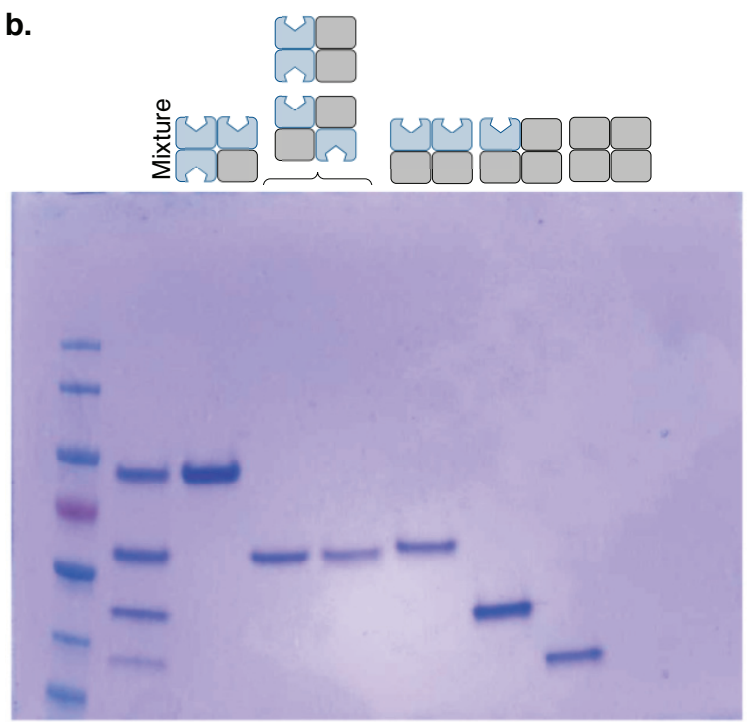

Figure S1. a. FPLC trace of refolded streptavidins. b. SDS-PAGE image of the refolded mixture of streptavidins and the separated individual peaks (after CBB staining and destaining). The possible tetramers are illustrated as combinations of active monomers (light blue indented boxes) and $\mathrm{D}_{4}$-tagged, dead monomers (grey boxes). 


\section{Kinetics Experiments}

Representative Procedure $D$ for the Kinetics Measurement of the Reaction of 1a with 2a
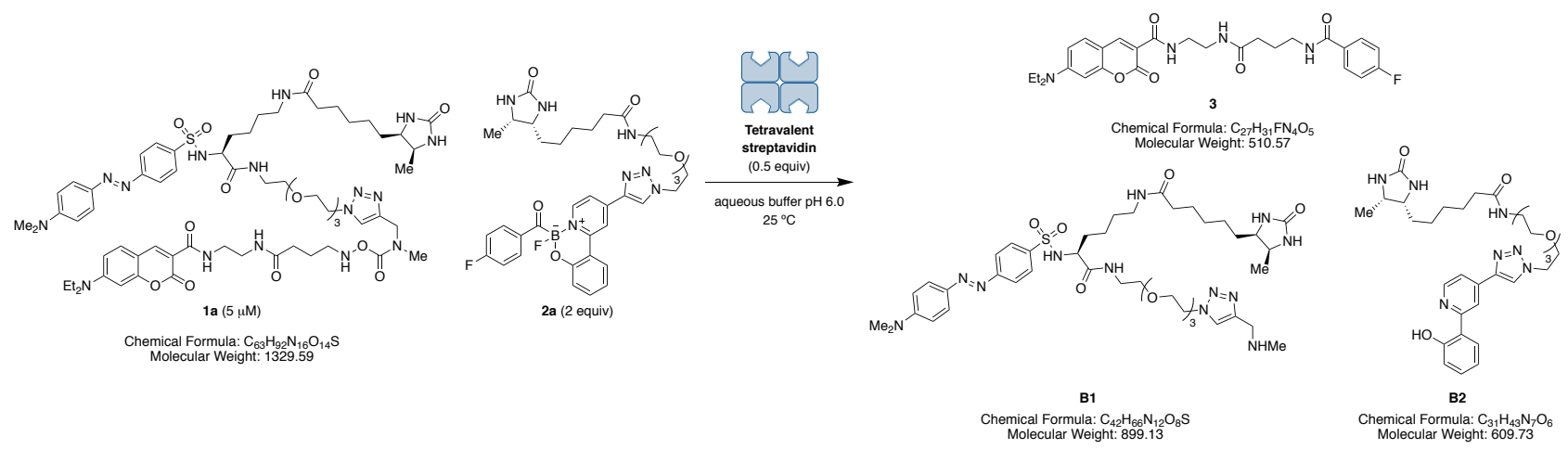

In a 96-well plate, aqueous buffer pH $6.0(153.8 \mu \mathrm{L}, 25 \mathrm{mM}$, prepared by dissolving citric acid monohydrate $(663 \mathrm{mg}, 3.2 \mathrm{mmol})$ and sodium citrate anhydrous $(5.63 \mathrm{~g}, 21.8 \mathrm{mmol})$ in distilled water $(1 \mathrm{~L})$; the final $\mathrm{pH}$ was adjusted using $1 \mathrm{M} \mathrm{NaOH}$ and $\mathrm{HCl}$ solutions) was added into three wells. Freshly deprotected $1 \mathrm{a}$ from Boc-1a (22.0 $\mu \mathrm{L}, 1.00 \mathrm{nmol}, 1.00$ equiv) was added from stock solution (45.4 $\mu \mathrm{M}$ in aqueous citrate buffer $\mathrm{pH} 6.0$ prepared as described above, the concentration was measured by UV-Vis at $425 \mathrm{~nm}$ using the extinction coefficient $\varepsilon_{425}=41.500 \mathrm{M}^{-1} \mathrm{~cm}^{-1}$ ) into each well, followed by expressed tetravalent streptavidin (20.2 $\mu \mathrm{L}, 0.50 \mathrm{nmol}, 0.50$ equiv) added from stock solution (24.7 $\mu \mathrm{M}$ in in aqueous buffer $\mathrm{pH} 6.0)$. After incubation for 5 minutes, acylboronate $2 \mathrm{a}(4.0 \mu \mathrm{L}, 2.00 \mathrm{nmol}, 2.00$ equiv) was added from stock solution (500 $\mu \mathrm{M}$ in 1:1 $\mathrm{CH}_{3} \mathrm{CN} /$ aqueous buffer $\left.\mathrm{pH} 6.0\right)$ and fluorescence monitored at $\lambda_{\mathrm{ex}}=430 \mathrm{~nm}, \lambda_{\mathrm{em}}=485 \mathrm{~nm}$ (final volume per well $200 \mu \mathrm{L}$ ).

To measure the maximum achievable conversion, the following control was carried out in every experiment: in separate wells containing aqueous buffer $\mathrm{pH} 6.0(174.0 \mu \mathrm{L}), 1 \mathrm{a}(22.0 \mu \mathrm{L}, 1.00 \mathrm{nmol}, 1.00$ equiv) from the same stock solution $(45.4 \mu \mathrm{M})$ was added followed by $4(4 \mu \mathrm{L}, 200 \mathrm{nmol}, 200$ equiv) from stock solution (50 mM in 1:1 $\mathrm{CH}_{3} \mathrm{CN} /$ aqueous buffer $\mathrm{pH} 6.0$ ).

Conversion values were extrapolated from the following formula:

$$
\% \operatorname{conv}=\frac{100 \cdot\left(F_{t}-F_{0}\right)}{\left(F_{\max }-F_{0}\right)}
$$

$F_{\mathrm{t}}$ is the fluorescence value at each time interval t. $F_{0}$ is the corresponding fluorescence at time zero.

$F_{\max }$ is the fluorescence output from the full conversion control experiments using 4.

Conv values obtained via the formula above were plotted over time, as follows: 


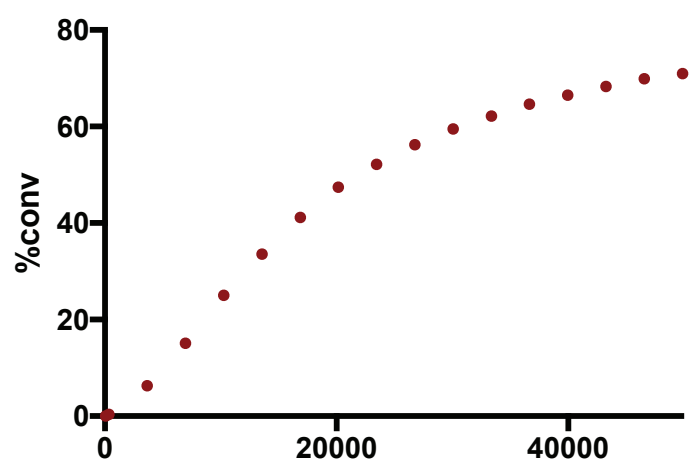

$\mathbf{t}(\mathbf{s})$

The last point after the kinetics measurement was analyzed by LC-MS (Figure S2, below). Only side products B1 and B2 (peak 1), product 3 (peak 2) and starting material 1a (peak 3) could be detected at $425 \mathrm{~nm}$.

\section{LC-MS Chromatogram of the Last Point from the Reaction of 1a with $2 a$ Templated by Tetravalent S} (plot 3a.1, reproduced above)
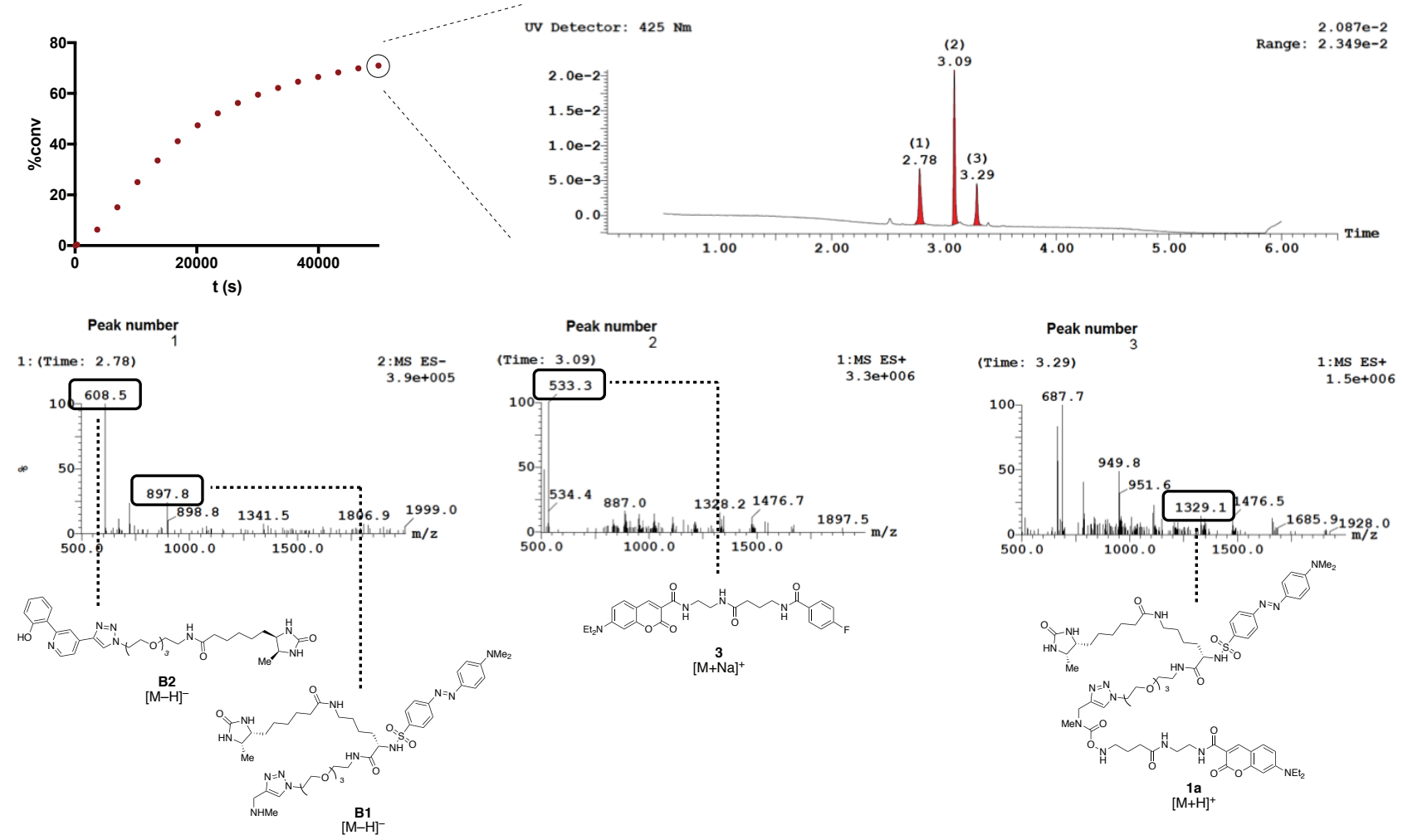

Figure S2. LC-MS analysis of the reaction of $1 \mathrm{a}(5.0 \mu \mathrm{M})$ with $2 \mathrm{a}(2.00$ equiv) in the presence of tetravalent $\mathbf{S}$ (0.50 equiv) in aqueous buffer $\mathrm{pH}$ 6.0. Peak 1 mass correspond to byproducts $\mathbf{B} 1[\mathrm{M}-\mathrm{H}]^{-}$and $\mathbf{B} 2[\mathrm{M}-\mathrm{H}]^{-}$. Peak 2 shows the mass of product $3[\mathrm{M}+\mathrm{Na}]^{+}$. Peak 3 correspond to $1 \mathrm{a}[\mathrm{M}+\mathrm{H}]^{+}$. 
Figure 3a-1 Experiments
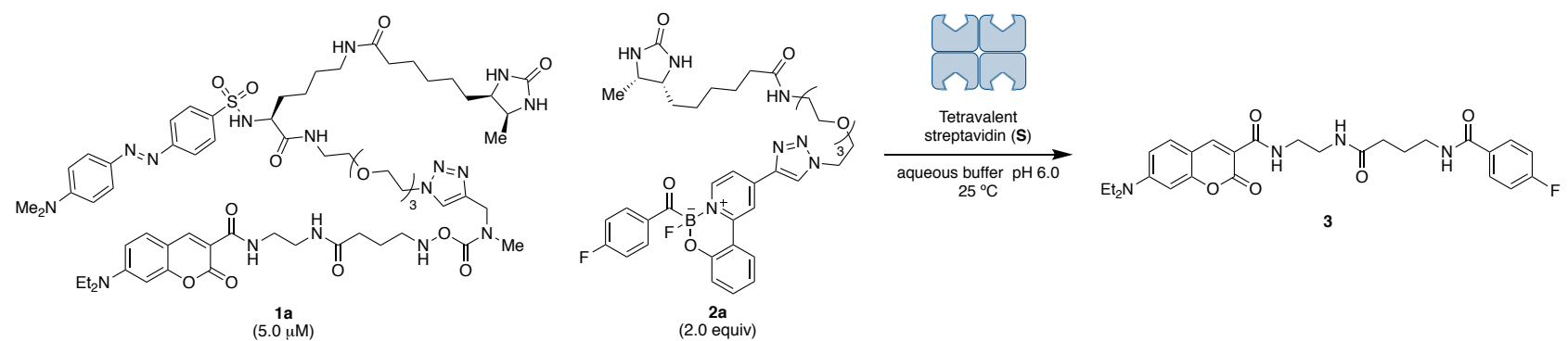

Following Representative Procedure D, the conversion over time graphs shown below were generated for a number of reaction conditions (displayed on each graph). Each plot is shown as mean values of three experiments with the corresponding error bars.
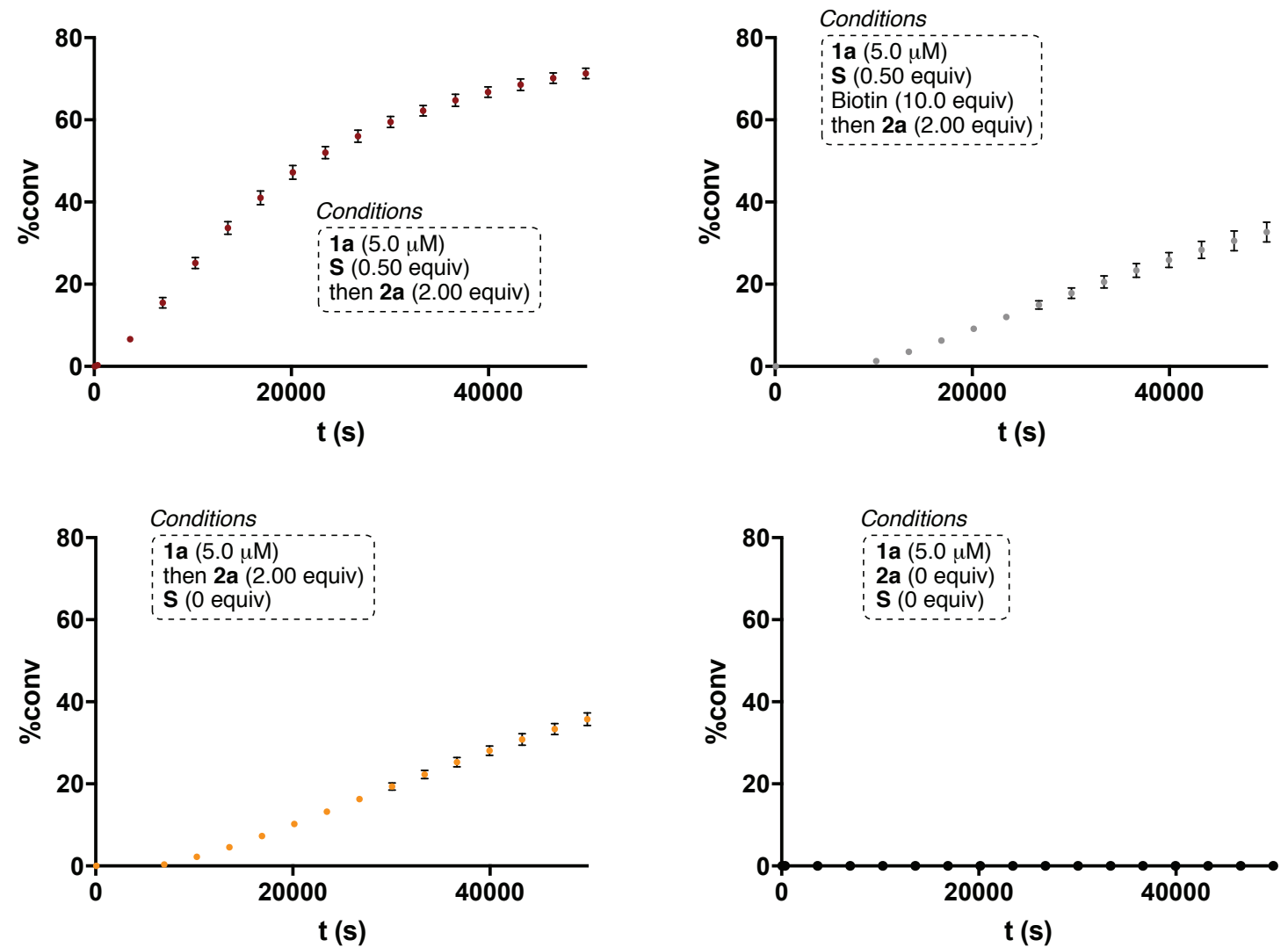
Figure 3a-2 Experiments
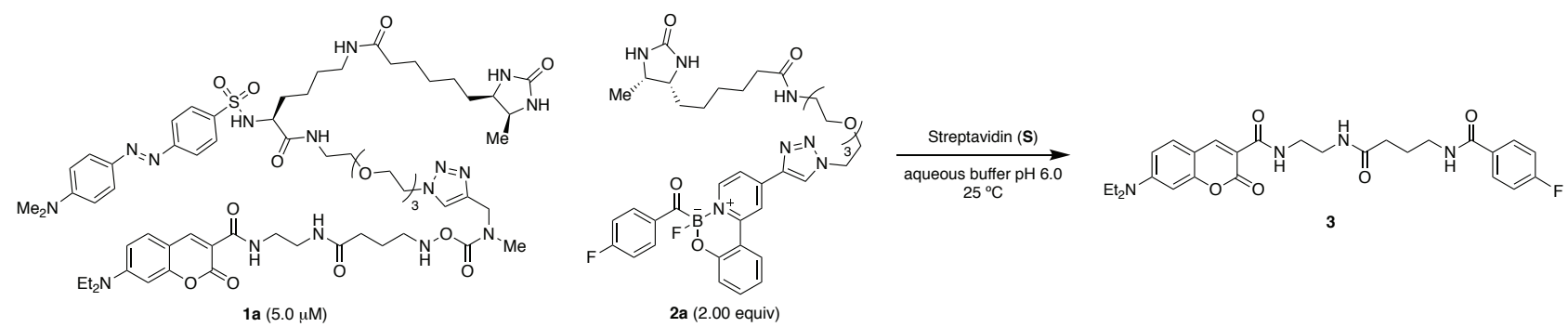

Following Representative Procedure D, the conversion over time graphs shown below were generated for a number of tested streptavidin mutants (displayed on each graph). Each plot is shown as mean values of three experiments with the corresponding error bars.
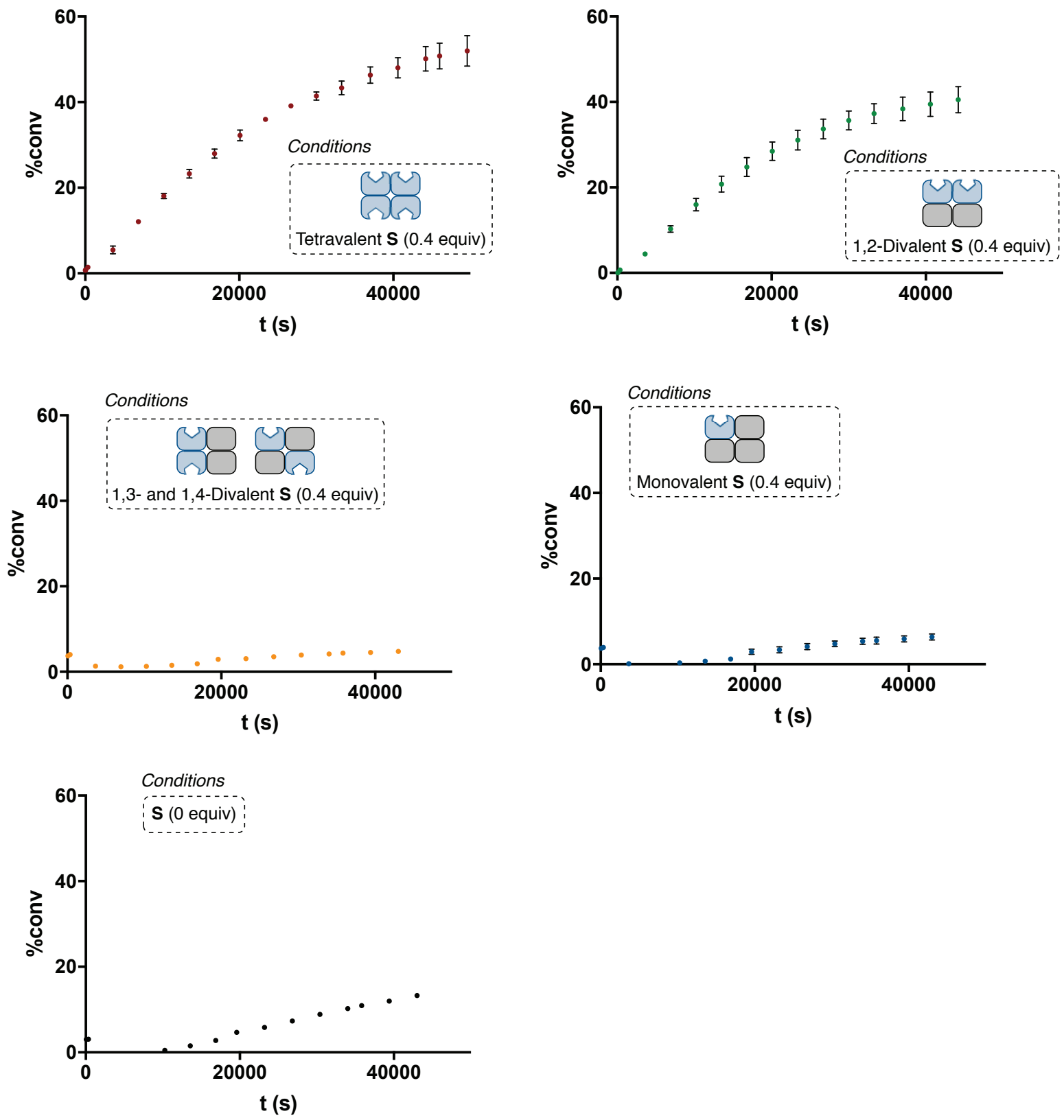
Figure 3a-3 Experiments
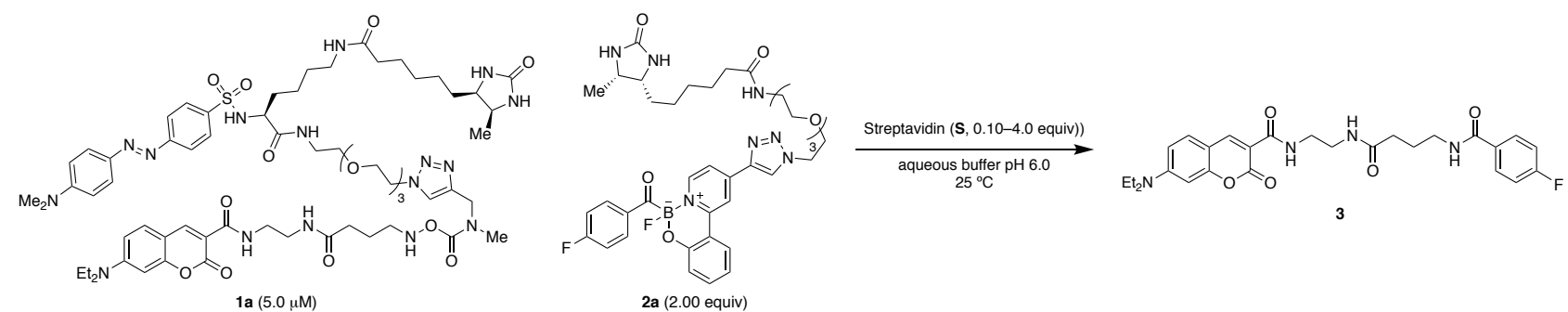

Following Representative Procedure D, conversion over time was measured for studies on streptavidin equivalents loading. At $6 \mathrm{~h}$ time point, conversion was plotted over $\mathbf{S}$ equivalents to generate the graphs below. Each plot corresponds to single run experiments.
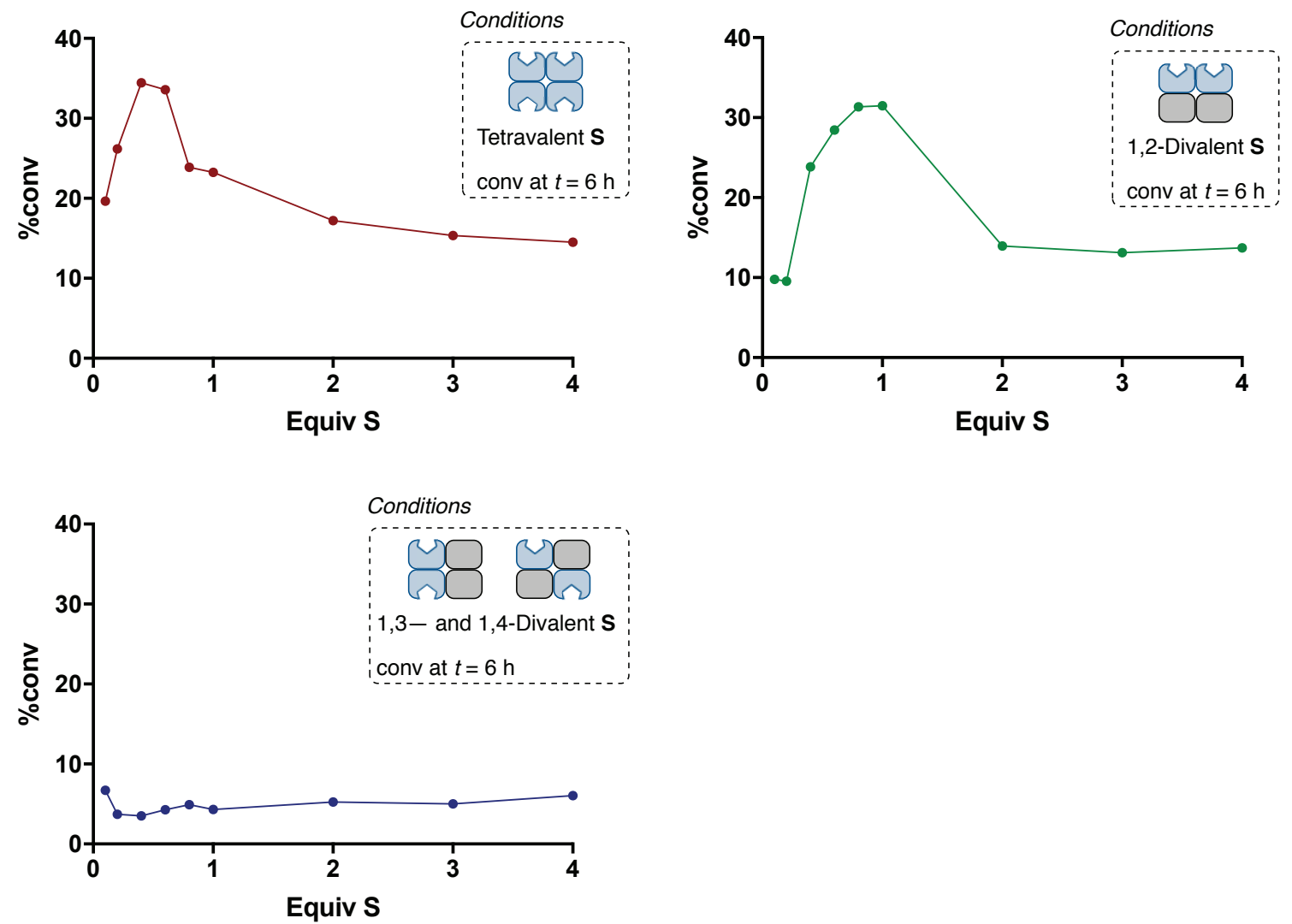

Figure 3a-4 Experiments

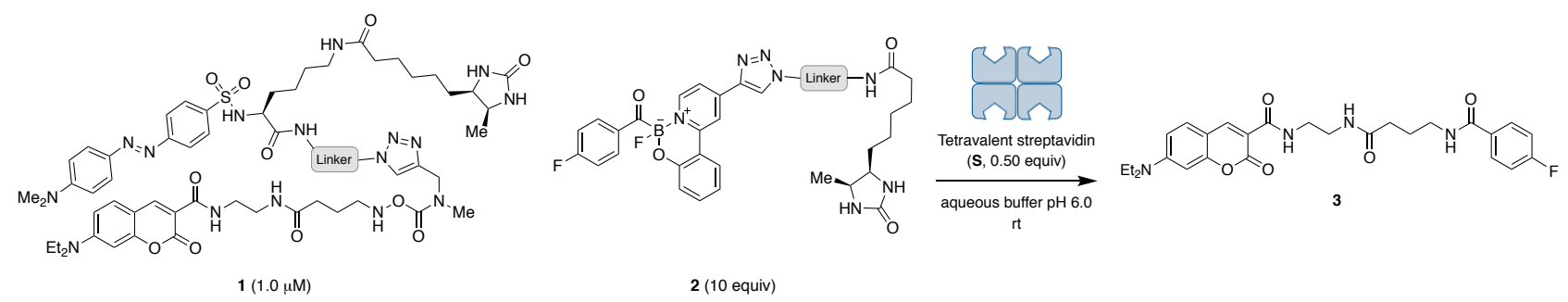

Following Representative Procedure D, the conversion over time graphs shown below were generated for reactions using starting materials equipped with different linkers (displayed on each graph) in the presence 
of tetravalent streptavidin (S, 0.50 equiv). Each plot is shown as mean values of three experiments with the corresponding error bars.
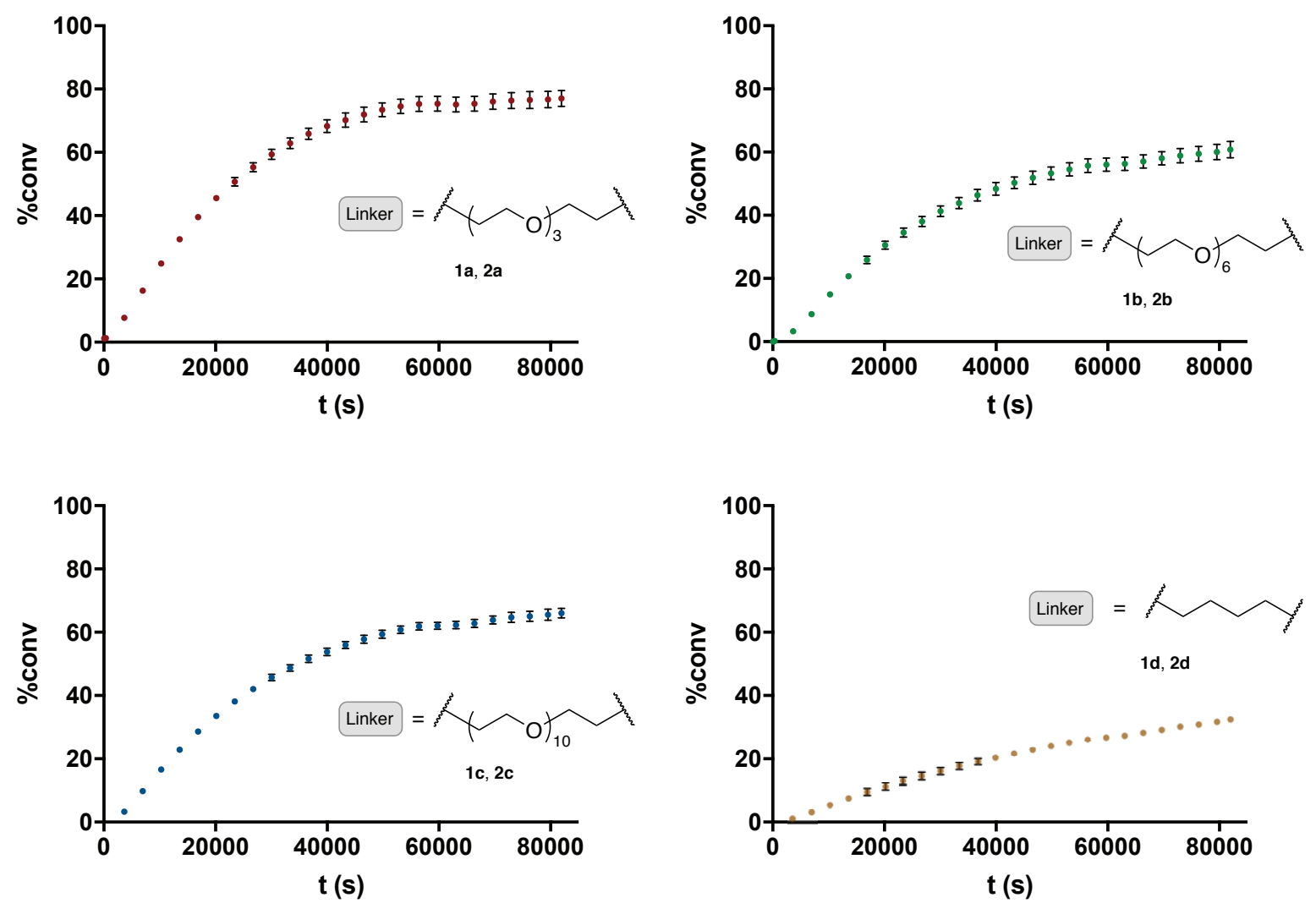

\section{Preparation of Complex 1a-S}
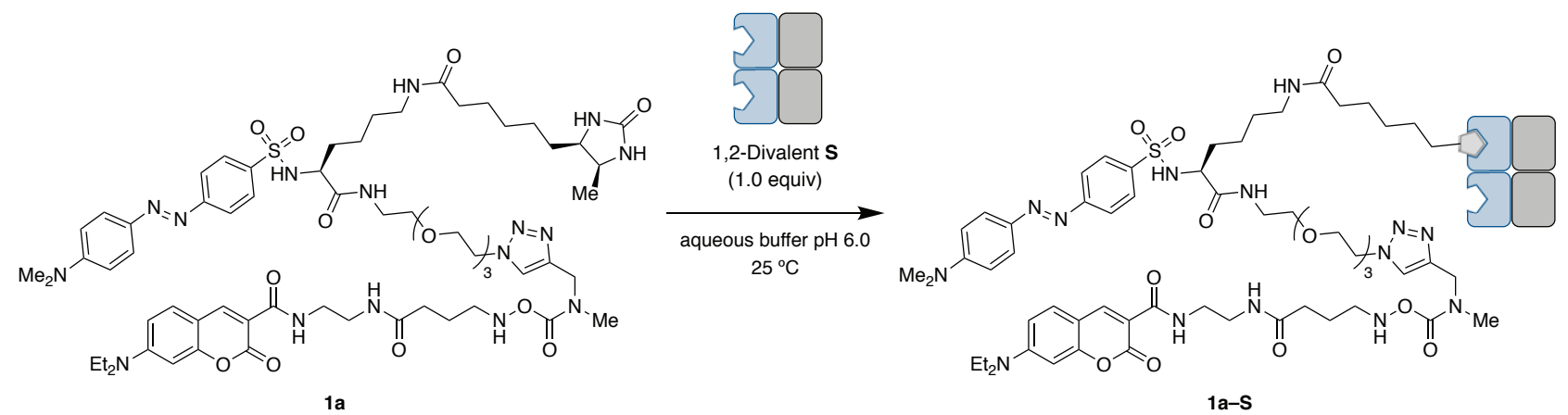

Hydroxylamine 1a (7.50 nmol, 1.00 equiv, $129 \mu \mathrm{L}$ from $58.0 \mu \mathrm{M}$ stock solution in aqueous buffer $\mathrm{pH} 6.0)$ was added into a solution of 1,2-divalent streptavidin $(7.50 \mathrm{nmol}, 1.00$ equiv, $300 \mu \mathrm{L}$ from $1.42 \mathrm{mg} / \mathrm{mL}$ stock solution in aqueous buffer $\mathrm{pH}$ 6.0). The solutions were mixed gently by pipetting. The mixture was purified by FPLC anion-exchange chromatography (eluting with Tris buffer $20 \mathrm{mM}, \mathrm{pH} 8.0$, linear gradient of 0-1 M $\mathrm{NaCl}$ over $100 \mathrm{CV}$ ). The corresponding peak (showing absorption at 280, 425 and $500 \mathrm{~nm}$, see Figure S3 below) was collected and concentrated by spin filtration (MWCO $10 \mathrm{kDA}$ ) replacing the elution buffer to aqueous buffer $\mathrm{pH} 6.0$. 


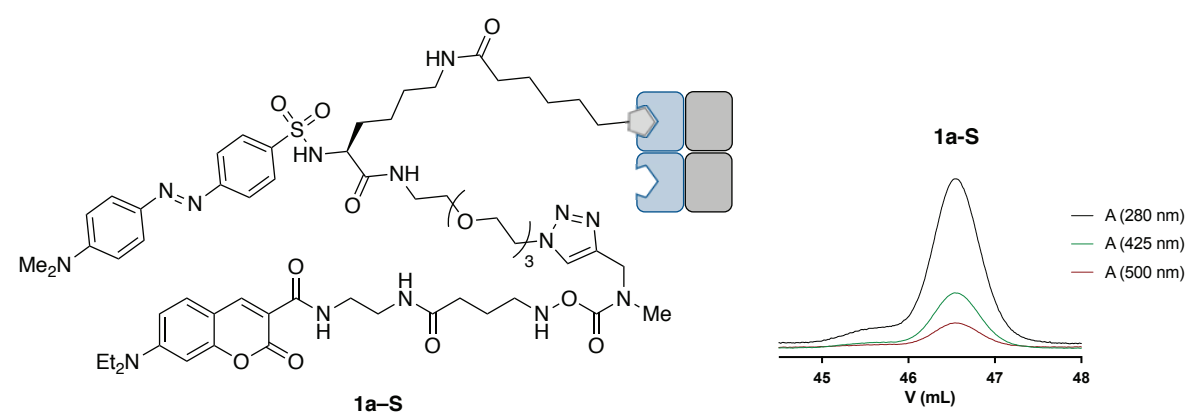

Figure S3. FPLC chromatogram of isolated 1 a-S complex (monitoring at 280 , 425 and $500 \mathrm{~nm})$.

\section{Conversion over time plot of the reaction of $1-S$ with $2 a$}
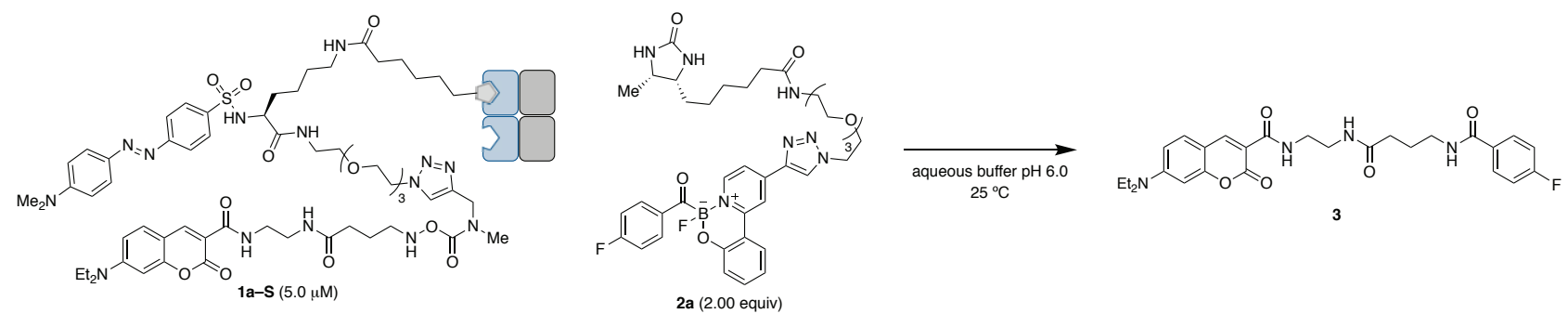

Carried out by following Representative Procedure D using 1a-S complex (5.0 $\mu \mathrm{M})$ and $2 \mathrm{a}$ (2.00 equiv) or KAT 4 (2.00 equiv) in the presence or absence of biotin (5.00 equiv). The corresponding conversion over time plots are shown as mean values of three experiments with the corresponding error bars.
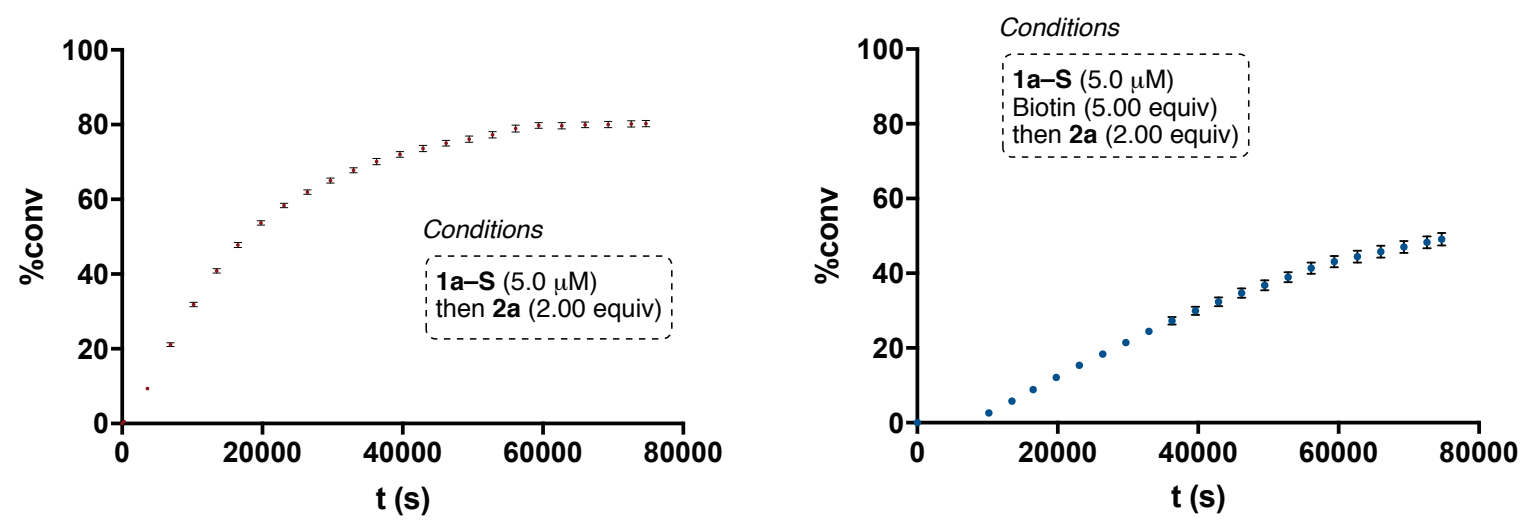


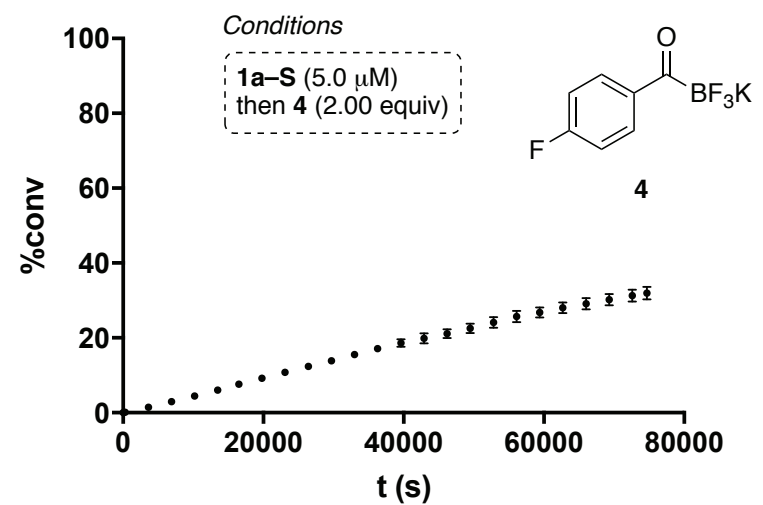

Figure 3a-4. Experiments and non-Linear Model Fit
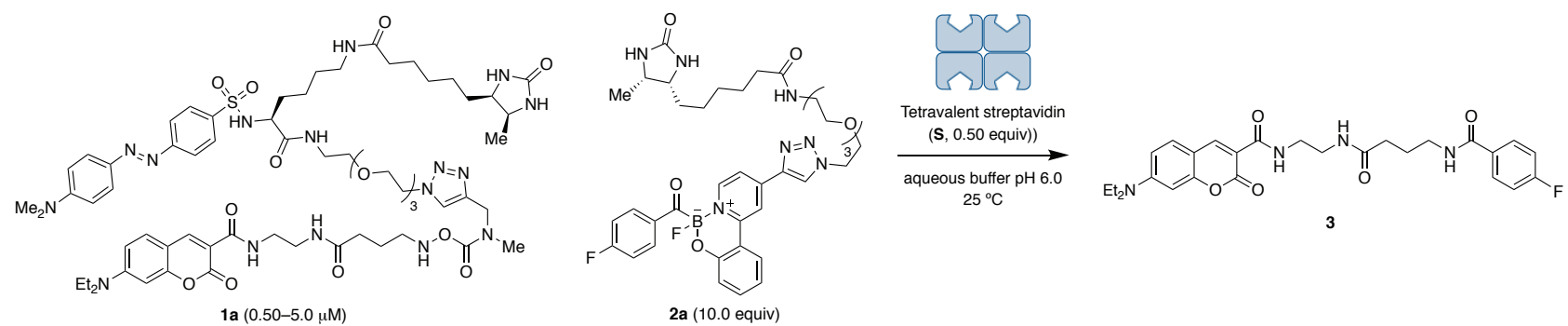

Following Representative Procedure D, the conversion over time graphs shown below were generated for a number of reaction conditions (displayed on each graph). Each plot is shown as mean values of three experiments with the corresponding error bars. Conversion points were fitted into a biexponential non-linear fit (Equation 1, below). Fitting curves are shown as thin black lines, and each specific fit equation displayed on the corresponding plot.

\section{Equation 1}

$$
\% \operatorname{conv}=\frac{100 \cdot[3]}{[1]_{0}}=F \cdot\left[1-e^{\left(-k^{\mathrm{T}} \cdot t\right)}\right]+(100-F) \cdot\left[1-e^{\left(-k^{\mathrm{B}} \cdot[2]_{0} \cdot t\right)}\right]
$$

$F=$ initial fraction of productive complex $=\frac{100 \cdot[\text { Productive complex }]_{0}}{[1]_{0}}$

$k^{\mathrm{T}}=$ first order rate constant of templated amide formation $\left(\mathrm{s}^{-1}\right)$

$k^{\mathrm{B}}=$ pseudo-first order background rate constant $\left(\mathrm{M}^{-1} \mathrm{~s}^{-1}\right)$

$[2]_{0} \gg[1]_{0}$

Assumed irreversible binding of $\mathbf{1}$ and $\mathbf{2}$ with $\mathbf{S}$ 

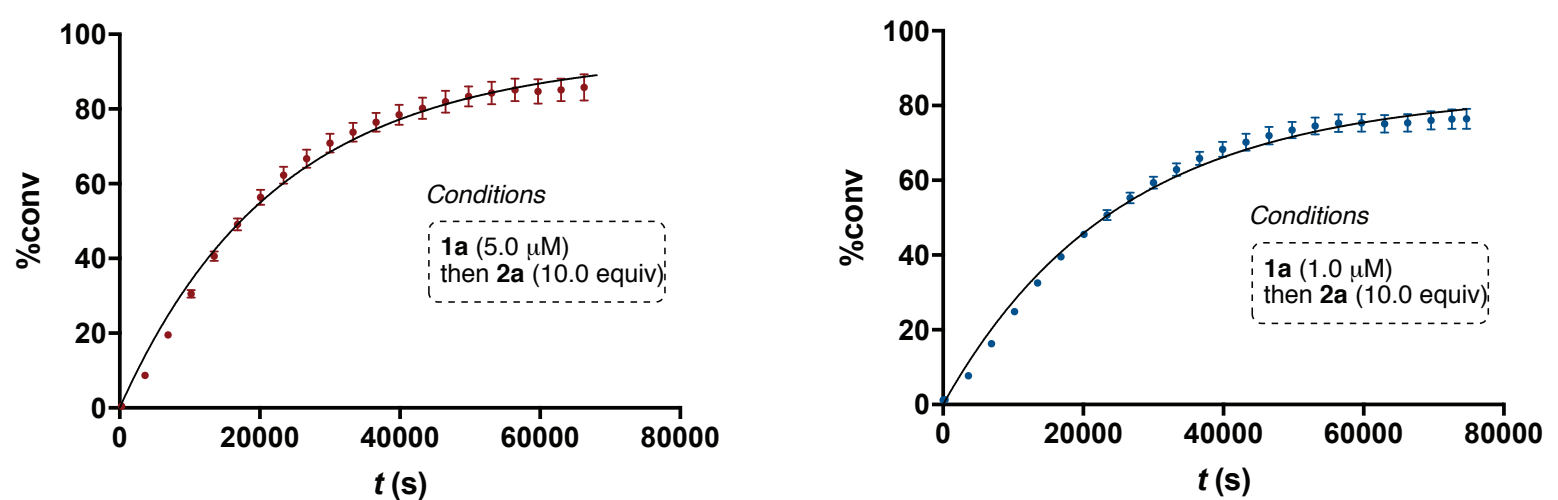

$$
\begin{gathered}
\% \text { conv }=85.0 \cdot\left[1-e^{\left(-4.75 \cdot 10^{-5} t\right)}\right]+15 \cdot\left[1-e^{\left(-0.2 \cdot 5.0 \cdot 10^{-5} t\right)}\right] \\
F=85 \% \quad k^{\mathrm{T}}=4.75 \cdot 10^{-5} \mathrm{~s}^{-1} \quad \begin{array}{l}
k^{\mathrm{B}}=0.2 \mathrm{M}^{-1} \mathrm{~s}^{-1} \\
\text { (constrained) }
\end{array}
\end{gathered}
$$

$\% \operatorname{conv}=79.4 \cdot\left[1-e^{\left(-4.16 \cdot 10^{-5} t\right)}\right]+20.6\left[\cdot 1-e^{\left(-0.2 \cdot 1.0 \cdot 10^{-5} t\right)}\right]$

$F=79 \% \quad k^{\mathrm{T}}=4.2 \cdot 10^{-5} \mathrm{~s}^{-1}$ $k^{\mathrm{B}}=0.2 \mathrm{M}^{-1} \mathrm{~s}^{-1}$ (constrained)

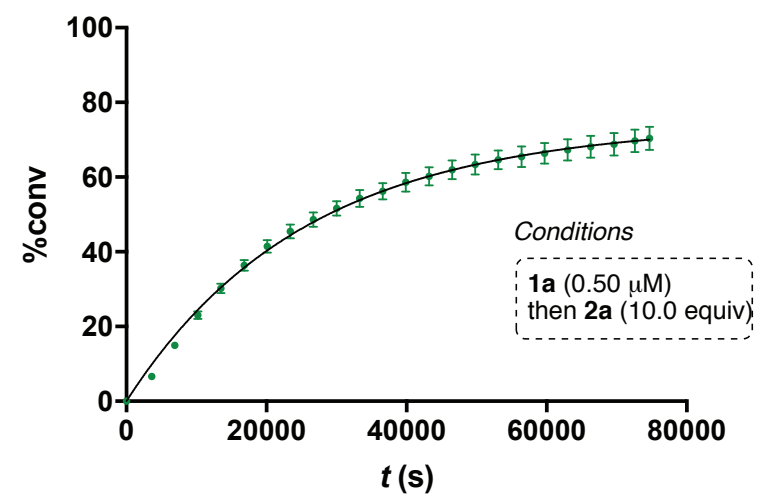

$$
\begin{array}{cll}
\% \operatorname{conv}=71.5 \cdot\left[1-e^{\left(-4.05 \cdot 10^{-5} t\right)}\right]+28.5[ & \left.1-e^{\left(-0.2 \cdot 5.0 \cdot 10^{-6} t\right)}\right] \\
F=71 \% \quad k^{\mathrm{T}}=4.05 \cdot 10^{-5} \mathrm{~s}^{-1} & \begin{array}{l}
k^{\mathrm{B}}=0.2 \mathrm{M}^{-1} \mathrm{~s}^{-1} \\
\text { (constrained) }
\end{array}
\end{array}
$$

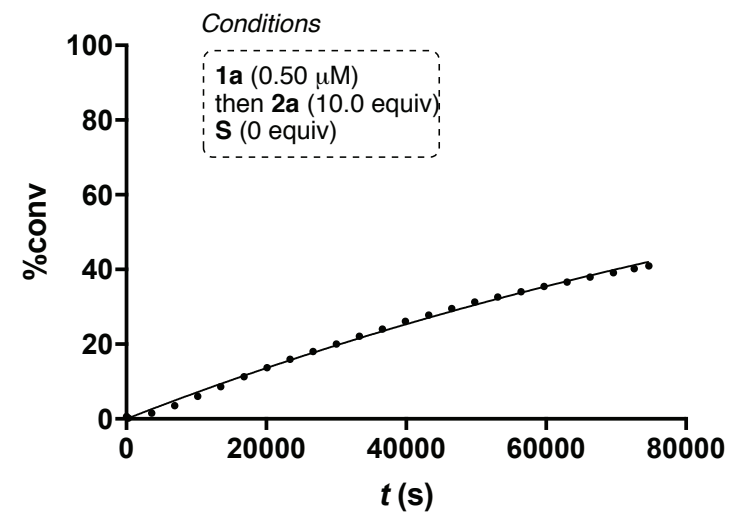

$$
\begin{aligned}
& \text { \%conv }=100 \cdot\left[1-e^{\left(-1.4 \cdot 5.0 \cdot 10^{-6} t\right)}\right] \\
& F=0 \% \quad k^{\mathrm{T}}=\mathrm{N} . \mathrm{D} \quad k^{\mathrm{B}}=1.4 \mathrm{M}^{-1} \mathrm{~s}^{-1}
\end{aligned}
$$

\section{Acylboronate 2a Loading Studies}
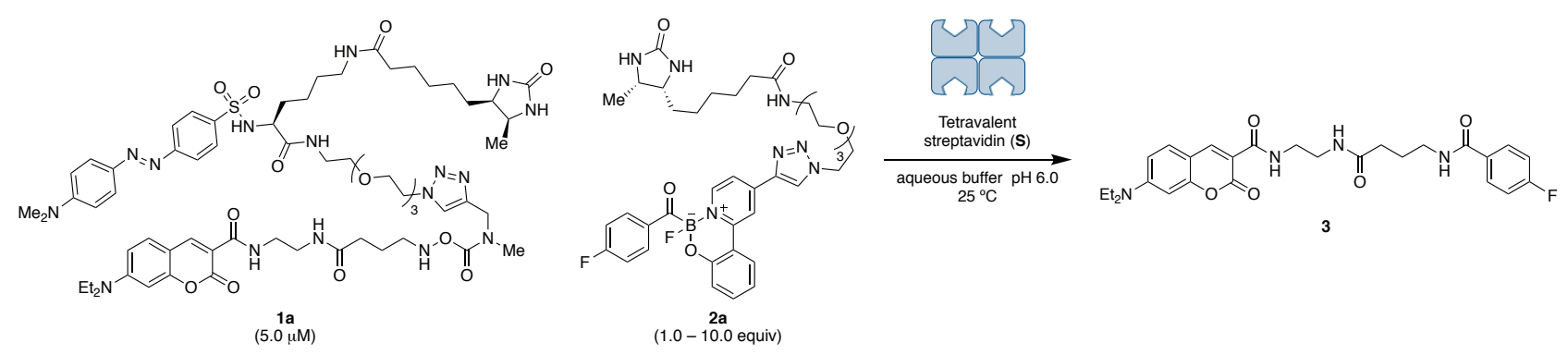

Following Representative Procedure D, conversion over time was measured for different equivalent loadings of acylboronate 2a. Each plot corresponds to single run experiments. 
Combined graph

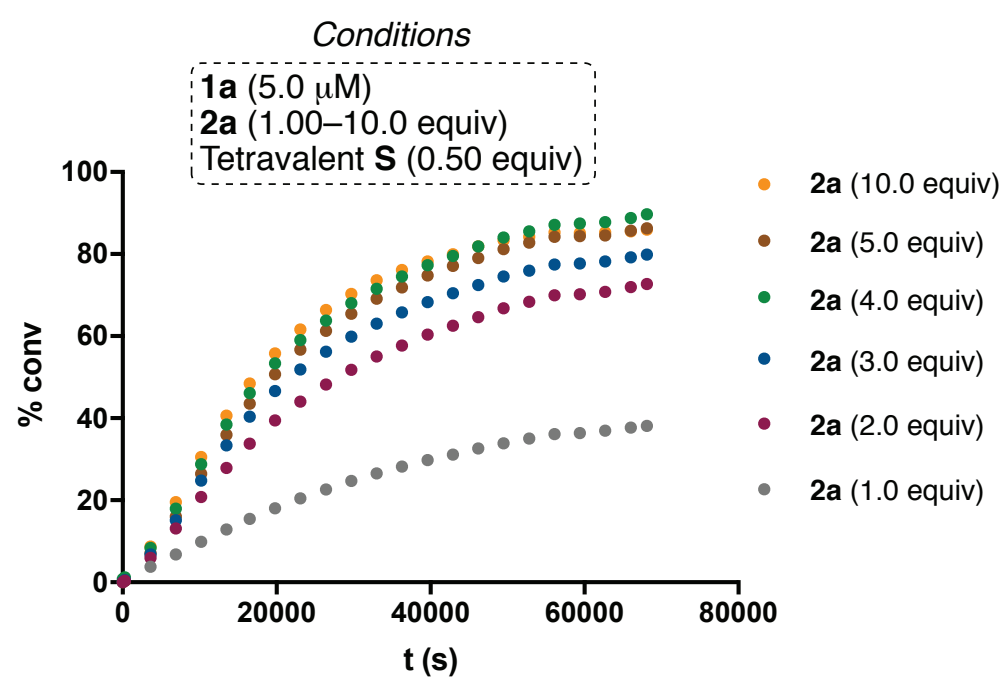

Individual graphs
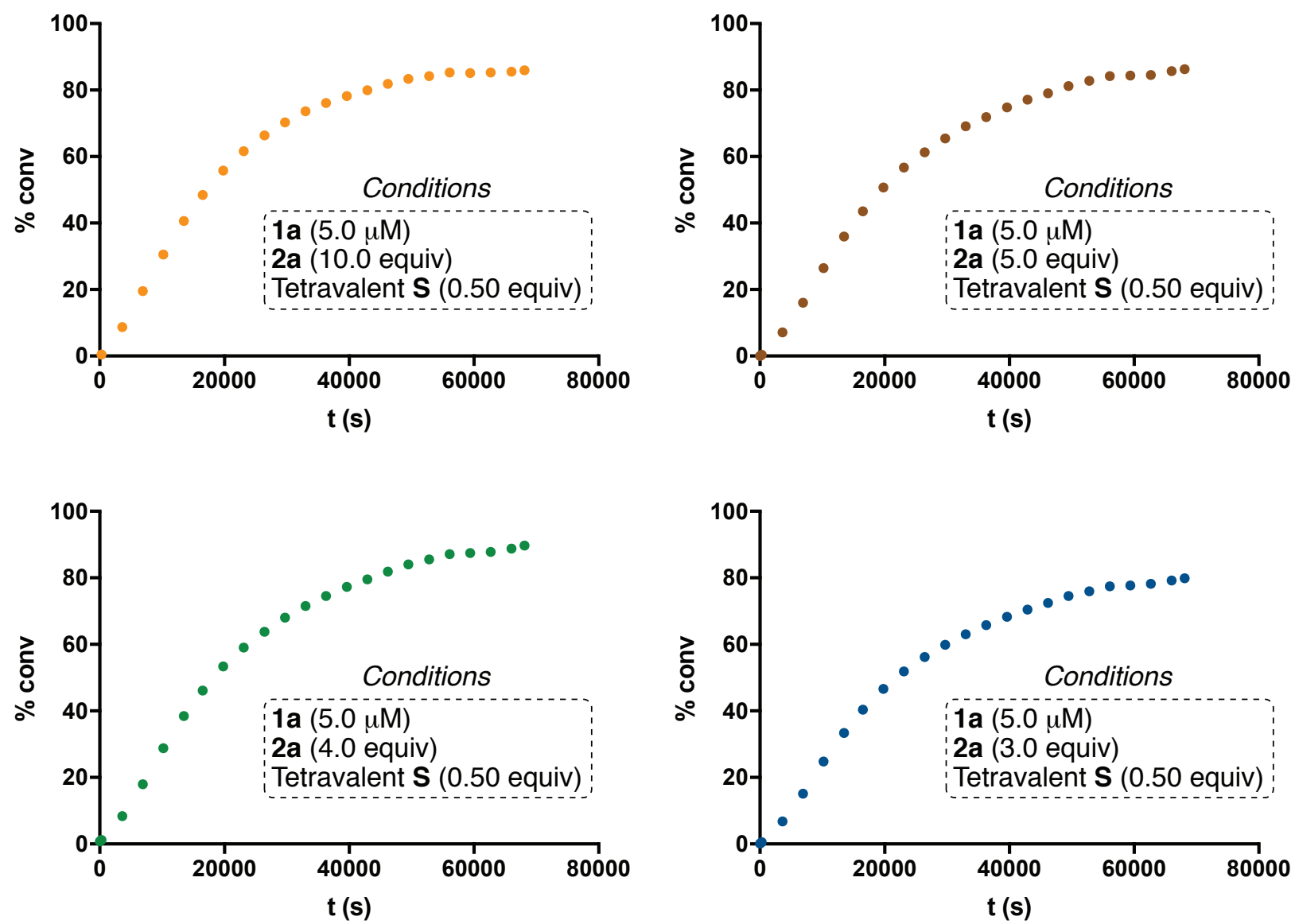

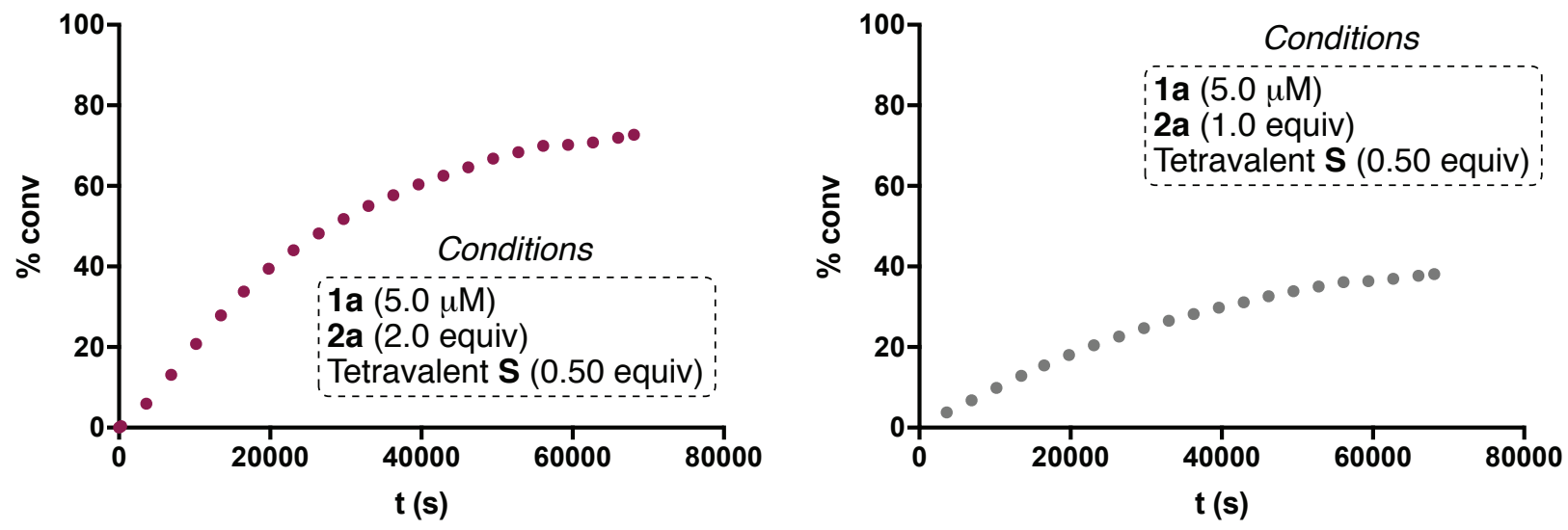


\section{Spectroscopic Data}

tert-Butyl-N-(7-diethylamino-2-oxo-2H-chromene-3-carboxamidoethyl)carbamate (S2).

${ }^{1} \mathrm{H}$ NMR $\left(500 \mathrm{MHz}, \mathrm{CDCl}_{3}\right)$

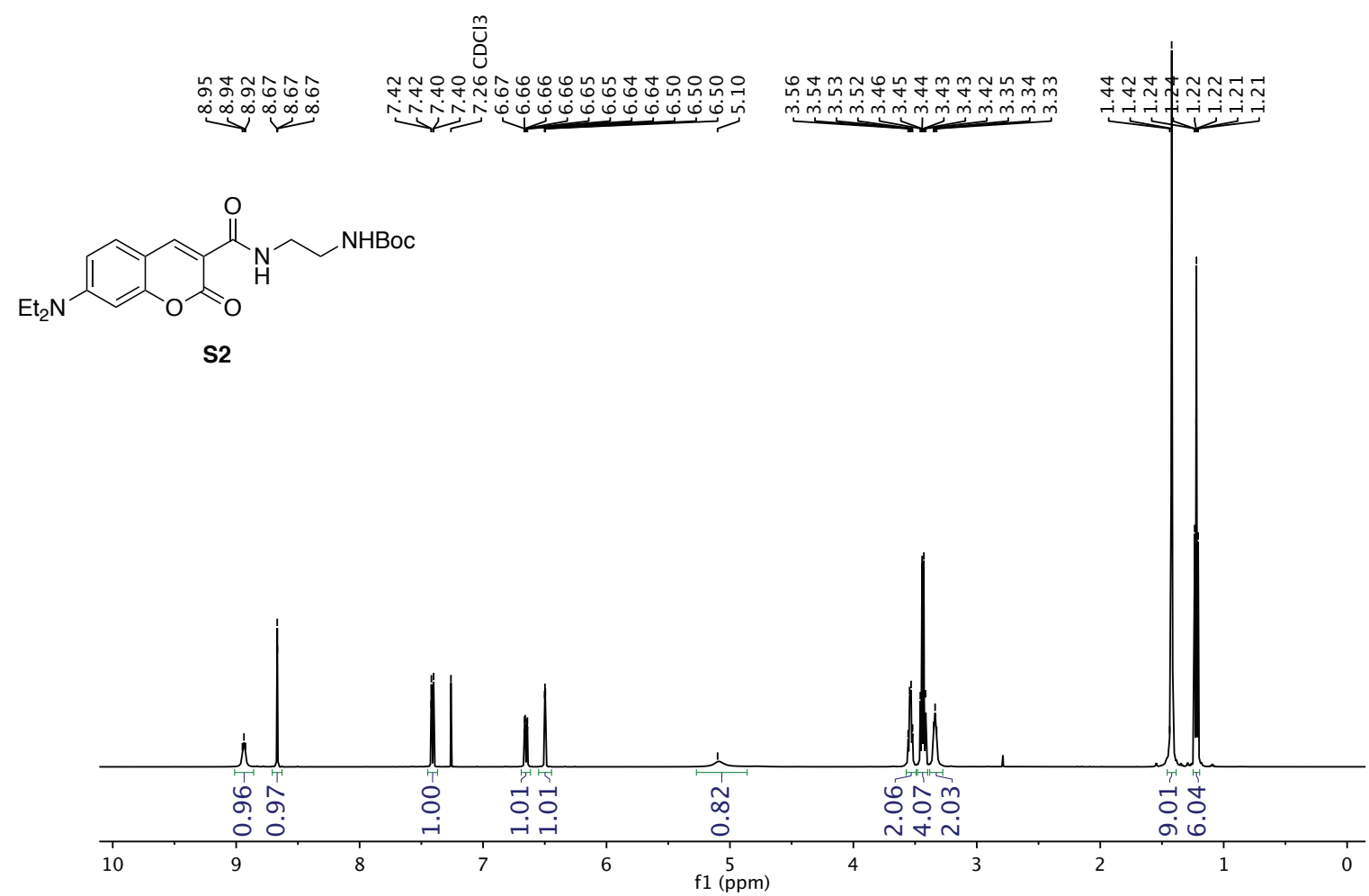

${ }^{13} \mathrm{C}$ NMR (126 MHz, $\mathrm{CDCl}_{3}$ )

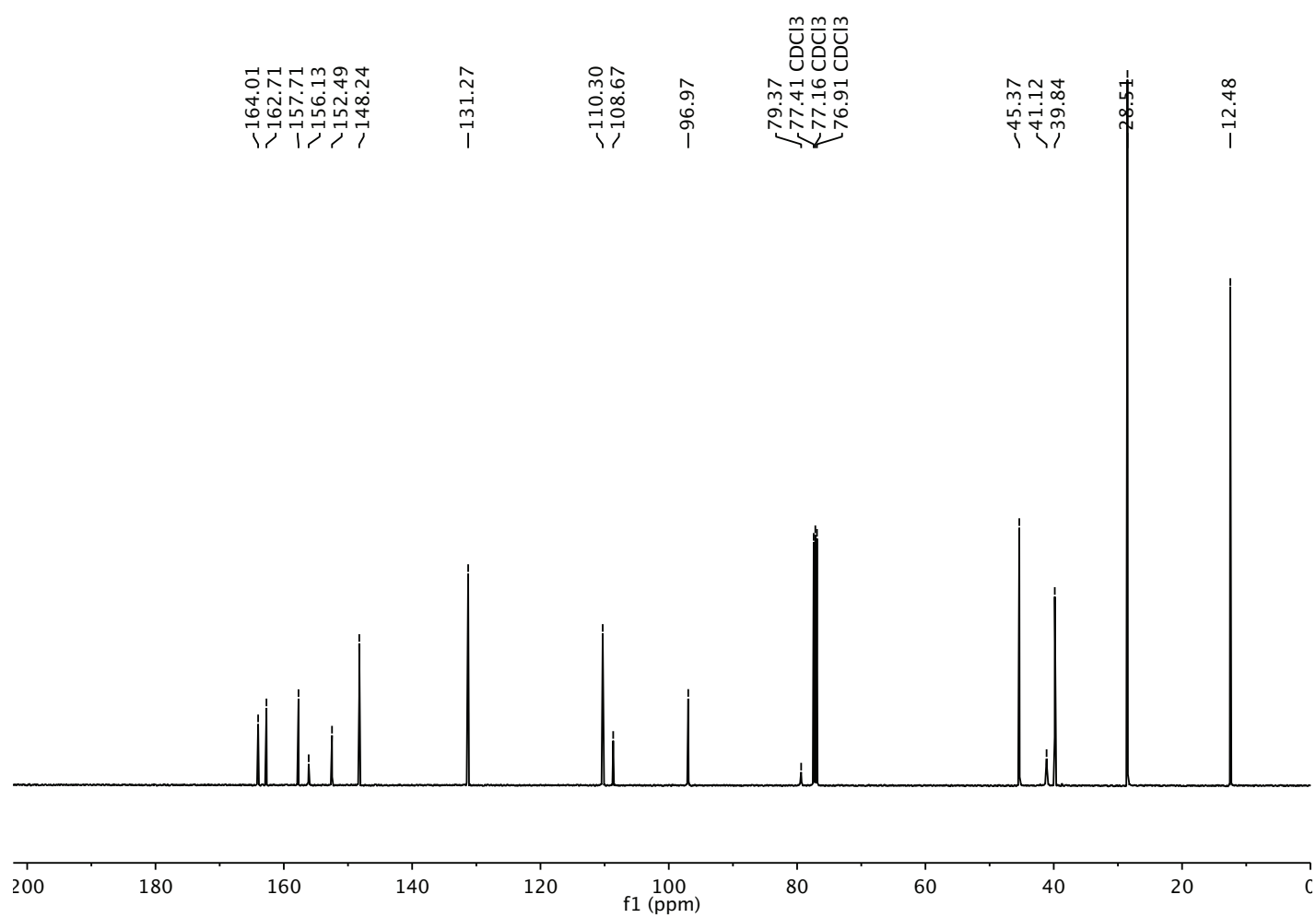


7-Diethylamino-2-oxo-2H-chromene-3-carboxamidoethylammonium trifluoroacetate (S3)

${ }^{1} \mathrm{H}$ NMR (500 MHz, $\mathrm{CD}_{3}$ OD)

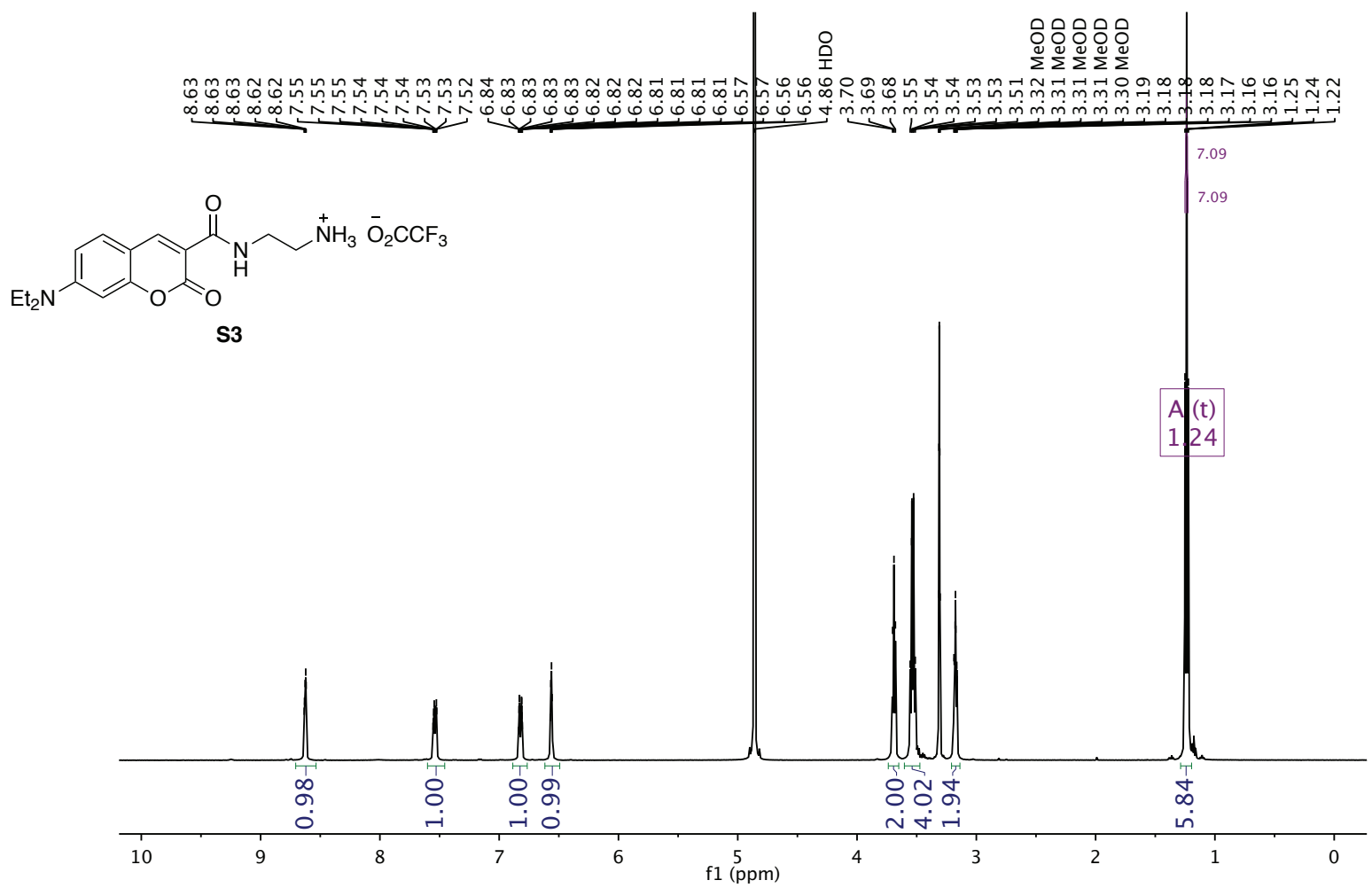

${ }^{13} \mathrm{C}$ NMR (126 MHz, $\mathrm{CD}_{3} \mathrm{OD}$ )

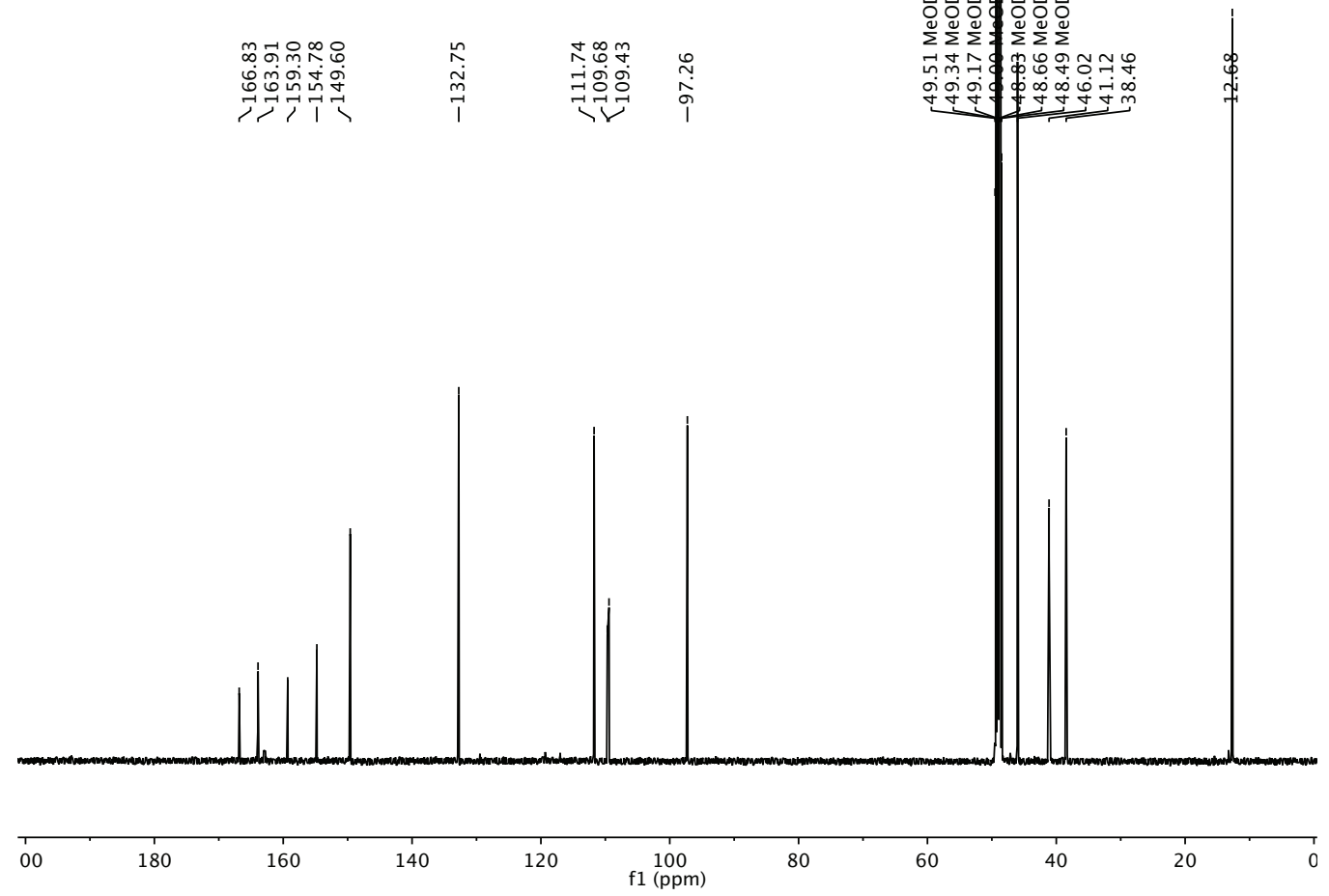


N-tert-Butoxycarbonyl-O-(N'-methyl-N'-propargylcarbamoyl)hydroxylamine (S4)

${ }^{1} \mathrm{H}$ NMR (500 MHz, $\left.\mathrm{CDCl}_{3}\right)$

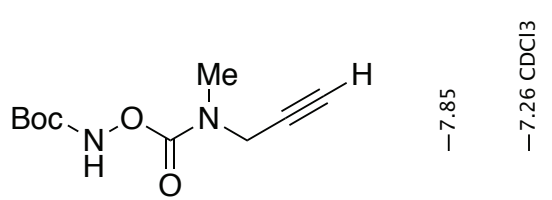

S4

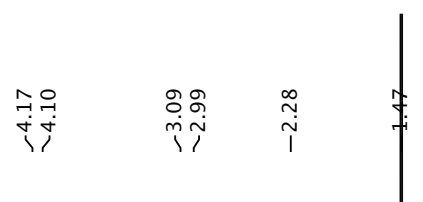

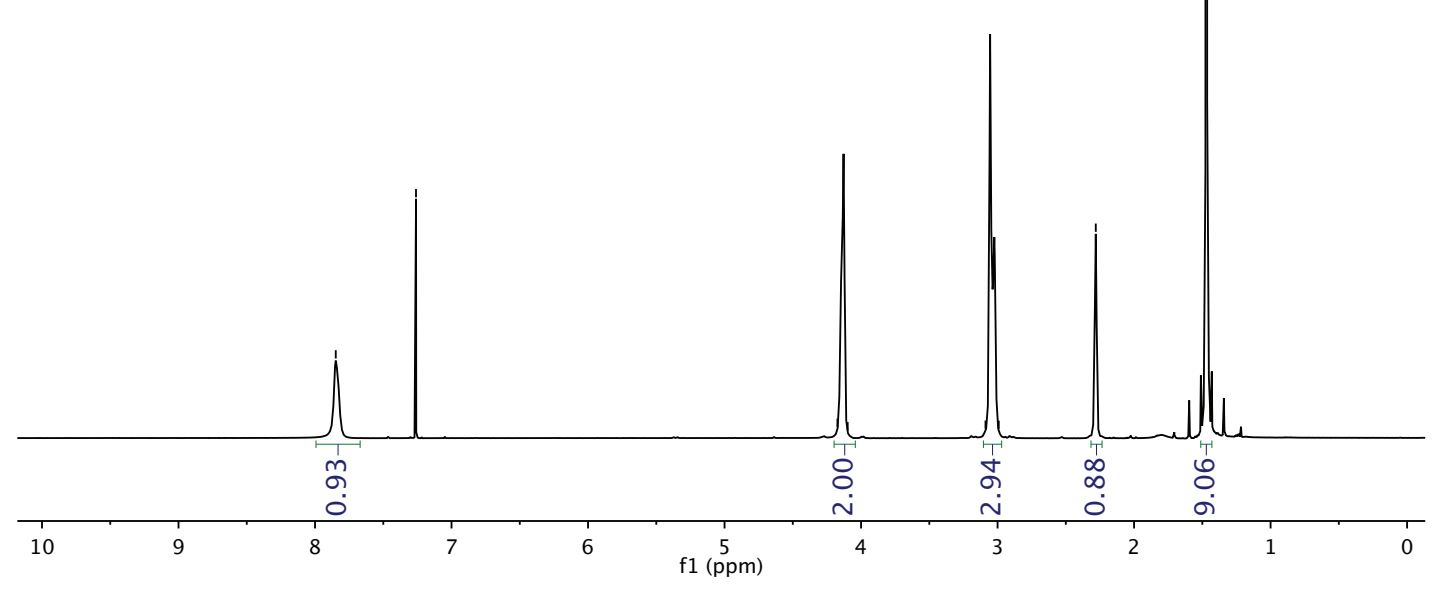

${ }^{13} \mathrm{C}$ NMR (126 MHz, $\left.\mathrm{CDCl}_{3}\right)$

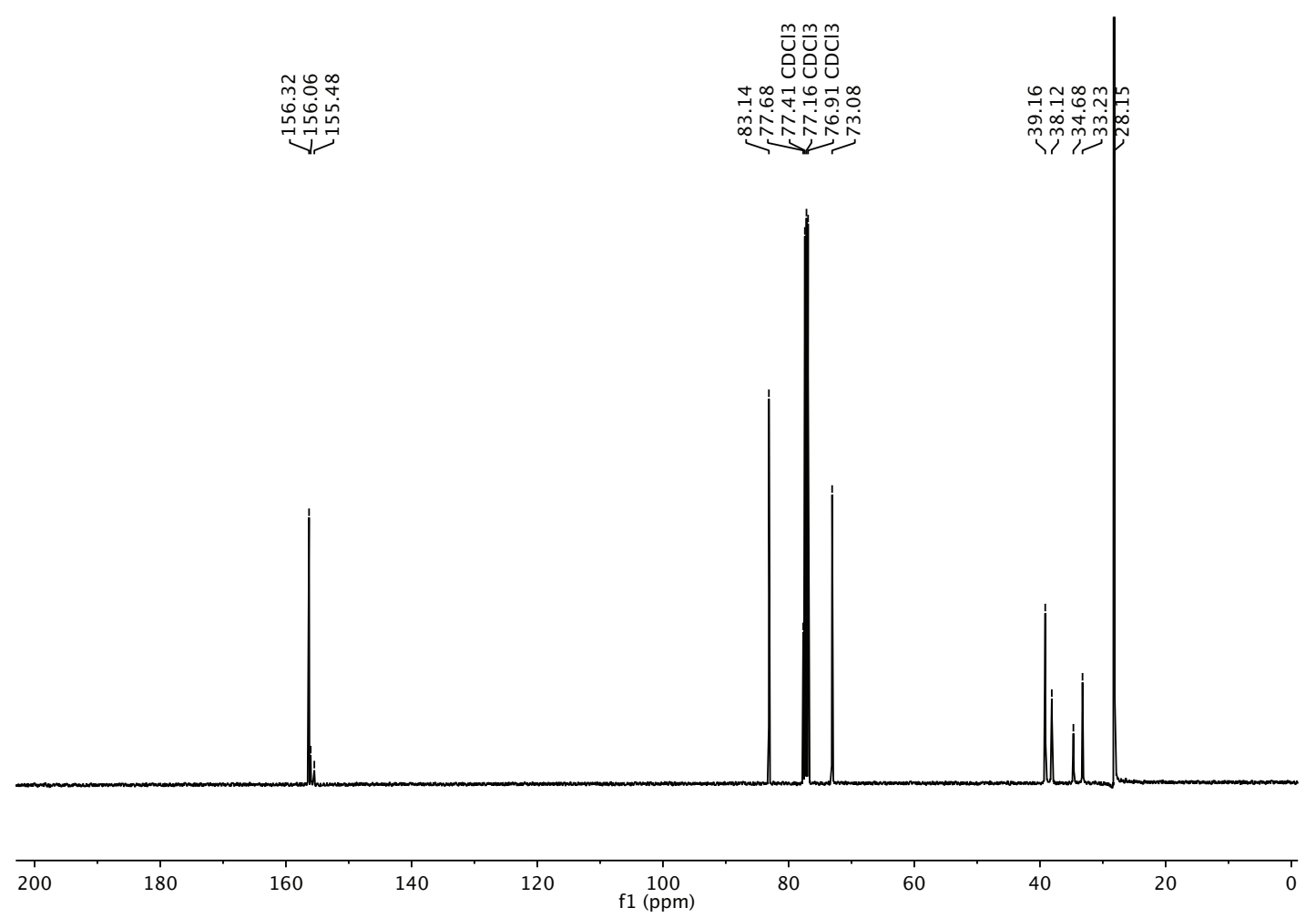


Ethyl 4-(N-tert-butoxycarbonyl-N-(N'-methyl-N'-propargylcarbamoyloxy)amino)butanoate (S5)

${ }^{1} \mathrm{H}$ NMR (500 MHz, $\mathrm{CDCl}_{3}$ )<smiles>C#CC=CN(C)C(=O)ON(CCCC(=O)OCC)C(=O)OCC</smiles>

S5
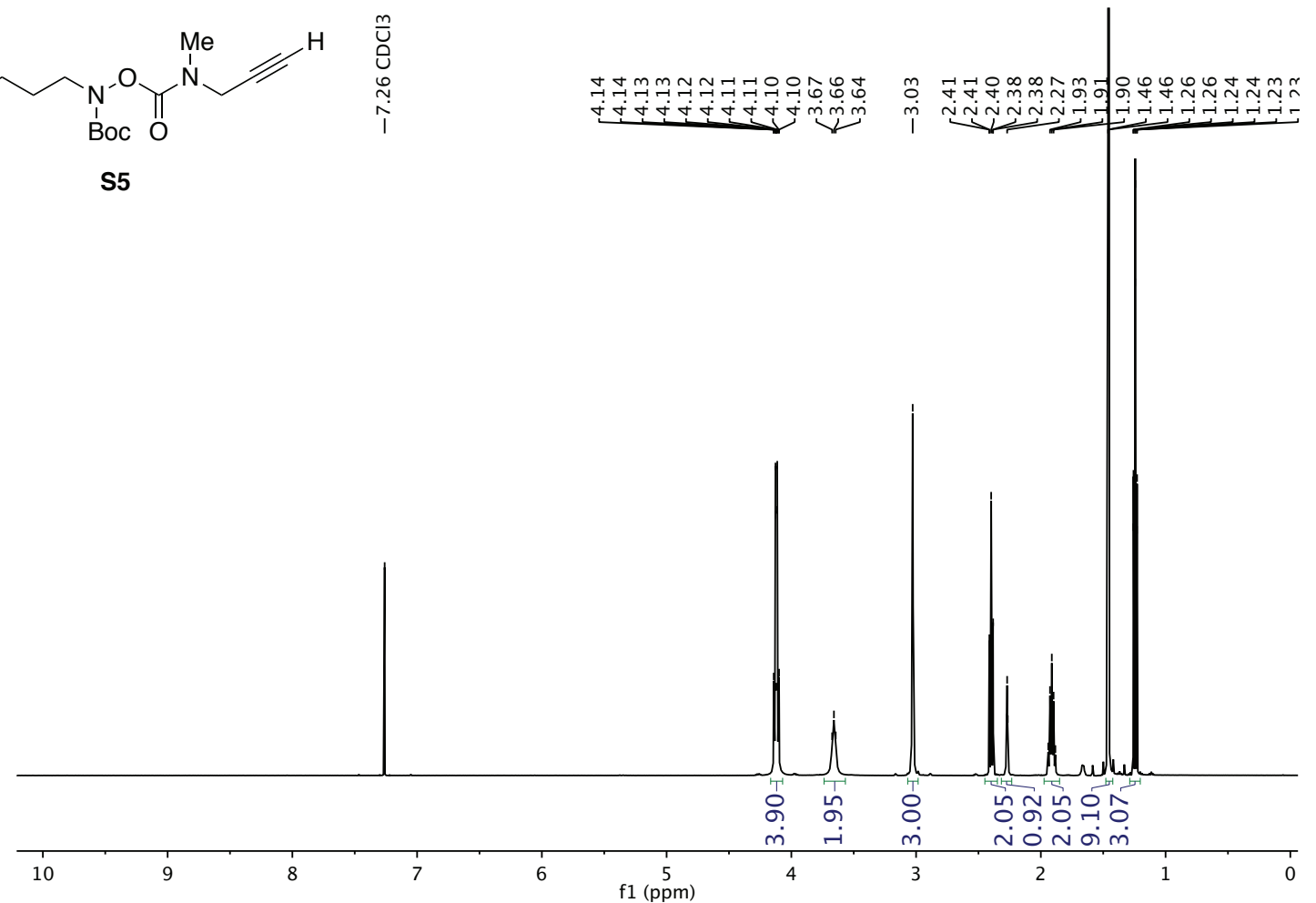

${ }^{13} \mathrm{C}$ NMR (126 MHz, $\left.\mathrm{CDCl}_{3}\right)$
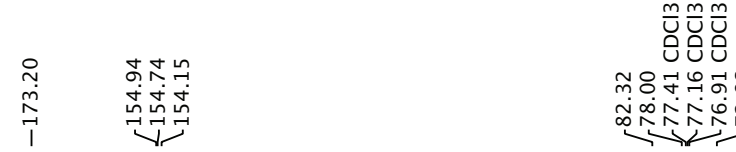

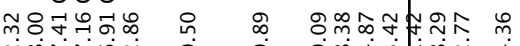

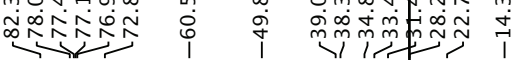

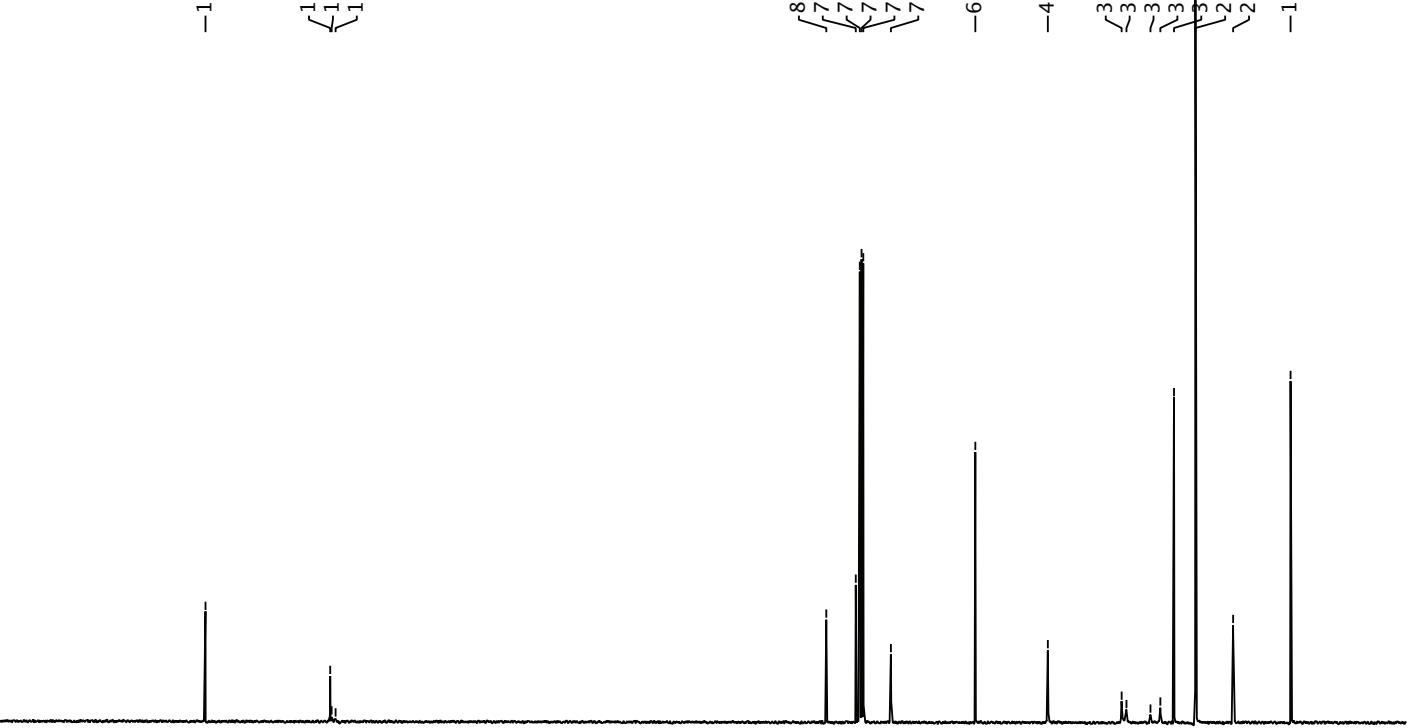

200

180

160

140

120

100
f1 $(\mathrm{ppm})$

80

60

40

20 0 
4-(N-tert-Butoxycarbonyl-N-(N'-methyl-N'-propargylcarbamoyloxy)amino)butanoic acid (S6)

${ }^{1} \mathrm{H}$ NMR (500 MHz, $\mathrm{CDCl}_{3}$ )<smiles>CC#CC#CCN(C)C(=O)ON(CCCC(=O)O)C(=O)O</smiles>

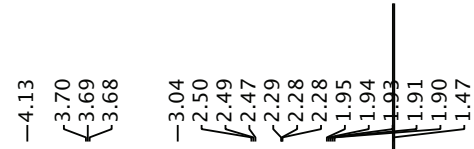

S6

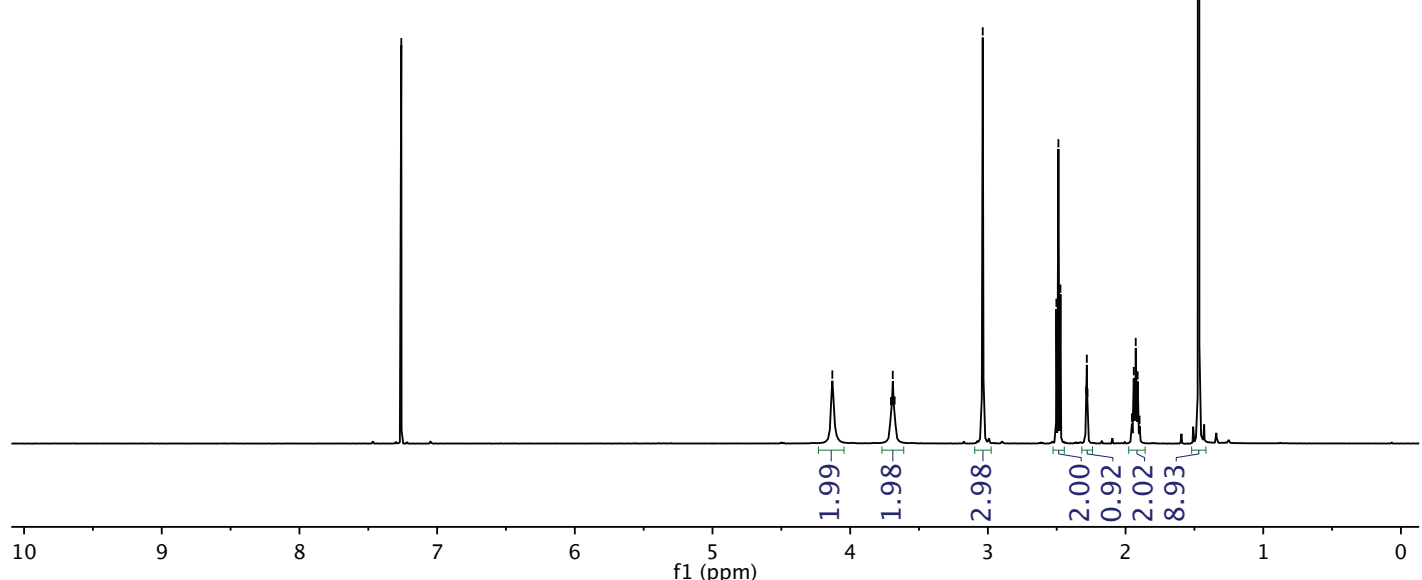

${ }^{13} \mathrm{C}$ NMR (126 MHz, $\mathrm{CDCl}_{3}$ )

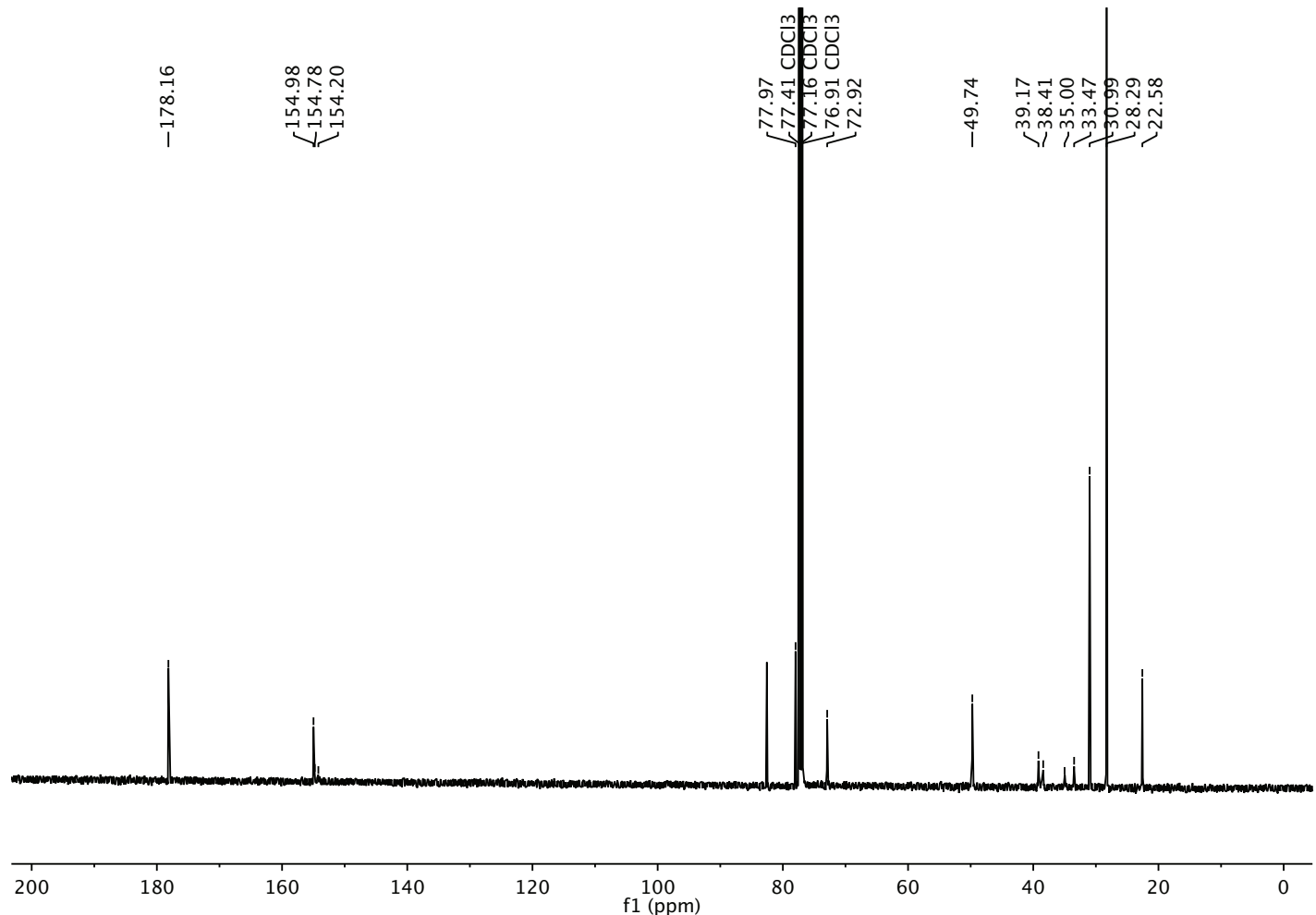


$\mathrm{N}$-(7-Diethylamino-2-oxo-2H-chromene-3-carboxamidoethylcarbamoyl)propyl)- $\mathrm{N}$-tert-butoxycarbonylO-(N'-methyl-N'-propargylcarbamoyl)hydroxylamine (S7)

${ }^{1} \mathrm{H}$ NMR $\left(500 \mathrm{MHz}, \mathrm{CDCl}_{3}\right)$

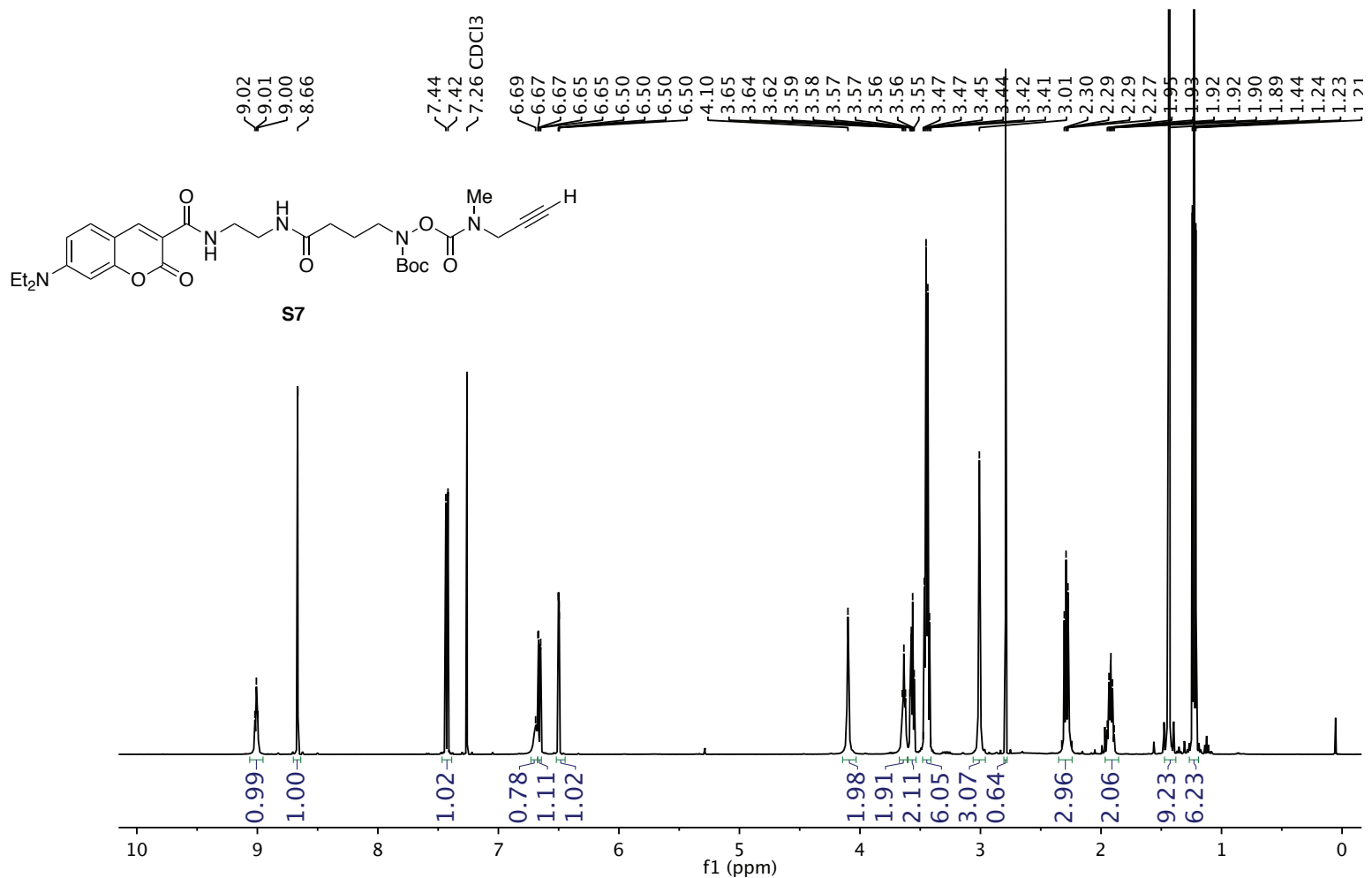

${ }^{13} \mathrm{C}$ NMR (126 MHz, $\mathrm{CDCl}_{3}$ )

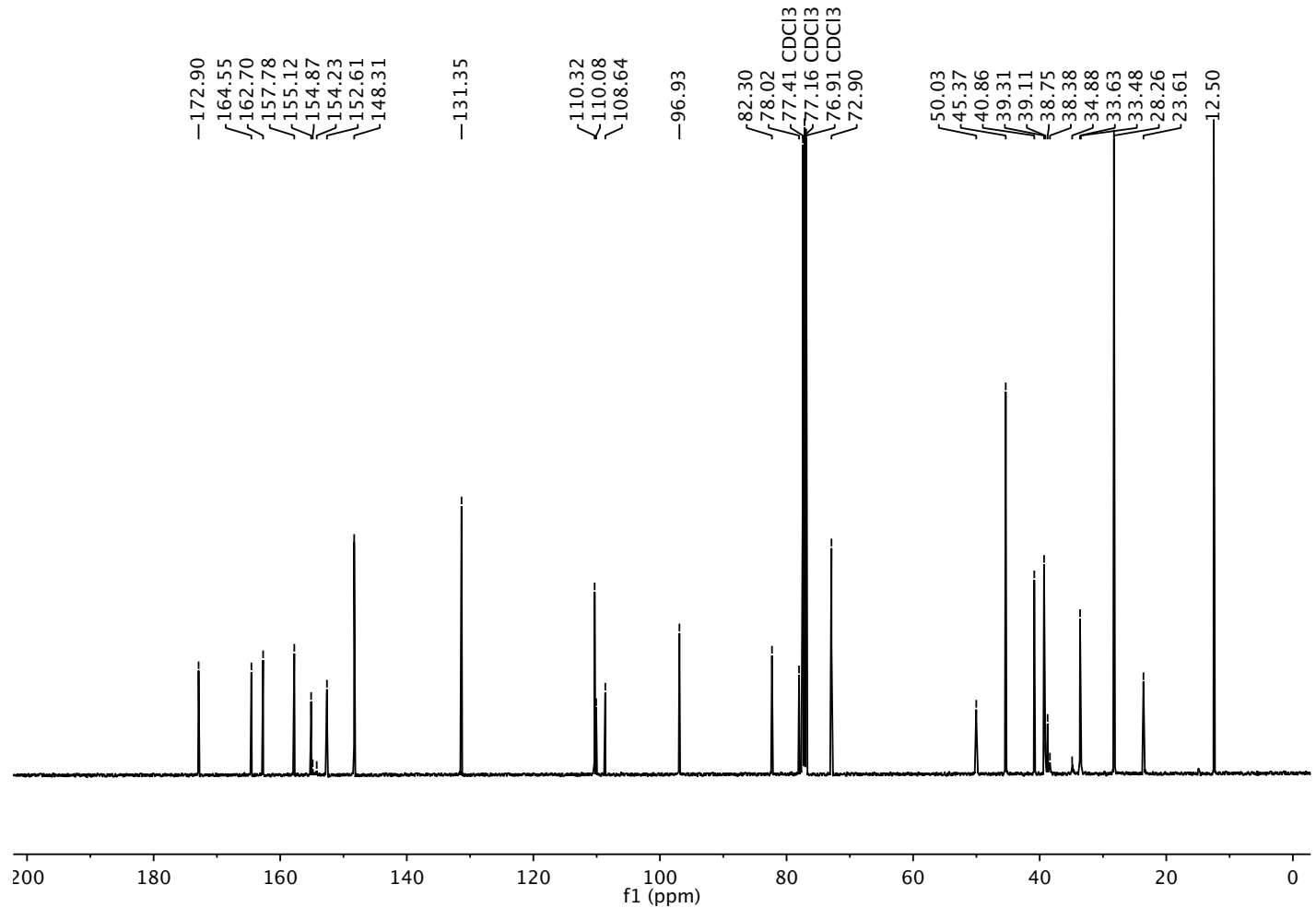


$\boldsymbol{N}^{\alpha}$-(4-Dimethylaminophenylazo)benzenesulfonyl)- $\boldsymbol{N}^{\varepsilon}$-tert-butoxycarbonyl-L-lysine methyl ester (S8).

${ }^{1} \mathrm{H}$ NMR (500 MHz, $\mathrm{CDCl}_{3}$ )

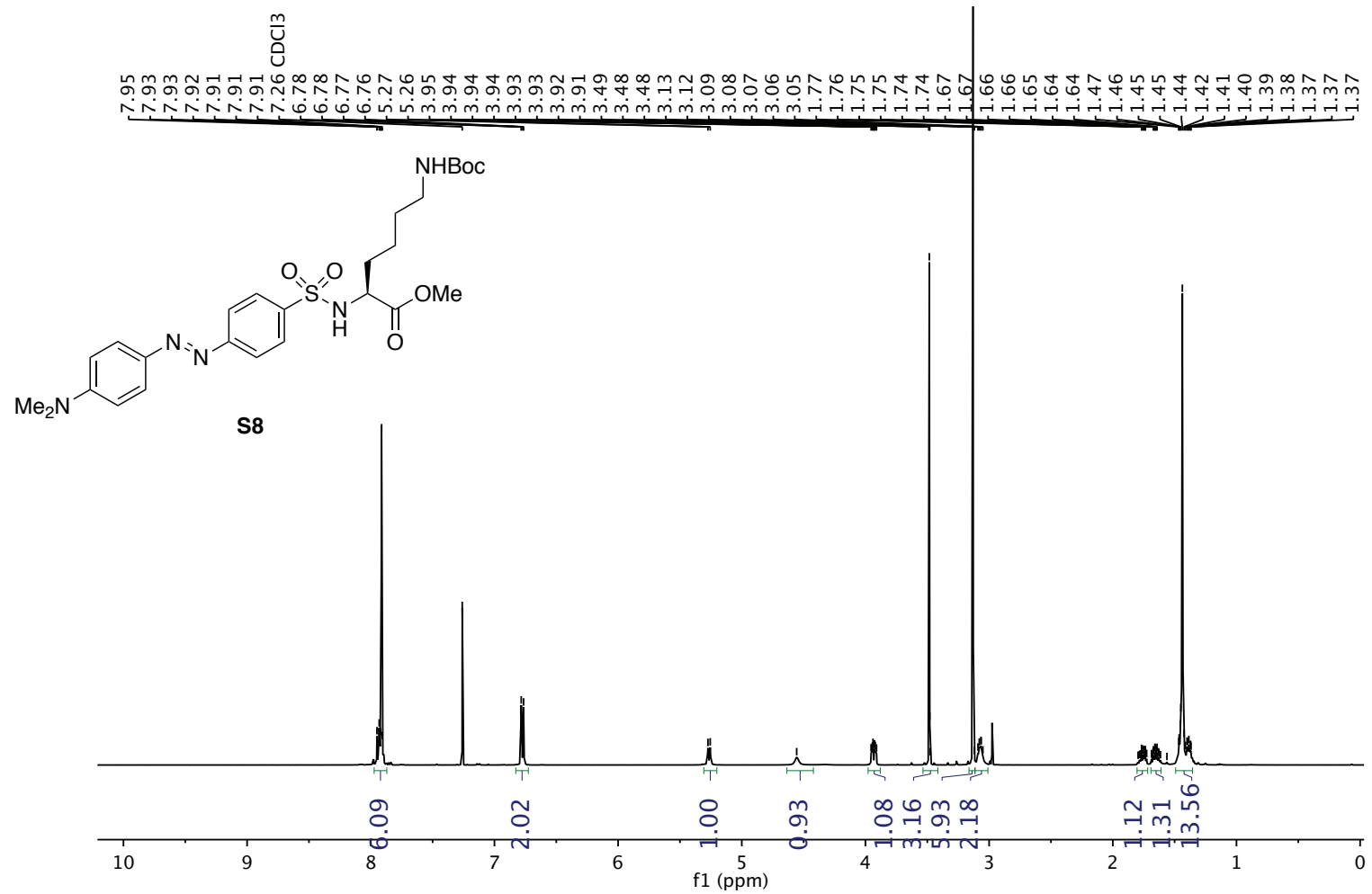

${ }^{13} \mathrm{C}$ NMR (126 MHz, $\left.\mathrm{CDCl}_{3}\right)$
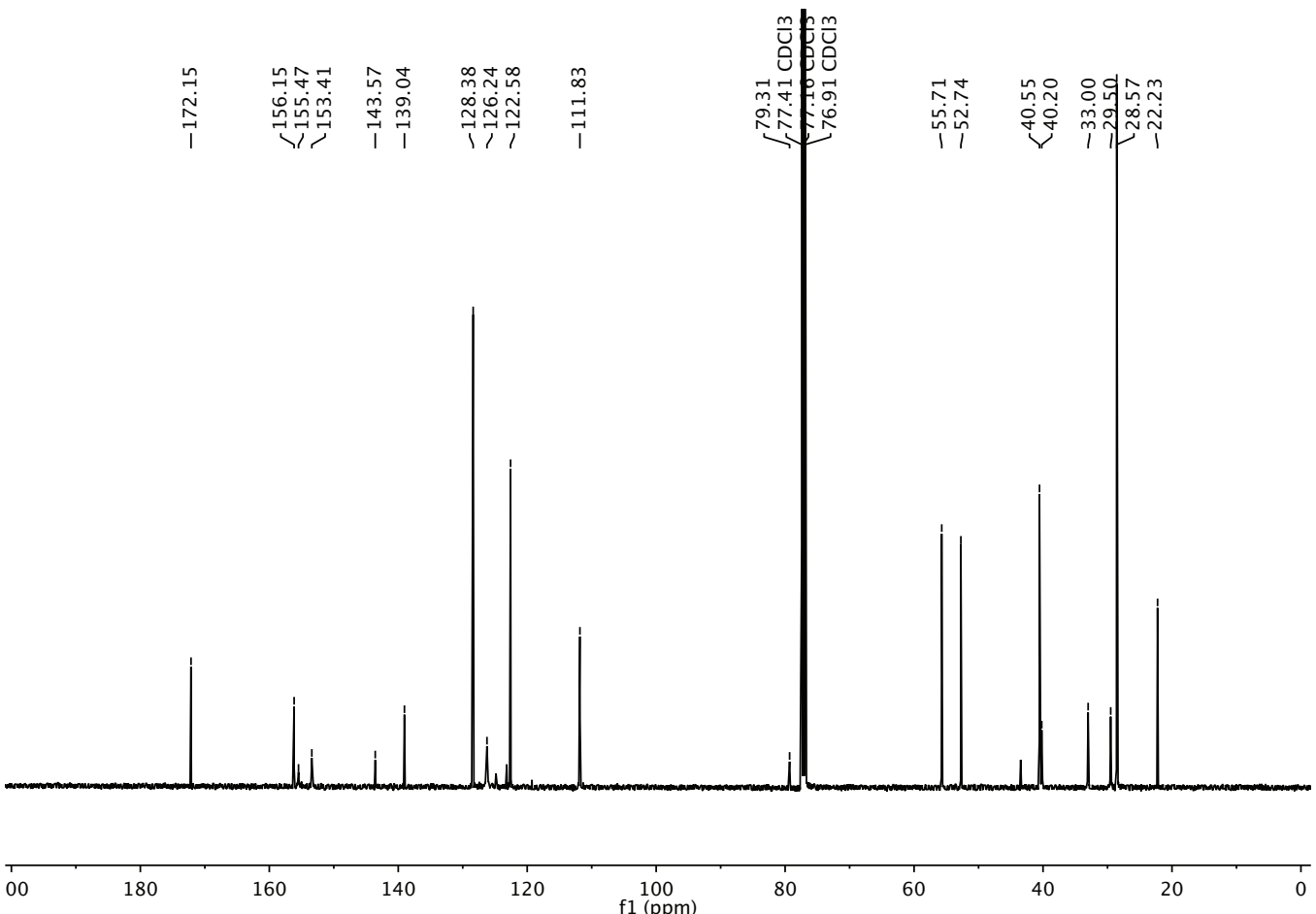
$N^{\alpha}$-(4-Dimethylaminophenylazo)benzenesulfonyl)- $\boldsymbol{N}^{\varepsilon}$-tert-butoxycarbonyl-L-lysine (S9).

${ }^{1} \mathrm{H}$ NMR (500 MHz, $\mathrm{CD}_{3} \mathrm{OD}$ )

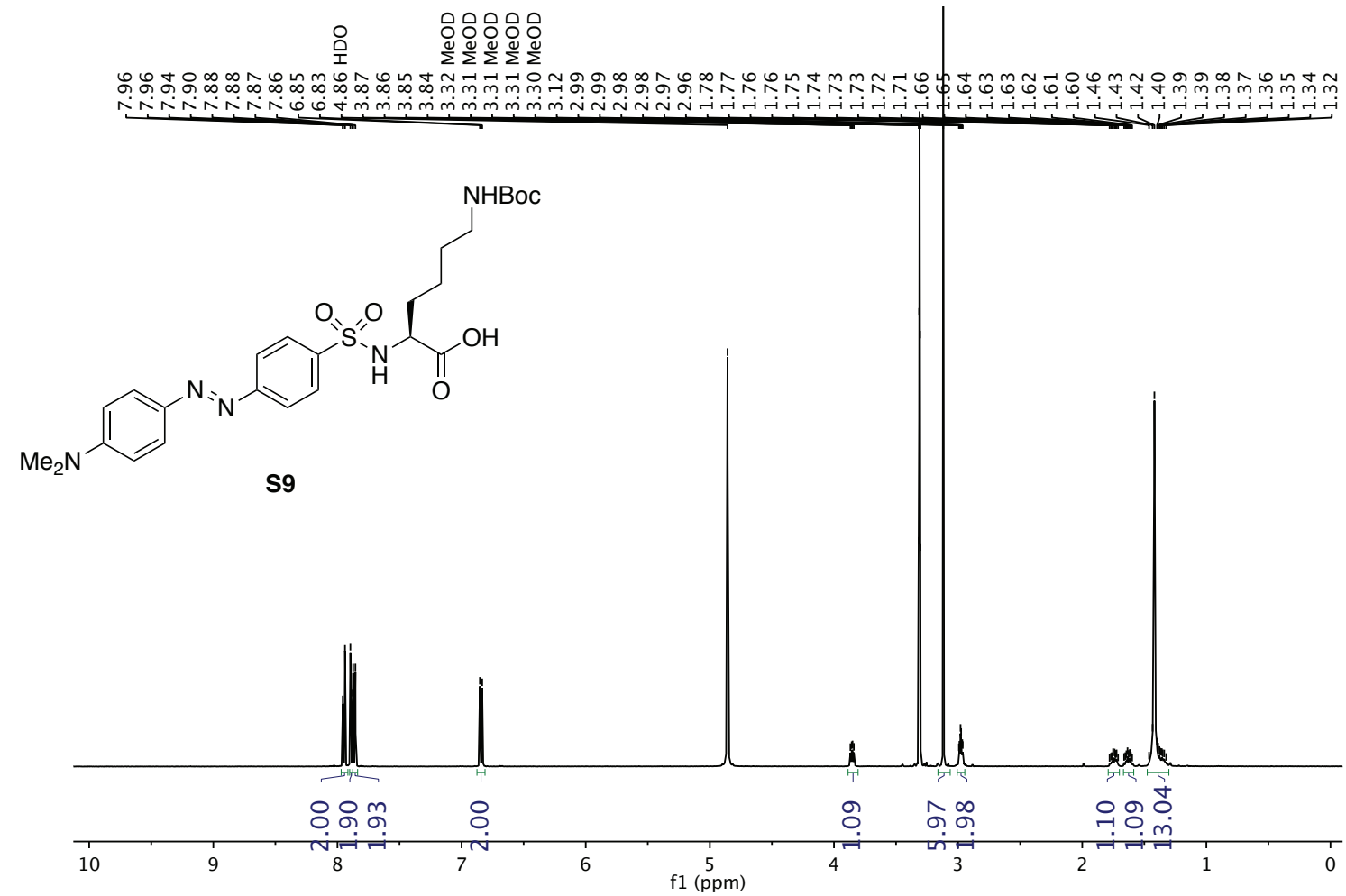

${ }^{13} \mathrm{C}$ NMR (126 MHz, $\left.\mathrm{CD}_{3} \mathrm{OD}\right)$

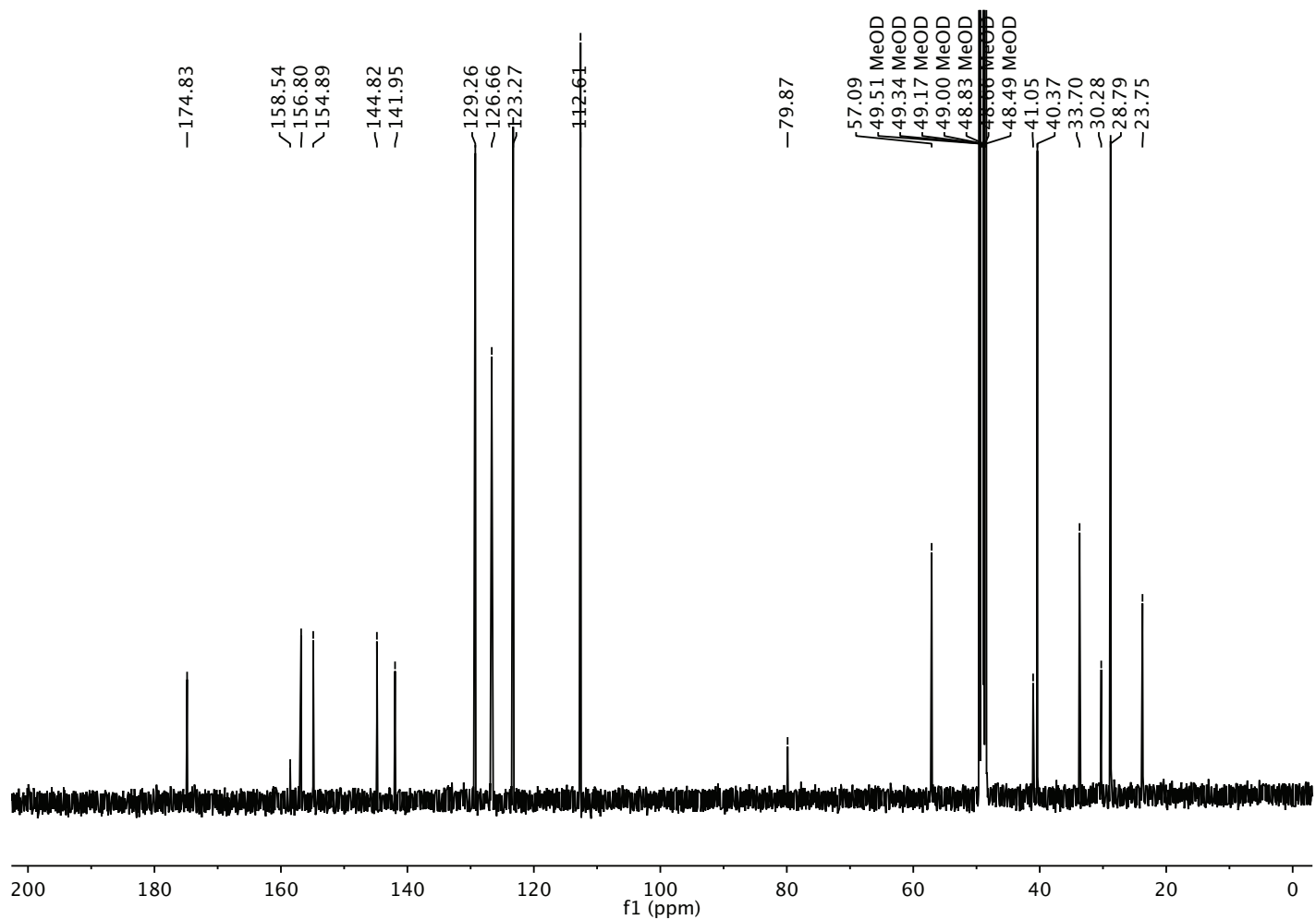


(S)-N-(11-Azido-3,6,9-trioxaundecyl)-2-(4-dimethylaminophenylazo)benzenesulfonamido)-6-(tertbutoxycarbonylamino) hexanamide (S10)

${ }^{1} \mathrm{H}$ NMR (500 MHz, $\mathrm{CDCl}_{3}$ )

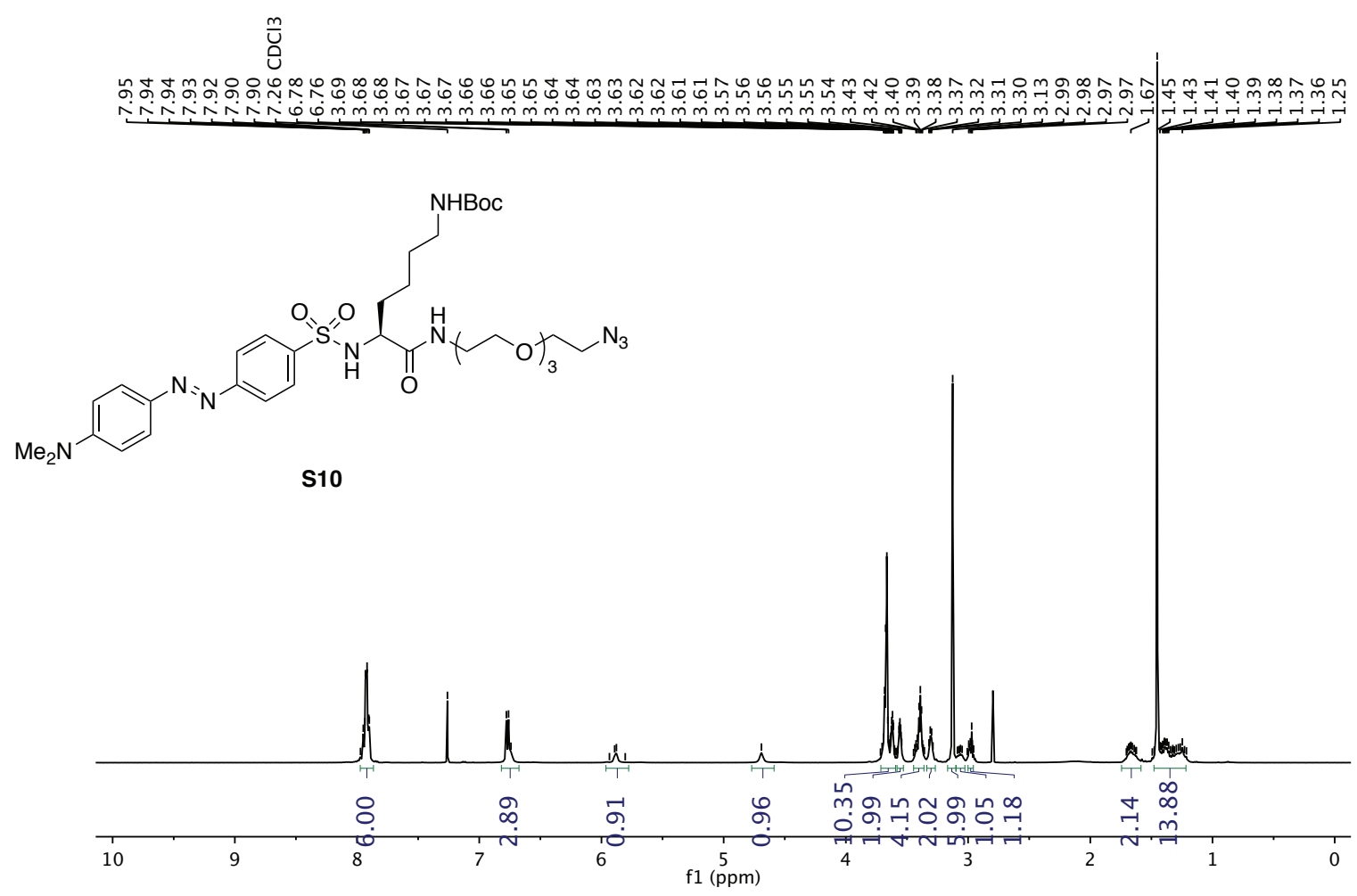

${ }^{13} \mathrm{C}$ NMR (126 MHz, $\mathrm{CDCl}_{3}$ )

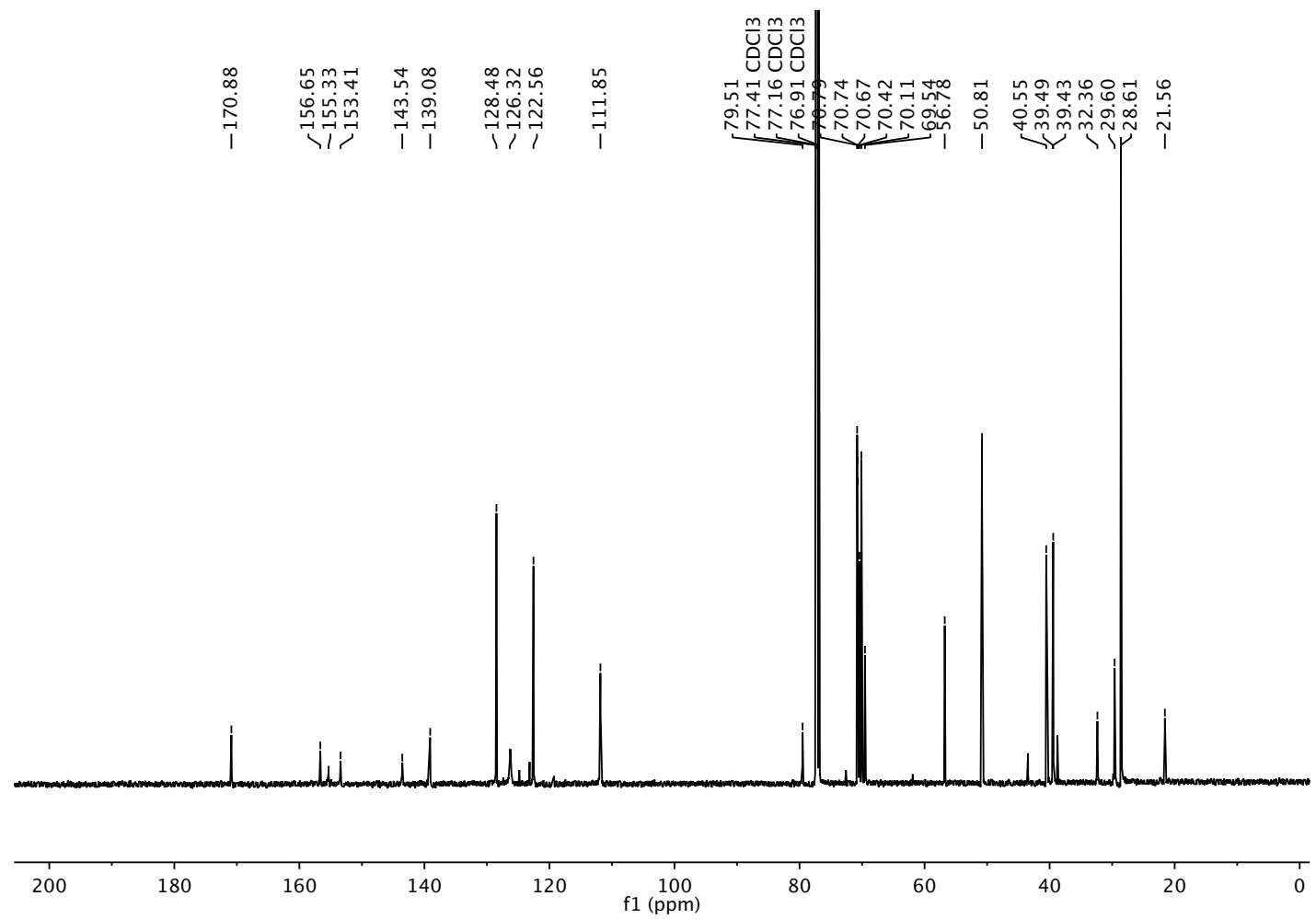


(S)-N-(20-Azido-3,6,9,12,15,18-hexaoxaeicosyl)-2-(4-dimethylaminophenylazo) benzenesulfonamido)-

\section{6-(tert-butoxycarbonylamino)hexanamide (S11)}

${ }^{1} \mathrm{H}$ NMR (500 MHz, $\mathrm{CDCl}_{3}$ )

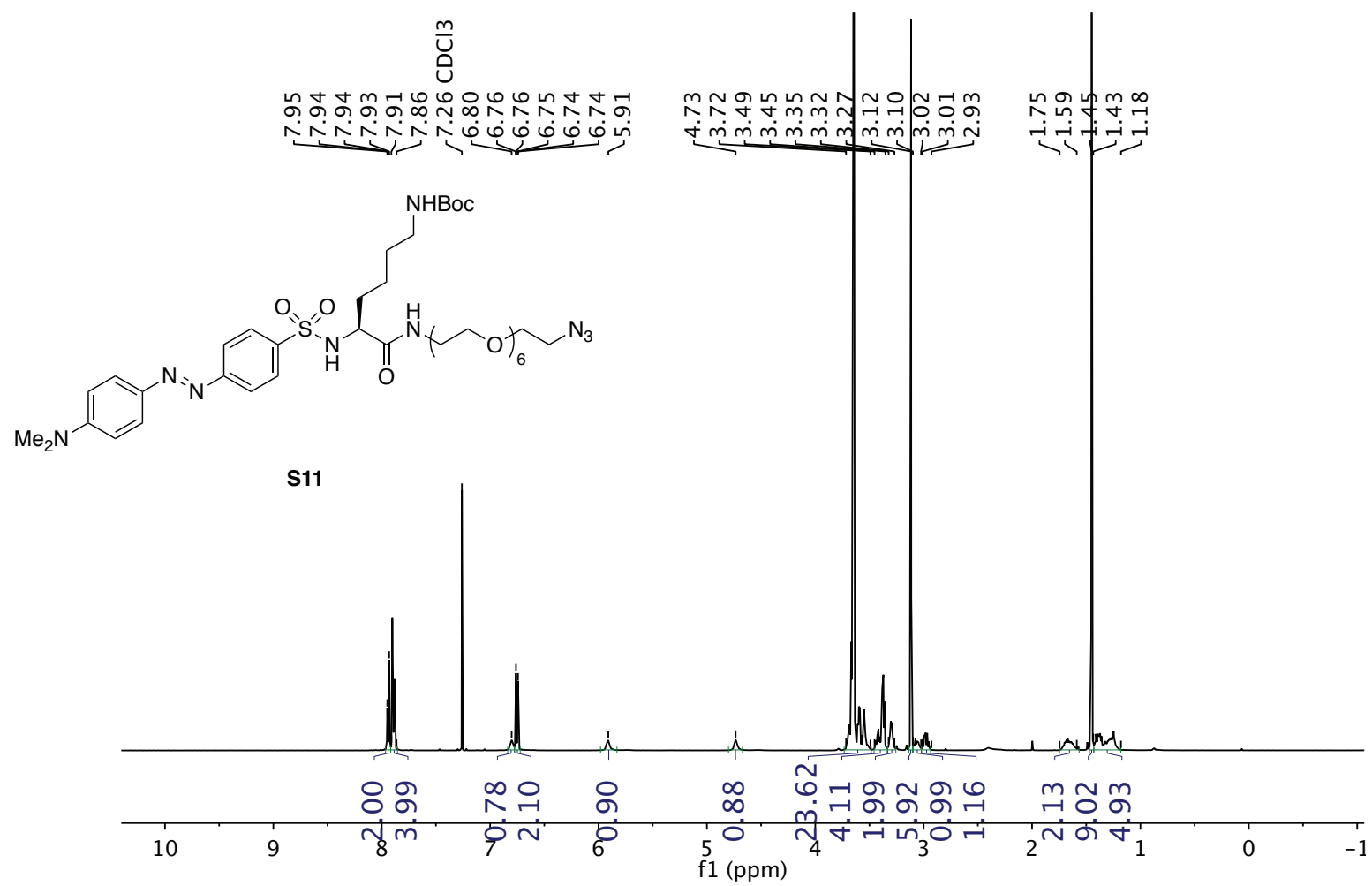

${ }^{13} \mathrm{C}$ NMR (126 MHz, $\mathrm{CDCl}_{3}$ )

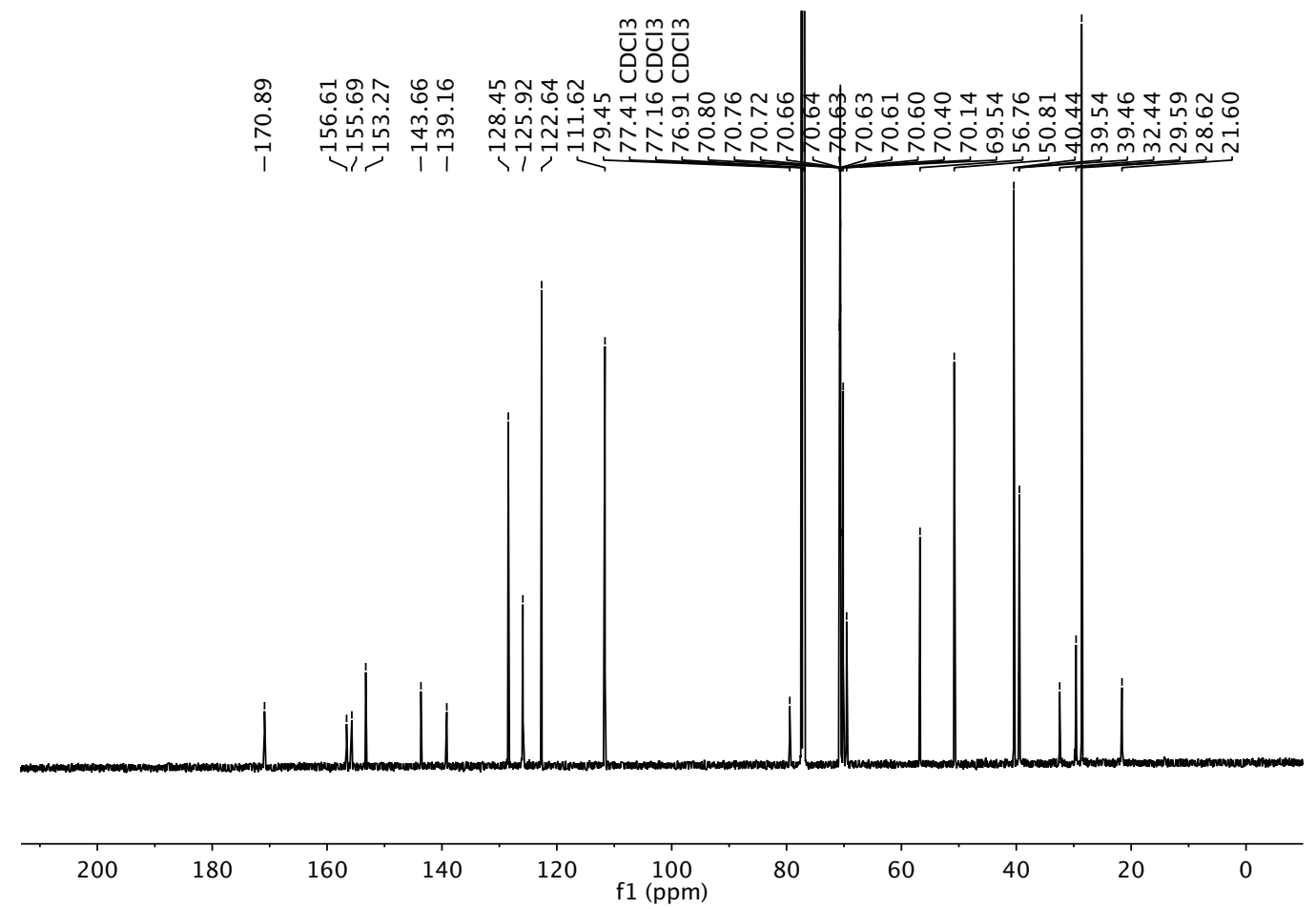


(S)-N-(32-Azido-3,6,9,12,15,18,21,24,27,30-decaoxadotriacontyl)-2-(4-dimethylaminophenylazo)

benzenesulfonamido)-6-(tert-butoxycarbonylamino)hexanamide (S12)

${ }^{1} \mathrm{H}$ NMR $\left(500 \mathrm{MHz}, \mathrm{CDCl}_{3}\right)$

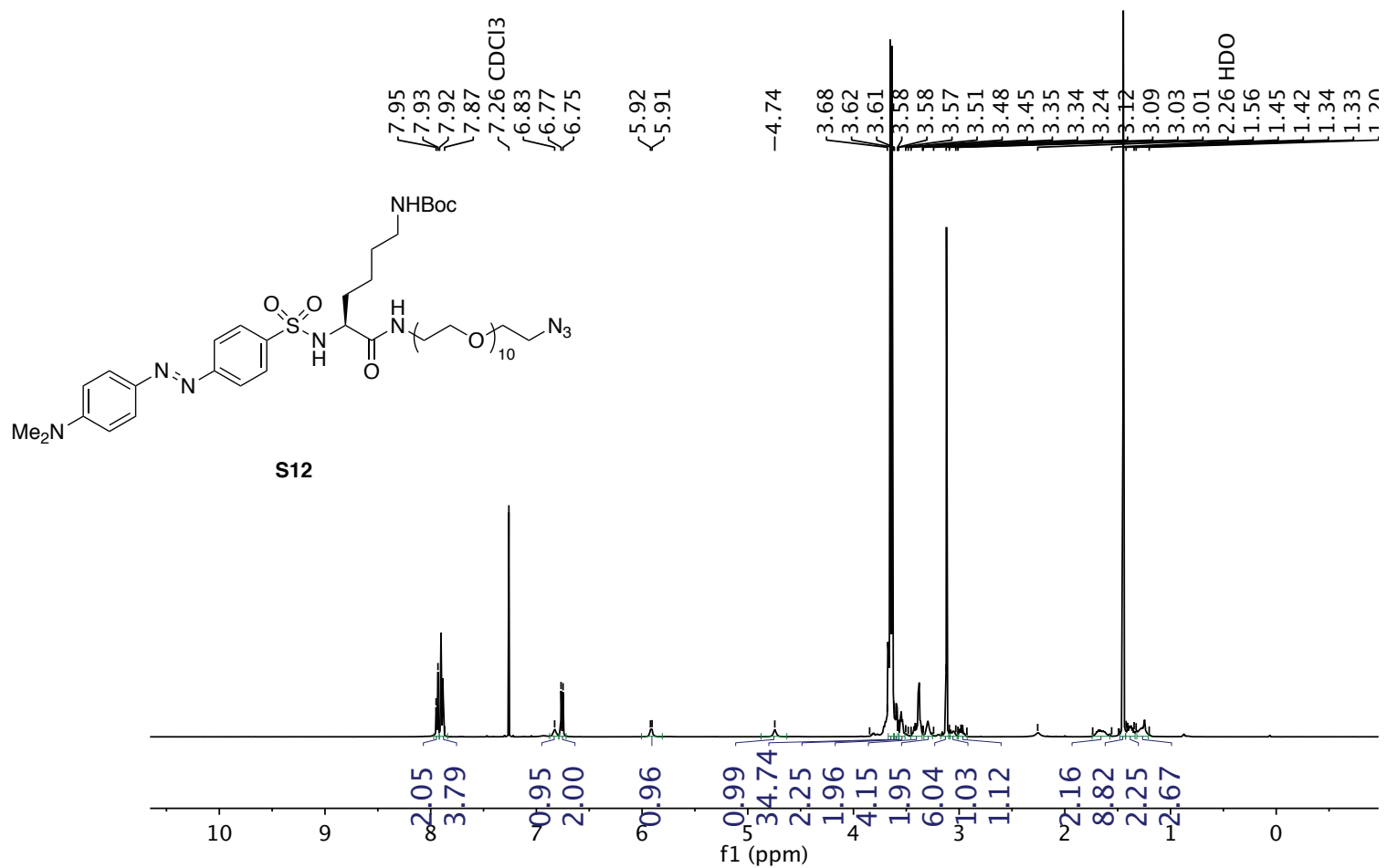

${ }^{13} \mathrm{C} \mathrm{NMR}\left(126 \mathrm{MHz}, \mathrm{CDCl}_{3}\right)$

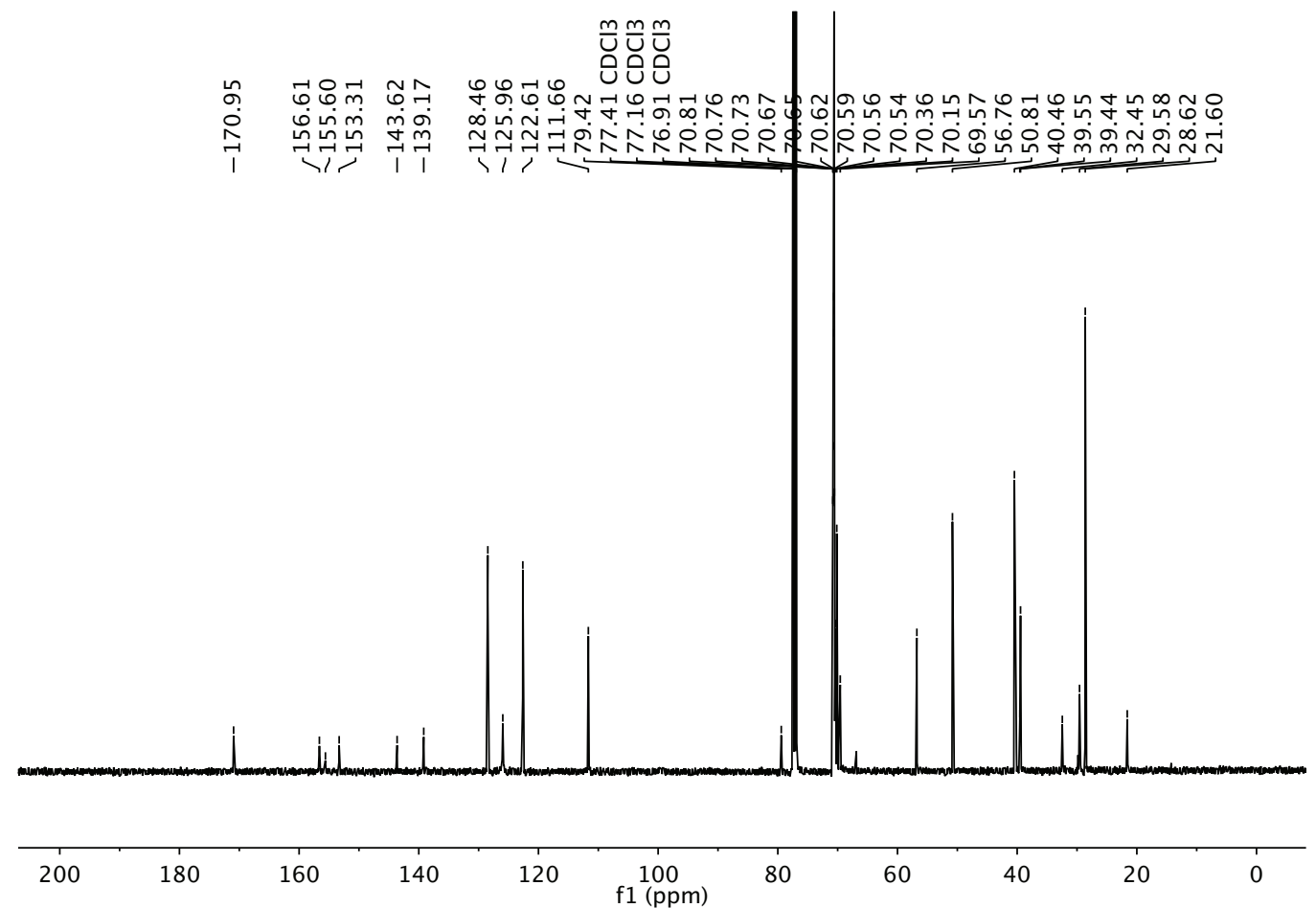


$N$-(4-Azidobutyl)phthalimide (S13)

${ }^{1} \mathrm{H}$ NMR (500 MHz, $\mathrm{CDCl}_{3}$ )

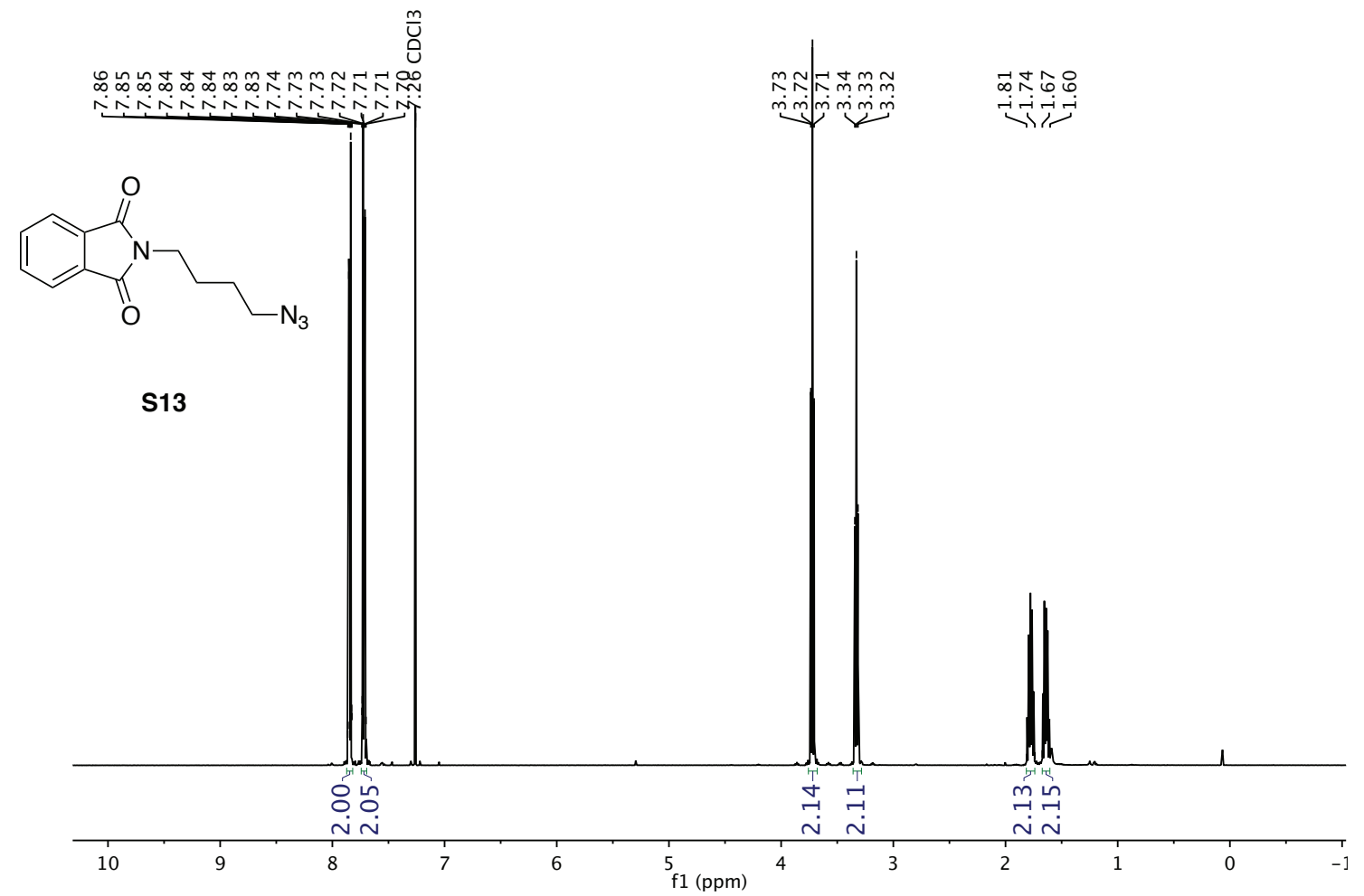

${ }^{13} \mathrm{C}$ NMR (126 MHz, $\mathrm{CDCl}_{3}$ )

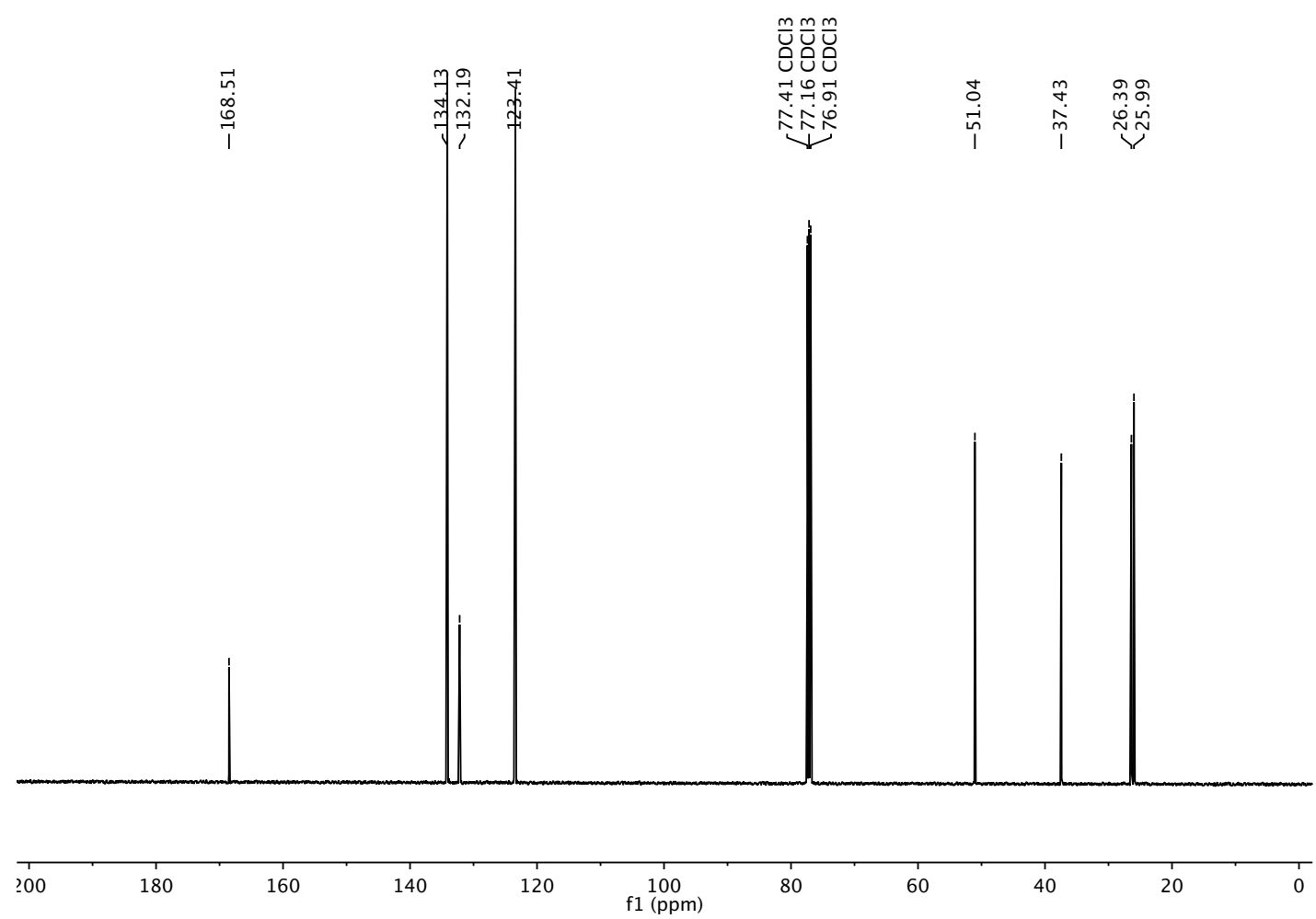


(S)-N-(4-Azidobutyl)-2-(4-dimethylaminophenylazo)benzenesulfonamido)-6-(tert-

butoxycarbonylamino) hexanamide (S14)

${ }^{1} \mathrm{H}$ NMR $\left(500 \mathrm{MHz}, \mathrm{CDCl}_{3}\right)$

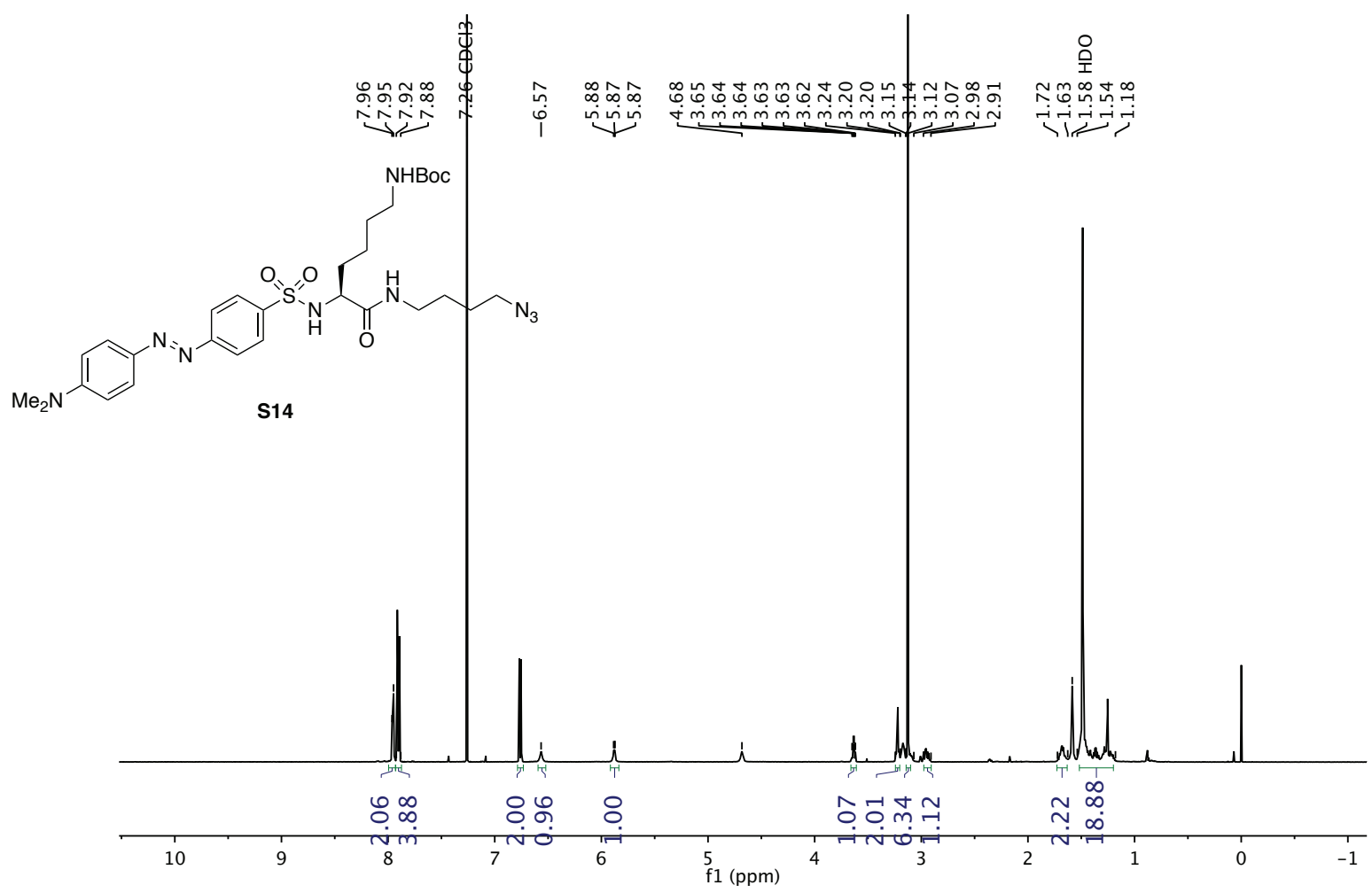

${ }^{13} \mathrm{C}$ NMR (126 MHz, $\mathrm{CDCl}_{3}$ )

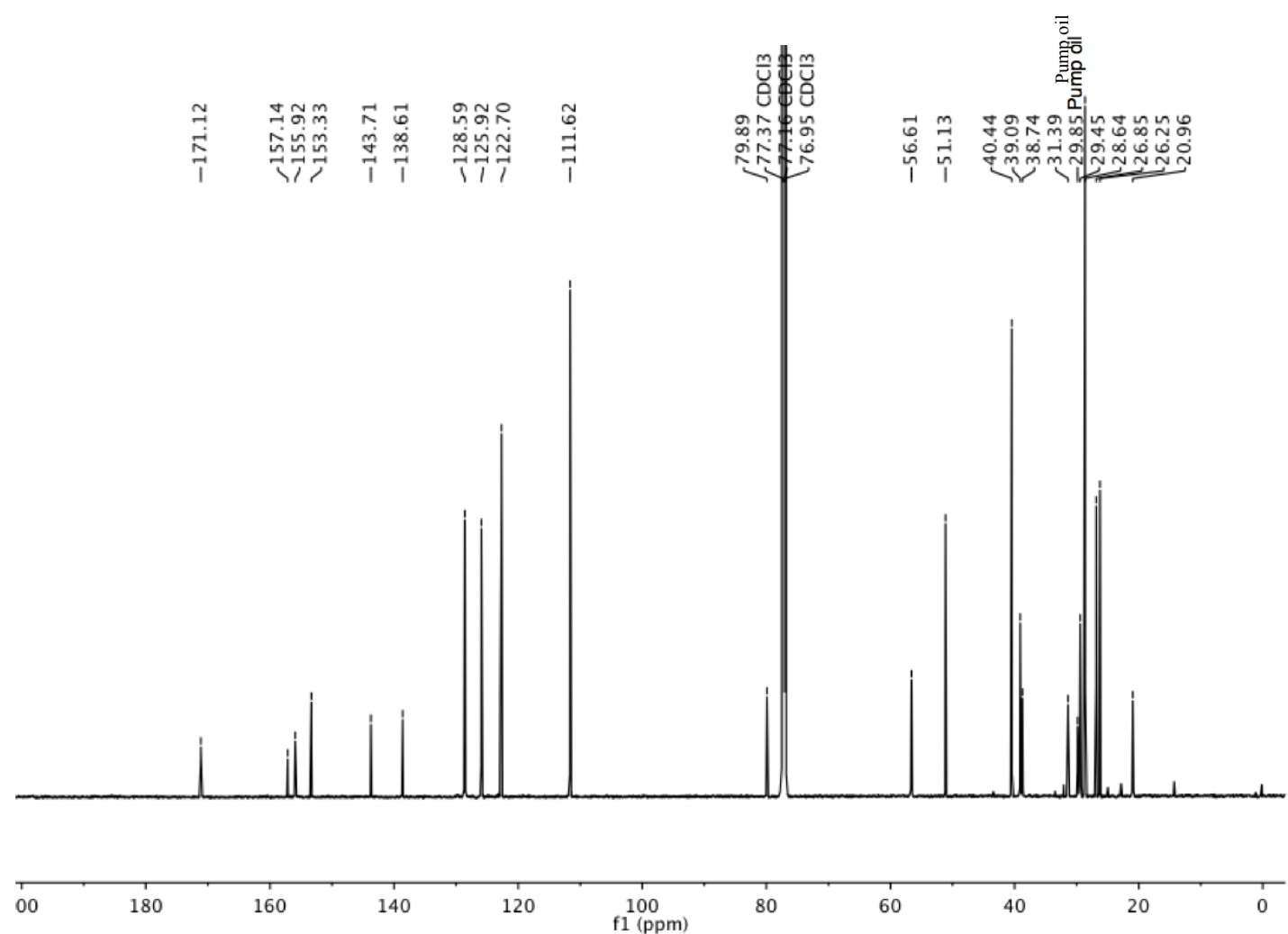


(S)-N-(11-Azido-3,6,9-trioxaundecyl)-2-(4-dimethylaminophenylazo)benzenesulfonamido)-6-(6((4R,5S)-5-methyl-2-oxoimidazolidin-4-yl)hexanamido)hexanamide (S16)

${ }^{1} \mathrm{H}$ NMR (500 MHz, $\mathrm{CD}_{3} \mathrm{OD}$ )

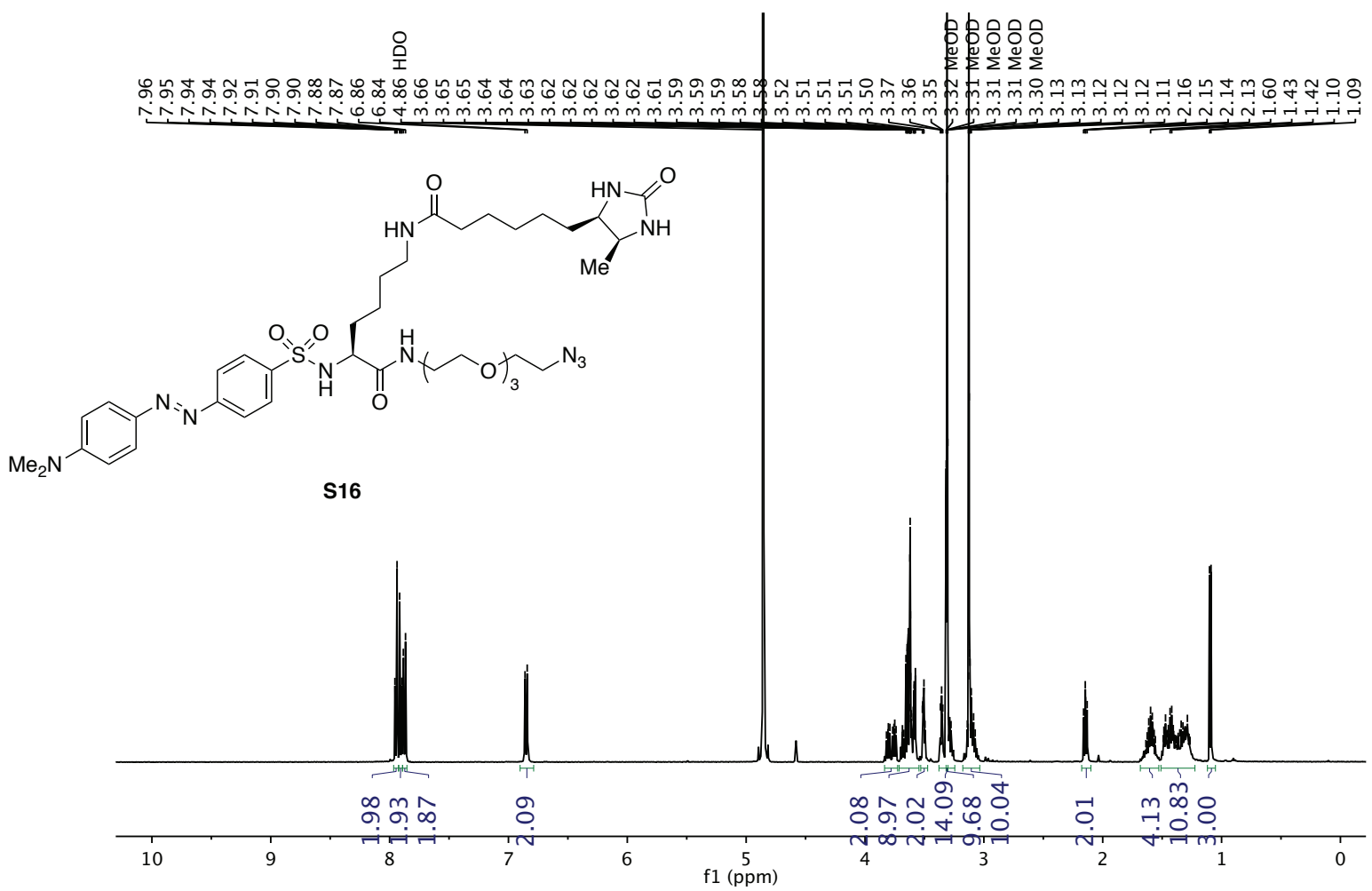

${ }^{13} \mathrm{C}$ NMR (126 MHz, CD ${ }_{3} \mathrm{OD}$ )

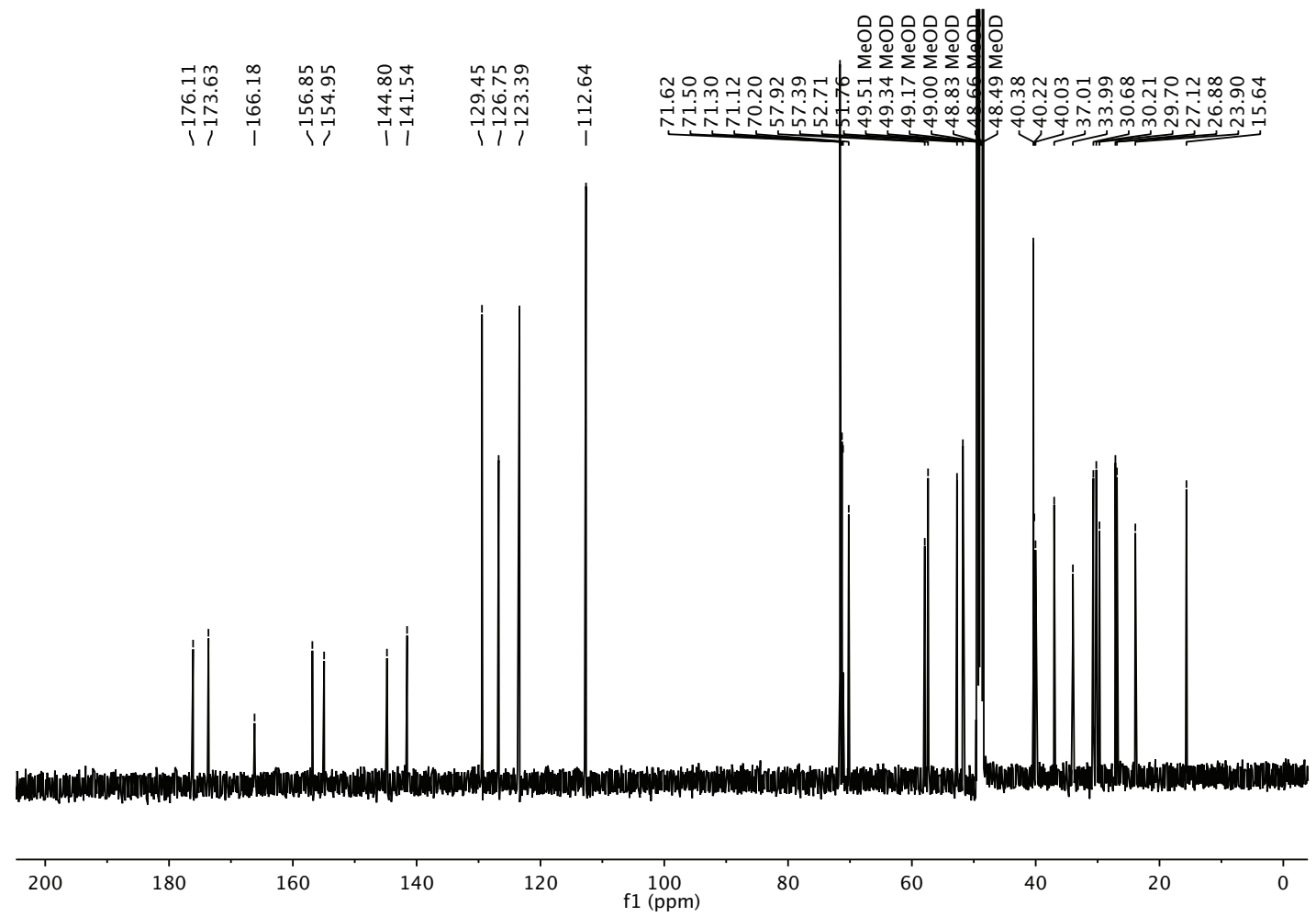


(S)-N-(20-Azido-3,6,9,12,15,18-hexaoxaeicosyl)-2-(4-dimethylaminophenylazo)benzenesulfonamido)-

6-(6-((4R,5S)-5-methyl-2-oxoimidazolidin-4-yl)hexanamido)hexanamide (S17)

${ }^{1} \mathrm{H}$ NMR (500 MHz, $\mathrm{CDCl}_{3}$ )

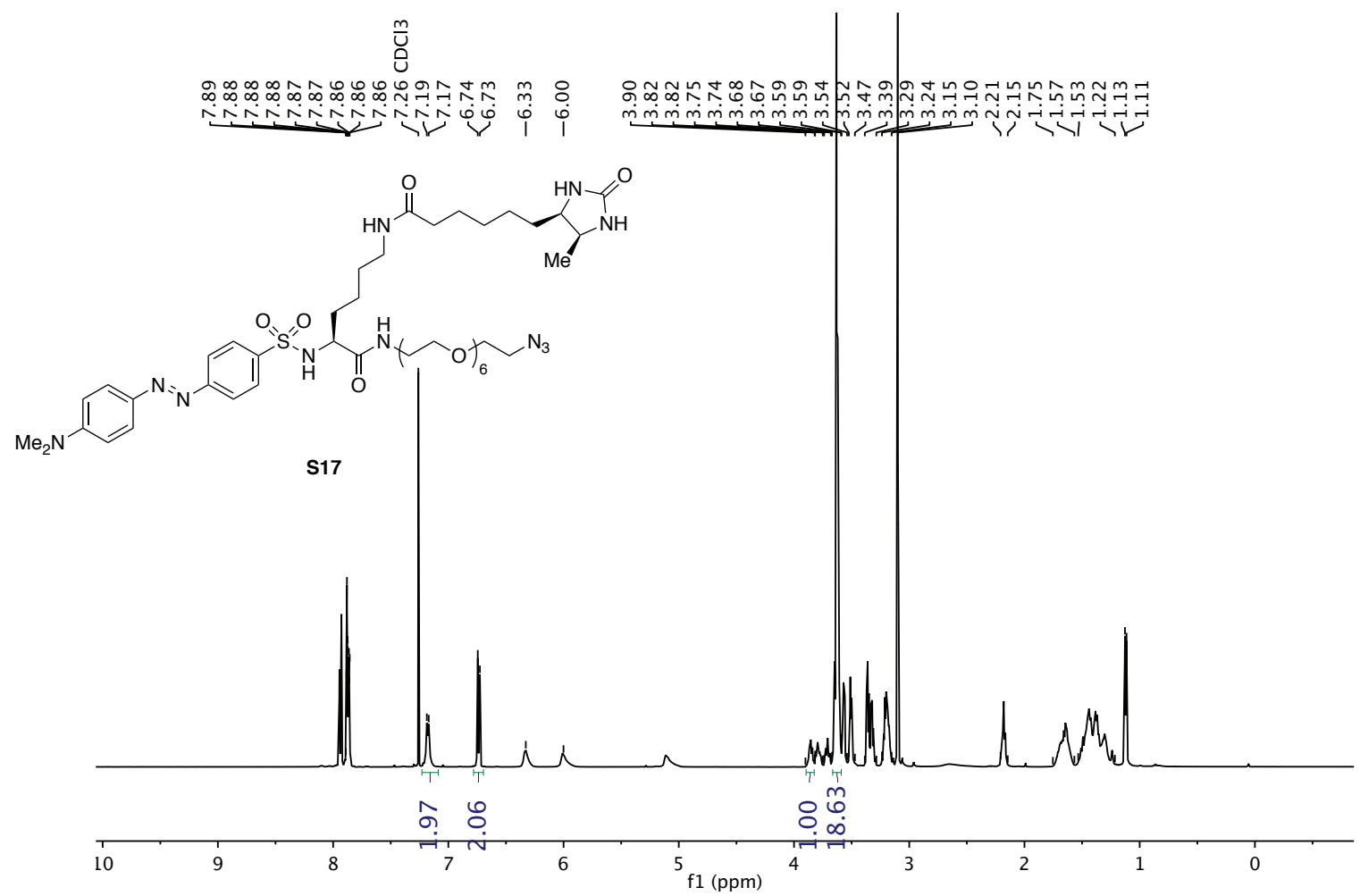

${ }^{13} \mathrm{C}$ NMR (126 MHz, $\mathrm{CDCl}_{3}$ )

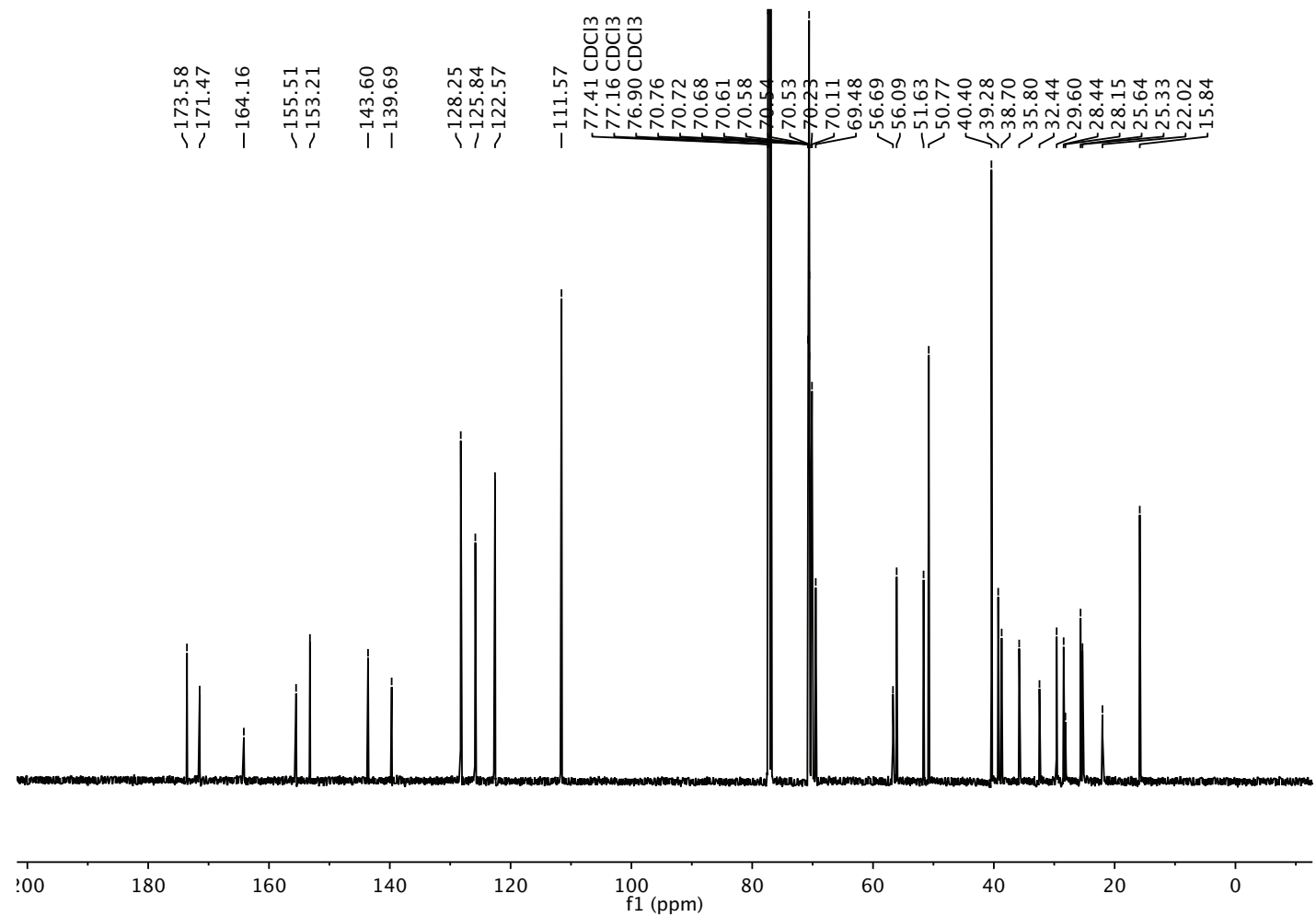


(S)-N-(32-Azido-3,6,9,12,15,18,21,24,27,30-decaoxadotriacontyl)-2-(4-dimethylaminophenylazo)

benzenesulfonamido)-6-(6-((4R,5S)-5-methyl-2-oxoimidazolidin-4-yl)hexanamido)hexanamide (S18)

${ }^{1} \mathrm{H}$ NMR $\left(500 \mathrm{MHz}, \mathrm{CDCl}_{3}\right)$

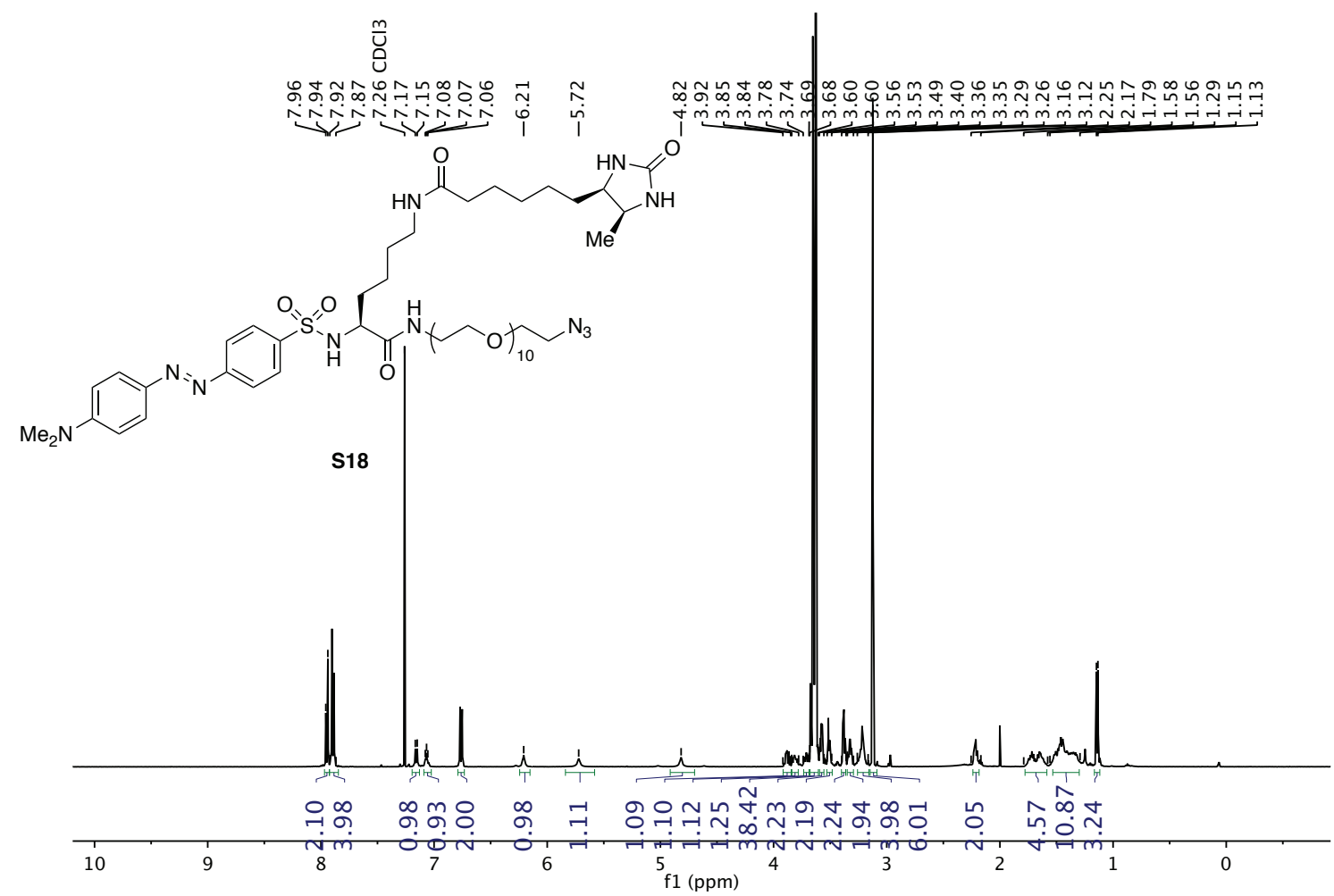

${ }^{13} \mathrm{C}$ NMR (126 MHz, CDCl $\left.{ }_{3}\right)$

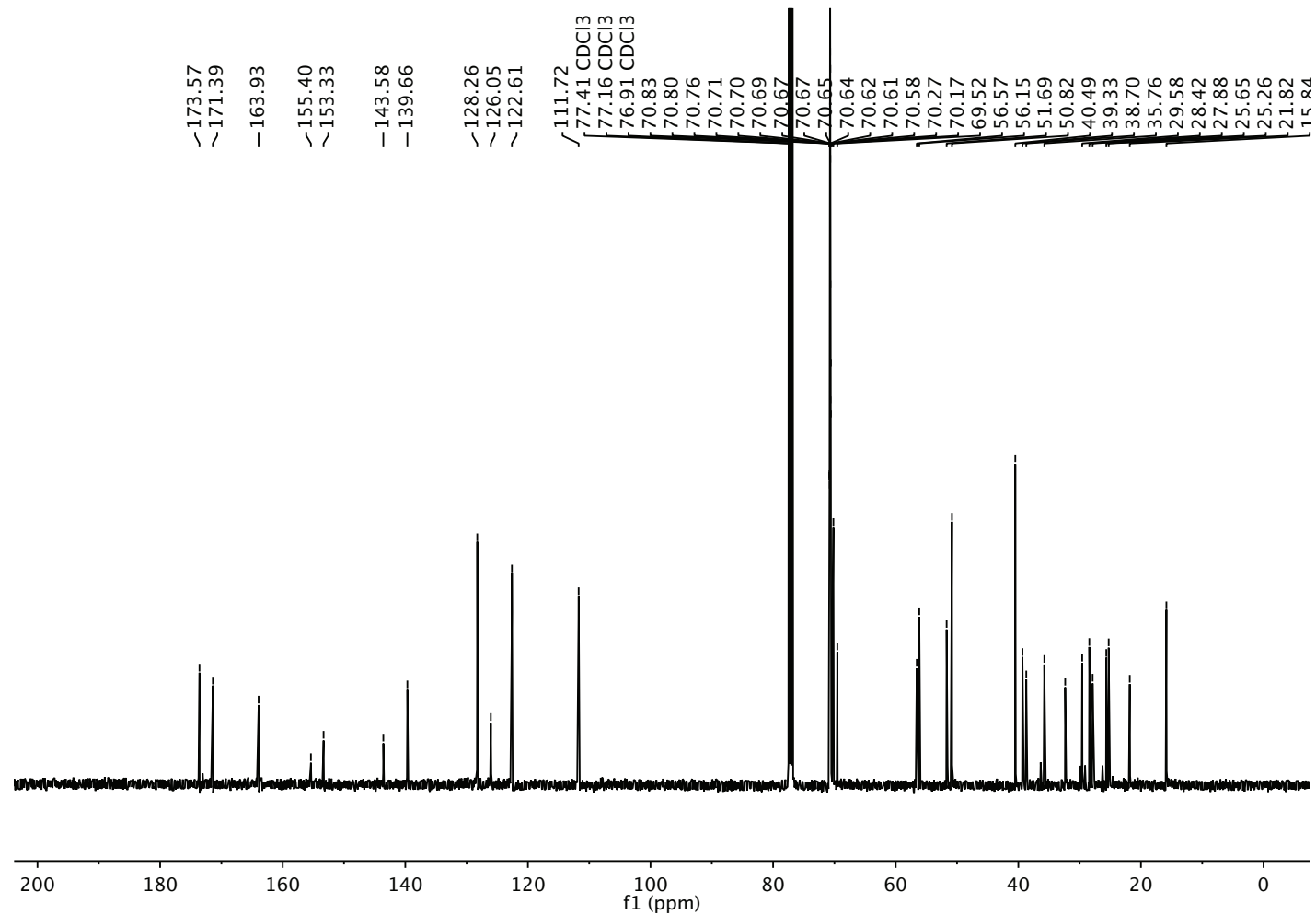


(S)-N-(4-Azidobutyl)-2-(4-dimethylaminophenylazo)benzenesulfonamido)-6-(6-((4R,5S)-5-methyl-2oxoimidazolidin-4-yl)hexanamido)hexanamide (S19)

${ }^{1} \mathrm{H}$ NMR (500 MHz, $\left.\mathrm{CD}_{3} \mathrm{OD}\right)$

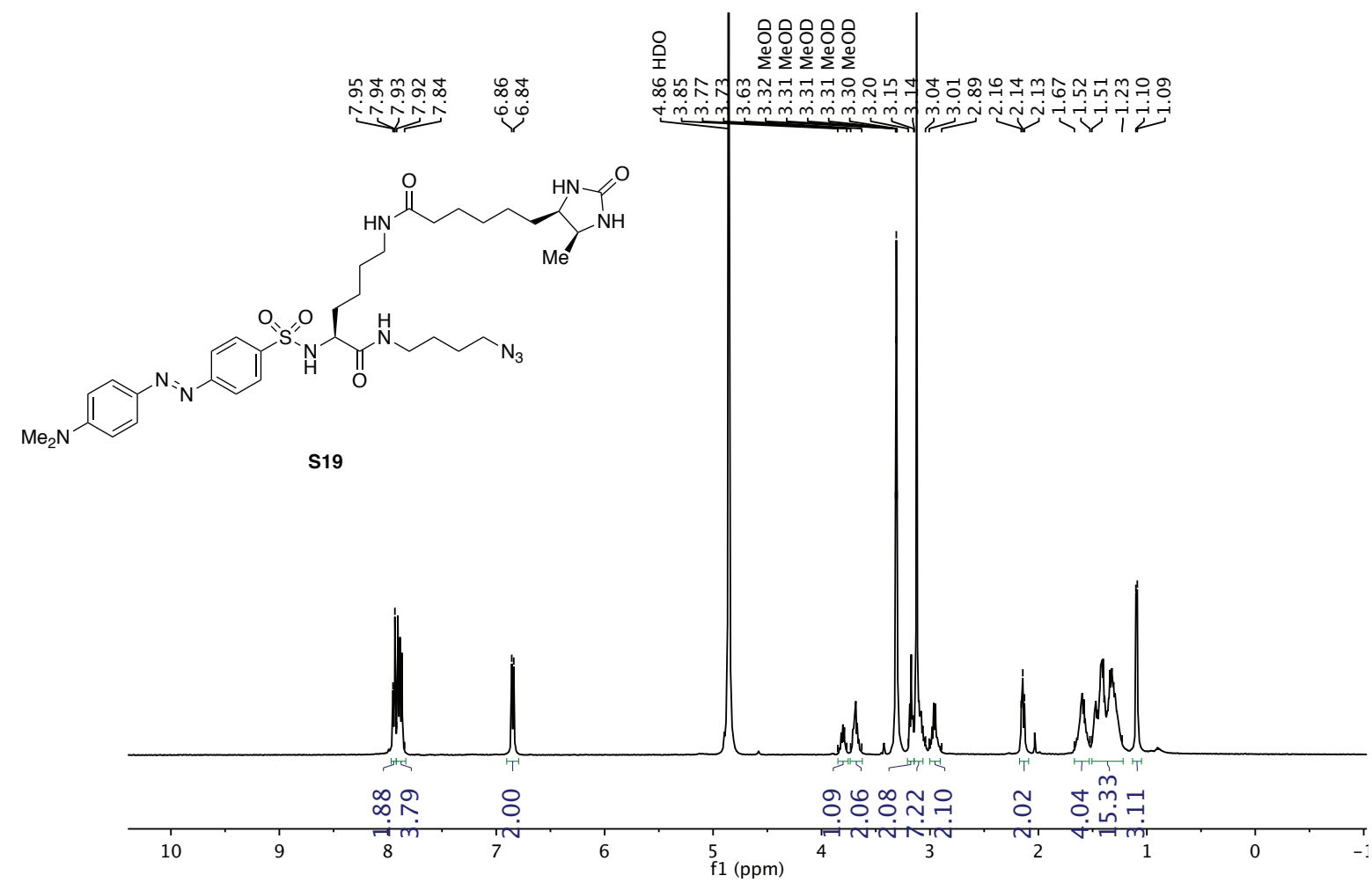

${ }^{13} \mathrm{C}$ NMR (126 MHz, CD ${ }_{3} \mathrm{OD}$ )

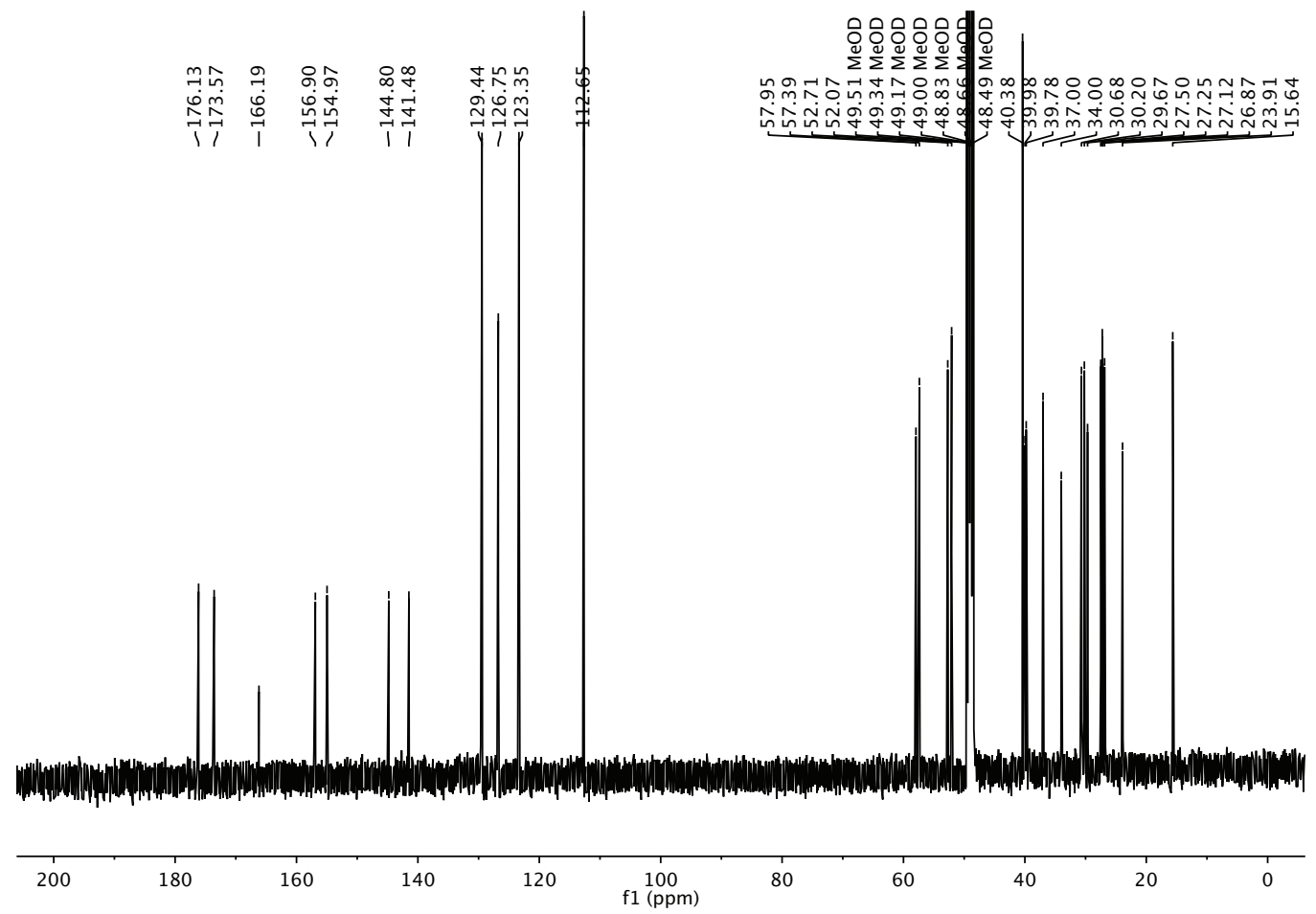




\section{Reagent 1a precursor (Boc-1a)}

${ }^{1} \mathrm{H}$ NMR (500 MHz, $\mathrm{CDCl}_{3}$ )

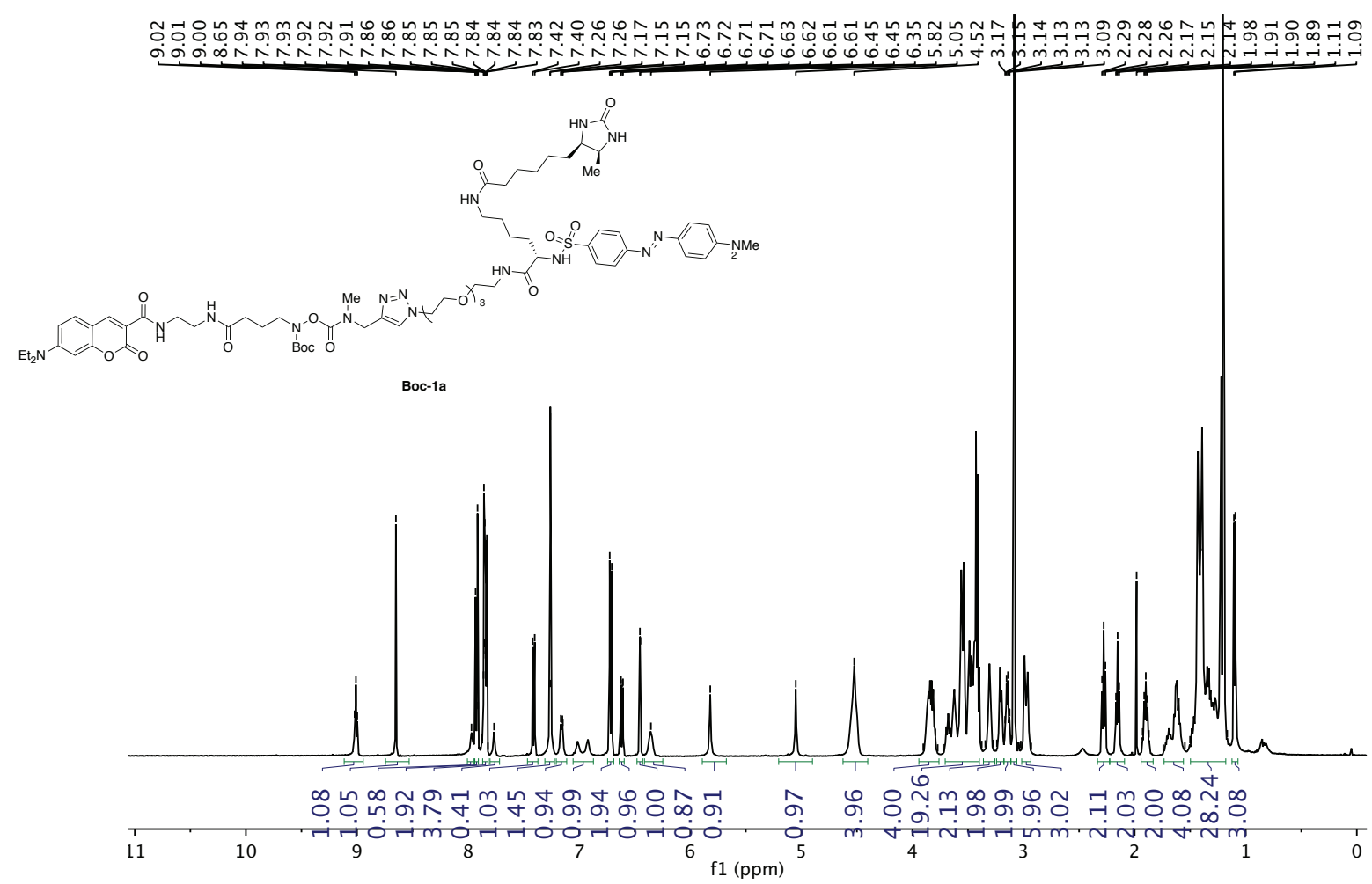

${ }^{13} \mathrm{C}$ NMR (126 MHz, $\left.\mathrm{CDCl}_{3}\right)$

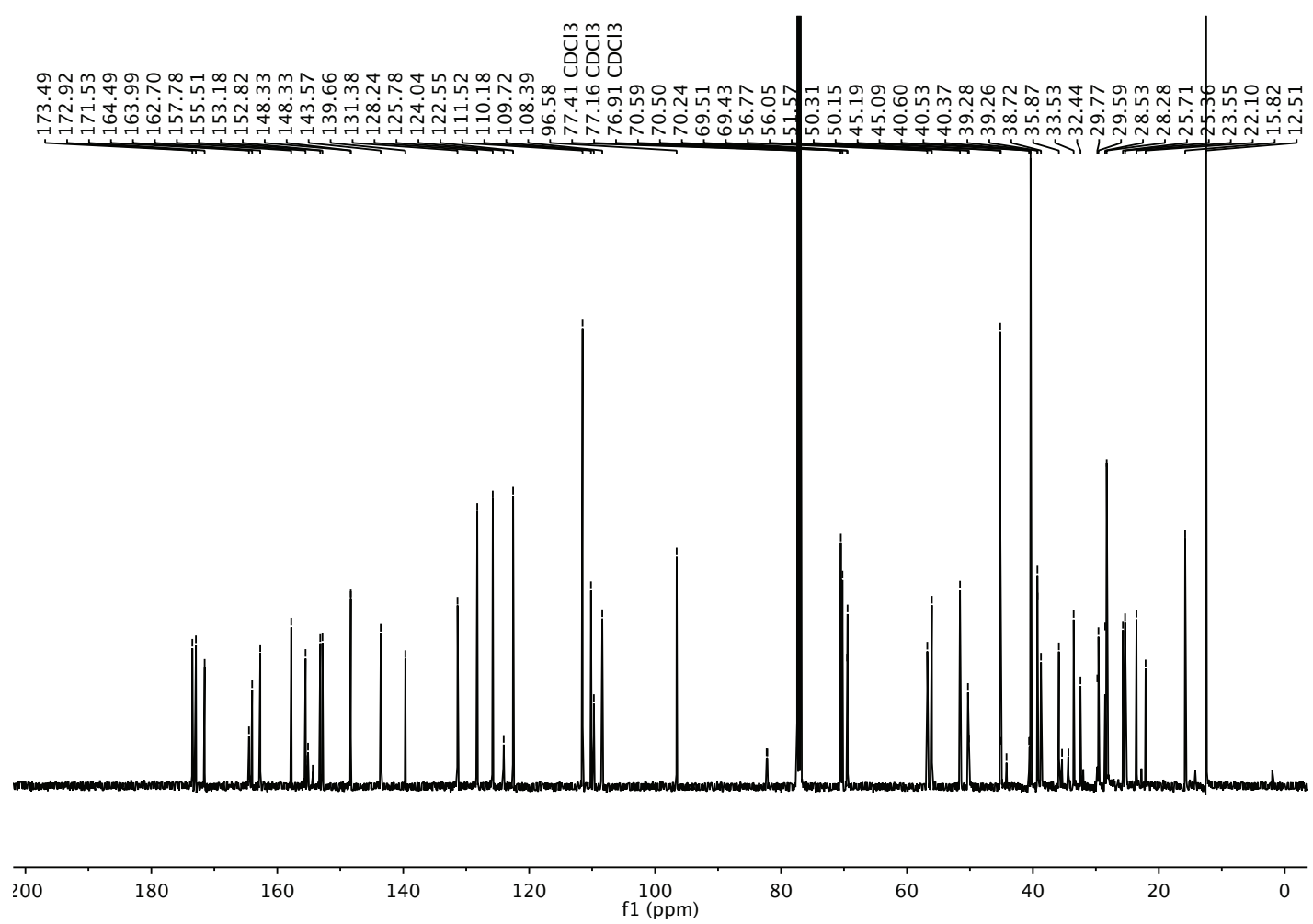


Reagent 1b precursor (Boc-1b)

${ }^{1} \mathrm{H}$ NMR (500 MHz, $\mathrm{CDCl}_{3}$ )

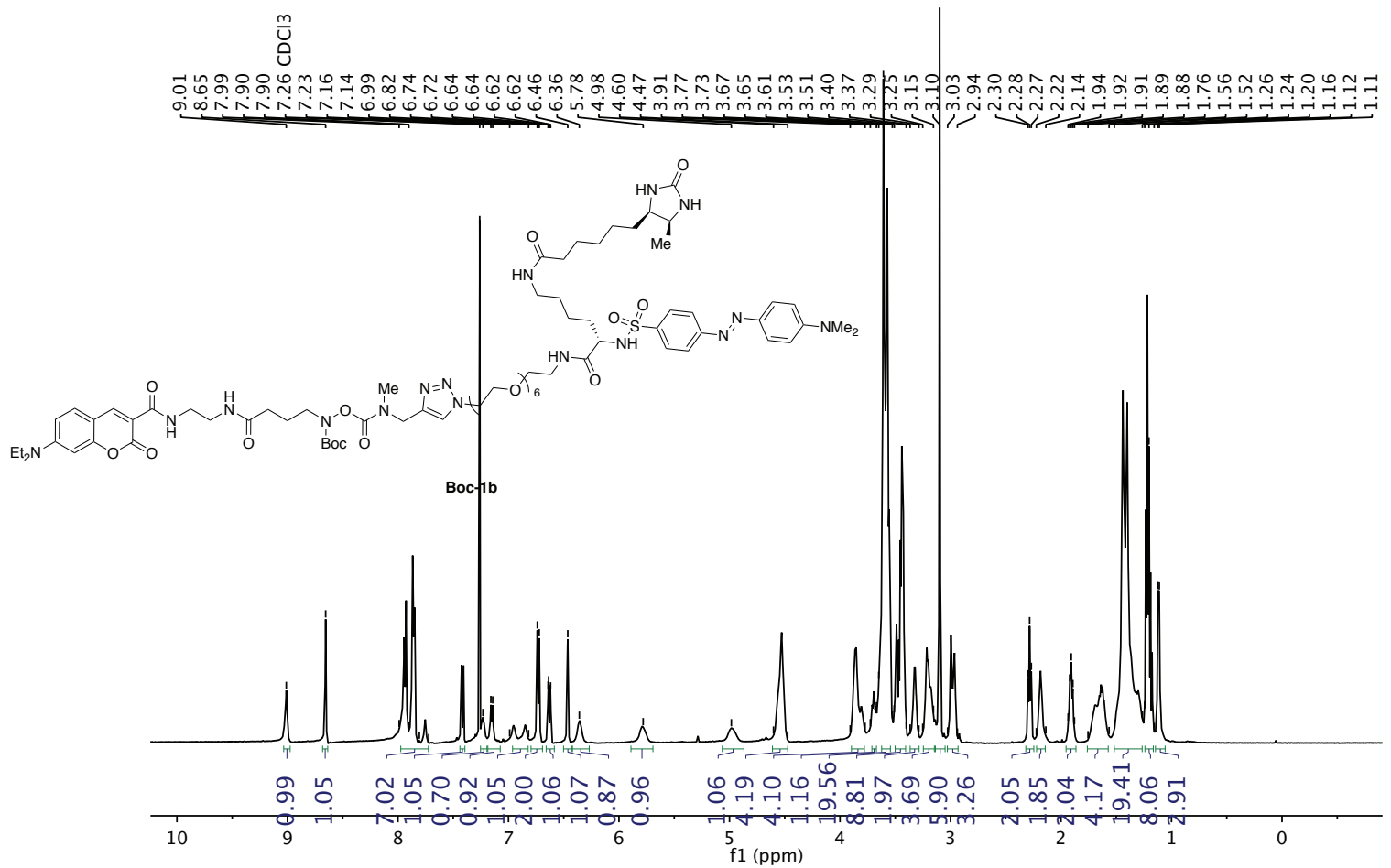

${ }^{13} \mathrm{C}$ NMR $\left(126 \mathrm{MHz}, \mathrm{CDCl}_{3}\right)$

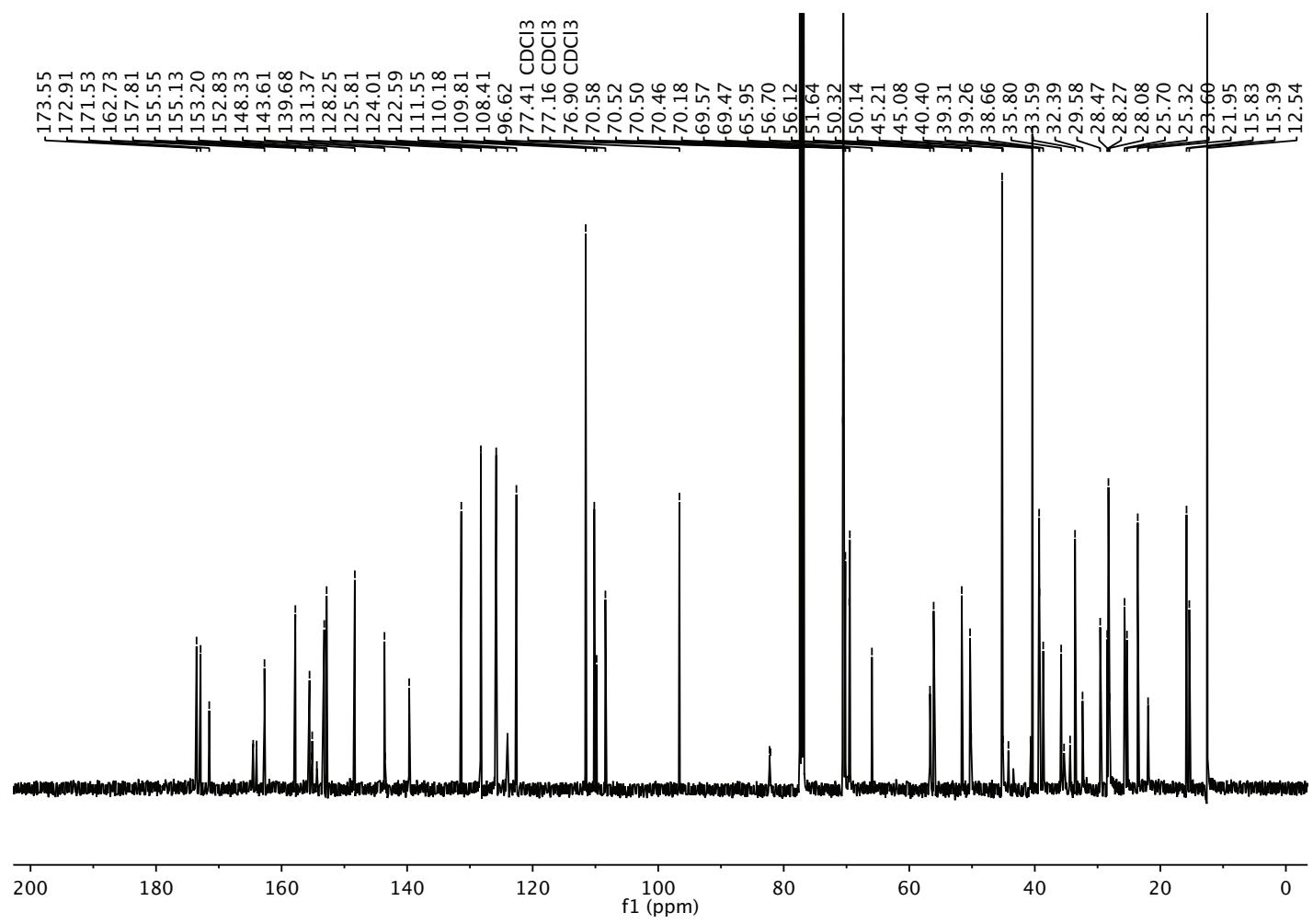




\section{Reagent 1c precursor (Boc-1c)}

${ }^{1} \mathrm{H}$ NMR (500 MHz, $\left.\mathrm{CDCl}_{3}\right)$

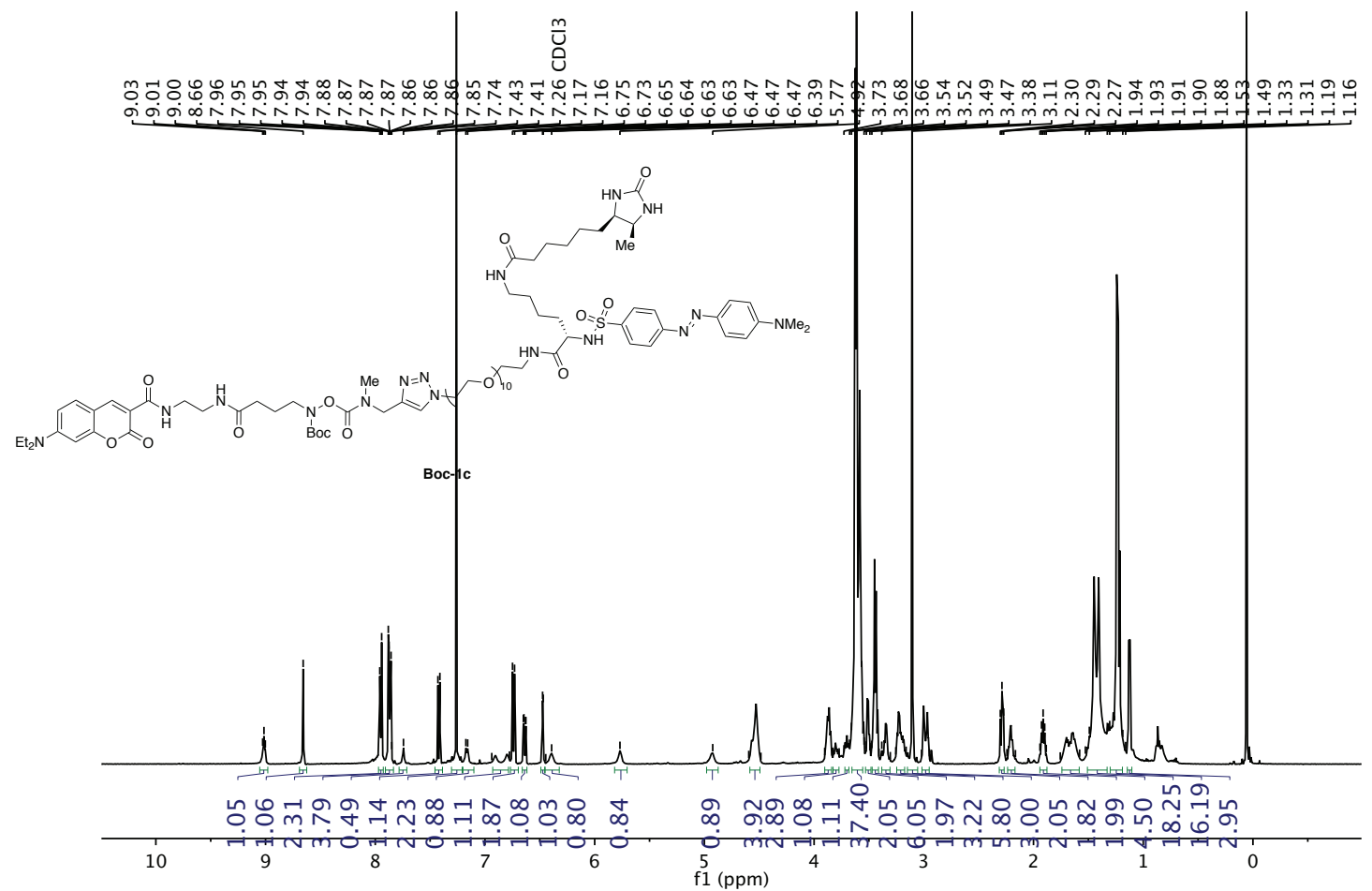

${ }^{13} \mathrm{C}$ NMR $\left(126 \mathrm{MHz}, \mathrm{CDCl}_{3}\right)$

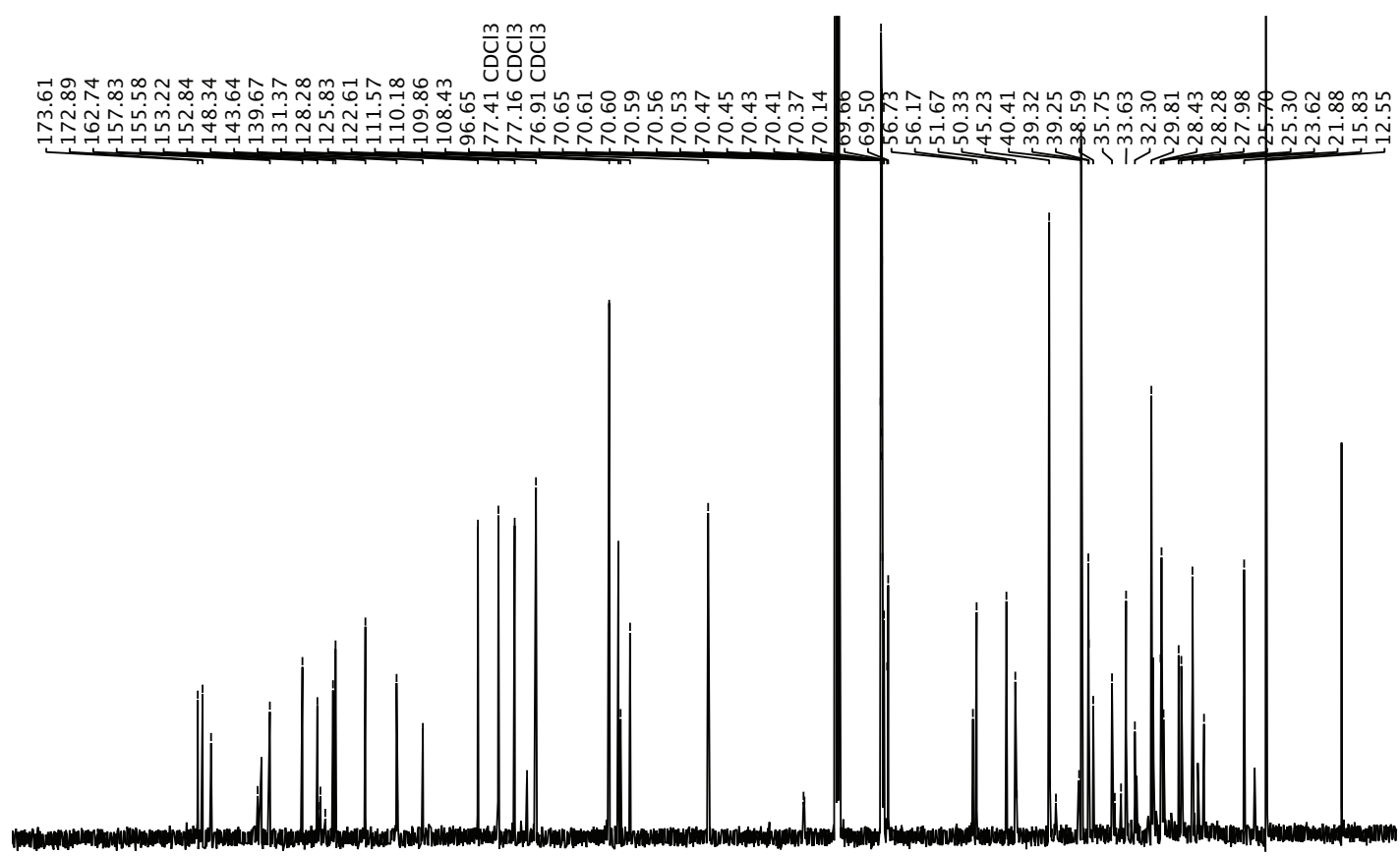

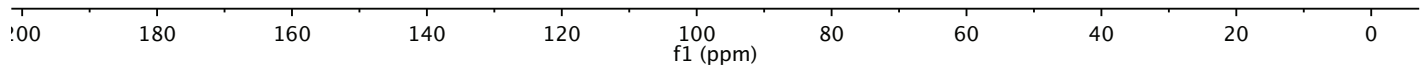




\section{Reagent 1d precursor (Boc-1d)}

${ }^{1} \mathrm{H}$ NMR $\left(500 \mathrm{MHz}, \mathrm{CDCl}_{3}\right)$

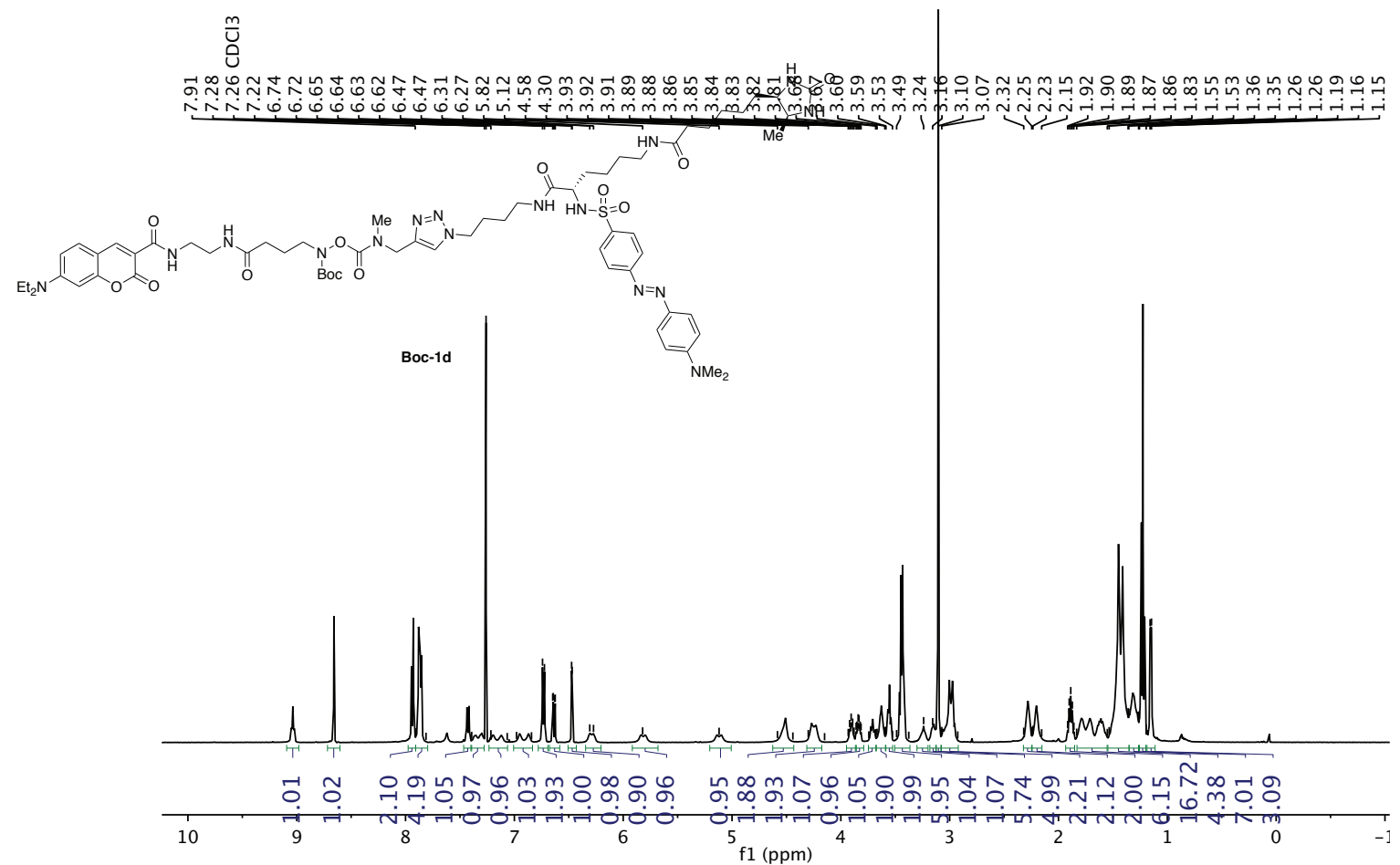

$\left.{ }^{13} \mathrm{C} \mathrm{NMR} \mathrm{(126} \mathrm{MHz,} \mathrm{CDCl}_{3}\right)$

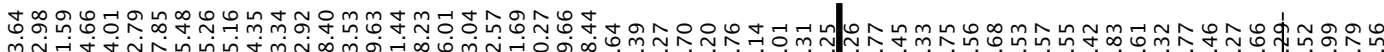

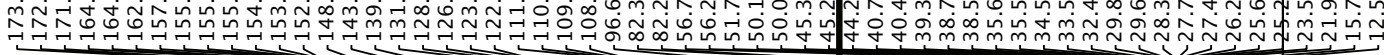

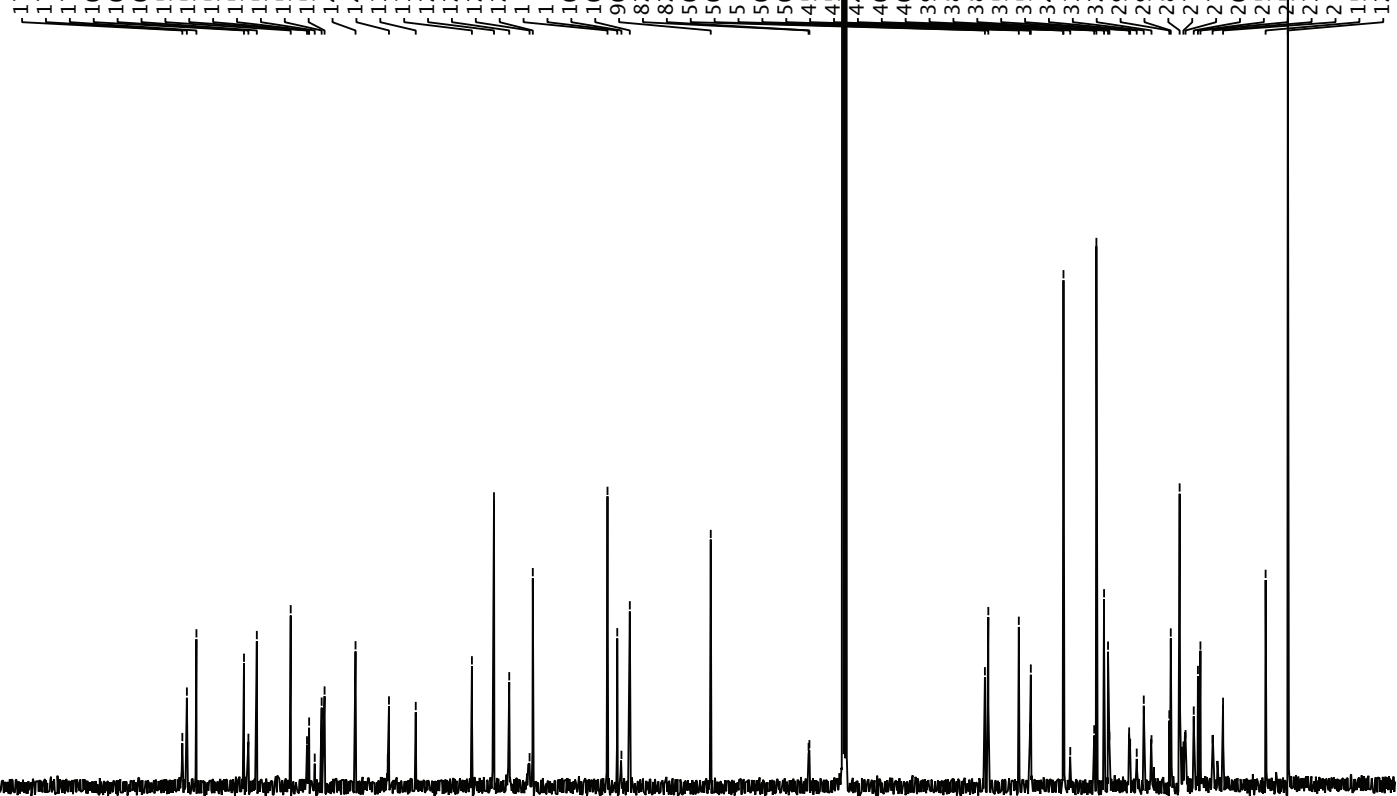

200

120

100
$\mathrm{f} 1(\mathrm{ppm})$

80

60

40

20

0 
2-(2-Hydroxyphenyl)pyridine-4-carboxaldehyde (S20)

${ }^{1} \mathrm{H}$ NMR (500 MHz, $\left.\mathrm{CDCl}_{3}\right)$

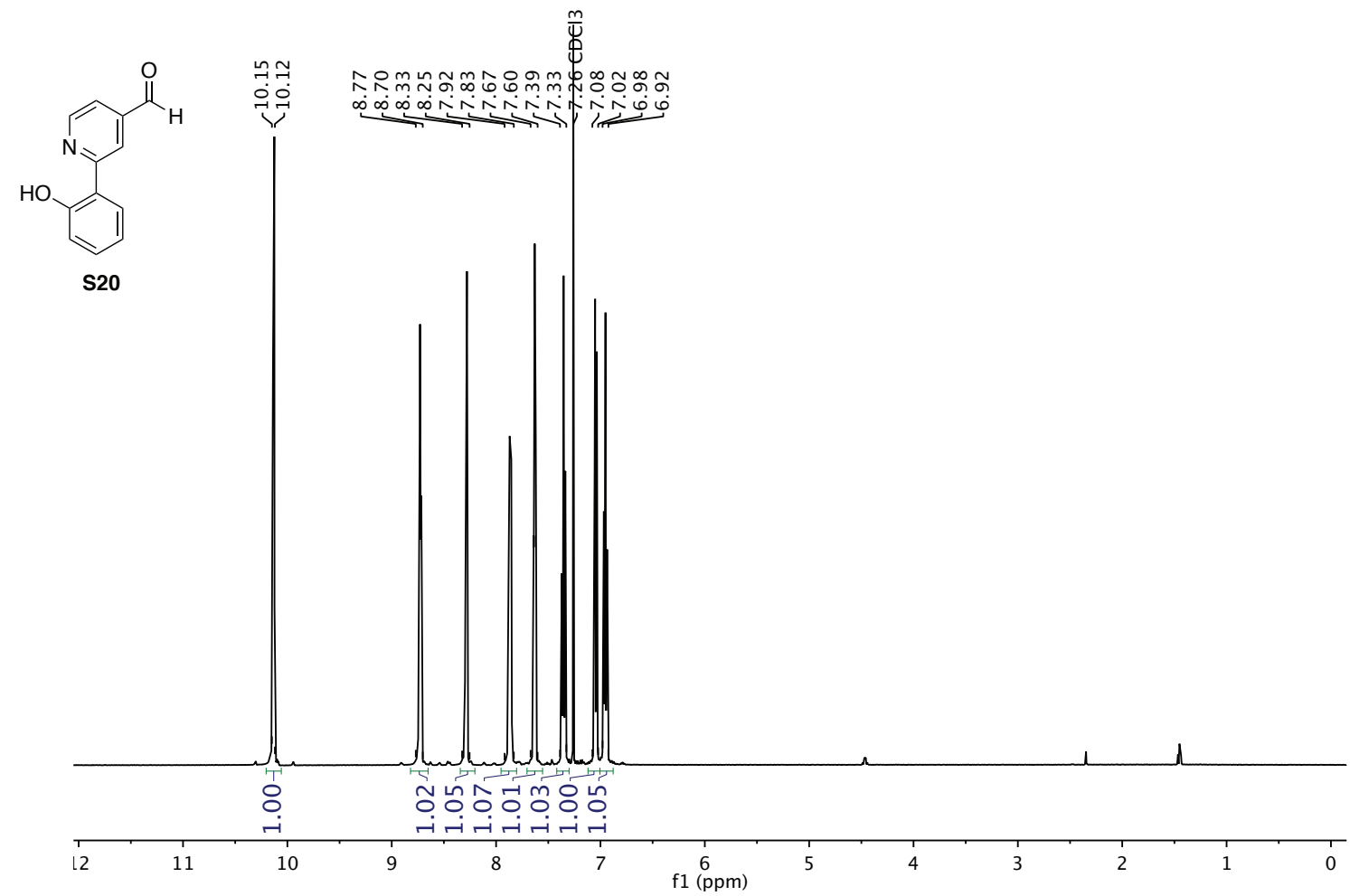

${ }^{13} \mathrm{C}$ NMR (126 MHz, $\left.\mathrm{CDCl}_{3}\right)$

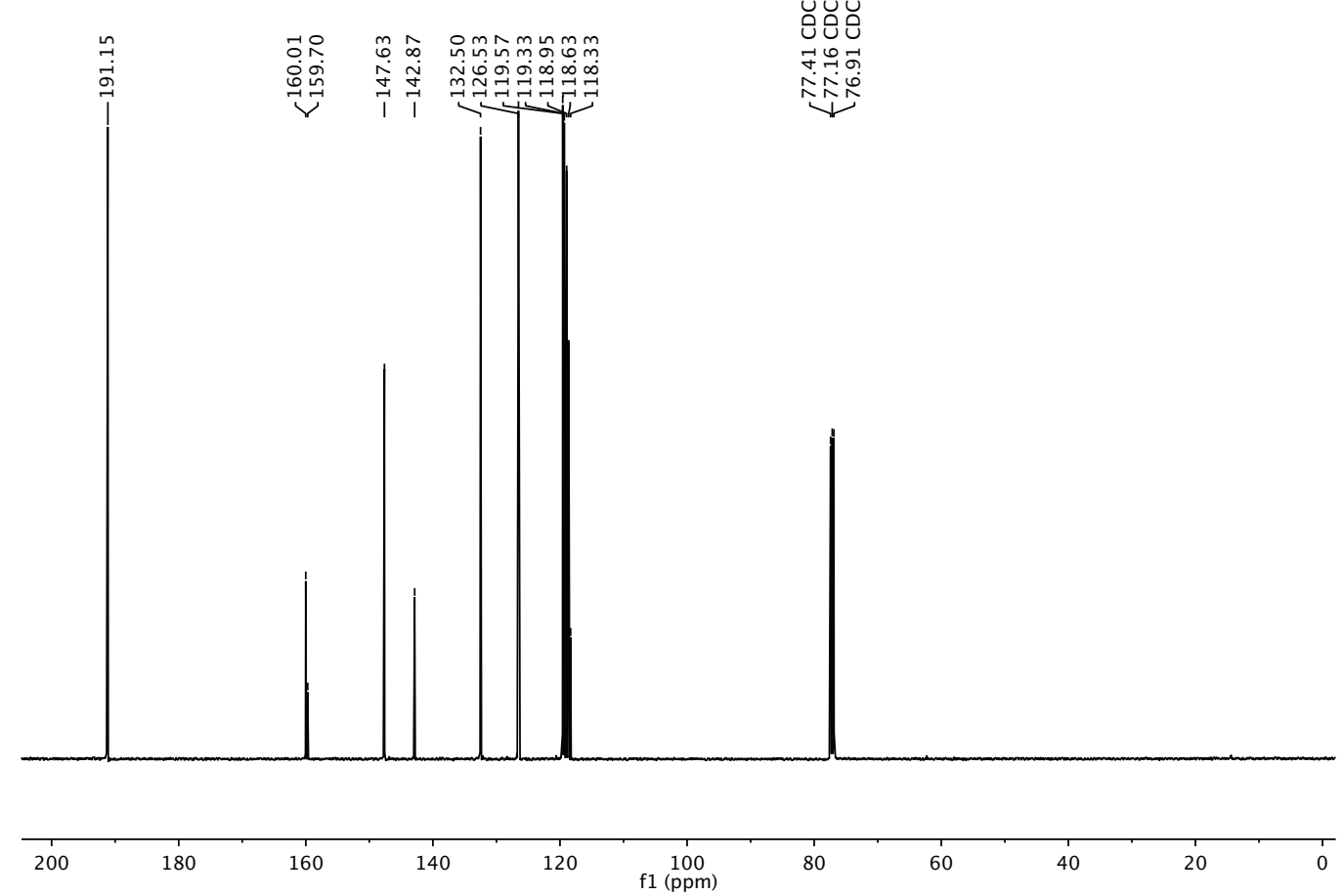


2-(2-Hydroxyphenyl)-4-ethynylpyridine (S22)

${ }^{1} \mathrm{H}$ NMR $\left(400 \mathrm{MHz}, \mathrm{CDCl}_{3}\right)$

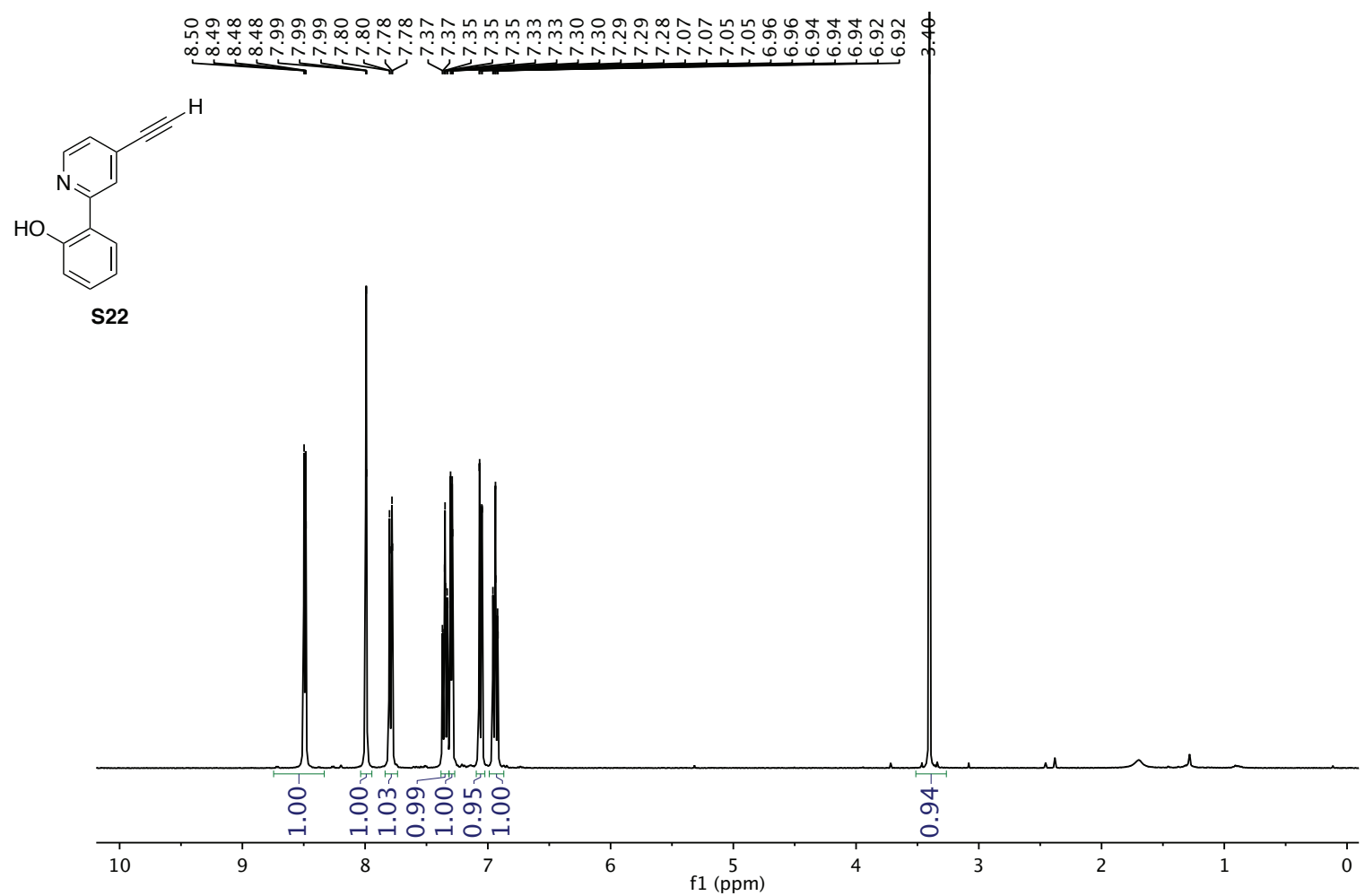

${ }^{13} \mathrm{C}$ NMR $\left(126 \mathrm{MHz}, \mathrm{CDCl}_{3}\right)$

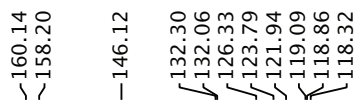

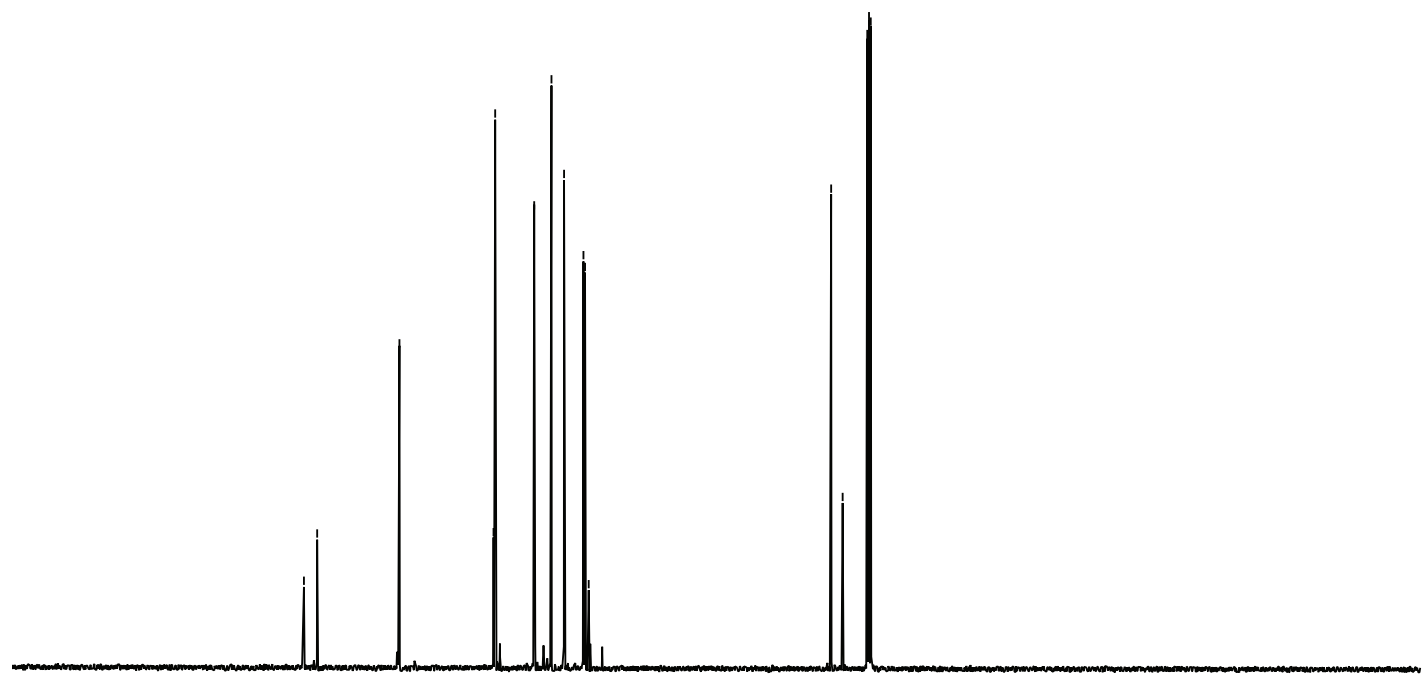

200

180

160

140

120

100
$\mathrm{f} 1(\mathrm{ppm})$

80

60

40

20 
10-(4-Fluorobenzoyl)-3-ethynyl-10-fluoro-9-oxa-10a-aza-10-boraphenanthrene (S24)

${ }^{1} \mathrm{H}$ NMR $\left(600 \mathrm{MHz}, \mathrm{CDCl}_{3}\right)$

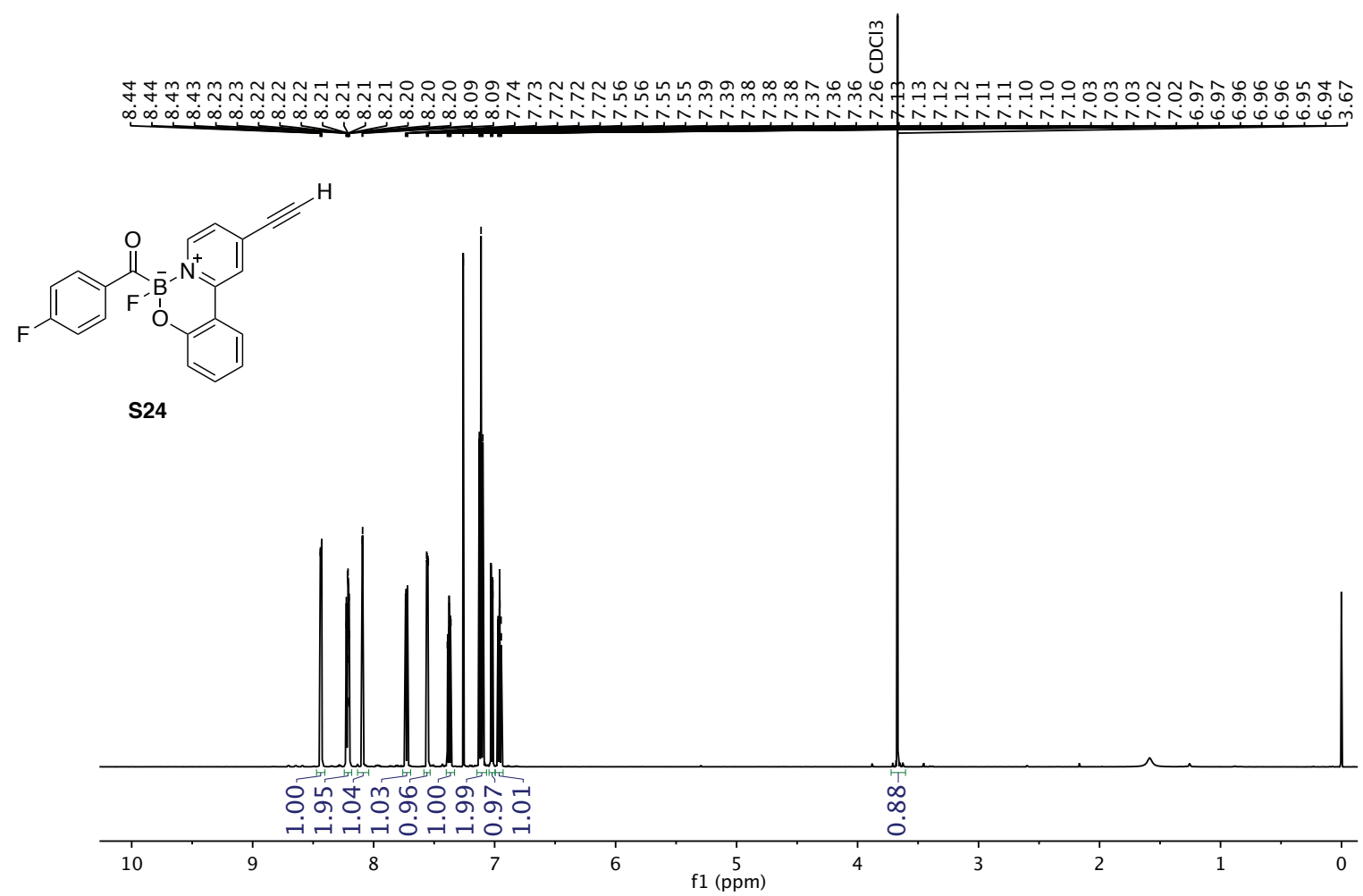

${ }^{13} \mathrm{C}$ NMR $\left(151 \mathrm{MHz}, \mathrm{CDCl}_{3}\right)$
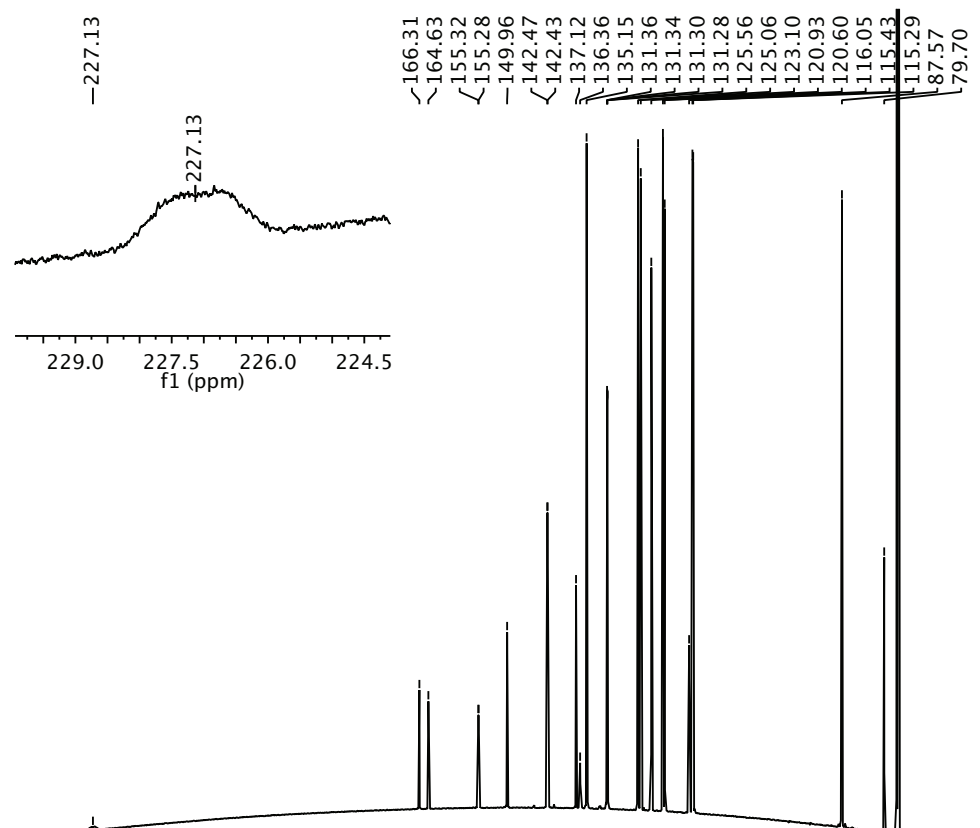

\begin{tabular}{lllllllllll}
1 & 1 \\
\hline & 220 & 200 & 180 & 160 & 140 \\
$\mathrm{f} 1(\mathrm{ppm})$ & 120 & 100 & 80 & 60 & 40 & 20 & 0
\end{tabular}


${ }^{19} \mathrm{~F} \mathrm{NMR}\left(471 \mathrm{MHz}, \mathrm{CDCl}_{3}\right.$ )
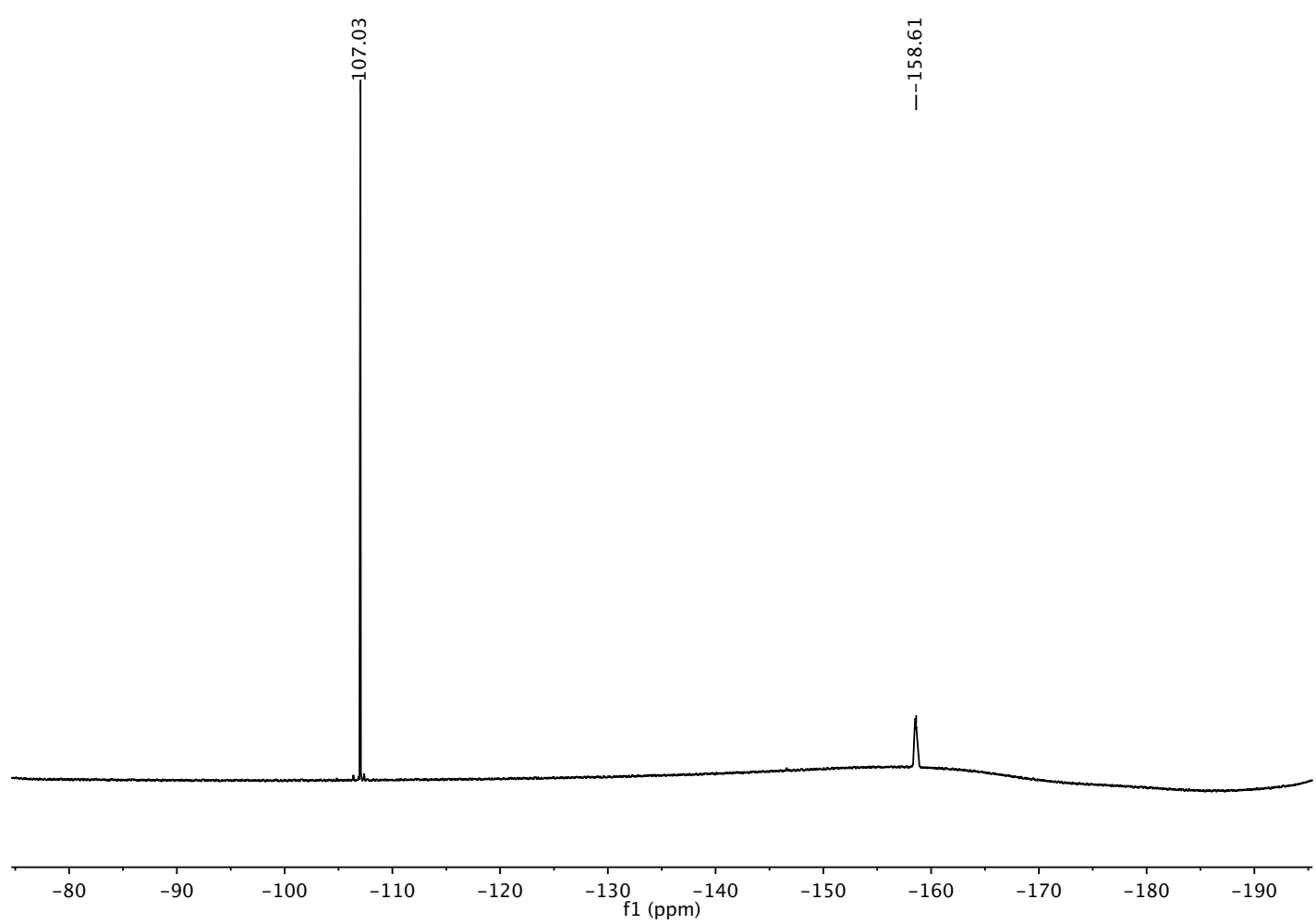

${ }^{11} \mathrm{~B}$ NMR (160 MHz, $\mathrm{CDCl}_{3}$ )

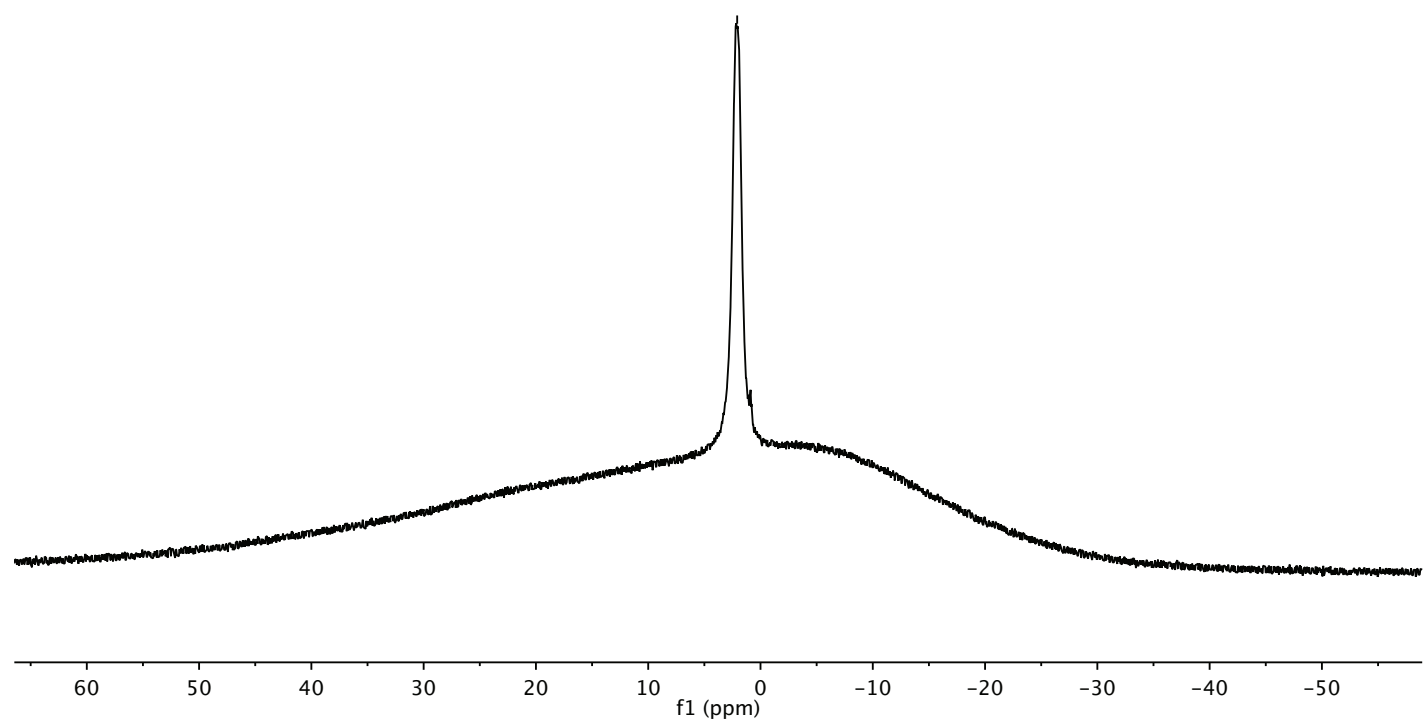


$N$-(11-Azido-3,6,9-trioxaundecyl)-6-((4R,5S)-5-methyl-2-oxoimidazolidin-4-yl) hexanamide (S25)

${ }^{1} \mathrm{H}$ NMR $\left(500 \mathrm{MHz}, \mathrm{CDCl}_{3}\right)$

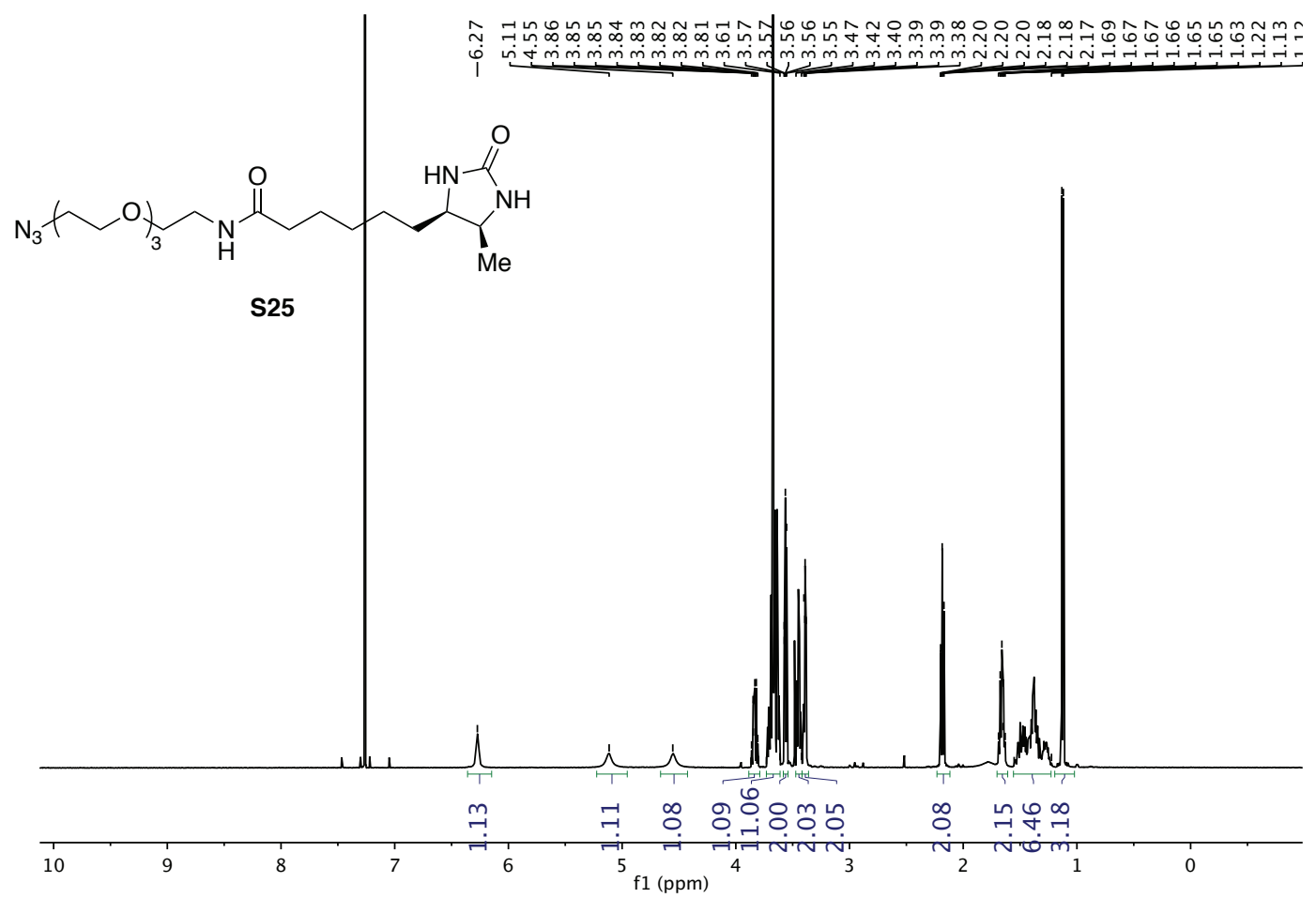

${ }^{13} \mathrm{C}$ NMR (126 MHz, $\mathrm{CDCl}_{3}$ )

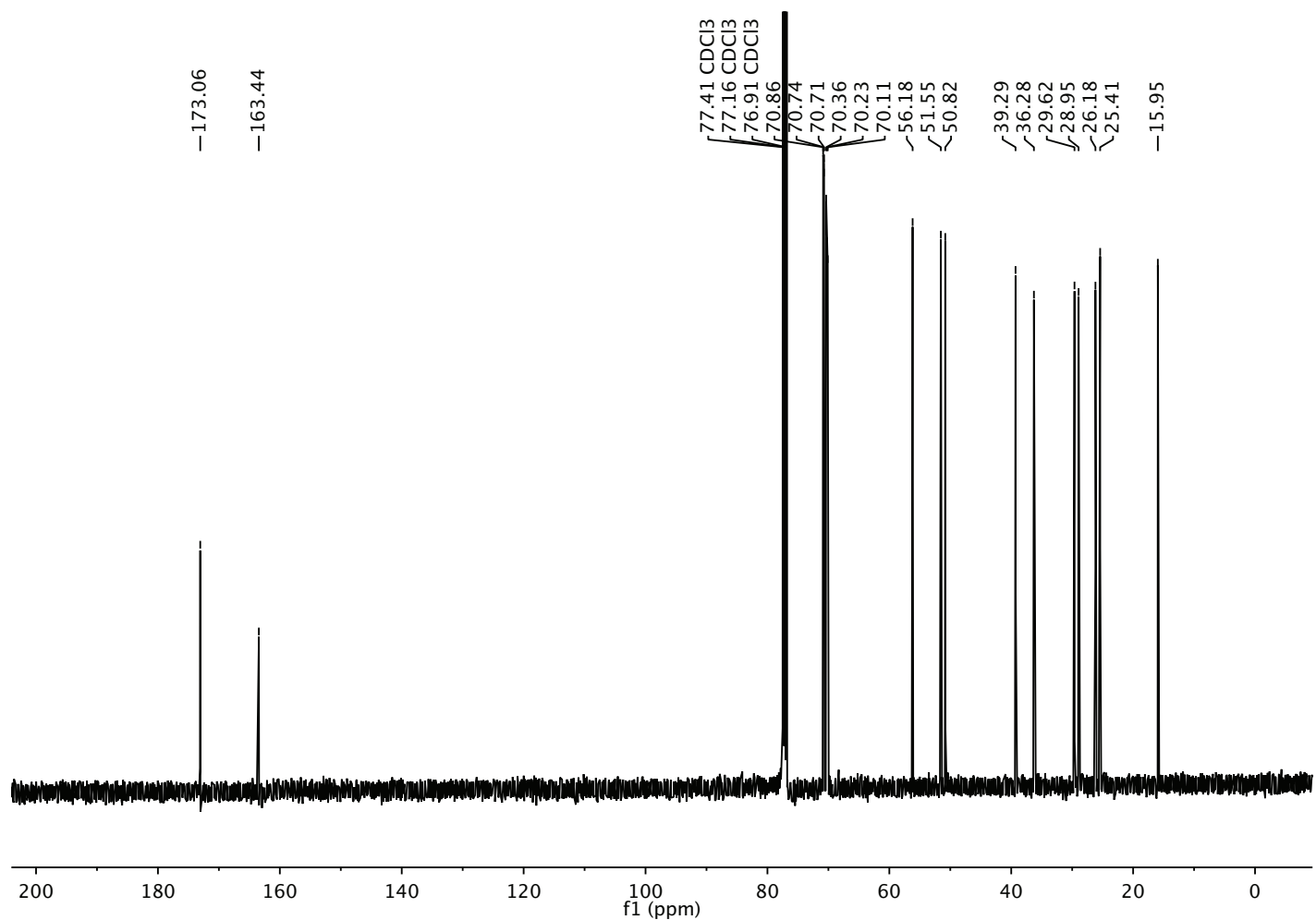


N-(11-(4-(10-(4-Fluorobenzoyl)-10-fluoro-9-oxa-10a-aza-10-boraphenanthren-3-yl)-1 H-1,2,3-triazol-1-

yl)-3,6,9-trioxaundecyl)-6-((4R,5S)-5-methyl-2-oxoimidazolidin-4-yl)hexanamide (2a)

${ }^{1} \mathrm{H}$ NMR (600 MHz, $\left.\mathrm{CDCl}_{3}\right)$

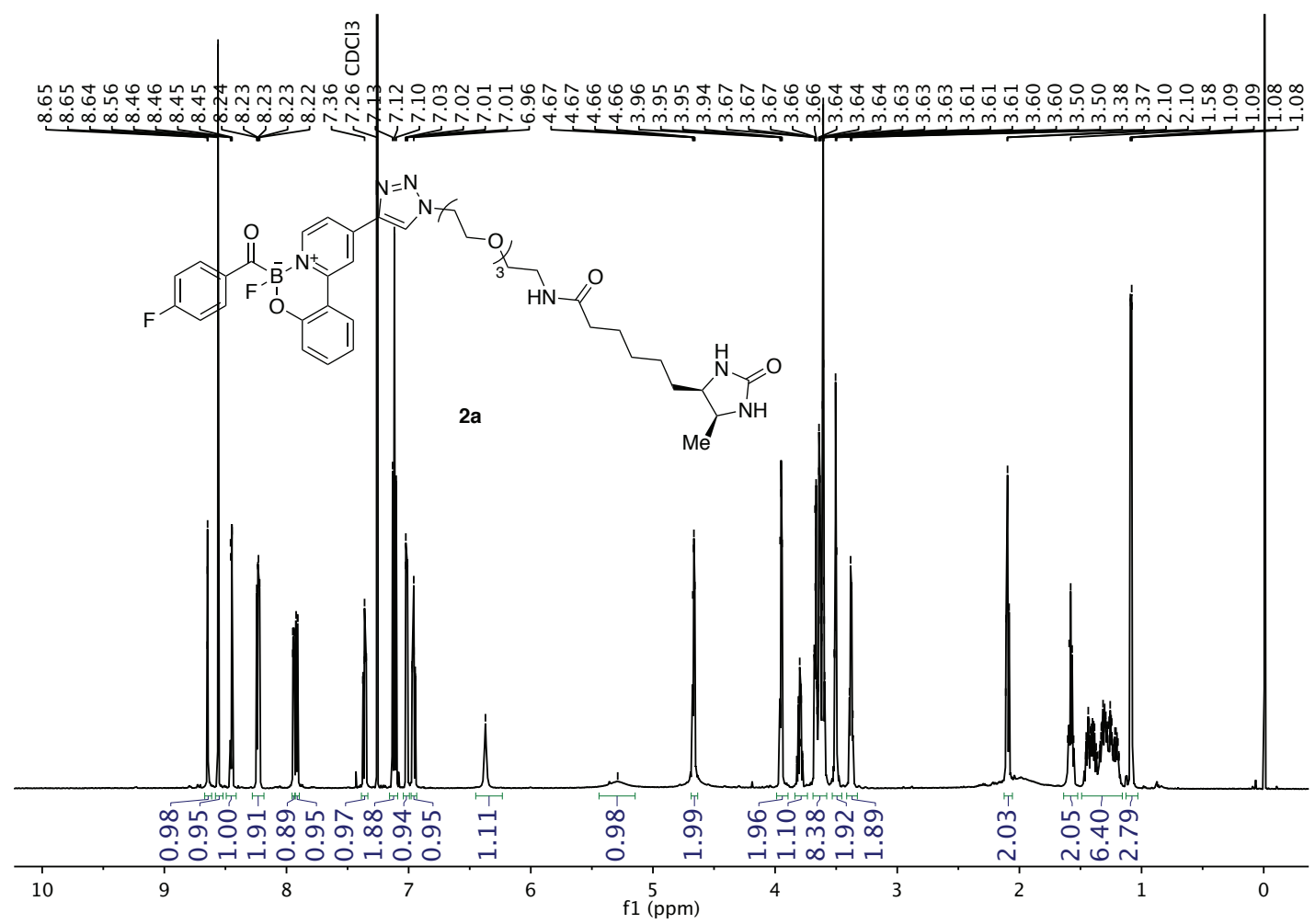

${ }^{13} \mathrm{C}$ NMR (151 MHz, $\mathrm{CDCl}_{3}$ )

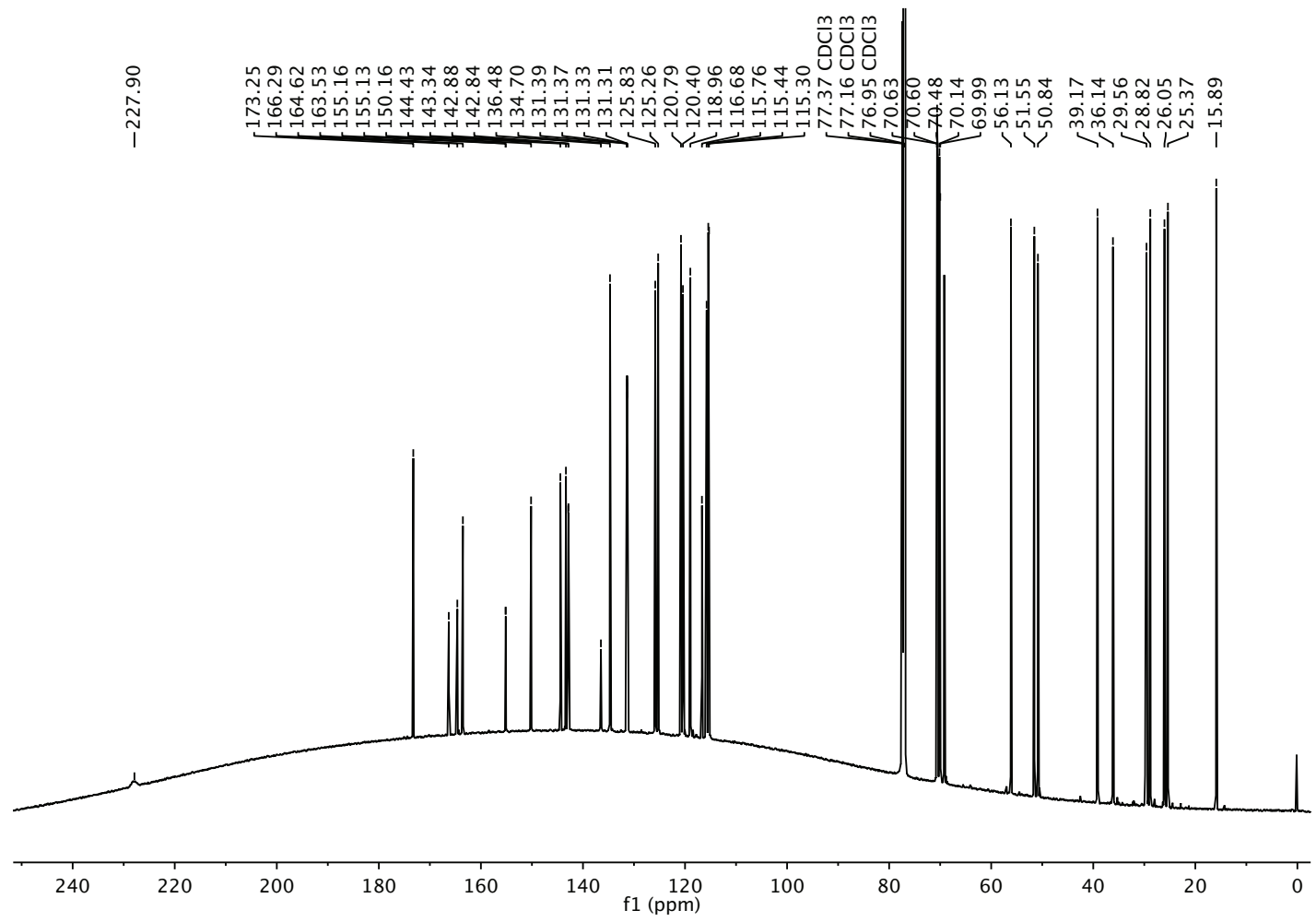


${ }^{19}$ F NMR (471 $\left.\mathrm{MHz}, \mathrm{CDCl}_{3}\right)$

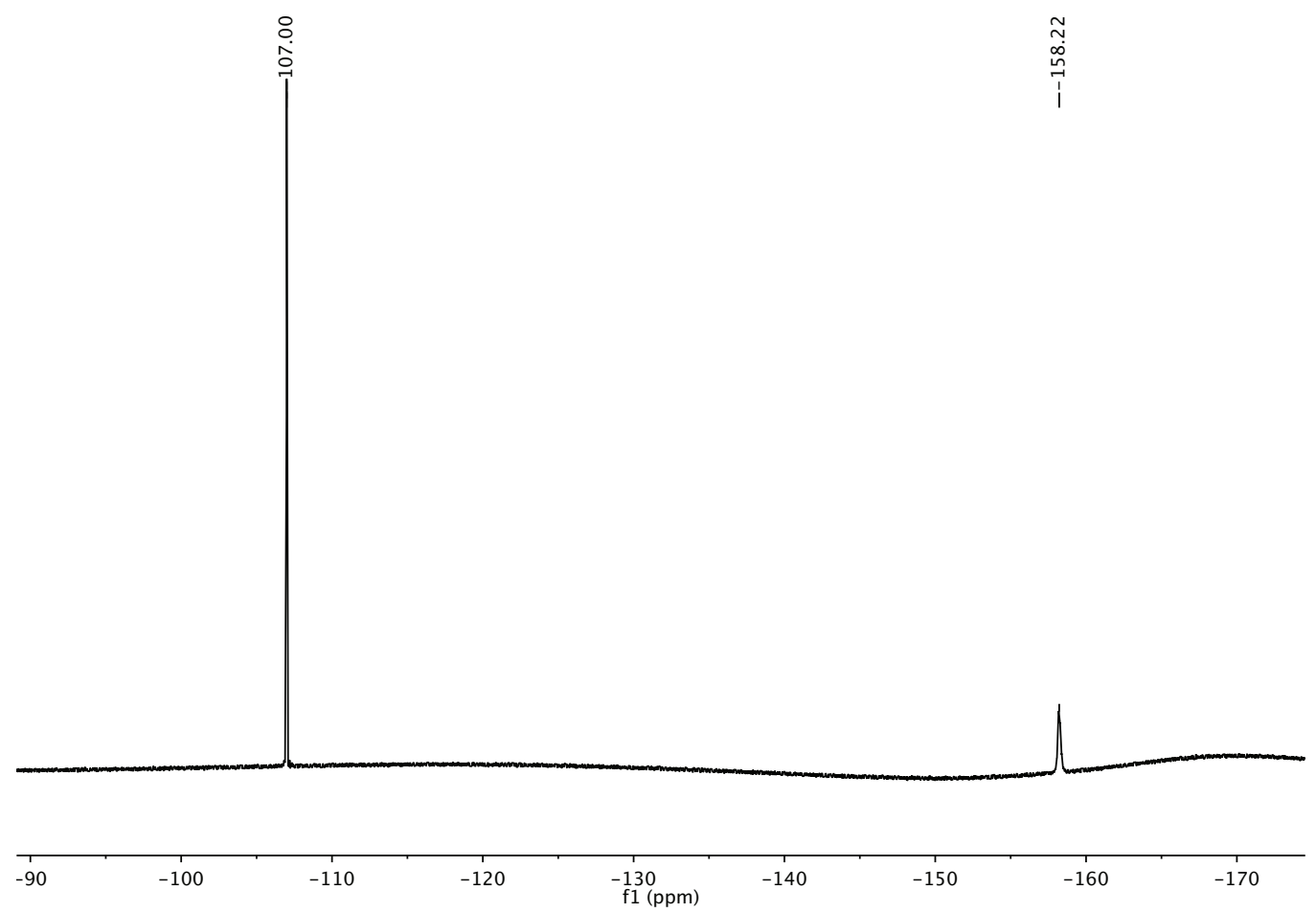

${ }^{11} \mathrm{~B}$ NMR $\left(160 \mathrm{MHz}, \mathrm{CDCl}_{3}\right)$

$\stackrel{\substack{i \\ i}}{i}$

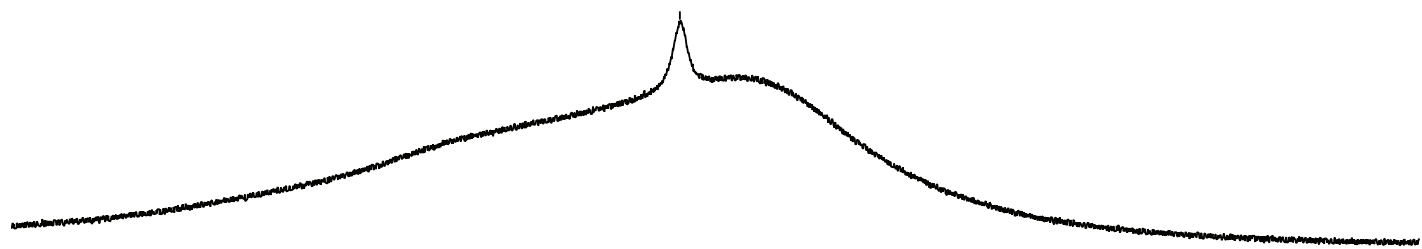

\begin{tabular}{|c|c|}
\hline 60 & \\
\hline
\end{tabular}


N-(20-(4-(10-(4-Fluorobenzoyl)-10-fluoro-9-oxa-10a-aza-10-boraphenanthren-3-yl)-1 H-1,2,3-triazol-1-

yl)-3,6,9,12,15,18-hexaoxaeicosyl)-6-((4R,5S)-5-methyl-2-oxoimidazolidin-4-yl)hexanamide (2b)

${ }^{1} \mathrm{H}$ NMR (600 MHz, $\left.\mathrm{CDCl}_{3}\right)$

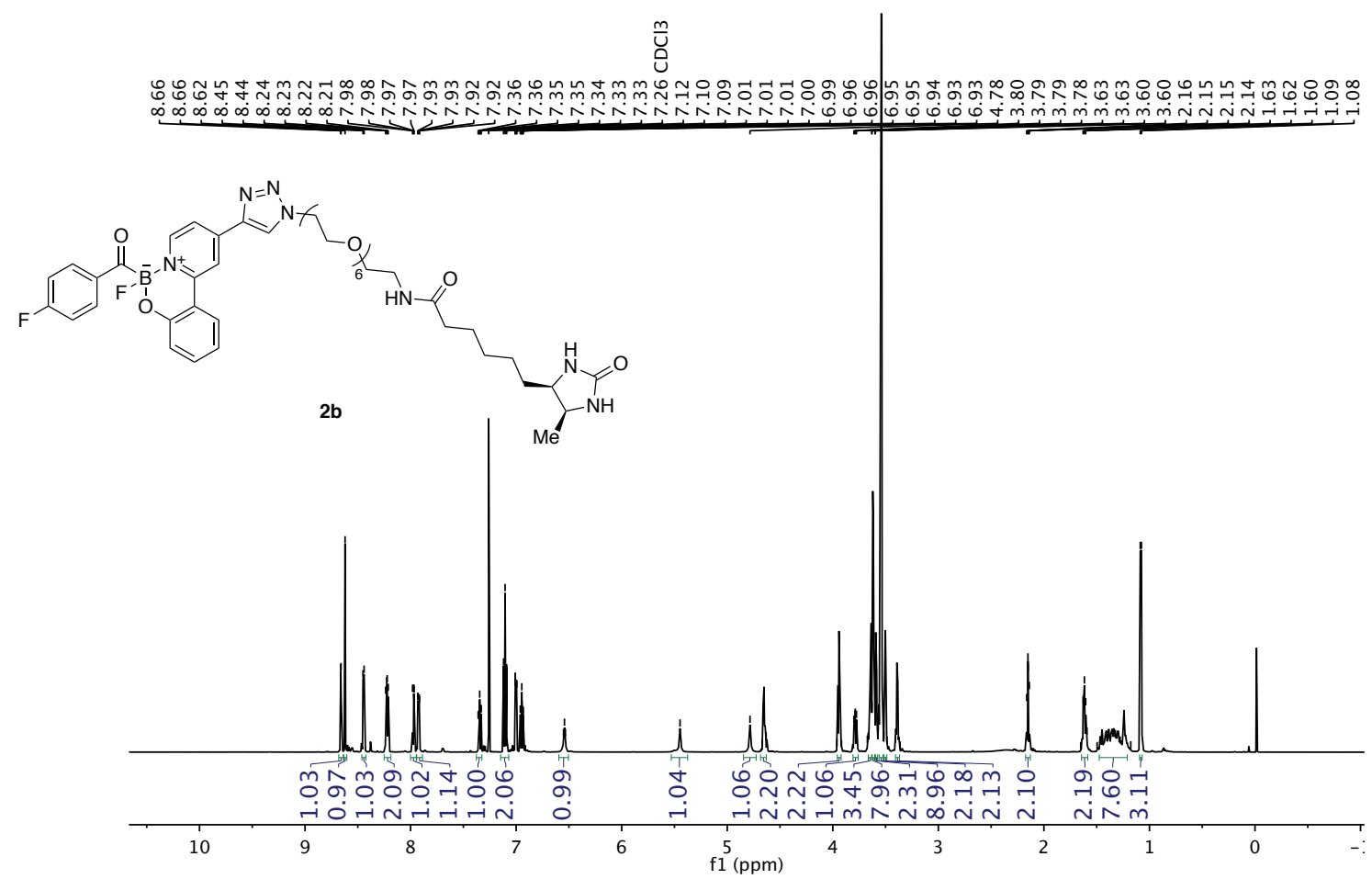

${ }^{13} \mathrm{C}$ NMR (151 MHz, $\mathrm{CDCl}_{3}$ )

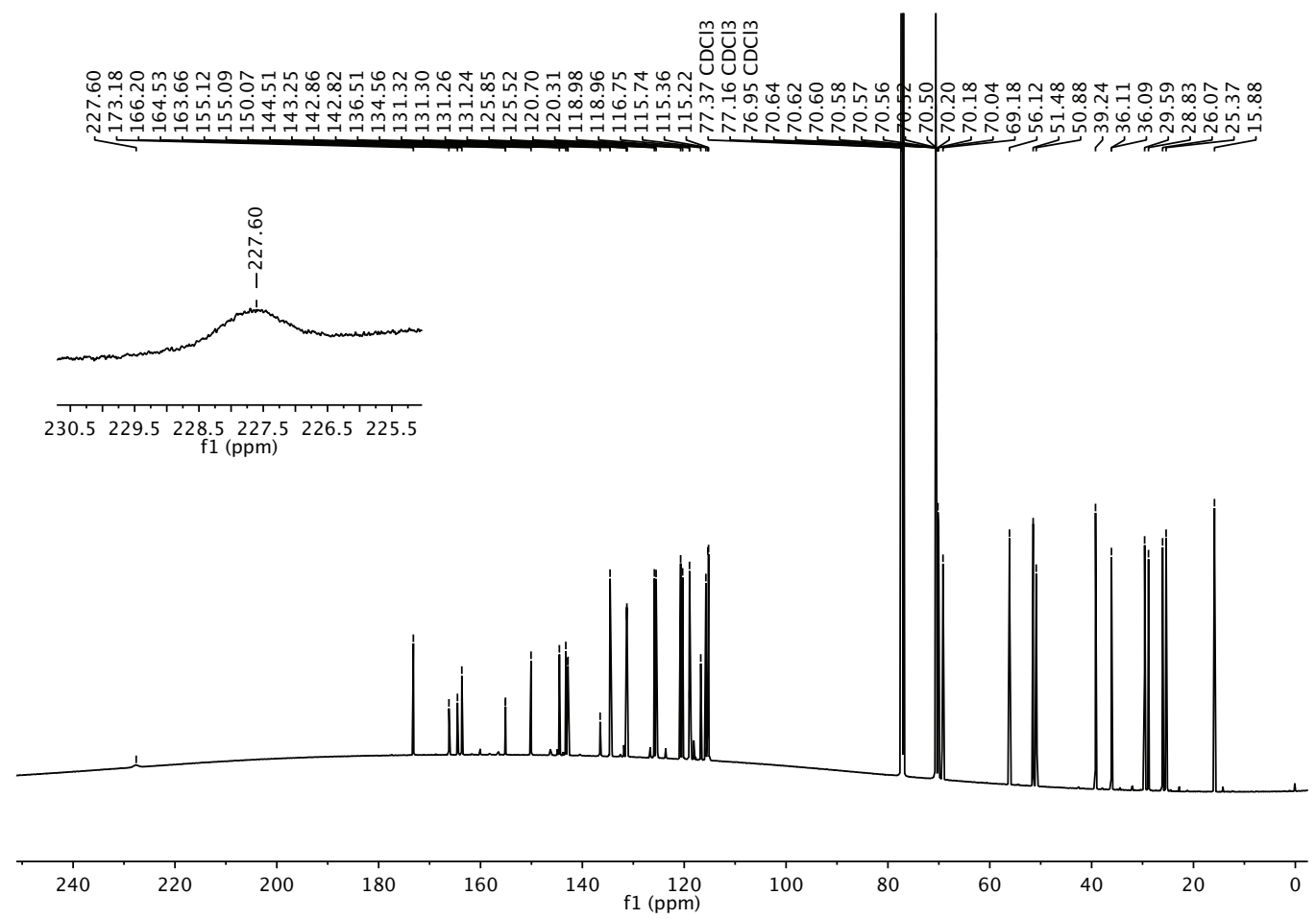


${ }^{19}$ F NMR (471 $\left.\mathrm{MHz}, \mathrm{CDCl}_{3}\right)$

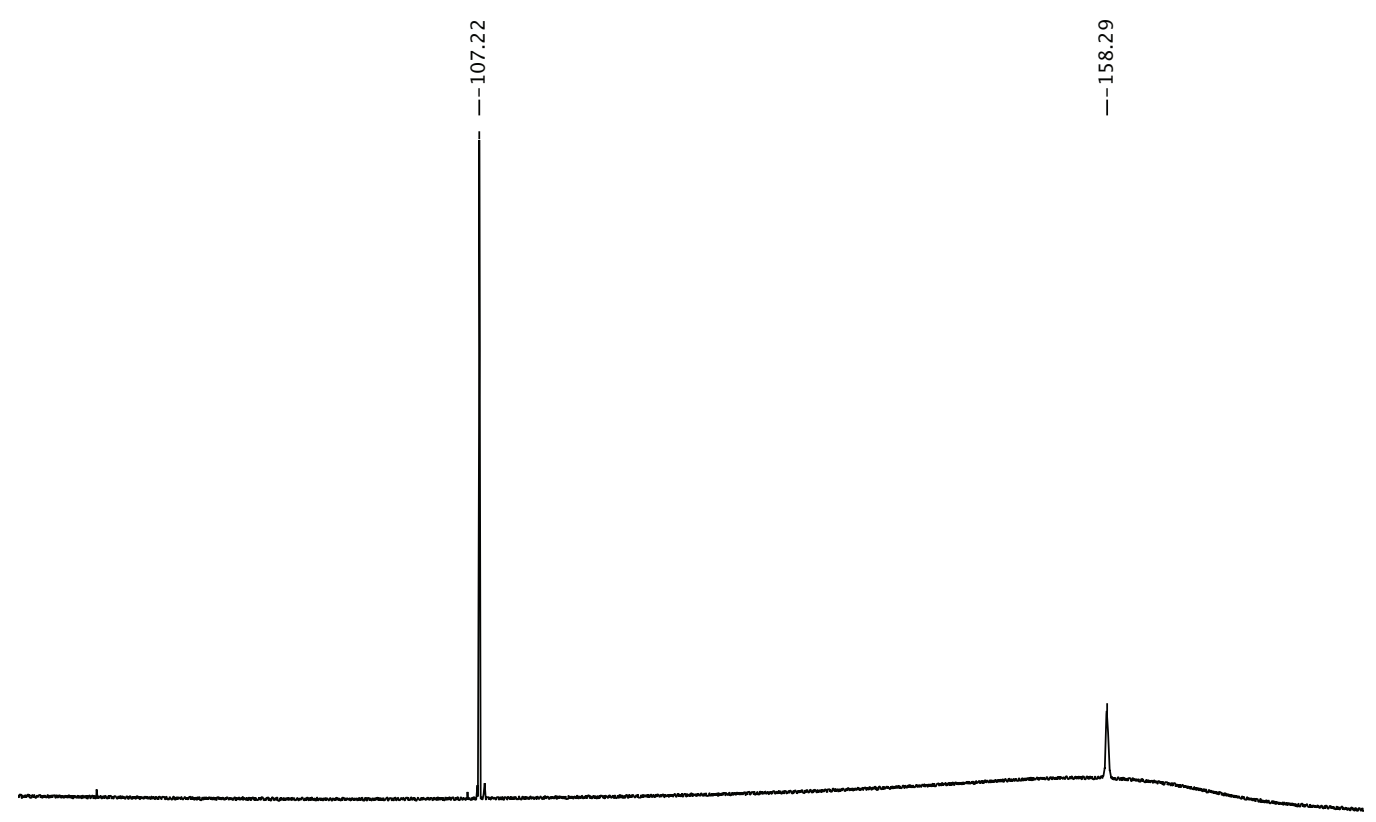

\begin{tabular}{lllllllll}
\hline 70 & -80 & -90 & -100 & -110 & -120 & -1 \\
$\mathrm{f} 1(\mathrm{ppm})$ & -130 & -140 & -150 & -160 & -170
\end{tabular}

${ }^{11} \mathrm{~B}$ NMR (160 MHz, $\left.\mathrm{CDCl}_{3}\right)$

$\stackrel{\stackrel{n}{\sim}}{i}$

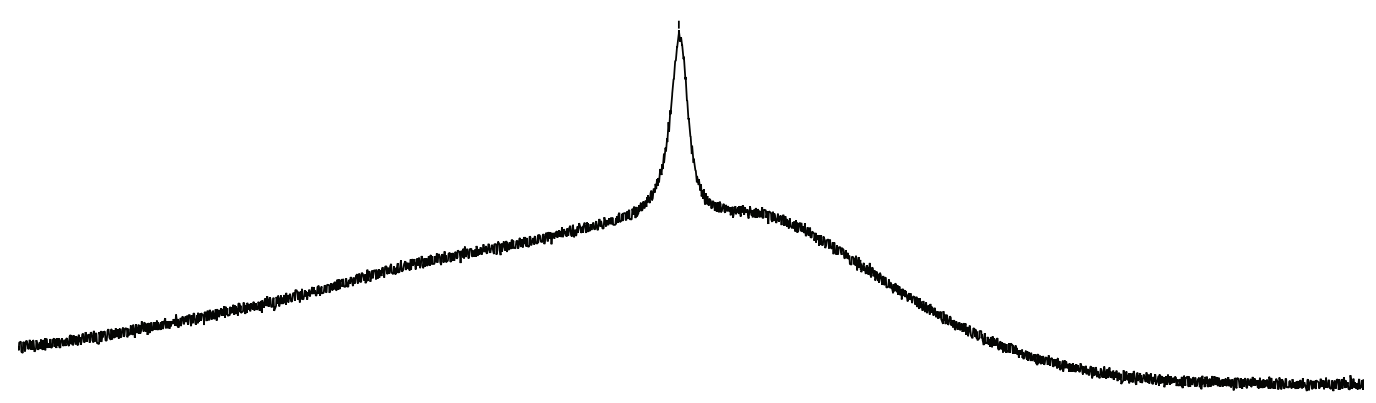

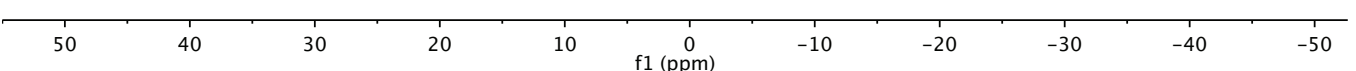


N-(32-(4-(10-(4-Fluorobenzoyl)-10-fluoro-9-oxa-10a-aza-10-boraphenanthren-3-yl)-1 H-1,2,3-triazol-1-

yl)-3,6,9,12,15,18,21,24,27-decaoxadotriacontyl)-6-((4R,5S)-5-methyl-2-oxoimidazolidin-4-

yl)hexanamide (2c)

${ }^{1} \mathrm{H}$ NMR (600 MHz, $\mathrm{CDCl}_{3}$ )

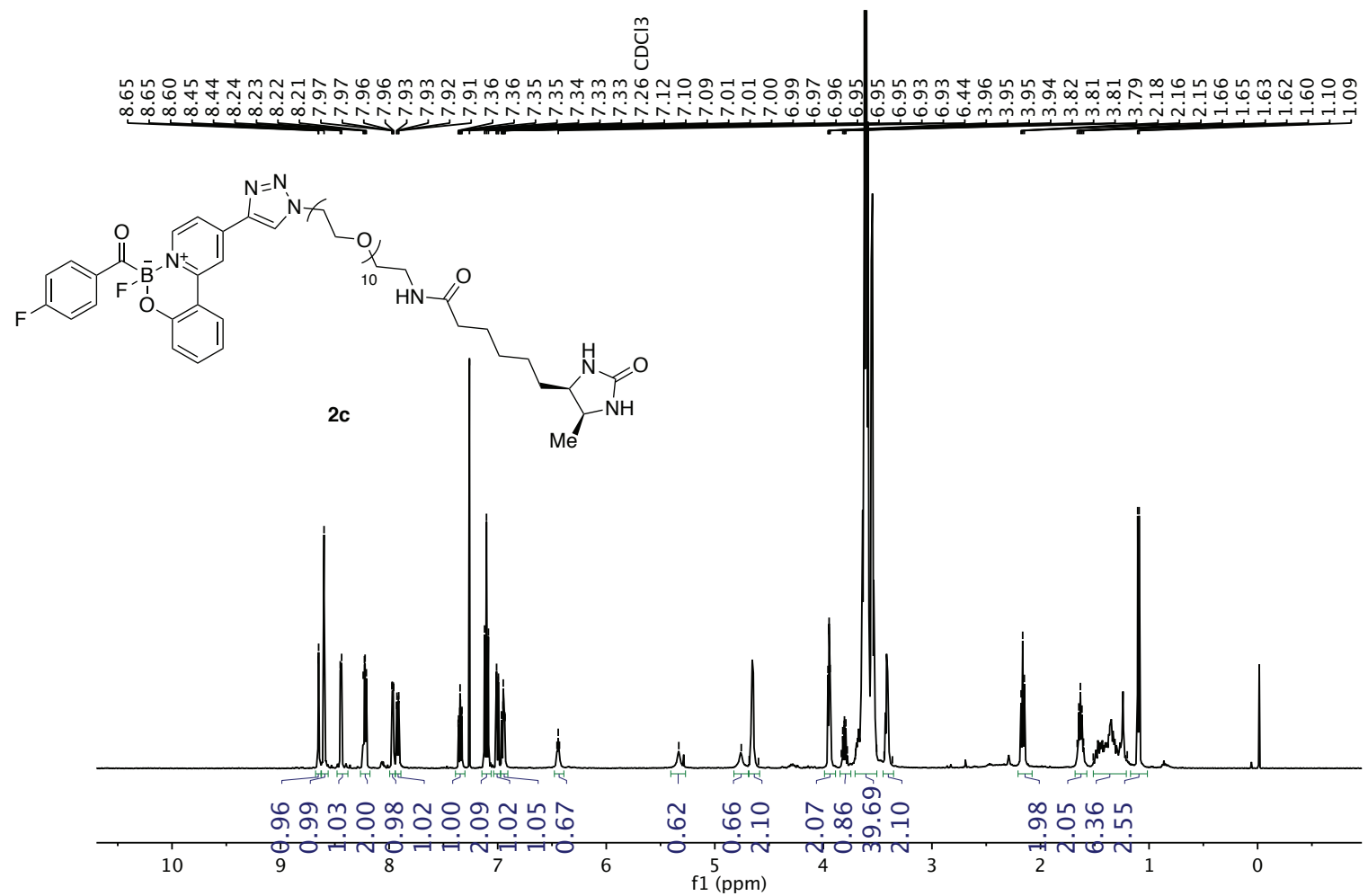

${ }^{13} \mathrm{C}$ NMR (151 MHz, $\mathrm{CDCl}_{3}$ )

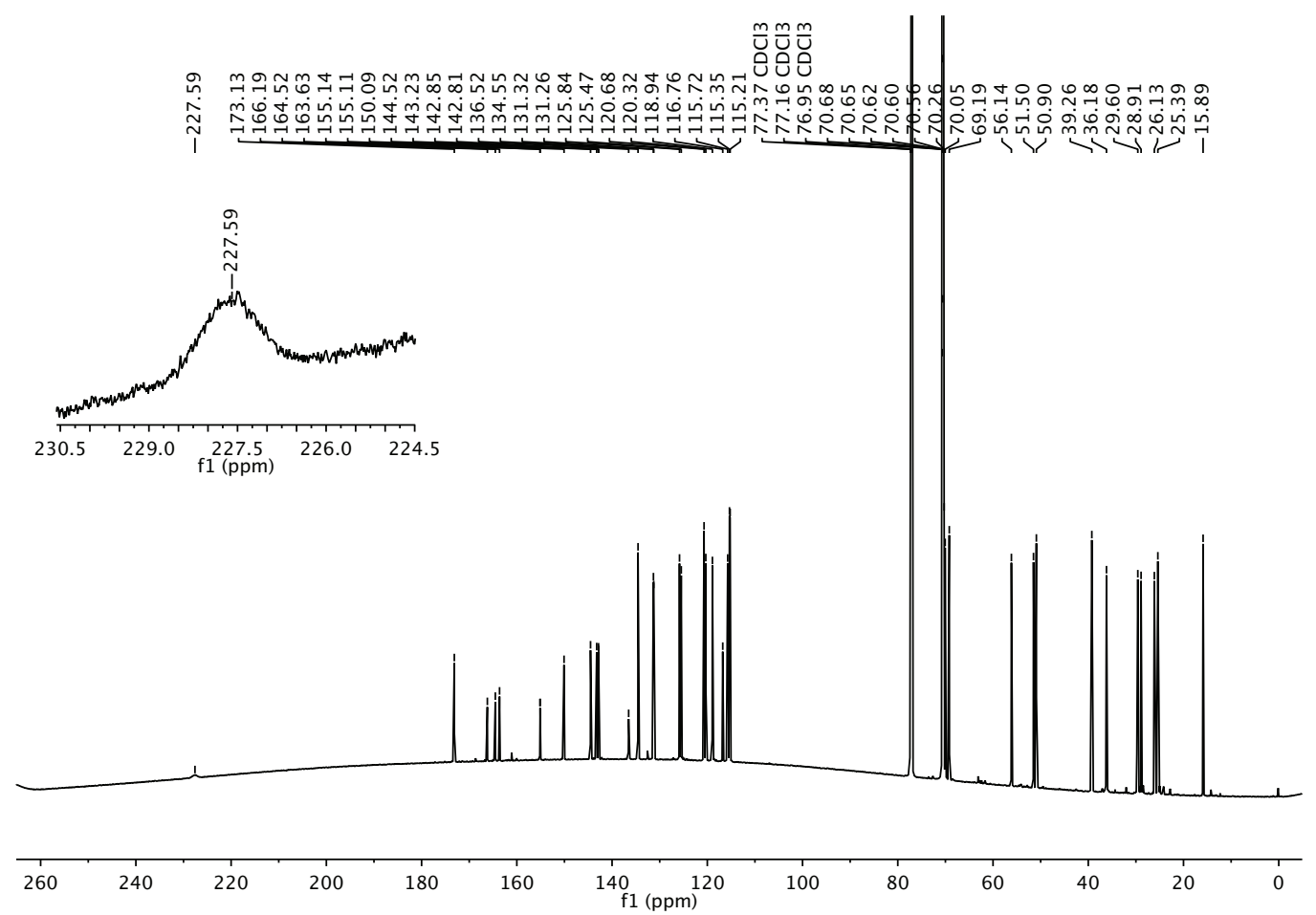


${ }^{19}$ F NMR (471 $\left.\mathrm{MHz}, \mathrm{CDCl}_{3}\right)$
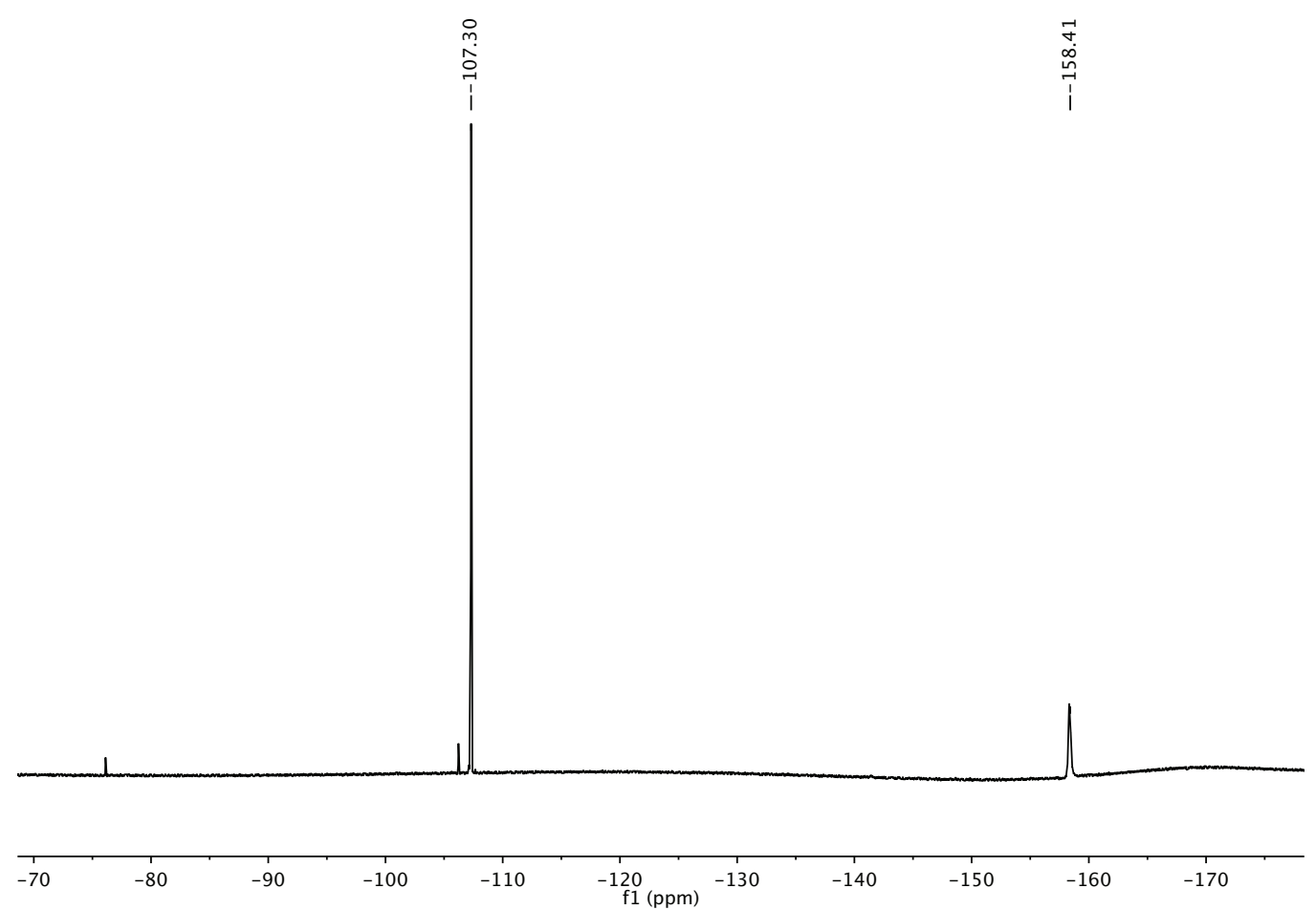

${ }^{11} \mathrm{~B}$ NMR $\left(160 \mathrm{MHz}, \mathrm{CDCl}_{3}\right)$

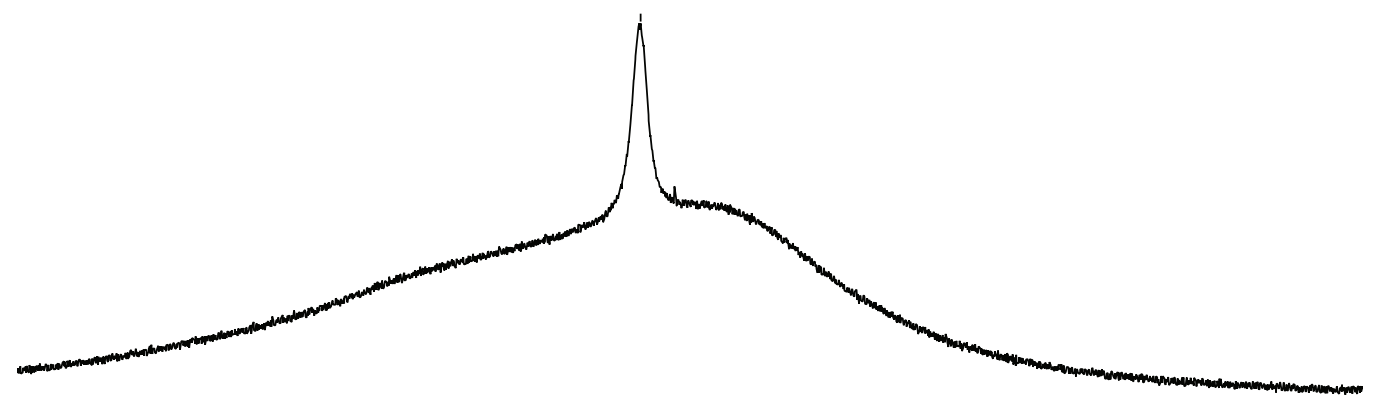

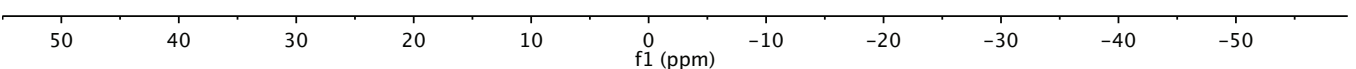


$N$-(4-azidobutyl)-6-((4R,5S)-5-methyl-2-oxoimidazolidin-4-yl)hexanamide (S26)

${ }^{1} \mathrm{H}$ NMR (500 MHz, $\mathrm{CD}_{3} \mathrm{OD}$ )

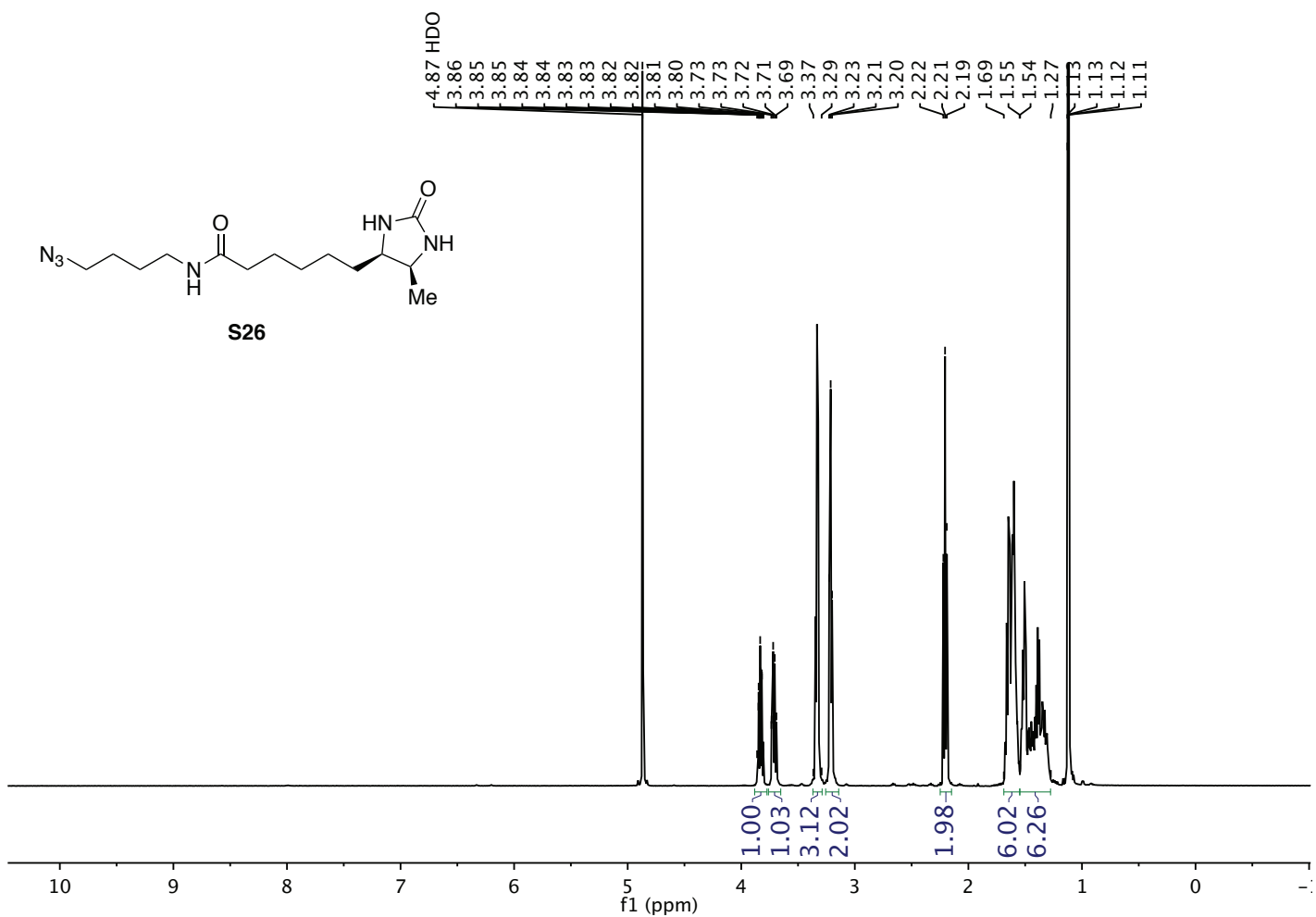

${ }^{13} \mathrm{C}$ NMR (126 MHz, $\left.\mathrm{CD}_{3} \mathrm{OD}\right)$

$$
\begin{array}{ll}
0 & 9 \\
0 & -1 \\
0 & 0 \\
1 & 0 \\
1 & 1
\end{array}
$$

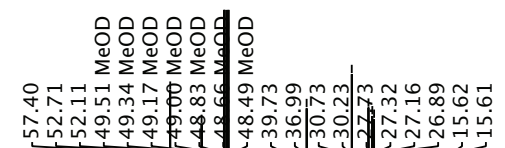

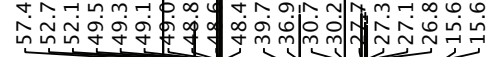

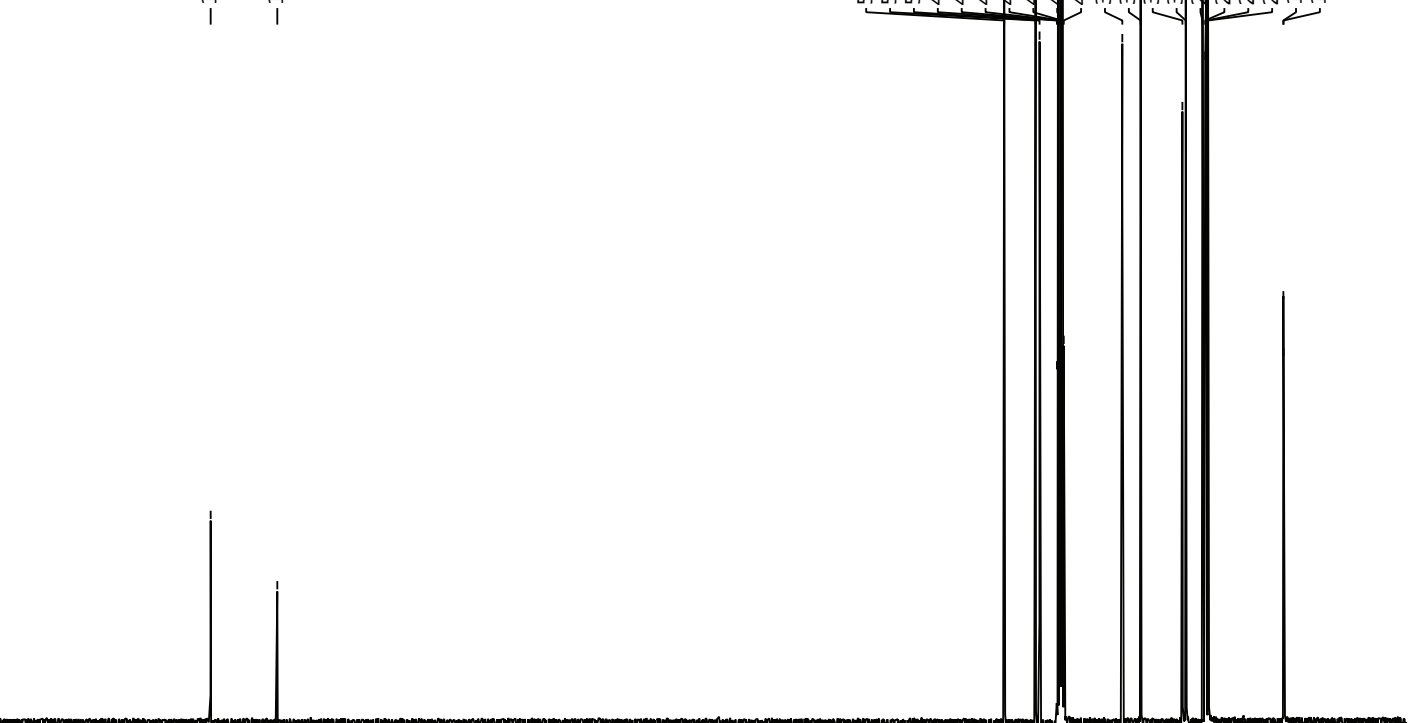

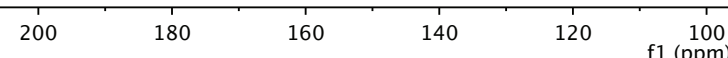

80

60

40

20

0 
N-(4-(4-(10-(4-Fluorobenzoyl)-10-fluoro-9-oxa-10a-aza-10-boraphenanthren-3-yl)-1 H-1,2,3-triazol-1-

yl)butyl)-6-((4R,5S)-5-methyl-2-oxoimidazolidin-4-yl)hexanamide (2d)

${ }^{1} \mathrm{H}$ NMR $\left(600 \mathrm{MHz}, \mathrm{CDCl}_{3}\right)$

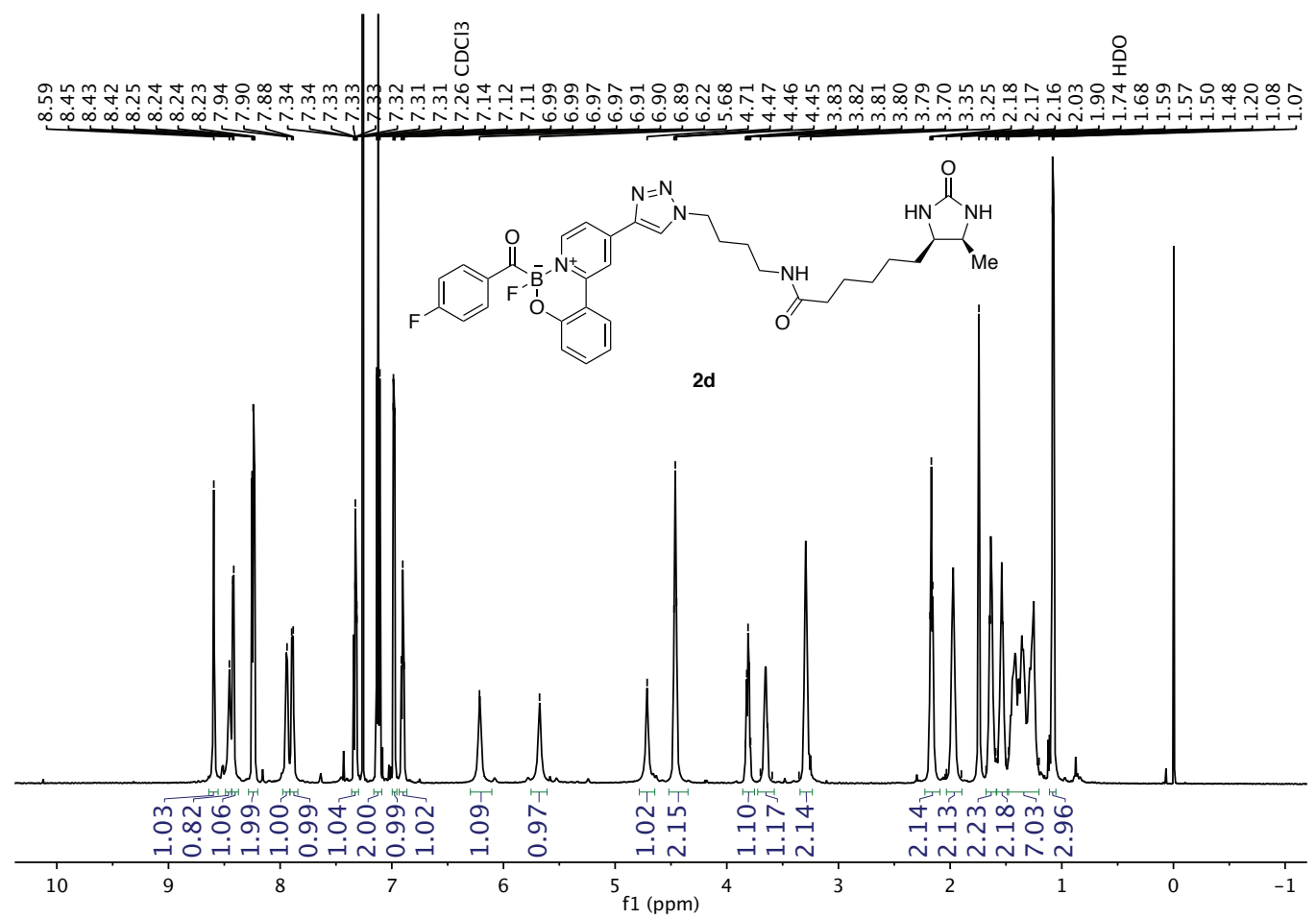

${ }^{13} \mathrm{C}$ NMR $\left(151 \mathrm{MHz}, \mathrm{CDCl}_{3}\right)$

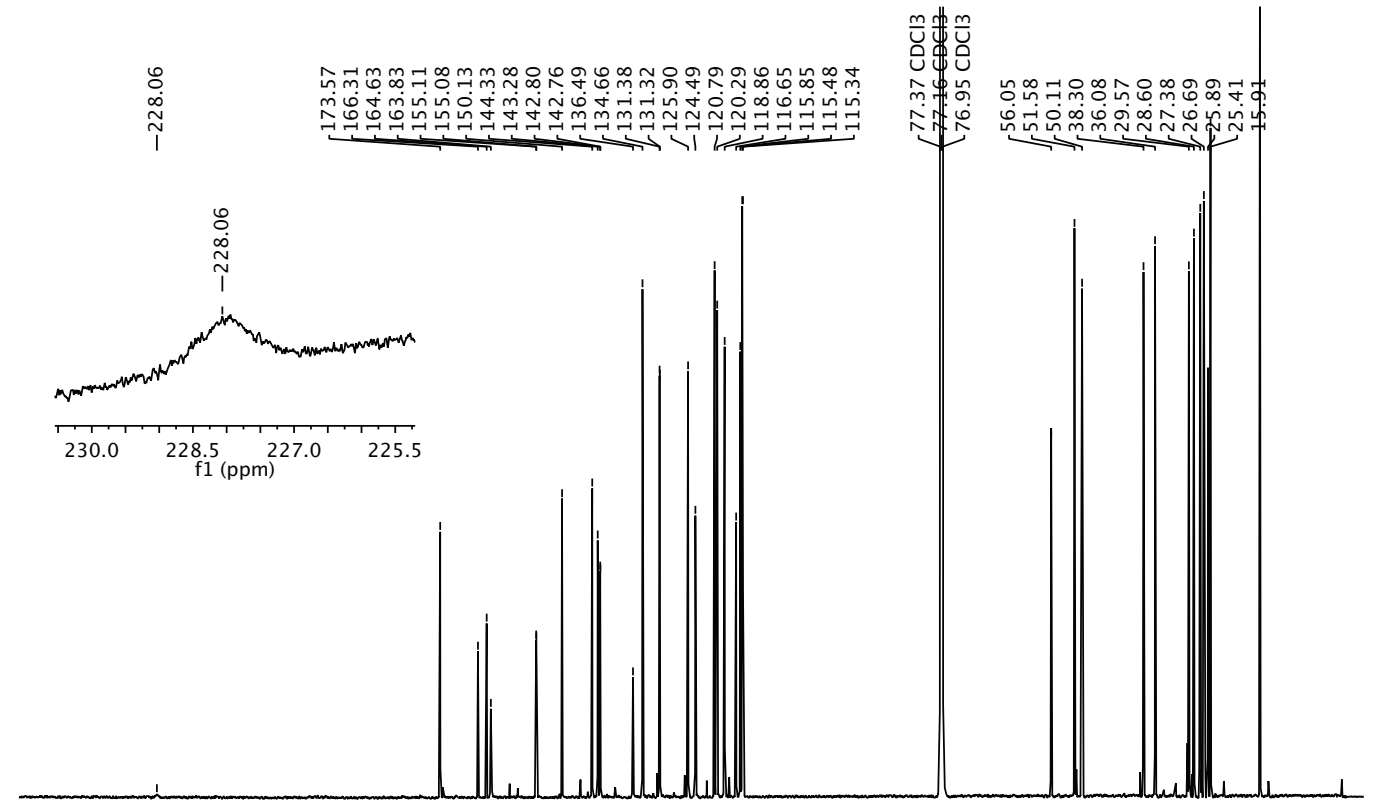

\begin{tabular}{|c|c|c|c|c|c|c|c|c|c|c|c|}
\hline 240 & 220 & 200 & 180 & 160 & 140 & $\begin{array}{r}120 \\
\text { (npm) }\end{array}$ & 100 & 80 & 60 & 40 & 20 \\
\hline
\end{tabular}


${ }^{19}$ F NMR (471 $\left.\mathrm{MHz}, \mathrm{CDCl}_{3}\right)$

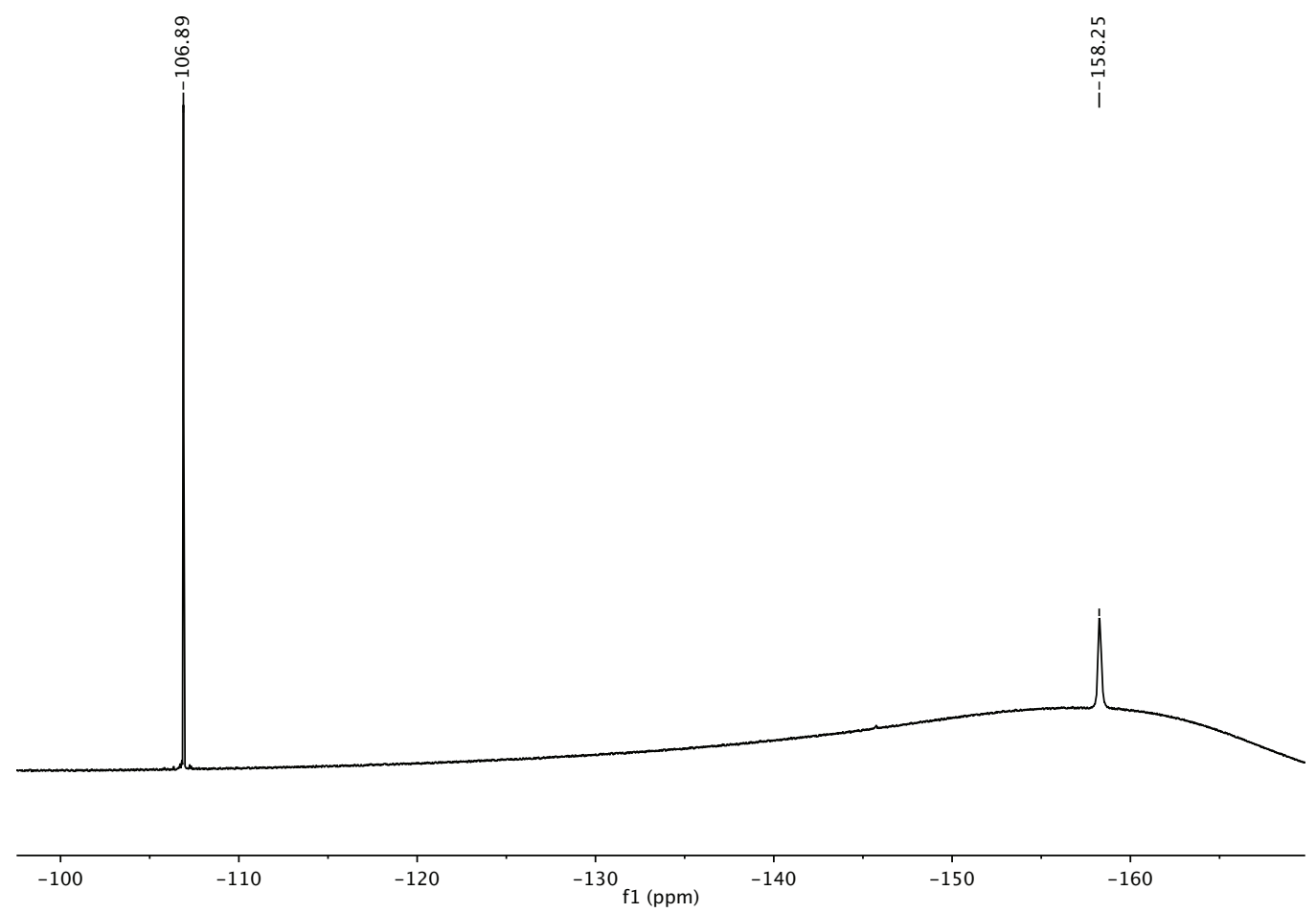

${ }^{11} \mathrm{~B}$ NMR (160 MHz, $\left.\mathrm{CDCl}_{3}\right)$

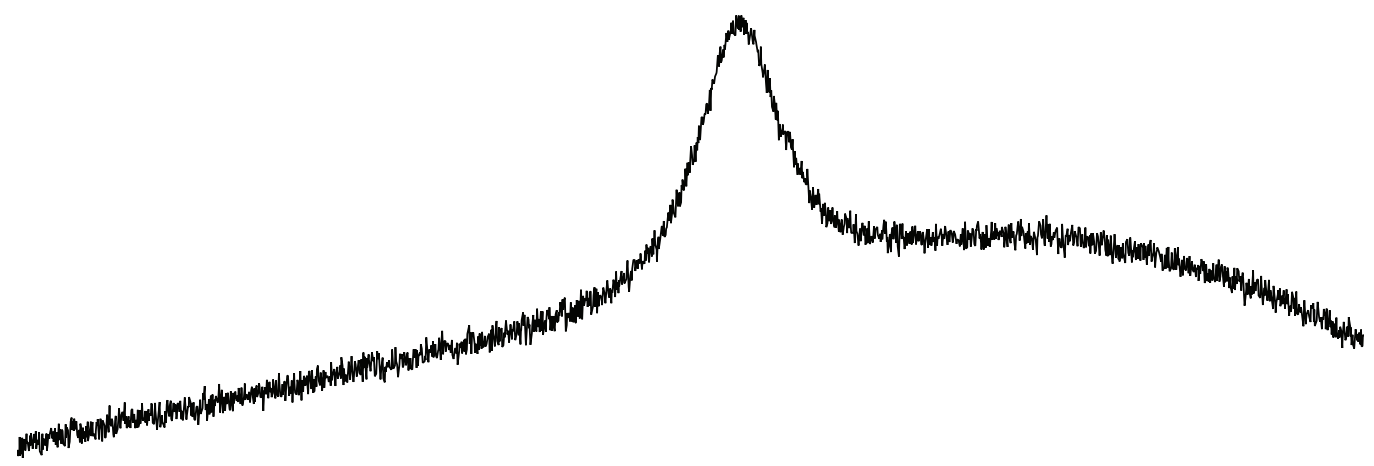

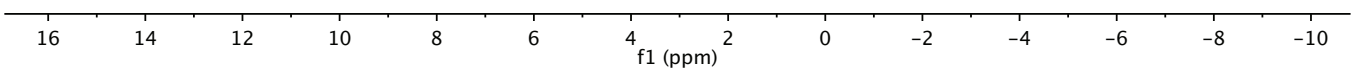


N-(2-(4-(4-Fluorobenzamido)butanamido)ethyl)-7-(diethylamino)-2-oxo-2H-chromene-3-carboxamide

(3)

${ }^{1} \mathrm{H}$ NMR (500 $\left.\mathrm{MHz}, \mathrm{CDCl}_{3}\right)$

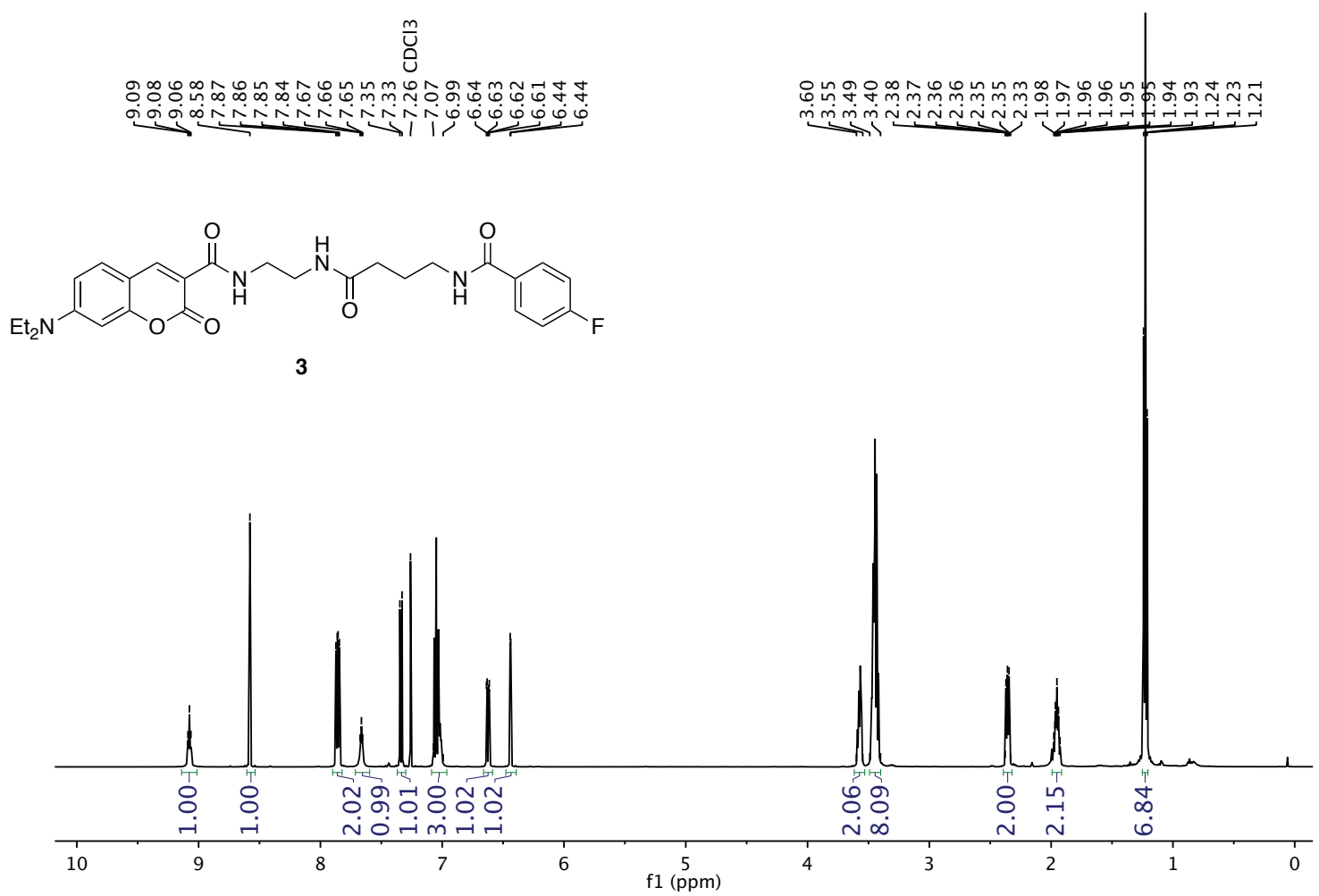

${ }^{13} \mathrm{C}$ NMR (126 MHz, $\mathrm{CDCl}_{3}$ )

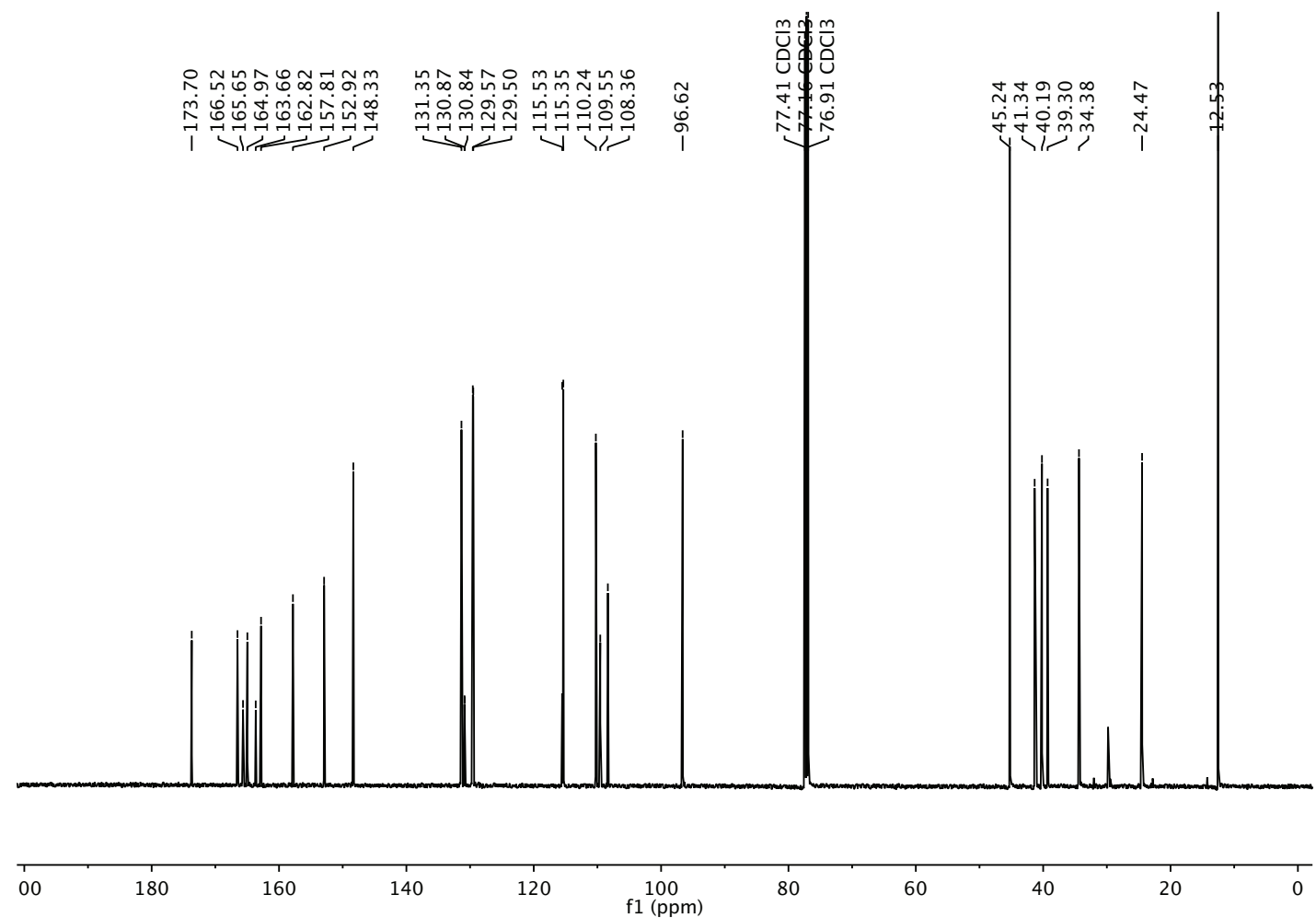


${ }^{19} \mathrm{~F} \mathrm{NMR}\left(471 \mathrm{MHz}, \mathrm{CDCl}_{3}\right.$ )

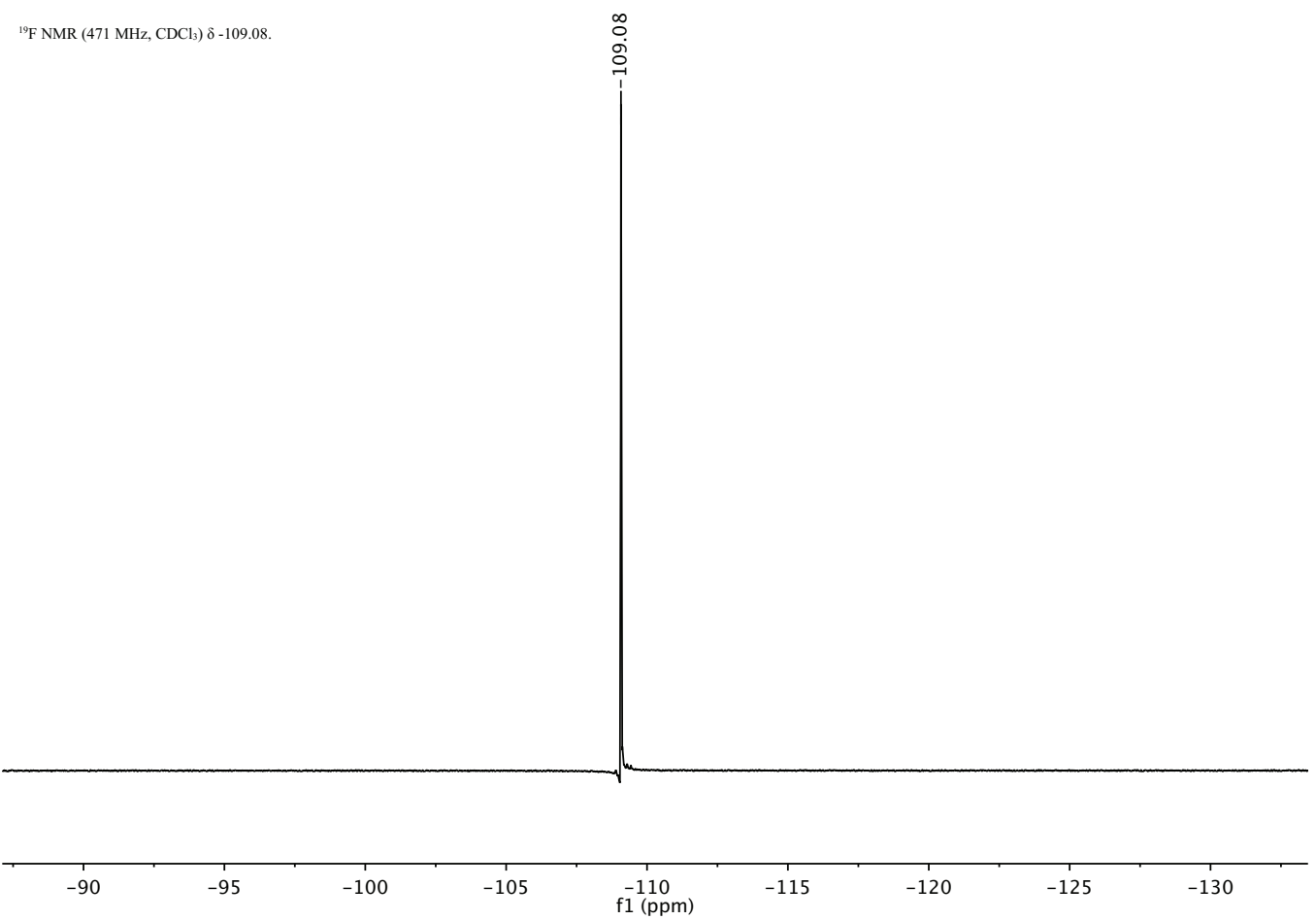




\section{References}

(1) Du, T.; Du, F.; Ning, Y.; Peng, Y. Org. Lett. 2015, 17, 1308-1311.

(2) Laemmli, U. K. Nature 1970, 227, 680-685.

(3) Fors, B. P.; Poelma, J. E.; Menyo, M. S.; Robb, M. J.; Spokoyny, D. M.; Kramer, J. W.; Waite, J. H.; Hawker, C. J. J. Am. Chem. Soc. 2013, 135, 14106-14109.

(4) Fischer, F.; Siegle, A. F.; Checinski, M.; Fischer, C.; Kral, K.; Thede, R.; Trapp, O.; Hapke, M. J. Org. Chem. 2016, 81, 3087-3102.

(5) Duan, X.; Ruan, Q.; Gan, Q.; Song, X.; Fang, S.; Zhang, X.; Zhang, J. J. Organomet. Chem. 2018, 868, $154-163$

(6) Noda, H.; Bode, J. W. J. Am. Chem. Soc. 2015, 137, 3958-3966.

(7) Mangubat-Medina, A. E.; Martin, S. C.; Hanaya, K.; Ball, Z. T. J. Am. Chem. Soc. 2018, 140, 8401-8404.

(8) Howarth, M.; Ting, A. Y. Nat. Protoc. 2008, 3, 534-545.

(9) Fairhead, M.; Krndija, D.; Lowe, E. D.; Howarth, M. J. Mol. Biol. 2014, 426, 199-214. 